\title{
Oximation optimization and applications in cardiovascular research
}

Citation for published version (APA):

Agten, S. M. (2016). Oximation optimization and applications in cardiovascular research. [Doctoral Thesis, Maastricht University]. Maastricht University. https://doi.org/10.26481/dis.20161215sa

Document status and date:

Published: 01/01/2016

DOI:

10.26481/dis.20161215sa

Document Version:

Publisher's PDF, also known as Version of record

\section{Please check the document version of this publication:}

- A submitted manuscript is the version of the article upon submission and before peer-review. There can be important differences between the submitted version and the official published version of record.

People interested in the research are advised to contact the author for the final version of the publication, or visit the DOI to the publisher's website.

- The final author version and the galley proof are versions of the publication after peer review.

- The final published version features the final layout of the paper including the volume, issue and page numbers.

Link to publication

\footnotetext{
General rights rights.

- You may freely distribute the URL identifying the publication in the public portal. please follow below link for the End User Agreement:

www.umlib.nl/taverne-license

Take down policy

If you believe that this document breaches copyright please contact us at:

repository@maastrichtuniversity.nl

providing details and we will investigate your claim.
}

Copyright and moral rights for the publications made accessible in the public portal are retained by the authors and/or other copyright owners and it is a condition of accessing publications that users recognise and abide by the legal requirements associated with these

- Users may download and print one copy of any publication from the public portal for the purpose of private study or research.

- You may not further distribute the material or use it for any profit-making activity or commercial gain

If the publication is distributed under the terms of Article $25 \mathrm{fa}$ of the Dutch Copyright Act, indicated by the "Taverne" license above, 


\section{OXIMATION OPTIMIZATION}

AND APPLICATIONS IN CARDIOVASCULAR RESEARCH 
OXIMATION OPTIM IZATION AND APPLICATIONS IN CARDIOVASCULAR RESEARCH

Thesis Universiteit $M$ aastricht

ISBN: 978-94-028-0421-8

Production: IPSkamp printing

(c) Stijn M . Agten, M aastricht 2016

Cover design by Cyrille Pollaert \& Stijn Agten 


\section{OXIM ATION OPTIM IZATION}

\section{AND APPLICATIONS IN CARDIOVASCULAR RESEARCH}

\section{PROEFSCHRIFT}

ter verkrijging van de graad van doctor aan de Universiteit M aastricht, op gezag van de Rector Magnificus, Prof. Dr. Rianne M . Letschert, volgens het besluit van het College van Decanen,

in het openbaar te verdedigen op donderdag 15 december 2016 om 16:00 uur

door

Stijn M athijs Agten

Geboren op 12 maart 1987 te Heerlen 


\section{Promotor}

Prof. Dr. T.M. Hackeng

\section{Co-promotor}

Dr. R.R. Koenen

\section{Beoordelingscommissie}

Prof. Dr. C.G. Schalkwijk, voorzitter

Prof. Dr. C.F.W. Becker (University of Vienna, Austria)

Prof. Dr. P. Timmerman (Universiteit van Amsterdam)

Prof. Dr. Ir. E.A.L. Biessen

Financial Support by Stichting Hart Onderzoek Nederland, an initiative of the Heart Research Institute (www.hartonderzoek.nu) is gratefully acknowledged

Financial Support by the Dutch Heart Foundation for the publication of this thesis is gratefully acknowledged 
Contents:

$\begin{array}{lll}\text { Chapter } 1 & \text { Introduction } & 7\end{array}$

Chapter 2 Oxime conjugation in protein chemistry: from carbonyl 15 incorporation to nucleophilic catalysis

Chapter 3 Chemoselective oxime reactions in proteins and 33 peptides by using an optimized oxime strategy: the demise of levulinic acid

Chapter $4 \quad$ Oxime catalysis by freezing 59

Chapter 5 Probing functional heteromeric chemokine protein73 protein interactions through conformation-assisted oxime ligation

Chapter 6 Chemokine interactome mapping enables tailored 95 intervention in acute and chronic inflammation

Chapter 7 Covalent attachment of tissue type plasminogen 155 activator to fibrin through $\mathrm{N}$-terminal modification with a fibrin crosslinking sequence from $\alpha_{2}$-antiplasmin

Chapter 8 Discussion

Chapter 9 Summary 179

Samenvatting 183

Valorisation 187

Curriculum vitae 191

Publications 195

Dankwoord 199 

Chapter 1

Introduction 
Proteins form the basis of life and are designed to perform a variety of functions. The function of a protein is largely determined by its amino acid sequence; therefore proteins have been studied extensively using molecular biology techniques. Mutation of individual residues to achieve altered function or insertion of new functionalities by fusing multiple protein segments was accomplished using molecular biology. Although impressive results were achieved, the modifications that are possible using these techniques are quite limited from a chemical point of view. For this reason chemical protein synthesis plays a huge role in the elucidation of protein function.

\section{Chemical Protein Synthesis}

Total chemical synthesis of proteins opens up a nearly unlimited array of modifications once synthetic access to a protein is established. Moreover, there are no limitations to the number of or position at which these modifications are introduced. The specificity with which this can be achieved is useful for a wide range of applications, i.e. fluorescent- or isotope labelling.

Synthetic access to proteins has become an established technique to study various protein functionalities. This was, however, not possible without the development of several synthetic pathways. Early work by Fischer led to the synthesis of a tetra peptide[1]; this was followed by the introduction of the carboxybenzoyl group (Cbz) as an amine protecting group in peptide synthesis.[2] The Cbz group allowed reversible $\mathrm{N}(\alpha)$ protection, could be deprotected under mild conditions and was protected from racemization during carbonyl activation[2], which led to the synthesis of oxytocin[3] and later insulin.[4] A second breakthrough came with the introduction of solid phase peptide synthesis (SPPS) as introduced by Merrifield.[5] While initially met with skepticism, SPPS quickly emerged as a robust technique for the synthesis of peptides (Scheme 1). The main advantage lies in the facile purification by filtration and washing after each coupling step due to the solid support, which enables the use of large excesses of activated amino acids. $\mathrm{N}(\alpha)$ protection in SPPS was initially performed with the Cbz group, and later optimized to tert-butyloxycarbonyl (tBoc) or fluorenylmethyloxycarbonyl chloride (Fmoc)[6], which are still used, decades after their introduction. Optimization and automatization of SPPS has led to its widespread use beyond the initial chemical settings, into biological laboratories. Although optimization of the original protocol led to a vast improvement of yield obtained by SPPS, realistically the synthesis is limited to a linear peptide chain of 40 to 60 amino acids. This meant that the majority of proteins were out of synthetic reach. This was, however, overcome by employing site specific condensation reactions to link two or more unprotected peptide fragments. Initial ligation chemistry used a nucleophilic reaction of thiocarboxylate with a bromoacetyl to yield two peptide fragments linked by a thioester bond.[7] While this technique was successfully applied and originally 
resulted in active HIV-1 protease, critics argued that such a non-native bond could be unstable and not be used when studying the molecular basis of protein function.

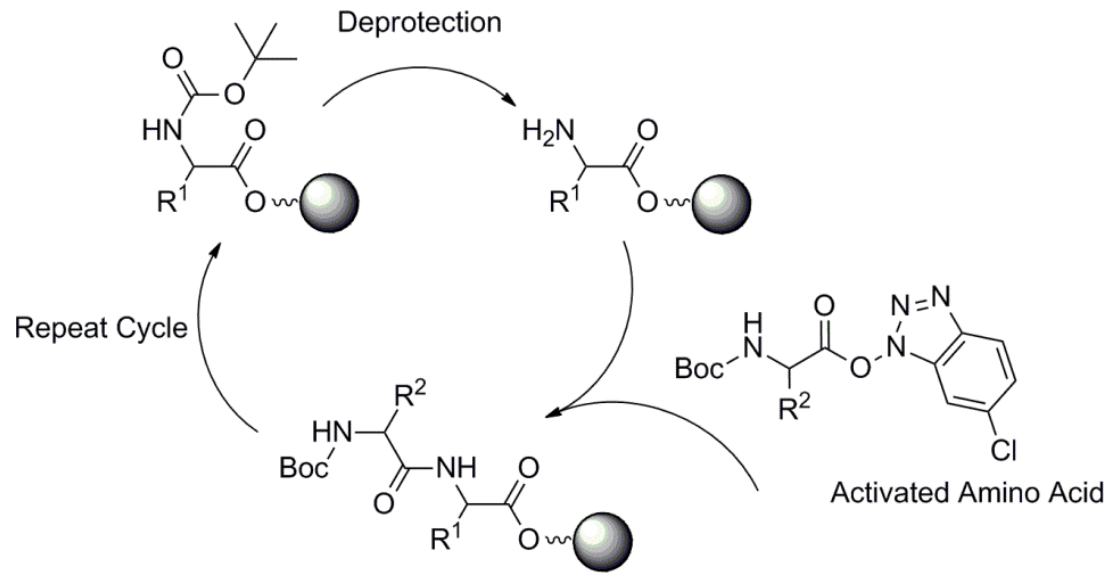

Coupling

Scheme 1: Schematic representation of solid phase peptide synthesis. Steps include the deprotection of the Na protecting group (tBoc in this case) followed by addition of an activated amino acid and coupling of this amino acid to the growing chain on the solid support. Steps are repeated until chain is completed.

Native Chemical Ligation

A method was sought with which unprotected peptide fragments could be ligated to result in a native peptide bond. An extension of the earlier employed thioesterforming ligation brought the solution. A reaction was designed in which a thioester moiety is reacted with a free thiol present in a cysteine residue to form a reversible thioester bond. This thioester can subsequently quickly undergo an $\mathrm{S}$ - to $\mathrm{N}$-acyl shift in presence of an intramolecular amine to form a native peptide bond (Scheme 2). This ligation is now known as native chemical ligation (NCL), and is the basis of chemical protein synthesis. [8] Initially, NCL could only be performed at cysteine ligation sites, but recent advances in desulfurization and the use of $ß$-thiol amino acids have made $\mathrm{NCL}$ possible at virtually any residue. $[9,10]$ 

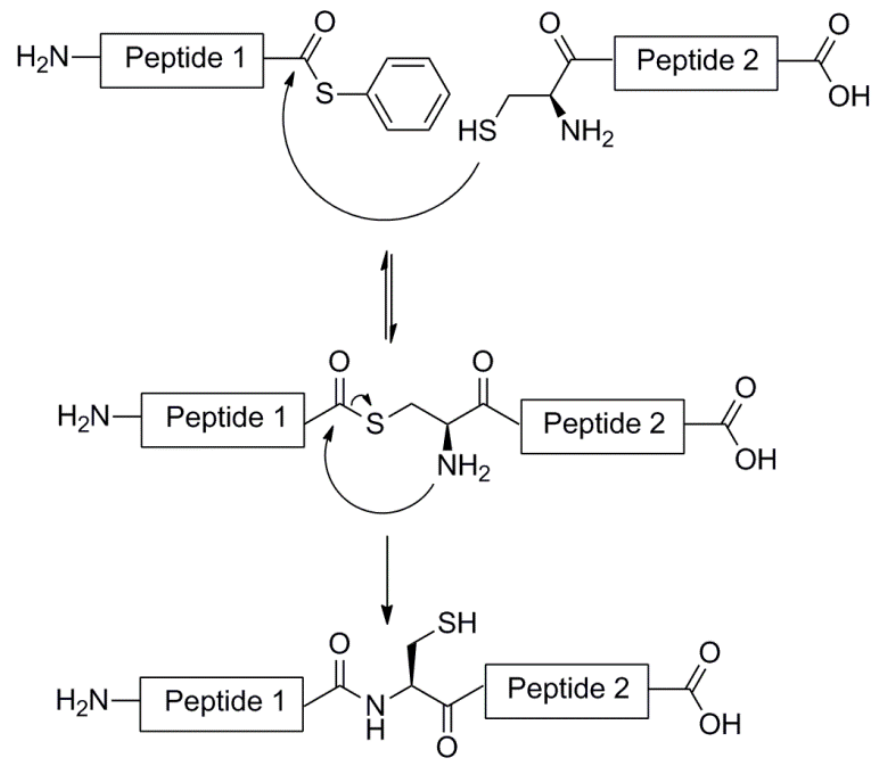

Scheme 2: Schematic representation of native chemical ligation. The reaction starts with two unprotected peptide fragments that undergo a transthioesterification reaction that results in a thioester link, that subsequently undergoes a $\mathrm{S}$ to $\mathrm{N}$ acyl shift to result in a native peptide bond.

The introduction of NCL opened up the possibility to chemically synthesize larger proteins. However, site specific bioconjugation methodologies were still necessary to modify these synthetic proteins to render them useful for i.e. imaging purposes.

\section{Bioconjugation}

A number of different techniques for bioconjugation of protein molecules have been developed, while keeping selectivity, compatibility and stability of the linkage in mind. Widely used are copper catalyzed azide-alkyne cycloadditions (CuAAC)[11, 12], inverse electron demand Diels-Alder cycloadditions (DA INv) [13] and reactions at cysteine residues. While these reactions all have their advantages, there are some drawbacks; CUAAC is restricted by the use of copper as a catalyst, which is furthermore toxic to cells, the complexity and instability of the reaction components required for DA INV make this reaction less favorable for protein labelling and finally, thiol additions often require an additional cysteine to be introduced to the protein, as most naturally occurring cysteines are present as disulfides. An often overlooked alternative ligation strategy employs an oxime bond to link molecules of interest.[14] This strategy uses easy to engineer starting products and the reaction is orthogonal and therefore site specific. The oxime bond is the major subject of this thesis and will be explained in more detail below. 
Oxime Ligation

An oxime is formed by reaction of a ketone or aldehyde with an aminooxy. The oxime is part of the imine family, which is formed by reaction of a carbonyl species with an amine (Scheme 3). In contrast to an imine which is reversible and readily hydrolyzed, an oxime forms a stable bond especially at neutral pH.[15] The difference is ascribed to the so-called $\alpha$-effect; an increased nucleophilic reactivity of the aminooxy moiety, because of the presence of an electronegative atom with a free electron pair adjacent to the nucleophilic amine.[16, 17] When both an amine and aminooxy are present the oxime will readily form a stable bond whereas the imine is not observed. When looking more closely at the mechanism of oxime formation, the reaction consists of several steps. In the first step the aminooxy adds to the carbonyl compound to form tetrahedral addition transition state.[18] This intermediate product then loses water to form the final oxime product (Scheme 3). At neutral pH this acid catalyzed dehydration step is rate-determining for the reaction. A decrease in $\mathrm{pH}$, however, leads to a change of the rate-determining step to the formation of the tetrahedral intermediate state. This is the result of protonation of the aminooxy moiety, which results in a slower formation of the intermediate state. For this reason oxime formation has an optimum at a pH of approximately 4.5.[18]

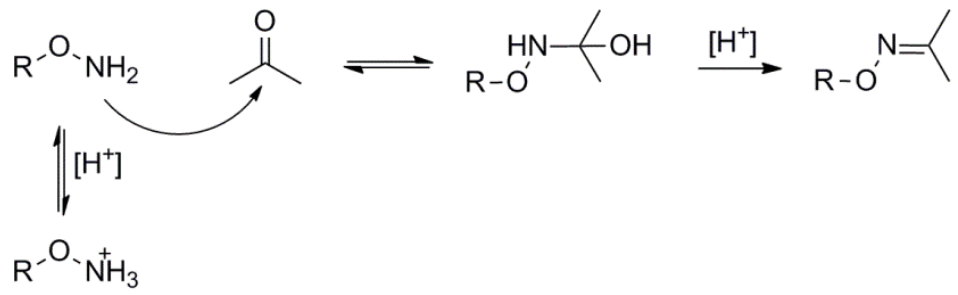

Scheme 3: Schematic representation of oxime forming reaction between a ketone and an aminooxy. In addition, the tetrahedral transition state and the protonated aminooxy are shown.

While oxime formation is a suitable chemoselective reaction for a number of applications, it was not very popular since the reaction rate was too slow, requiring high concentrations of reactants or elevated temperatures. Inspired by catalysis of semi-carbazone formation by aniline, nucleophilic catalysis by aniline was discovered as a method of catalyzing oxime formation.[19, 20] With the introduction of aniline renewed interest for oxime ligation emerged. The mechanism of aniline catalysis is based on the formation of a highly reactive protonated Schiff base. Because the equilibrium constant for formation of this Schiff base is extremely small, large excesses of aniline can be used. In the final step of catalysis the protonated Schiff base undergoes a transimination reaction with the desired aminooxy compound to yield an oxime. 
The aim of this thesis is to further develop the design and application of oxime bond chemistry for its practical use in peptides and proteins. After obtaining improved protocols for the use of oxime ligation, these methods will be applied to the synthesis of targets involved in cardiovascular research. 


\section{References}

1. Fischer, E., Synthese von Polypeptiden. XXIII. Berichte der deutschen chemischen Gesellschaft, 1908. 41(1): 850-864.

2. Bergmann, M. and L. Zervas, Über ein allgemeines Verfahren der Peptid-Synthese. Berichte der deutschen chemischen Gesellschaft (A and B Series), 1932. 65(7): 11921201.

3. Vigneaud, V.d., C. Ressler, C.J.M. Swan, C.W. Roberts, P.G. Katsoyannis, and S. Gordon, The synthesis of an octapeptide amide with the hormonal activity of oxytocin. J Am Chem Soc, 1953. 75(19): 4879-4880.

4. Katsoyannis, P.G., K. Fukuda, A. Tometsko, K. Suzuki, and M. Tilak, Insulin Peptides. X. The Synthesis of the B-Chain of Insulin and Its Combination with Natural or Synthetic A-Chain to Generate Insulin Activity. J Am Chem Soc, 1964. 86(5): 930-932.

5. Merrifield, R.B., Solid Phase Peptide Synthesis. I. The Synthesis of a Tetrapeptide. J Am Chem Soc, 1963. 85(14): 2149-2154.

6. Carpino, L.A. and G.Y. Han, 9-Fluorenylmethoxycarbonyl amino-protecting group. The Journal of Organic Chemistry, 1972. 37(22): 3404-3409.

7. Schnolzer, M. and S.B. Kent, Constructing proteins by dovetailing unprotected synthetic peptides: backbone-engineered HIV protease. Science, 1992. 256(5054): 221-225.

8. Dawson, P.E., T.W. Muir, I. Clark-Lewis, and S.B. Kent, Synthesis of proteins by native chemical ligation. Science, 1994. 266(5186): 776-779.

9. Wan, Q. and S.J. Danishefsky, Free-radical-based, specific desulfurization of cysteine: a powerful advance in the synthesis of polypeptides and glycopolypeptides. Angew Chem Int Ed Engl, 2007. 46(48): 9248-9252.

10. Malins, L.R. and R.J. Payne, Recent extensions to native chemical ligation for the chemical synthesis of peptides and proteins. Curr Opin Chem Biol, 2014. 22: 70-78.

11. Rostovtsev, V.V., L.G. Green, V.V. Fokin, and K.B. Sharpless, A stepwise huisgen cycloaddition process: copper(I)-catalyzed regioselective "ligation" of azides and terminal alkynes. Angew Chem Int Ed Engl, 2002. 41(14): 2596-2599.

12. Tornoe, C.W., C. Christensen, and M. Meldal, Peptidotriazoles on solid phase: [1,2,3]triazoles by regiospecific copper(i)-catalyzed 1,3-dipolar cycloadditions of terminal alkynes to azides. The Journal of organic chemistry, 2002. 67(9): 3057-3064.

13. Knall, A.C. and C. Slugovc, Inverse electron demand Diels-Alder (iEDDA)-initiated conjugation: a (high) potential click chemistry scheme. Chem Soc Rev, 2013. 42(12): 5131-5142.

14. Rose, K., Facile Synthesis of Homogeneous Artificial Proteins. J Am Chem Soc, 1994. 116(1): 30-33.

15. Kalia, J. and R.T. Raines, Hydrolytic stability of hydrazones and oximes. Angew Chem Int Ed Engl, 2008. 47(39): 7523-7526.

16. Edwards, J.O. and R.G. Pearson, The Factors Determining Nucleophilic Reactivities. J Am Chem Soc, 1962. 84(1): 16-24.

17. Jencks, W.P. and J. Carriuolo, Reactivity of Nucleophilic Reagents toward Esters. J Am Chem Soc, 1960. 82(7): 1778-1786.

18. Jencks, W.P., Studies on the Mechanism of Oxime and Semicarbazone Formation1. J Am Chem Soc, 1959. 81(2): 475-481.

19. Cordes, E.H. and W.P. Jencks, Nucleophilic Catalysis of Semicarbazone Formation by Anilines. J Am Chem Soc, 1962. 84(5): 826-831.

20. Dirksen, A., T.M. Hackeng, and P.E. Dawson, Nucleophilic catalysis of oxime ligation. Angew Chem Int Ed Engl, 2006. 45(45): 7581-7584 



\section{Chapter 2}

Oxime conjugation in protein chemistry:

From carbonyl incorporation to
nucleophilic catalysis

Agten SM, Dawson PE, Hackeng TM .

J Pept Sci 2016; 22(5): 271-9 


\section{Abstract}

Use of oxime forming reactions has become a widely applied strategy for peptide and protein bioconjugation. The efficiency of the reaction and robust stability of the oxime product has led to the development of a growing list of methods to introduce the required ketone or aldehyde functionality site specifically into proteins. Early methods focused on site-specific oxidation of an N-terminal serine or threonine and more recently transamination methods have been developed to convert a broader set of $\mathrm{N}$ terminal amino acids into a ketone or aldehyde. More recently, site specific modification of protein has been attained through engineering enzymes involved in posttranslational modifications in order to accommodate aldehyde containing substrates. Similarly, a growing list of unnatural amino acids can be introduced through development of selective amino-acyl tRNA synthetase/tRNA pairs combined with codon reassignment. In the case of glycoproteins, glycans can be selectively modified chemically or enzymatically to introduce aldehyde functional groups. Finally, the total chemical synthesis of proteins complements these biological and chemoenzymatic approaches. Once introduced, the oxime ligation of these aldehyde and ketone groups can be catalyzed by aniline or a variety of aniline derivatives to tune the activity, $\mathrm{pH}$ preference, stability and solubility of the catalyst.

\section{Introduction}

Oxime ligation has gained considerable attention over the past decade and is being used for a large number of applications, mainly in the field of bioconjugation. Examples include synthetic proteins [1-6], bioconjugates [7-11] and multivalent constructs [3, 12-14].An oxime bond is the result of a condensation reaction of a ketone or aldehyde and an aminooxy moiety to result in a ketoxime or aldoxime respectively (Scheme 1). Oximes are part of the imine family with general formula $R^{1} R^{2} C=N R^{3}$ and are also known as Schiff's bases when all $R$ groups are either an alkyl or aryl group. $[15,16]$ While imines are generally considered to be unstable bonds, the $\alpha$-effect, caused by a heteroatom (oxygen on $\mathrm{R}^{3}$ ) adjacent to the amine in an aminooxy ensures hydrolytic stability of the oxime bond and thus suitability for conjugation purposes. $[17,18]$ A related reaction of a ketone or aldehyde with a hydrazine (nitrogen on $\mathrm{R}^{3}$ ) to yield a hydrazone is significantly less stable, but is useful for rapid conjugation for in vitro uses and has been shown to be useful for reversible protein conjugates and libraries. [19-22] 


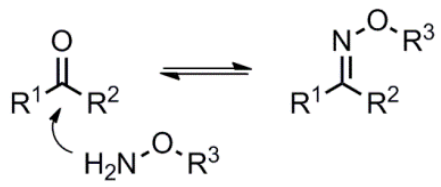

Scheme 1: Schematic representation of the reaction of a ketone with an aminooxy to yield an oxime bond.

Since a ketone functionality is not present in natural proteins, a suitable method must be chosen for its introduction. In this review we highlight several approaches that have been utilized for the site specific oxime modification of proteins. Furthermore, introduction of aniline as a nucleophilic catalyst [23] for oxime ligations gave rise to a number of aromatic amine catalysts, with distinct reaction profiles. The development and reactivity of these catalysts will be reviewed in order to provide the reader with a more complete picture regarding oxime ligations as a tool in protein chemistry.

Carbonyl Incorporation

The introduction of ketones or aldehydes into polypeptides remains a limiting step in the use of oxime ligations. In the past decade, a number of new techniques have emerged that range from total chemical synthesis approaches to genetic incorporation of the desired ketone or aldehyde. Several strategies have been developed to introduce ketone/aldehyde moieties by means of chemical treatment, enzymatic modification, genetic methods, glycan modification and chemical synthesis.

One of the biggest advantages of the carbonyl functionality is its absence in normal proteins; side reactions are unlikely to occur and modifications can be made site specifically without the use of protective groups. However, this also limits the use of this functional group as a starting point for modifications.

Chemical treatment

Early methods to generate an aldehyde or ketone in a protein were reactions to site specifically modify one or more residues in the desired molecule. The most well known and most used is the oxidation with sodium periodate. More specifically this reaction takes advantage of the extreme selectivity of 1-amino 2-alcohol compounds towards hypervalent iodine species such as metaperiodate (Scheme 2). [24] In proteins, this functional group is exclusively found at the site of $\mathrm{N}$-terminal serine or threonine. [25-27] The selectivity of this reagent, ensures a highly specific reaction under conditions that rarely affect amino acids prone to oxidation. 


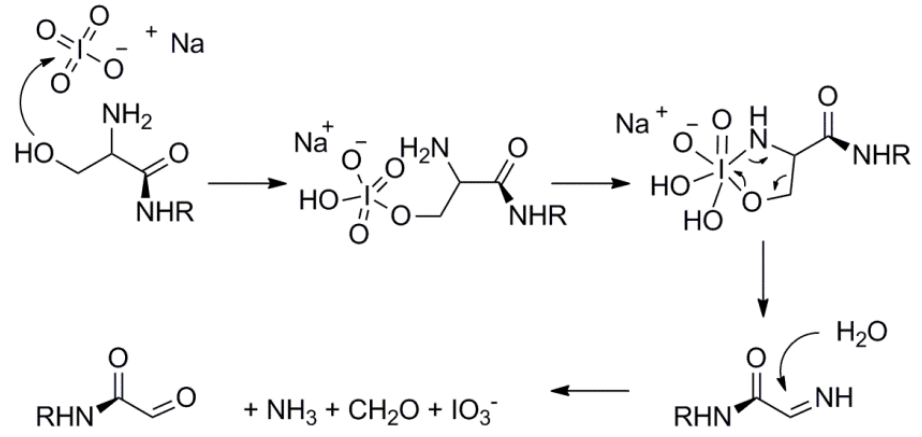

Scheme 2:. Schematic representation of sodium periodate oxidation of an $\mathrm{N}$-terminal serine. The intermediate periodate ester opens to give a Schiff base of ammonia that subsequently hydrolyzes to yield the final glyoxylyl product.

This oxidative cleavage yields a glyoxylyl product that can be used to react with various (aminooxy) functionalized labels. [3, 28-30] The disadvantage of this method is the necessity of a serine or threonine at the N-terminal position, which when not found naturally, must be introduced through mutagenesis. In order to introduce ketones and aldeydes into a wider spectrum of naturally occurring proteins, transamination approaches have been developed. In early work, Dixon found that proteins treated with glyoxylate, a bivalent metal ion such as $\mathrm{Cu}(\mathrm{II})$ at $\mathrm{pH}$ 5-7, underwent transamination to the desired carbonyl species. [27] The biological cofactor frequently involved in transamination reactions, pyridoxal 5'-phosphate (PLP), was evaluated but in conjunction with $\mathrm{Cu}(\mathrm{II})$ was found to be inferior to glyoxylate. Recently metal free transaminations using PLP have found utility for the mild Nterminal transamination of intact proteins. Francis found that the reaction does not require the presence of metal ions and can be performed at neutral $\mathrm{pH}$ and $37^{\circ} \mathrm{C}$ in good yields. [31] The reaction is compatible to some extent with any N-terminal amino acid other than Pro and results in the corresponding glyoxylyl (Gly) or ketoamide. Reaction yields differ depending on the terminal amino acid, His, Trp, Pro and Lys proceed in low yield due to an adduct with PLP itself, in the case of His and Trp most likely through a Pictet-Spengler type reaction. [32] Furthermore, caution has to be taken when performing a subsequent oxime reaction as yields of this reaction also depend on the amino acid used. In the case of glutamine a high yield of transamidated product is observed but this product does not react to an oxime, a stable intermediate of the ketone with the glutamine side chain is the most likely explanation. [32] Optimization of the transamination reaction and subsequent oxime ligation is possible by altering the amino acids in position 2 and 3 . A lysine in position 3 leads to high reaction yields, although this does not hold true when combined with for example phenylalanine or histidine. The authors conclude that a synergistic effect of the internal sequence is the reason for the observed difference in reaction yield. [32] 


\section{Enzymatic modifications}

In order to introduce aldehydes and ketones into internal positions of the protein, researchers have leveraged the high specificity of naturally occurring enzymes involved in posttranslational modifications. One of the most straightforward strategies has been to modify the substrates of specific enzymes to contain aldehydes or ketone functional groups. Protein farnesyltransferase (PFTase) has been used for this purpose. [33] In nature this enzyme catalyzes the reaction of a farnesyl isoprenoid group from farnesyl diphosphate to a sulfur atom present in cysteine. Only cysteines present in a recognition site at the $\mathrm{C}$-terminus of a protein will be modified. This recognition site consists of 4 amino acids in the so-called CaaX box, where $C$ is the cysteine to be prenylated, $\mathrm{a}$ is any aliphatic amino acid and $\mathrm{X}$ is $\mathrm{M}, \mathrm{S}, \mathrm{Q}, \mathrm{A}$ or $\mathrm{C}$ in the case of PFTase. The farnesyl diphosphate substrate has been modified to contain either a simple aldehyde or an aryl aldehyde, both of which are still recognized by PFTase. [34] Lipoic acid ligase (LpIA) present in E.Coli can be used for the same purpose. The enzyme catalyses the reaction of lipoic acid to a 13 amino acid recognition site called LAP (LpIA acceptor peptide). The substrate pocket of the enzyme has been shown to accept mutations which can subsequently be used to fit modified substrates with unnatural functional groups. [35-37] The addition of an aryl aldehyde conjugated to the lipoic acid substrate proved to be possible by mutation of Trp 37 in LpIA. Hydrazine probes were used to site specifically label the desired protein. [38] An alternative enzyme used is tubulin tyrosine ligase (TTL), which normally attaches a tyrosine residue to the carboxy terminal end of $\alpha$-tubulin. TTL accepts very minor changes in its tyrosine substrate, one of which is 3-formyltyrosine. The enzyme was used to label $\alpha$-tubulin in living cells with a hydrazine label. [39] Later it was found that the enzyme can be used to introduce 3-formyltyrosine in any protein as long as a recognition site was present. The recognition sequence (Tub-tag) consists of 14 amino acids and needs to be installed in at the C-terminus of the protein of interest. [40] One limitation in the use of co-factor enzymes to introduce a carbonyl functionality is the necessity of acceptor sites.

An alternative approach for enzymatic introduction of a reactive carbonyl group is to use enzymes that modify natural amino acid side chains into the reactive group. One example is the site specific conversion of Cys into formylglycine. This modification occurs co-translationally by the formylglycine generating enzyme (FGE).[41, 42] The required consensus sequence was found to be LCXPXR, where $X$ stands for any amino acid. FGE will convert the cysteine residue into a formylglycine that can be used for subsequent oxime ligation. In one example, the LCXPXR motif was placed at the Nand C-terminus of different proteins and the cysteine was shown to be converted into a formylglycine. Although a formylglycine generating enzyme is naturally present in E. Coli, the yield is best when coexpressed with an additional prokaryotic FGE. [42] 


\section{Genetic methods}

Enzymatic approaches typically require specific peptide sequences to be introduced near the modification site. In order to restrict modifications to just a single amino acid residue, codons can be reassigned to recognize a tRNA loaded with the unnatural amino acid. This approach can be utilized in cells through the development of selective amino-acyl tRNA synthetase/tRNA (aaRS/tRNA) pairs. [43] Using this approach, amino acids that contain an aldehyde or ketone moiety can be introduced site selectively into proteins. The most commonly utilized unnatural amino acid for oxime ligations has been $p$-acetyl-L-phenylalanine which introduces an arylketo group into proteins at the site of a suppressed amber nonsense codon. [44] The keto group can subsequently be used to site specifically label proteins with groups such as a fluorophore or biotin, both in vitro and in vivo. An analogue of p-acetyl-Lphenylalanine, namely $\mathrm{m}$-acetyl-L-phenylalanine was later used for a similar purpose. [45] These keto amino acids were used for a number a purposes from PEGylation to spin-labelling and the modification of Fab fragments. [46-48] One limitation has been that this ketone is quite unreactive, which is a benefit for stability in the cellular environment, but oxime ligation typically requires high label concentrations, long reaction times at low $\mathrm{pH}$. Other carbonyl containing amino acids have been explored. For example a diketone containing amino acid was synthesized and used in a similar manner as p-acetyl-L-phenylalanine. [49]

Another example of introduction of a ketone group by means of genetic modification is found in the lanthipeptide family. These small peptides are ribosomally synthesized and post-translationally modified to contain thioether bridges. For this purpose serine and threonine residues are dehydrated to dehydroalanine and dehydrobutyrine respectively. A subsequent reaction with cysteines present in the sequence will form the thioether bridges. Some lanthipeptides contain an N-terminal modification in the form of a ketone that arises from a dehydrated serine or threonine at position 1 in the final sequence that does not form a thioether bridge. The dehydration of threonine and removal of the leader peptide in this case leads to spontaneous hydrolysis of the $\mathrm{N}$-terminal enamine to a $\alpha$-ketoamide. It was found that this modification could be introduced in a range of lanthipeptides to result in an $\mathrm{N}$-terminal ketone that can be modified using an aminooxy. [50]

\section{Chemical Synthesis}

While ribosomal synthesis has clear advantages for the production of large proteins, chemical synthesis and semisynthesis allows protein modifications that are not compatible with the biological assembly machinery. Solid phase peptide synthesis (SPPS) and chemical ligation can be used for the total synthesis of proteins, in which ketones or aldehydes can be incorporated at any desired position. For this purpose, 
amino acid building blocks containing a ketone can be used. The earlier mentioned p-acetyl-L-phenylalanine, used in the genetic approach, is also available for peptide synthesis. Additionally, it is possible to site specifically introduce an aldehyde by coupling a serine or threonine residue to the side chain of an orthogonally protected lysine. Alternatively keto proline can be used, which can be synthesized from the commercially available hydroxyproline by Jones oxidation. [51] Keto proline was an intermediate product in a study of proline 4-hydroxylase, but was shown to be accepted in the triple helix of collagen in a recent study. After incorporation of keto proline in the collagen sequence it was used to introduce a biotin tag via oxime ligation. [52] Furthermore, aldehydes have been introduced in peptides using a glyoxylyl moiety. Approaches have been described for incorporation of the functional group at the C-terminus using special peptidyl resins and at the N-terminus using newly designed amino acid building blocks. [53, 54] For a more site specific modification keto acids can be used. The N-terminus of a protein or alternatively, orthogonally protected lysines can be used for site specific ketone incorporation. For this purpose pyruvic acid and levulinic acid have been used. $[1,2,11,14,55]$ However, the choice of ketone is not arbitrary; we found that levulinic acid is prone to an intramolecular cyclization reaction. [56] This reaction leads to a cyclic species that is unable to form an oxime bond when reacted with an aminooxy moiety. In the same study alternatives for levulinic acid were investigated. It was found that elongation of the carbon chain with only a single carbon atom was sufficient to prevent the cyclization reaction. Furthermore, it was found that aromatic ketones are considerably less reactive than alkyl ketones. [56]

Apart from the use of carbonyl containing amino acids, the ketone can be introduced into chemically synthesized or ribosomally expressed proteins through reactions at specific side chains. Stabilizing elements are often used to overcome the disordered nature of short peptide fragments. These elements are mostly inert, but recently it was shown that the incorporation of a ketone can be achieved by macrocyclization using dichloroacetone (DCA). [57] DCA was shown to react with nucleophiles present in the peptide sequence, i.e. cysteines. The resulting product could be modified with aminooxy containing compounds, allowing the modification to occur in the middle of the crosslink. [57]

\section{Glycan M odifications}

Previously it was mentioned that ketones are not present within natural proteins, as none of the 20 natural amino acids has a carbonyl moiety. Glycosylated proteins, however, contain saccharide groups that can be used as starting points for carbonyl incorporation. In a synthetic approach, an 0-linked glycopeptide was synthesized using a Ser/Thr building block modified with GalNac. This galactose derivative could be enzymatically converted by galactase into a C- 6 aldehyde, which subsequently was 
used to incorporate an oligosaccharide using oxime ligation. [58] Furthermore, advantage can be taken of the naturally occurring open form of saccharides, in which an aldehyde is present as opposed to the closed hemiacetal form. The free aldehyde was used for modification using oxime ligation. $[59,60]$ Interesting to note is the fact that the cyclic structure of the saccharide can be conserved after oxime ligation. [60, $61]$ In addition, sialic acid has been used to introduce aldehydes into glycan structures. Sialic acid contains a diol that can be oxidized using sodium periodate (Scheme 3). [62] Oxidation of sialic acid was first used as a means of quantifying sialic acid contents in biological mixtures. The obtained aldehyde was used in a condensation reaction with resorcinol to yield stable chromogens with which sialic acid could be quantified. [63] Later, the site specific glycan modification was used to introduce radioactive labels in glycoconjugates. [64, 65] More recently the oxidation of sialic acid was used in combination with oxime ligation to introduce new functional groups on proteins. [66] The approach could even be used to label live cells which present sialic acid containing glycans on their cell surface. [67] Finally, modification of cell surface glycans was achieved by presenting cells with an unnatural derivative of $\mathrm{N}$-acetyl-mannosamine (ManLev). This glycan contains a ketone group, is converted into an unnatural sialic acid and incorporated into glycans present on the cell surface. The ketone groups present on the cell surface could subsequently be used to label cells with hydrazines.[68]

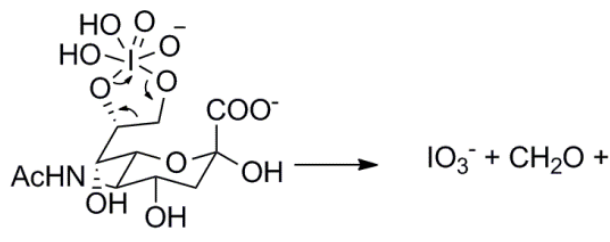<smiles>CNC1C(O)C(O)CC(O)(C(=O)[O-])CC1(O)C(=O)[O-]</smiles><smiles>CC(C)NC1C(O)CC(O)(C(=O)[O-])CC1C(=O)O</smiles>

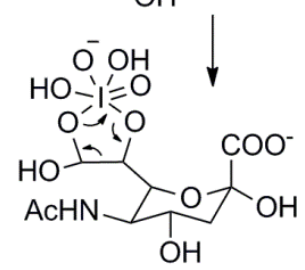

Scheme 3: Schematic representation of sodium periodate oxidation of sialic acid through a two-step procedure. In the first step, a hydroxy aldehyde is generated. The hydrated form of the aldehyde can subsequently be oxidized again by sodium periodate to yield the final product. 
Table 1: Overview of the different possibilites of carbonyl introduction in proteins and peptides

\section{Chemical treatment}

\begin{tabular}{|c|c|c|c|}
\hline $\begin{array}{l}\text { Method } \\
\text { Oxidation of N- } \\
\text { terminal } \\
\text { Ser/Thr }\end{array}$ & $\begin{array}{l}\text { Conditions } \\
\text { Accessible Ser/Thr } \\
\text { at N-terminus. } \\
\text { Treatment with } \\
\mathrm{NaIO}_{4}\end{array}$ & Resulting carbonyl moiety & $\begin{array}{l}\text { ref } \\
{[3,} \\
25- \\
27]\end{array}$ \\
\hline $\begin{array}{l}\text { Transamidation } \\
\text { of } \mathrm{N} \text {-terminal } \\
\text { residue }\end{array}$ & $\begin{array}{l}\text { Oxidation using } \\
\text { glyoxylate, } \\
\text { copper(II)salts, 1M } \\
\text { pyridine, 1M HOAc. } \\
\text { Reaction } \\
\text { conditions are } \\
\text { quite harsh. }\end{array}$ & . & [27] \\
\hline $\begin{array}{l}\text { Transamidation } \\
\text { of } \mathrm{N} \text {-terminal } \\
\text { residue }\end{array}$ & $\begin{array}{l}\text { Oxidation using } \\
\text { pyridoxal 5'- } \\
\text { phosphate. } \\
\text { Conditions are } \\
\text { milder }\end{array}$ & O & $\begin{array}{l}{[31,} \\
32]\end{array}$ \\
\hline
\end{tabular}

\section{Enzymatic modification}

Prenylation of
cysteine by
PFTase using
modified
substrate

CaaX box present in C-terminus of protein. Synthesis of a modified farnesyl substrate<smiles>CCCSCC=C(C)COC(=O)c1ccc(C=O)cc1</smiles>
[33, is required

Lipoic acid
ligase used to
ligate modified
substrate to
acceptor site

13 aa LAP site present in protein. Mutation of Lipoic acid ligase.

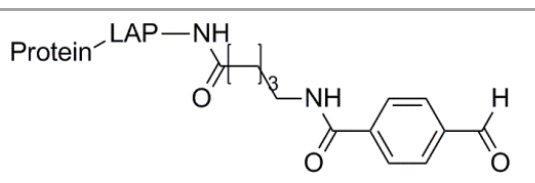

[38] Synthesis of modified substrate

3-
Formyltyrosine
incorporation
by Tubulin
tyrosine ligase

Tub-tag (14aa) required in protein to be modified. Synthesis of tyrosine derivative<smiles>O=Cc1cc(C[C@H](NC(=O)[OH2+])C(=O)O)ccc1O</smiles>
is necessary. 
Table 1 (continued):
Cysteine is
LCXPXR motif present
enzymatically
in desired protein.
converted into
Coexpression with an
formyl glycine
additional eukaryotic
${ }_{\mathrm{H}}^{\mathrm{H}} \mathrm{M}_{\mathrm{O}}^{\mathrm{H}}$

[42]

by FGE

FGE.

\section{Genetic methods}

Introduced by Use of a modified tRNA

amber

amino acid complex to

suppression

accept the keto amino

acid in response to

amber nonsense<smiles>[R]NC(Cc1ccc(C(C)=O)cc1)C([R])=O</smiles>

[44-

48]

codon.

$\begin{array}{ll}\text { N-terminal } & \text { Presence of a dehydro } \\ \text { ketone in } & \text { amino acid at position } \\ \text { lanthipeptides } & 1 \text { of the final } \\ \text { by hydrolysis of } & \text { lanthipeptide } \\ \text { a dehydro } & \\ \text { amino acid. } & \end{array}$<smiles>CCCC[GeH2]C(=O)C(=O)CC</smiles>

[50]

\section{Total chemical synthesis}

Oxidation of a
serine or
threonine
coupled to a
lysine side
chain

An orthogonally protected lysine is required, which is side chain modified with a serine or threonine residue

Solid phase peptide synthesis using keto-proline

\section{Jones oxidation of} hydroxyproline and subsequent protection of amino group with Fmoc or Boc.<smiles>N[C@@H](CCCCNC(=O)C=O)C(=O)O</smiles>

[52]

\begin{tabular}{|c|c|}
\hline $\begin{array}{l}\text { Glyoxylyl } \\
\text { introduction at } \\
\mathrm{N} \text {-terminus of } \\
\text { peptide chain }\end{array}$ & $\begin{array}{l}\text { The Fmoc protected } \\
\alpha, \alpha^{\prime} \\
\text {-diaminoacetic acid } \\
\text { needs to introduced at } \\
\text { the end of peptide } \\
\text { chain }\end{array}$ \\
\hline
\end{tabular}<smiles>O=C1CN[C@H](C(=O)O)C1</smiles> 
Table 1 (continued):

Macrocyclization Nucleophilic using DCA. groups present in

Acetone group molecule for can be used for formation of<smiles>CSCC(=O)CSC</smiles>

[57] modification macrocyclic ring

$\begin{array}{ll}\text { Amine } & \text { On resin coupling } \\ \text { modification } & \text { of desired keto- } \\ \text { using keto-acids } & \text { acid }\end{array}$<smiles>[R]NC(=O)CCCC(C)=O</smiles>

\section{Glycan modifications}

$\begin{array}{llll}\text { Natural open } & \text { Free saccharide } & \text { [59- } \\ \text { state of glycan } & \text { needs to be } \\ \text { contains an } & \text { present } & \text { OH } & \text { 61] } \\ \text { aldehyde } & & \text { O }\end{array}$

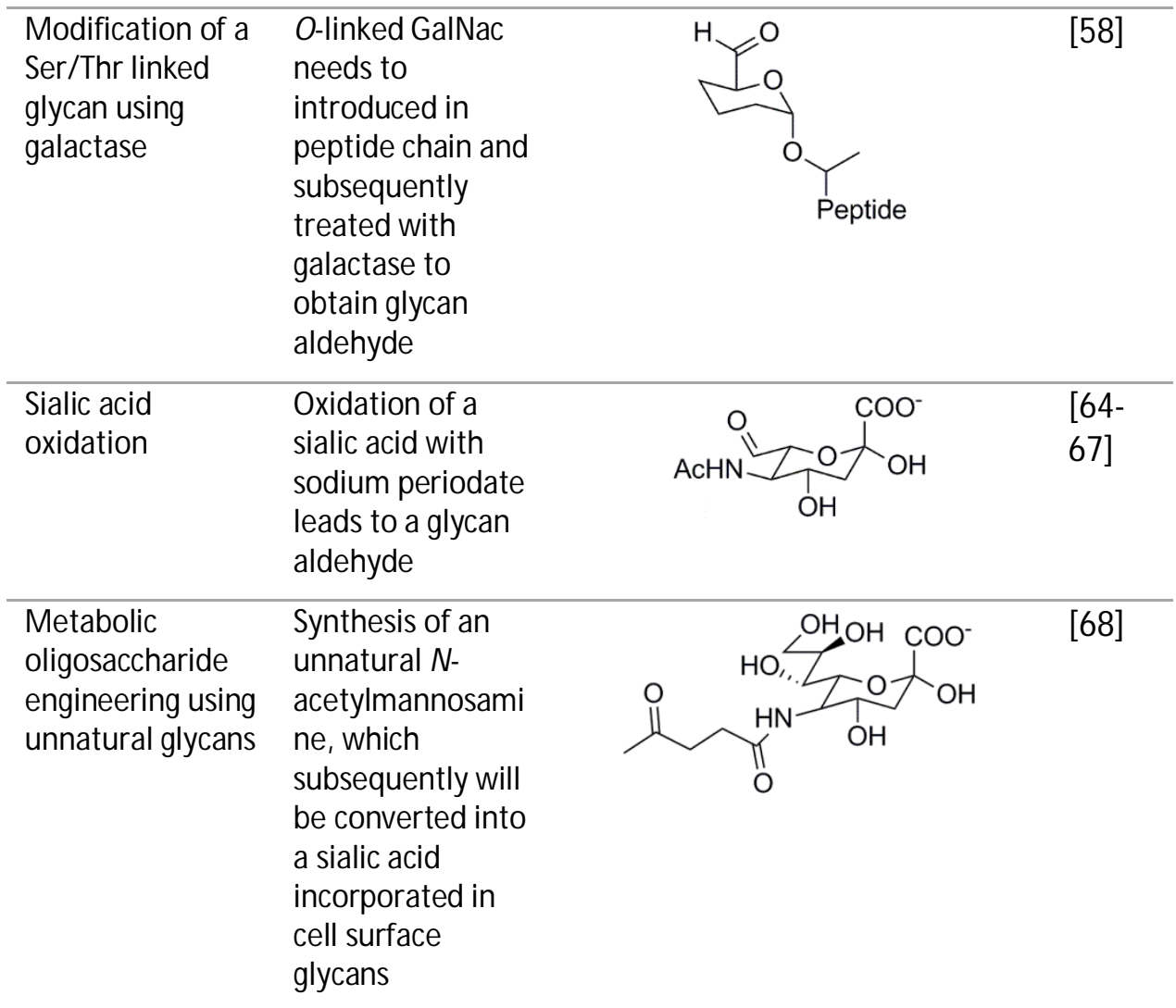




\section{Catalysis}

In the previous section it was shown that multiple techniques are available for the incorporation of ketones or aldehydes in proteins. The high chemoselectivity of the oxime bond led to a wide application in bioconjugation. Furthermore, mild reaction conditions can be used, which is particularly important when modifying folded proteins. A drawback, however, are the slow kinetics of oxime formation, which typically require the use of high concentrations or large excesses of reactants in order to obtain high yields of protein conjugation. A breakthrough came with the introduction of aniline as a nucleophilic catalyst for oxime formation which was shown to enhance oxime ligation significantly. [23] Rate enhancements of 400- and 40-fold at $\mathrm{pH} 4.5$ and 7.0 were obtained, respectively. The use of aniline as a nucleophilic catalyst was first observed by Jencks in the case of semicarbazone formation. $[18,69]$ Nucleophilic catalysis was explained by the formation of a highly reactive protonated aniline Schiff's base, subsequent transimination leads to the desired oxime bond (Scheme 4). [19, 23] It was also found that anisidine ( $\mathrm{p}-\mathrm{MeO}$-aniline) was highly effective at $\mathrm{pH} 7$, as suggested by its higher $\mathrm{pK}_{a}$ (aniline has a $\mathrm{pK}_{a}$ of 4.6 , anisidine 5.3). Aniline catalysis has been used widely for conjugation reactions on enzymes, antibodies, viral coat proteins and even the surface of human cells and inside bacterial cells. $[67,70-72]$

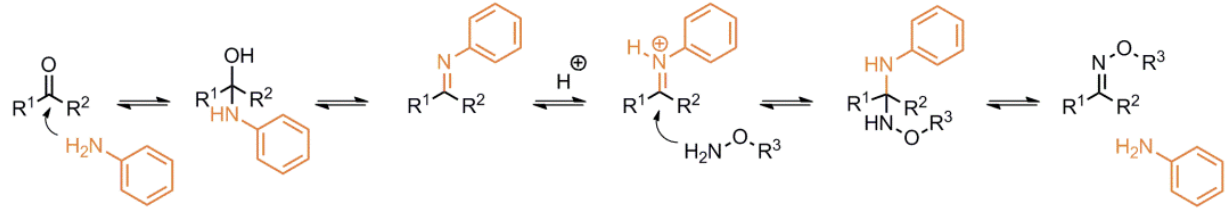

Scheme 4: Schematic representation of the mechanism of nucleophilic catalysis by aniline in the oxime-forming reaction.

In recent years, derivatives of aniline have been used to customize aniline catalysis for specific uses. It was found that at high concentrations, $100 \mathrm{mM}$ and long reaction times, aniline can destabilize some proteins. [73] For example, tubulin could no longer polymerize after treatment with high concentraitons of aniline, thus an alternative was sought. A substituted phenylalanine, 4-amino phenylalanine (4a-Phe), showed a slightly lower catalytic activity compared to aniline but maintained the polymerization activity of tubulin. [73] The catalytic activity of aniline has been tuned through neighboring groups on the ring and a number of derivatives have been investigated. These mainly focused on altering the $\mathrm{pK}_{\mathrm{a}}$ value of aniline (4.6) or increasing its water solubility by substitution of the benzene ring. In the original description of aniline catalysis for oxime ligation, anisidine (p-methoxyaniline, pMeOAn) was shown to be highly effective at neutral $\mathrm{pH}$, since $\mathrm{pMeOAn}$ has an elevated $\mathrm{pK}_{\mathrm{a}}$ of 5.3. [23] The effect of pMeOAn was subsequently analyzed in more detail and was found to work 
moderately better than aniline at neutral pH for the conjugation of glycans. [60] The water solubility of aniline is limited to $100 \mathrm{mM}$, and the development of more soluble catalysts was addressed by several groups. It was found that some commercially available anthranilic acids have both a higher solubility compared to aniline as well as an increased catalytic activity at neutral pH. The substituted anthranilic acid, 5methoxyanthranilic acid (5-MeO-AA), showed the highest increase in catalytic activity. [74] In more recent studies an extensive analysis of substituted anilines was performed. Effects of pM eOAn and 5-MeO-AA were confirmed, but were shown to be inferior to phenylenediamines, which have two potential Schiff's base forming functionalities. [48, 75] The second amine group makes phenylenediamines particularly useful in a broad pH range, since the second amine has a lower $\mathrm{pK}_{\mathrm{a}}$ (3.29) and can thus be used from $\mathrm{pH} 4$ to 7 . However, one study found m-phenylenediamine to be a superior catalyst, with higher water solubility and increased nucleophilic catalysis, whereas a more recent study finds an inhibitory effect of all meta substituted anilines and argues p-phenylenediamine is the best choice [75] No mechanistic explanation for this observation is given, but the authors speculate that their use of a glyoxylyl moiety might be a reason for the observed effect. The recent application of phenylenediamines for the introduction of a spin-label, however, found a decreased activity of $\mathrm{m}$ - or $\mathrm{p}$-phenylenediamine when compared to pM eOAn. [76] Overall, aniline and anisidine can be used as catalysts for a wide variety of oxime ligations and if rates need to be enhanced, a series of aniline analogs can be tested for suitability with the ketone/aldehyde at the $\mathrm{pH}$ that is desired.

Summary

Incorporation of ketones and aldehydes in proteins of choice has received increased attention over the past decade. Methods are now available ranging from amber suppression to total chemical synthesis of ketone containing proteins, thus making the starting point for oxime ligation available for every lab. Moreover, examples of (bio)conjugation in a variety of molecules are now available, demonstrating the wide use of the oxime bond. Development of catalysts for oxime ligation has started since the introduction of aniline as nucleophilic catalyst. Various substituted anilines are used to increase water solubility or increase catalyst activity. Recent examples, however, have shown that it is difficult to find a catalyst suitable for the general oxime reaction. The optimal catalyst has to be found for every reaction, which most likely means new oxime catalysts will keep emerging. This does, however, not mean that newer is always better. 
Table 2: Overview of nucleophilic catalysts used in oxime ligation with their properties

\begin{tabular}{|c|c|c|c|c|}
\hline Catalyst & Structure & Properties & $\mathrm{pK}_{\mathrm{a}}[77]$ & ref \\
\hline Aniline & & $\begin{array}{l}\text { First generation } \\
\text { nucleophilic catalyst. } \\
\text { Most active at acidic } \\
\text { pH. Limited water } \\
\text { solubility }\end{array}$ & 4.62 & $\begin{array}{l}{[19,} \\
23]\end{array}$ \\
\hline $\begin{array}{l}\text { 4-amino } \\
\text { phenylalanine }\end{array}$ & & $\begin{array}{l}\text { More biocompatible } \\
\text { than aniline, slightly } \\
\text { lower activity. }\end{array}$ & & [73] \\
\hline p-methoxy aniline & $\mathrm{IV}$ & $\begin{array}{l}\text { Aniline derivative } \\
\text { with increased } \mathrm{pK}_{\mathrm{a}} \text {, } \\
\text { more active at } \\
\text { neutral } \mathrm{pH} \text {. }\end{array}$ & 5.29 & $\begin{array}{l}{[23,} \\
60]\end{array}$ \\
\hline $\begin{array}{l}\text { 5-methoxy } \\
\text { anthranilic acid }\end{array}$ & $\mathrm{MeO}$ & $\begin{array}{l}\text { High water } \\
\text { solubility, increased } \\
\text { activity at neutral } \\
\text { pH compared to } \\
\text { aniline. }\end{array}$ & & [74] \\
\hline m-phenylenediamine & & $\begin{array}{l}\text { Two amine groups } \\
\text { with different } \mathrm{pK}_{\mathrm{a}} \\
\text { values, active over } \\
\text { broad pH range. } \\
\text { Shown to be } \\
\text { inhibitory in a } \\
\text { protein PEGylation } \\
\text { using an N-terminal } \\
\text { glyoxylyl group. } \\
\text { Prone to oxidation } \\
\text { to quinone species }\end{array}$ & $\begin{array}{l}4.88 \\
2.65\end{array}$ & $\begin{array}{l}{[48,} \\
75]\end{array}$ \\
\hline p-phenylenediamine & & $\begin{array}{l}\text { Two amine groups } \\
\text { with different } \mathrm{pK}_{\mathrm{a}} \\
\text { values, active over } \\
\text { broad pH range. } \\
\text { Prone to oxidation } \\
\text { to quinone species. }\end{array}$ & $\begin{array}{l}6.08 \\
3.29\end{array}$ & [75] \\
\hline
\end{tabular}




\section{References}

1. Roberts, K.D., J.N. Lambert, N.J. Ede, and A.M. Bray, Preparation of cyclic peptide libraries using intramolecular oxime formation. J Pept Sci, 2004. 10(11): 659-665.

2. Sohma, Y. and S.B. Kent, Biomimetic synthesis of lispro insulin via a chemically synthesized "mini-proinsulin" prepared by oxime-forming ligation. J Am Chem Soc, 2009. 131(44): 16313-16318.

3. Rose, K., Facile Synthesis of Homogeneous Artificial Proteins. J Am Chem Soc, 1994. 116(1): 30-33.

4. Borgia, J.A. and G.B. Fields, Chemical synthesis of proteins. Trends Biotechnol, 2000. 18(6): 243-251.

5. Kent, S.B., Total chemical synthesis of proteins. Chem Soc Rev, 2009. 38(2): 338-351.

6. Dawson, P.E. and S.B. Kent, Synthesis of native proteins by chemical ligation. Annu Rev Biochem, 2000. 69: 923-960.

7. Gauthier, M.A. and H.A. Klok, Peptide/protein-polymer conjugates: synthetic strategies and design concepts. Chem Commun, 2008(23): 2591-2611.

8. Mackenzie, K.J. and M.B. Francis, Recyclable thermoresponsive polymer-cellulase bioconjugates for biomass depolymerization. J Am Chem Soc, 2013. 135(1): 293-300.

9. Venkatesan, N. and B.H. Kim, Peptide conjugates of oligonucleotides: synthesis and applications. Chem Rev, 2006. 106(9): 3712-3761.

10. Singh, Y., P. Murat, and E. Defrancq, Recent developments in oligonucleotide conjugation. Chem Soc Rev, 2010. 39(6): 2054-2070.

11. Kochendoerfer, G.G., S.Y. Chen, F. Mao, S. Cressman, S. Traviglia, H. Shao, C.L. Hunter, D.W. Low, E.N. Cagle, M. Carnevali, V. Gueriguian, P.J. Keogh, H. Porter, S.M. Stratton, M.C. Wiedeke, J. Wilken, J. Tang, J.J. Levy, L.P. Miranda, M.M. Crnogorac, S. Kalbag, P. Botti, J. Schindler-Horvat, L. Savatski, J.W. Adamson, A. Kung, S.B. Kent, and J.A. Bradburne, Design and chemical synthesis of a homogeneous polymer-modified erythropoiesis protein. Science, 2003. 299(5608): 884-887.

12. Vadas, O., O. Hartley, and K. Rose, Characterization of new multimeric erythropoietin receptor agonists. Biopolymers, 2008. 90(4): 496-502.

13. Shao, J. and J.P. Tam, Unprotected Peptides as Building-Blocks for the Synthesis of Peptide Dendrimers with Oxime, Hydrazone, and Thiazolidine Linkages. J Am Chem Soc, 1995. 117(14): 3893-3899.

14. Lempens, E.H., M. Merkx, M. Tirrell, and E.W. Meijer, Dendrimer display of tumorhoming peptides. Bioconjug Chem, 2011. 22(3): 397-405.

15. Belowich, M.E. and J.F. Stoddart, Dynamic imine chemistry. Chem Soc Rev, 2012. 41(6): 2003-2024.

16. Schiff, H., Ann. Chem. Pharm., 1864. 131: 118-119.

17. Kalia, J. and R.T. Raines, Hydrolytic stability of hydrazones and oximes. Angew Chem Int Ed Engl, 2008. 47(39): 7523-7526.

18. Cordes, E.H. and W.P. Jencks, On the Mechanism of Schiff Base Formation and Hydrolysis. J Am Chem Soc, 1962. 84(5): 832-837.

19. Dirksen, A., S. Dirksen, T.M. Hackeng, and P.E. Dawson, Nucleophilic catalysis of hydrazone formation and transimination: implications for dynamic covalent chemistry. J Am Chem Soc, 2006. 128(49): 15602-15603.

20. Cousins, G.R.L., S.A. Poulsen, and J.K.M. Sanders, Dynamic combinatorial libraries of pseudo-peptide hydrazone macrocycles. Chem Commun, 1999(16): 1575-1576.

21. Lam, R.T., A. Belenguer, S.L. Roberts, C. Naumann, T. Jarrosson, S. Otto, and J.K. Sanders, Amplification of acetylcholine-binding catenanes from dynamic combinatorial libraries. Science, 2005. 308(5722): 667-669.

22. Dubs, P., L. Bourel-Bonnet, G. Subra, A. Blanpain, O. M elnyk, A.M. Pinel, H. Gras-Masse, 
and J. Martinez, Parallel synthesis of a lipopeptide library by hydrazone-based chemical ligation. J Comb Chem, 2007. 9(6): 973-981.

23. Dirksen, A., T.M. Hackeng, and P.E. Dawson, Nucleophilic catalysis of oxime ligation. Angew Chem Int Ed Engl, 2006. 45(45): 7581-7584.

24. Clamp, J.R. and L. Hough, The Periodate Oxidation of Amino Acids with Reference to Studies on Glycoproteins. Biochem J, 1965. 94: 17-24.

25. Gaertner, H.F., K. Rose, R. Cotton, D. Timms, R. Camble, and R.E. Offord, Construction of protein analogues by site-specific condensation of unprotected fragments. Bioconjug Chem, 1992. 3(3): 262-268.

26. Geoghegan, K.F. and J.G. Stroh, Site-directed conjugation of nonpeptide groups to peptides and proteins via periodate oxidation of a 2-amino alcohol. Application to modification at N-terminal serine. Bioconjug Chem, 1992. 3(2): 138-146.

27. Dixon, H.B.F., N-terminal modification of proteins-a review. J Protein Chem, 1984. 3(1): 99-108.

28. Ng, S., M.R. Jafari, W.L. Matochko, and R. Derda, Quantitative synthesis of genetically encoded glycopeptide libraries displayed on M13 phage. ACS Chem Biol, 2012. 7(9): 1482-1487.

29. Kitov, P.I., D.F. Vinals, S. Ng, K.F. Tjhung, and R. Derda, Rapid, hydrolytically stable modification of aldehyde-terminated proteins and phage libraries. J Am Chem Soc, 2014. 136(23): 8149-8152.

30. Tjhung, K.F., P.I. Kitov, S. Ng, E.N. Kitova, L. Deng, J.S. Klassen, and R. Derda, Silent Encoding of Chemical Post-Translational Modifications in Phage-Displayed Libraries. J Am Chem Soc, 2016. 138(1): 32-35.

31. Gilmore, J.M., R.A. Scheck, A.P. Esser-Kahn, N.S. Joshi, and M.B. Francis, N-terminal protein modification through a biomimetic transamination reaction. Angew Chem Int Ed Engl, 2006. 45(32): 5307-5311.

32. Scheck, R.A., M.T. Dedeo, A.T. Iavarone, and M.B. Francis, Optimization of a biomimetic transamination reaction. J Am Chem Soc, 2008. 130(35): 11762-11770.

33. Turek, T.C., I. Gaon, M.D. Distefano, and C.L. Strickland, Synthesis of farnesyl diphosphate analogues containing ether-linked photoactive benzophenones and their application in studies of protein prenyltransferases. J Org Chem, 2001. 66(10): 32533264.

34. Rashidian, M., J.M. Song, R.E. Pricer, and M.D. Distefano, Chemoenzymatic reversible immobilization and labeling of proteins without prior purification. J Am Chem Soc, 2012. 134(20): 8455-8467.

35. Baruah, H., S. Puthenveetil, Y.A. Choi, S. Shah, and A.Y. Ting, An engineered aryl azide ligase for site-specific mapping of protein-protein interactions through photo-crosslinking. Angew Chem Int Ed Engl, 2008. 47(37): 7018-7021.

36. Liu, D.S., A. Tangpeerachaikul, R. Selvaraj, M.T. Taylor, J.M. Fox, and A.Y. Ting, DielsAlder cycloaddition for fluorophore targeting to specific proteins inside living cells. J Am Chem Soc, 2012. 134(2): 792-795.

37. Uttamapinant, C., K.A. White, H. Baruah, S. Thompson, M. Fernandez-Suarez, S. Puthenveetil, and A.Y. Ting, A fluorophore ligase for site-specific protein labeling inside living cells. Proc Natl Acad Sci U SA, 2010. 107(24): 10914-10919.

38. Cohen, J.D., P. Zou, and A.Y. Ting, Site-specific protein modification using lipoic acid ligase and bis-aryl hydrazone formation. Chembiochem, 2012. 13(6): 888-894.

39. Banerjee, A., T.D. Panosian, K. M ukherjee, R. Ravindra, S. Gal, D.L. Sackett, and S. Bane, Site-specific orthogonal labeling of the carboxy terminus of alpha-tubulin. ACS Chem Biol, 2010. 5(8): 777-785.

40. Schumacher, D., J. Helma, F.A. Mann, G. Pichler, F. Natale, E. Krause, M.C. Cardoso, C.P. Hackenberger, and H. Leonhardt, Versatile and Efficient Site-Specific Protein 
Functionalization by Tubulin Tyrosine Ligase. Angew Chem Int Ed Engl, 2015. 54(46): 13787-13791.

41. Dierks, T., B. Schmidt, and K. von Figura, Conversion of cysteine to formylglycine: a protein modification in the endoplasmic reticulum. Proc Natl Acad Sci U S A, 1997. 94(22): 11963-11968.

42. Carrico, I.S., B.L. Carlson, and C.R. Bertozzi, Introducing genetically encoded aldehydes into proteins. Nat Chem Biol, 2007. 3(6): 321-322.

43. Wang, L., J. Xie, and P.G. Schultz, Expanding the genetic code. Annu Rev Biophys Biomol Struct, 2006. 35: 225-249.

44. Wang, L., Z. Zhang, A. Brock, and P.G. Schultz, Addition of the keto functional group to the genetic code of Escherichia coli. Proc Natl Acad Sci U SA, 2003. 100(1): 56-61.

45. Zhang, Z, B.A. Smith, L. Wang, A. Brock, C. Cho, and P.G. Schultz, A new strategy for the site-specific modification of proteins in vivo. Biochemistry, 2003. 42(22): 6735-6746.

46. Fleissner, M.R., E.M. Brustad, T. Kalai, C. Altenbach, D. Cascio, F.B. Peters, K. Hideg, S. Peuker, P.G. Schultz, and W.L. Hubbell, Site-directed spin labeling of a genetically encoded unnatural amino acid. Proc Natl Acad Sci U SA, 2009. 106(51): 21637-21642.

47. Kim, C.H., J.Y. Axup, A. Dubrovska, S.A. Kazane, B.A. Hutchins, E.D. W old, V.V. Smider, and P.G. Schultz, Synthesis of bispecific antibodies using genetically encoded unnatural amino acids. J Am Chem Soc, 2012. 134(24): 9918-9921.

48. Rashidian, M., M.M. Mahmoodi, R. Shah, J.K. Dozier, C.R. Wagner, and M.D. Distefano, A highly efficient catalyst for oxime ligation and hydrazone-oxime exchange suitable for bioconjugation. Bioconjug Chem, 2013. 24(3): 333-342.

49. Zeng, H., J. Xie, and P.G. Schultz, Genetic introduction of a diketone-containing amino acid into proteins. Bioorg M ed Chem Lett, 2006. 16(20): 5356-5359.

50. Bindman, N.A. and W.A. van der Donk, A general method for fluorescent labeling of the $\mathrm{N}$-termini of lanthipeptides and its application to visualize their cellular localization. J Am Chem Soc, 2013. 135(28): 10362-10371.

51. Baldwin, J.E., R.A. Field, C.C. Lawrence, K.D. Merritt, and C.J. Schofield, Proline 4Hydroxylase - Stereochemical Course of the Reaction. Tetrahedron Lett, 1993. 34(46): 7489-7492.

52. Choudhary, A., K.J. Kamer, M.D. Shoulders, and R.T. Raines, 4-ketoproline: An electrophilic proline analog for bioconjugation. Biopolymers, 2015. 104(2): 110-115.

53. El-M ahdi, O. and O. M elnyk, alpha-Oxo aldehyde or glyoxylyl group chemistry in peptide bioconjugation. Bioconjug Chem, 2013. 24(5): 735-765.

54. Far, S. and O. Melnyk, Synthesis of glyoxylyl peptides using an Fmoc-protected alpha,alpha'-diaminoacetic acid derivative. J Pept Sci, 2005. 11(7): 424-430.

55. Canne, L.E., A.R. Ferredamare, S.K. Burley, and S.B.H. Kent, Total Chemical Synthesis of a Unique Transcription Factor-Related Protein - Cmyc-M ax. J Am Chem Soc, 1995. 117(11): 2998-3007.

56. Agten, S.M., D. Suylen, H. Ippel, M. Kokozidou, G. Tans, P. van de Vijver, R.R. Koenen, and T.M. Hackeng, Chemoselective oxime reactions in proteins and peptides by using an optimized oxime strategy: the demise of levulinic acid. Chembiochem, 2013. 14(18): 2431-2434.

57. Assem, N., D.J. Ferreira, D.W. Wolan, and P.E. Dawson, Acetone-Linked Peptides: A Convergent Approach for Peptide Macrocyclization and Labeling. Angew Chem Int Ed Engl, 2015. 54(30): 8665-8668.

58. Rodriguez, E.C., K.A. Winans, D.S. King, and C.R. Bertozzi, A strategy for the chemoselective synthesis of O-linked glycopeptides with native sugar-peptide linkages. J Am Chem Soc, 1997. 119(41): 9905-9906.

59. Bondalapati, S., E. Ruvinov, O. Kryukov, S. Cohen, and A. Brik, Rapid End-Group Modification of Polysaccharides for Biomaterial Applications in Regenerative Medicine. 
Macromol Rapid Commun, 2014. 35(20): 1754-1762.

60. Thygesen, M.B., H. M unch, J. Sauer, E. Clo, M.R. Jorgensen, O. Hindsgaul, and K.J. Jensen, Nucleophilic catalysis of carbohydrate oxime formation by anilines. J Org Chem, 2010. 75(5): 1752-1755.

61. Peri, F., P. Dumy, and M. Mutter, Chemo- and stereoselective glycosylation of hydroxylamino derivatives: A versatile approach to glycoconjugates. Tetrahedron, 1998. 54(40): 12269-12278.

62. Van Lenten, L. and G. Ashwell, Studies on the chemical and enzymatic modification of glycoproteins. A general method for the tritiation of sialic acid-containing glycoproteins. J Biol Chem, 1971. 246(6): 1889-1894.

63. Jourdian, G.W., L. Dean, and S. Roseman, The sialic acids. XI. A periodate-resorcinol method for the quantitative estimation of free sialic acids and their glycosides. J Biol Chem, 1971. 246(2): 430-435.

64. Bhavanandan, V.P., M. Murray, and E.A. Davidson, Modification and Introduction of Various Radioactive Labels into the Sialic-Acid Moiety of Sialoglycoconjugates. Glycoconjugate J, 1988. 5(4): 467-484.

65. Gahmberg, C.G. and L.C. Andersson, Selective radioactive labeling of cell surface sialoglycoproteins by periodate-tritiated borohydride. J Biol Chem, 1977. 252(16): 58885894.

66. Dhal, P.K., S.C. Polomoscanik, D.A. Gianolio, P.G. Starremans, M. Busch, K. Alving, B. Chen, and R.J. Miller, Well-defined aminooxy terminated N-(2-hydroxypropyl) methacrylamide macromers for site specific bioconjugation of glycoproteins. Bioconjug Chem, 2013. 24(6): 865-877.

67. Zeng, Y., T.N. Ramya, A. Dirksen, P.E. Dawson, and J.C. Paulson, High-efficiency labeling of sialylated glycoproteins on living cells. Nat M ethods, 2009. 6(3): 207-209.

68. Mahal, L.K., K.J. Yarema, and C.R. Bertozzi, Engineering chemical reactivity on cell surfaces through oligosaccharide biosynthesis. Science, 1997. 276(5315): 1125-1128.

69. Cordes, E.H. and W.P. Jencks, Nucleophilic Catalysis of Semicarbazone Formation by Anilines. J Am Chem Soc, 1962. 84(5): 826-831.

70. Rayo, J., N. Amara, P. Krief, and M.M. Meijler, Live cell labeling of native intracellular bacterial receptors using aniline-catalyzed oxime ligation. J Am Chem Soc, 2011. 133(19): 7469-7475.

71. Behrens, C.R., J.M. Hooker, A.C. Obermeyer, D.W. Romanini, E.M. Katz, and M.B. Francis, Rapid chemoselective bioconjugation through oxidative coupling of anilines and aminophenols. J Am Chem Soc, 2011. 133(41): 16398-16401.

72. Byeon, J.Y., F.T. Limpoco, and R.C. Bailey, Efficient bioconjugation of protein capture agents to biosensor surfaces using aniline-catalyzed hydrazone ligation. Langmuir, 2010. 26(19): 15430-15435.

73. Blanden, A.R., K. Mukherjee, O. Dilek, M. Loew, and S.L. Bane, 4-aminophenylalanine as a biocompatible nucleophilic catalyst for hydrazone ligations at low temperature and neutral pH. Bioconjug Chem, 2011. 22(10): 1954-1961.

74. Crisalli, P. and E.T. Kool, Water-soluble organocatalysts for hydrazone and oxime formation. J Org Chem, 2013. 78(3): 1184-1189.

75. Wendeler, M., L. Grinberg, X. Wang, P.E. Dawson, and M. Baca, Enhanced catalysis of oxime-based bioconjugations by substituted anilines. Bioconjug Chem, 2014. 25(1): 93101.

76. Hahn, A., S. Reschke, S. Leimkuhler, and T. Risse, Ketoxime coupling of $p$ acetylphenylalanine at neutral $\mathrm{pH}$ for site-directed spin labeling of human sulfite oxidase. J Phys Chem B, 2014. 118(25): 7077-7084.

77. Jencks, W.P. and J. Regenstein, Ionization Constants of Acids and Bases, in Handbook of Biochemistry and Molecular Biology, Fourth Edition2010, CRC Press. p. 595-635. 


\section{Chapter 3}

Chemoselective oxime reactions in proteins and peptides using an optimized oxime strategy: the demise of levulinic acid

Agten SM , Suylen D, Ippel H, Kokozidou M, Tans G, van de Vijver $P$, Koenen RR, Hackeng TM.

Chembiochem 2013; 14(18): 2431-4 
Chemoselective conjugation of proteins and peptides allows the formation of a covalent bond without the need of protective group chemistry in labeling or assembling macromolecules. Chemical reactions yielding oxime bonds are highly suitable for this purpose. The oxime ligation comprises the reaction of a ketone or aldehyde (1) with an aminooxy (2) to form a special imine known as an oxime (3) (Scheme 1). Advantages of this strategy include its chemoselectivity, since a ketone is inert to most other reactions, and the mild conditions in which the reaction can be performed. Oxime formation has been thoroughly investigated and was found to proceed in a step-wise manner depending on the $\mathrm{pH}$ at which the reaction is performed. [1, 2] Although the reaction proceeds faster in acidic conditions (pH 4-5) oximes will also form at neutral $\mathrm{pH}$. Oxime formation can be accelerated by the addition of the catalyst aniline. [3, 4] Furthermore, oximes are stable at neutral pH. [5] Altogether, these properties make the oxime linkage one of the preferred methods for the chemoselective modification of peptides and proteins. [6] Levulinic acid (LA) is one of the most frequently used ketones for oxime formation, and is generally introduced by attachment to a lysine side chain $\varepsilon-\mathrm{NH}_{2}$ or an $\mathrm{N}$-terminal $\mathrm{NH}_{2}$ moiety. [7, 8] The reaction between the protein-levulinic acid complex and an aminooxy moiety proceeds well at millimolar concentrations. However, the relative low quantity and high molecular weight of most proteins result in submillimolar protein concentrations and limitations of the oxime reaction. Under those conditions, we and others have found that oxime reaction yields are low due to the formation of a levulinoyl derived side-product that competes with oxime bond formation. [7] As oxime ligations are still an increasingly attractive and orthogonal approach to label proteins, alternative ketone moieties for bioconjugation were explored. Our hypothesis is that the levulinoyl side-product, corresponding to a differential mass loss of $18 \mathrm{Da}$, is the result of an intramolecular cyclization of levulinic acid, thus preventing the LA ketone group from reacting with the aminooxy moiety. The formation of this by-product is mainly seen at low concentrations because under those conditions the concentrationindependent cyclization side-reaction will benefit from the slow oxime formation.

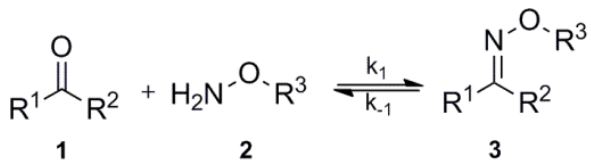

Scheme 1: Overall oxime reaction. A ketone or aldehyde (1) will react with an aminooxy (2) to form an oxime bond (3)

To study the molecular mechanism underlying levulinoyl cyclization, a pentapeptide LYRAK was synthesized with levulinic acid (LA) coupled to the lysine $\varepsilon$-amine, giving LYRAK(LA). Lyophilized LYRAK(LA) was dissolved in water under acidic conditions ( $\mathrm{pH}$ 4.5) and was left to cyclize spontaneously for $72 \mathrm{~h}$ at room temperature. The conversion to cyclized derivatives was monitored by ESI-M S and NM R (both in DM SO- 
$\mathrm{d}_{6}$ and $\mathrm{D}_{2} \mathrm{O}$ ) and structurally characterized by 2D NM R experiments (SI-1 and SI-2). The cyclization of levulinic acid was tested at 3 concentrations and was shown to be concentration independent (SI-3).

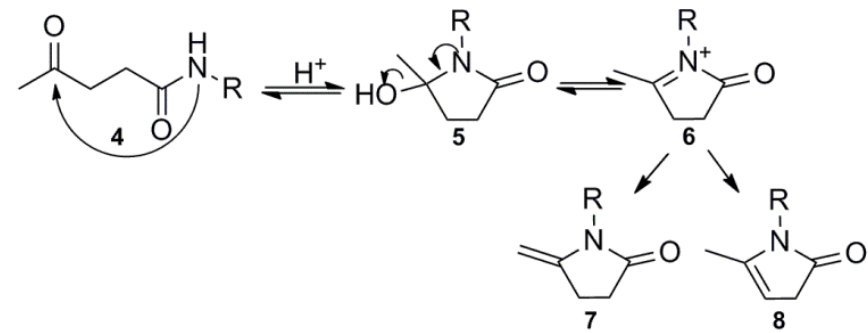

Scheme 2: Proposed mechanism for the formation of the cyclic species from levulinoyl-peptides

Based on these results, a reaction mechanism for intramolecular cyclization of the levulinoyl moiety is proposed (Scheme 2): The amide nitrogen in the linear levulinoyl peptide $\mathbf{4}$ performs a nucleophilic attack on the ketone carbonyl group resulting in the cyclic intermediate $\mathbf{5}$. This reaction was previously reported to be favored by protonation of the carbonyl. [9] Spontaneous dehydration of $\mathbf{5}$ leads to the iminium species $\mathbf{6}$ which is stabilized by TFA present in solution. Spontaneous isomerization of $\mathbf{6}$ leads to $\mathbf{7}$ and $\mathbf{8}$ as determined by 2D NM R methods (SI-1). The conversion of the exocyclic double bond containing species $\mathbf{7}$ from $\mathbf{5}$ has been reported, but not the formation of the endocyclic double bond. [10] Here, 8 is observed but is formed as a minor product compared to the major exocyclic species 7 (NM R analysis in DM SO- $\mathrm{d}_{6}$ showed $\mathbf{7 / 8}$ ratio of 5:1). In addition to NMR analysis, the formation of the cyclic species was deduced from MS data. Both the iminium (6) with a mass difference of $17 \mathrm{Da}$ and the final cyclic double bond species $(\mathbf{7 , 8})$ with a mass difference of $-18 \mathrm{Da}$ were observed (SI-4). Based on our observations and the proposed reaction mechanism, we hypothesize that only a small amount of the linear form is present after cleavage of the peptide from the resin, the majority being in the cyclized form (5) which shows no mass difference when compared to the linear form. Although it remains unclear whether the pyrrolidone $\mathbf{5}$ is formed during TFA treatment, HF cleavage, or under aqueous acidic conditions during the oxime ligation, the low oxime yields in the early experiments can be explained by the cyclic derivative being unable to react with the aminooxy moiety. 


4-acetylbenzoic acid (ABA)

Scheme 3: Keto-acids used in test oxime ligations

We selected a small set of commercially available keto-acids and compared these against levulinic acid for ketone functionalization and oxime conjugation of peptides and proteins. An overview of the different keto-acids used is shown in Scheme 3.

LYRAK test peptides were used with different keto-acids coupled through the $\varepsilon$-amine of the lysine side-chain. A VIPF peptide was synthesized and N-terminally modified with aminooxyacetic acid (AO) (SI-11). Each of the ketone derivatives was tested by reacting the ketone peptide with the aminooxy peptide at different concentrations ( 7 , 70 and $700 \mu \mathrm{M}$ ) in ammonium acetate buffer at pH 4.5, being the optimal pH for imine reactions. [3] The oxime reactions of the various ketones with aminooxy peptides were followed in time using UPLC-MS $(220,280 \mathrm{~nm})$ for $48 \mathrm{~h}$ at $37^{\circ} \mathrm{C}$, quantified by peak integration, and the relative intensities fitted to a reversible second-order reaction equation (Sl and Figure 1). 

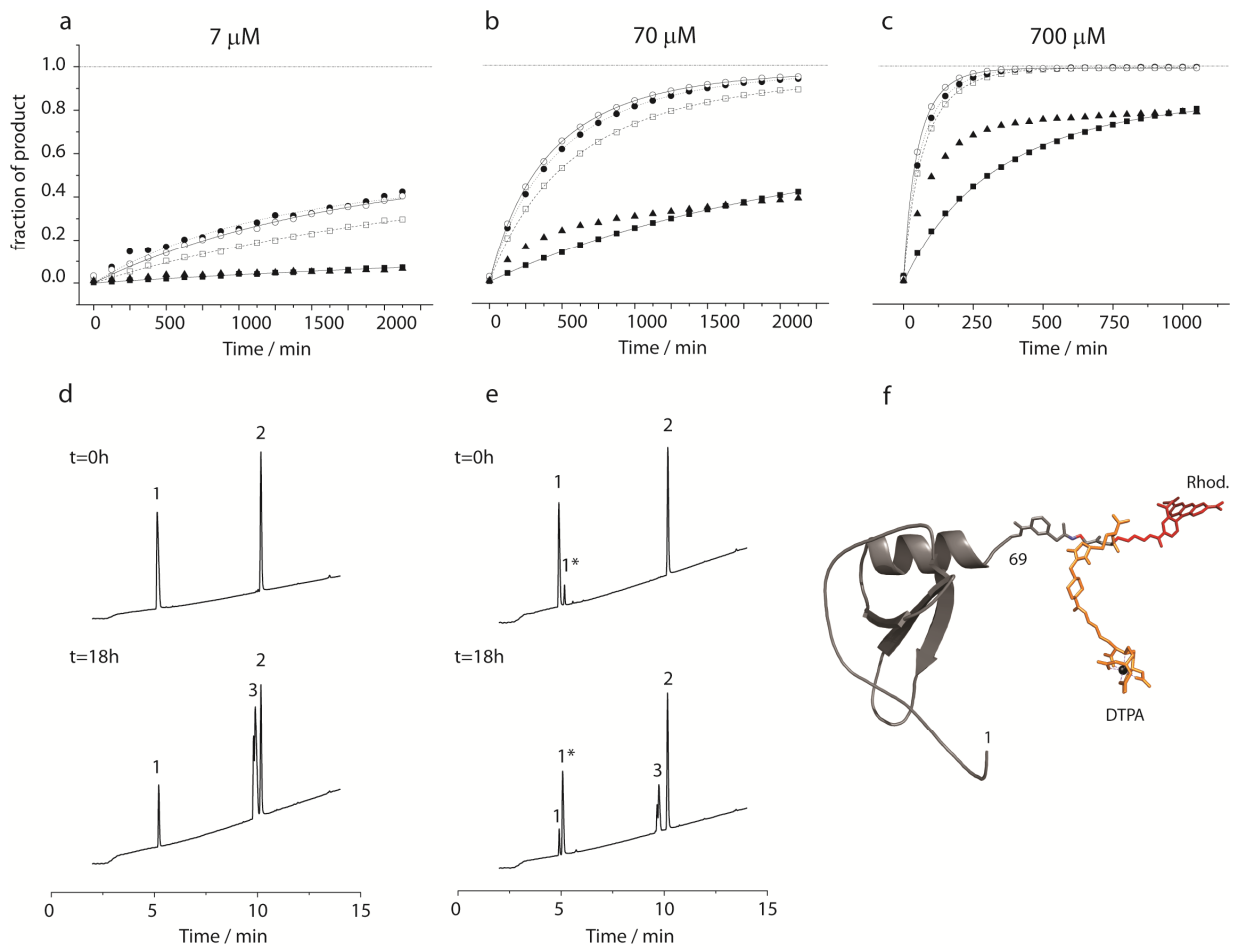

Figure 1: a: LYRAK-VIPF oxime product formation plotted in time at a concentration of $7 \mu \mathrm{M}$ ketone, b: $70 \mu \mathrm{M}$ ketone, c: $700 \mu \mathrm{M}$ ketone with — LYRAK(ABA), 口 LYRAK(AB), O LYRAK(OBA), • LYRAK(OOA), $\Delta$ LYRAK(LA). For all concentrations fits by a second order reversible reaction equation are shown, No fits could be obtained for LA under any conditions. d: UV ( $220 \mathrm{~nm})$ trace of the reaction of LYRAK peptide $(70 \mu \mathrm{M})$ modified with ketone $A B(1)$ with the VIPF aminooxy peptide (2) to form LYRAK-VIPF oxime product (3). e: UV trace of reaction of peptide modified with ketone LA (1). Major cyclic side product $\left(1^{*}\right)$ is formed in addition to oxime product (3). f: schematic representation of RANTES conjugated to a bimodal rhodamine/DTPA label through an oxime bond.

To validate this method, one of the reactions was repeated and analyzed by real-time NMR. Reaction rate constants of oxime ligation at $700 \mu \mathrm{M}$ between LYRAK(AB) and AO-VIPF were measured independently by following the oxime reaction in real-time (in sodium acetate- $d_{3}, \mathrm{pH} 4.5$ at $37^{\circ} \mathrm{C}$ ) by NM R spectroscopy. Isolated proton signals of $\mathrm{NH}$ Val1 in $\mathrm{AO}-\mathrm{VIPF}$ and $\mathrm{AB}\left(3-\mathrm{CH}_{2}\right)$ in $\operatorname{LYRAK}(\mathrm{AB})$ were used to integrate the population of reactants and final ligated oxime product as a function of time (SI-5, SI-9 and SI-10).

In each reaction the aminooxy peptide was taken in excess (2 eq. AO to 1 eq. ketone). Full conversion to the oxime product was reached for ketones $A B, O O A$ and OBA at both 70 and $700 \mu \mathrm{M}$ with average rate constants of $0.22,0.33$, and $0.33 \mathrm{M}^{-1} \mathrm{~s}^{-1}$ respectively. At a concentration of $7 \mu \mathrm{M}$ none of the reactions reached completion, but rate constants were in agreement with those determined at 70 and $700 \mu \mathrm{M}$ (Table $1)$. In the case of ABA the reaction rate was almost an order of magnitude lower at 
$0.04 \mathrm{M}^{-1} \mathrm{~s}^{-1}$. The oxime formation with levulinic acid did not reach completion in any of the tested concentrations, because of the formation of the cyclic pyrrolidone, and the oxime product reached a maximum of $5 \%, 30 \%$ or $75 \%$ theoretical yield at concentrations of 7,70 or $700 \mu \mathrm{M}$ respectively.

Table 1: Determined reaction constants

\begin{tabular}{|c|c|c|c|c|c|c|}
\hline \multirow[b]{2}{*}{ Ketone } & \multicolumn{6}{|c|}{$k_{1}\left(M^{-1} s^{-1}\right)$} \\
\hline & $700 \mu \mathrm{M}$ & $70 \mu \mathrm{M}$ & $7 \mu \mathrm{M}$ & Average & $\begin{array}{l}7 \mu \mathrm{M}+ \\
10 \mathrm{mM} \\
\text { aniline }\end{array}$ & $\begin{array}{l}7 \mu \mathrm{M}+ \\
100 \mathrm{mM} \\
\text { aniline }\end{array}$ \\
\hline Levulinic acid (LA) & n.d. & n.d. & n.d. & n.d. & n.d. & n.d. \\
\hline $\begin{array}{l}\text { 4-acetylbutyric acid } \\
\text { (AB) }\end{array}$ & 0.19 & 0.21 & 0.25 & $0.22 \pm 0.03$ & 0.30 & 1.56 \\
\hline $\begin{array}{l}\text { 7-oxooctanoic acid } \\
\text { (OOA) }\end{array}$ & 0.23 & 0.28 & 0.49 & $0.33 \pm 0.14$ & 0.66 & 2.32 \\
\hline $\begin{array}{l}\text { 4-acetylbenzoic acid } \\
\text { (ABA) }\end{array}$ & 0.03 & 0.04 & 0.05 & $0.04 \pm 0.01$ & 0.05 & 0.17 \\
\hline $\begin{array}{l}\text { 3-(2-oxopropyl)- } \\
\text { benzoic acid (OBA) }\end{array}$ & 0.28 & 0.32 & 0.39 & $0.33 \pm 0.06$ & 0.52 & 1.71 \\
\hline
\end{tabular}

Reaction constants were determined by fitting data to a second order reversible reaction equation (see supplemental information) with or without supplementation of catalyst aniline at 3 different concentrations. Reaction constants for Levulinic acid could not be determined because the progress curves could not be fitted to a second order reversible reaction. Average reaction constants \pm standard deviation are given.

Both $\mathrm{ABA}$ and $\mathrm{OBA}$ ketones have a rigid aromatic ring placed in between the two reactive groups and are too strained to allow intramolecular cyclization. In contrast, the $A B$ and $O O A$ derivatives can in theory form a 6- and 8-membered heterocycle respectively. Nevertheless no cyclization was observed for both $A B$ and $00 A$.

The UPLC-M S experiments show formation of the oxime with all ketones (Figure 1). The reaction was fastest for ketones OOA or OBA. The slowest reaction rate was observed for ABA. The reactivity of ketones in oxime reactions is likely governed by the stability of the formed carbocation. In all cases a secondary carbocation is formed, whereas in the case of ABA the secondary cation is stabilized by resonance, delocalizing the charge and decreasing its reactivity. This effect has also been observed for conjugated aldehydes.[11]

It has been reported that oxime and hydrazone reactions can be catalyzed with aniline. $[3,4,12]$ The effect of aniline was therefore evaluated by repeating the $7 \mu \mathrm{M}$ reactions in presence of 10 and $100 \mathrm{mM}$ aniline at which a maximal 6 -fold increase in $\mathrm{k}_{1}$ was observed (SI-6 and Table 1). The reaction rate constants for oxime formation were comparable with previously reported values. $[13,14]$ This resulted in 
dissociation constants $\left(K_{D}\right)$ around $1 \mu \mathrm{M}$ for the conditions tested. The hydrolysis rate was verified by following the rate of dissociation of a formed oxime bond at 7 and 70 $\mu \mathrm{M}$ in absence and presence of aniline at $\mathrm{pH} 4.5$. At $7 \mu \mathrm{M}$, approximately $15 \%$ of the oxime product was hydrolyzed within 7 days whereas at $70 \mu \mathrm{M}$ only $2 \%$ hydrolysis was observed (SI-7). The oxime bond dissociation constants were calculated by fitting the data points to the second order reversible reaction and were all around $1 \mu \mathrm{M}$ at $\mathrm{pH}$ 4.5 (SI, Table S1-4), in agreement with those determined above. Based on previous findings, we expect the hydrolysis of oxime bonds at comparable concentrations at neutral $\mathrm{pH}$ to be negligible making oxime bond formation a useful method for chemoselective bioconjugation and assembly of macromolecular complexes.[5]

The improved oxime ligation strategy was further validated by coupling a bimodal rhodamine/DTPA label to the chemokine CCL5/RANTES (Figure 1F). For this purpose, LA and OBA were chosen as ketones. LA to illustrate the interference by the unwanted side reaction, OBA as the best candidate for the novel oxime ligation strategy. RANTES was synthesized by solid phase peptide synthesis (SPPS) and native chemical ligation using a synthetic approach used previously in our lab for the synthesis of $\mathrm{N} \varepsilon$ thiaproline modified RANTES, substituting thiaproline for LA or OBA. [15] The incorporation of the ketones was done by coupling the keto-acids to the $\varepsilon$-amino of a lysine added at the C-terminal end of the protein. Following SPPS, native chemical ligation of the two fragments, and oxidative folding of the protein, the ketone functionalized chemokine was coupled with a bimodal imaging label containing a fluorescent rhodamine and a metal chelating DTPA moiety functionalized with aminooxyacetic acid. The oxime ligation was performed at a concentration of $100 \mu \mathrm{M}$ protein and two-fold excess of label. The coupling was followed by UPLC-MS and in agreement with results from the test peptides; coupling efficiency of RANTES(LA) was lower than that of RANTES(OBA). After 36 hours a coupling yield of $18 \%$ was reached in the case of RANTES(LA) versus $81 \%$ for RANTES(OBA) (SI-8). The resulting labeled chemokine was subsequently used to bind to and visualize its native receptor CCR5 expressed on macrophages. Macrophages were isolated from mouse bone marrow, cultured and incubated with the labeled RANTES derivatives. Before visualization, a nuclear stain was applied for 1 hour. 3T3 fibroblasts that do not express CCR5 were used as a negative control. The macrophages showed a dose-dependent cell surface labeling, whereas the 3T3 cells did not show cell surface labelling (Figure 2). 
Nomarski

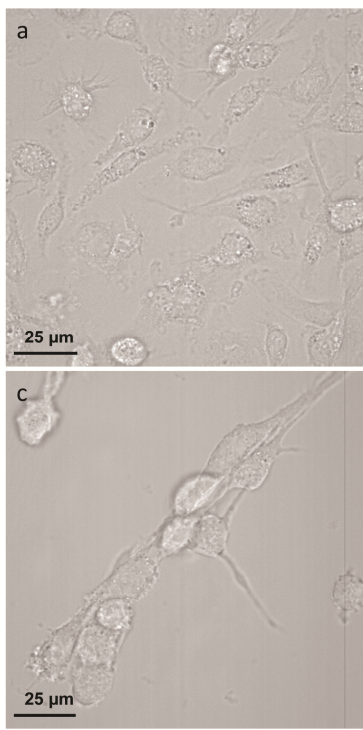

RANTES (1500 nM)

SYTO ${ }^{\otimes} 13(2 \mu \mathrm{M})$

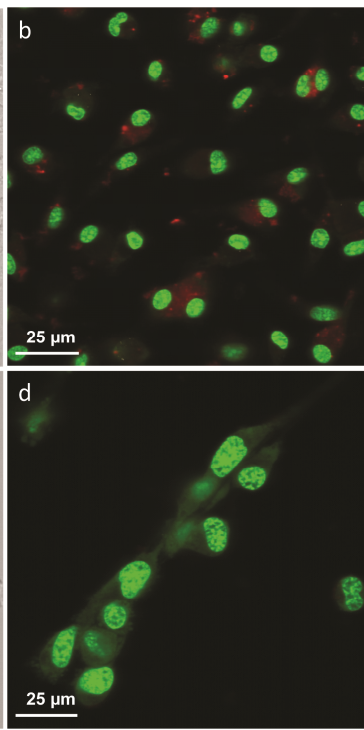

Figure 2: Confocal microscopy imaging of mouse bone marrow derived macrophages (BM DM $\varphi$ ) and 3 T3 fibroblasts. a: DIC contrast image of $\operatorname{BMDM} \varphi$. b: Merge image of cell staining by RANTES-rhodamine/DTPA and nuclei staining with SYTO 13. Dimensions $141 \times 141 \mu \mathrm{m}$ c: DIC contrast image of 3 T3 fibroblasts. d: Merge image of RANTES-rhodamine/DTPA labeling and SYTO 13 nuclei staining. Dimensions $144 \times 144 \mu \mathrm{m}$

The results show that levulinoylated lysine end groups are prone to intramolecular cyclization to a five-membered pyrrolidone ring that interferes with oxime formation when oxime formation is slow at low, biologically relevant protein concentrations. The current study provides evidence that the reaction rates and efficacy of oxime formation in peptides and proteins can greatly be improved by using alternative ketones to levulinic acid, aiding in facile synthesis of macromolecules and conjugated peptides and proteins. 


\section{References}

1. Rosenberg, S., S.M. Silver, J.M. Sayer, and W.P. Jencks, Evidence for two concurrent mechanisms and a kinetically significant proton transfer process in acid-catalyzed 0methyloxime formation. Journal of the American Chemical Society, 1974. 96(26): 7986-7998.

2. Sayer, J.M., B. Pinsky, A. Schonbrunn, and W. Washtien, Mechanism of carbinolamine formation. Journal of the American Chemical Society, 1974. 96(26): 7998-8009.

3. Dirksen, A. and P.E. Dawson, Rapid oxime and hydrazone ligations with aromatic aldehydes for biomolecular labeling. Bioconjug Chem, 2008. 19(12): 2543-2548.

4. Dirksen, A., T.M. Hackeng, and P.E. Dawson, Nucleophilic catalysis of oxime ligation. Angew Chem Int Ed Engl, 2006. 45(45): 7581-7584.

5. Kalia, J. and R.T. Raines, Hydrolytic stability of hydrazones and oximes. Angew Chem Int Ed Engl, 2008. 47(39): 7523-7526.

6. Canne, L.E., A.R. Ferre- D'Amare, S.K. Burley, and S.B.H. Kent, Total Chemical Synthesis of a Unique Transcription Factor-Related Protein: cM yc-Max. Journal of the American Chemical Society, 1995. 117(11): 2998-3007.

7. Lempens, E.H.M., M. M erkx, M. Tirrell, and E.W. Meijer, Dendrimer Display of TumorHoming Peptides. Bioconjug Chem, 2011. 22(3): 397-405.

8. Loidl, G., H.-J. Musiol, M. Groll, R. Huber, and L. Moroder, Synthesis of bivalent inhibitors of eucaryotic proteasomes. Journal of Peptide Science, 2000. 6(1): 36-46.

9. Padwa, A., P. Rashatasakhon, and M. Rose, Triflic anhydride mediated cyclization of 5hydroxy-substituted pyrrolidinones for the preparation of alphatrifluoromethylsulfonamido furans. J Org Chem, 2003. 68(13): 5139-5146.

10. Wedler, C., B. Costisella, and H. Schick, Reactions of 4-oxoalkanoic acids. III. Synthesis of 5-M ethyl- and 5-Methylenepyrrolidin-2-ones by reaction of $\alpha$-angelica lactone with methylamine. Journal für Praktische Chemie, 1990. 332(4): 557-562.

11. Rashidian, M., M.M. Mahmoodi, R. Shah, J.K. Dozier, C.R. Wagner, and M.D. Distefano, A highly efficient catalyst for oxime ligation and hydrazone-oxime exchange suitable for bioconjugation. Bioconjug Chem, 2013. 24(3): 333-342.

12. Cordes, E.H. and W.P. Jencks, General Acid Catalysis of Semicarbazone Formation. Journal of the American Chemical Society, 1962. 84(22): 4319-4328.

13. Calzadilla, M., A. Malpica, and T. Cordova, Effect of structure on reactivity in oxime formation of benzaldehydes. Journal of Physical Organic Chemistry, 1999. 12(9): 708712.

14. O'Ferrall, R.A.M. and D. O'Brien, Rate and equilibrium constants for hydrolysis and isomerization of (E)- and (Z)-p-methoxybenzaldehyde oximes. Journal of Physical Organic Chemistry, 2004. 17(6-7): 631-640.

15. Van de Vijver, P., D. Suylen, A. Dirksen, P.E. Dawson, and T.M. Hackeng, Nepsilon(thiaprolyl)-lysine as a handle for site-specific protein conjugation. Biopolymers, 2010. 94(4): 465-474. 


\section{Supporting Information}

Chemistry

Peptide synthesis. Peptides were synthesized manually by SPPS on a $0.25 \mathrm{mmol}$ scale on a MBHA resin. An in situ neutralization/HCTU activation for Boc chemistry was used[1]. Each synthetic cycle consisted of the Boc protective group removal by two 1minute treatments with TFA followed by a DMF wash, addition of the preactivated amino acid in presence of excess DIPEA, followed by another DMF wash. The Bocprotected amino acids $(1.1 \mathrm{mmol}$ ) were activated with $1 \mathrm{mmol}$ of HCTU and $3 \mathrm{mmol}$ DIPEA. Coupling of GIn residues was followed by a DCM wash before and after TFA deprotection to prevent intramolecular pyrrolidone formation. After coupling of the final amino acid the resin was dried by wash steps with DCM and DCM / M eOH.

After completion of the peptide chain, the peptides were deprotected and cleaved from the resin by treatment with anhydrous $\mathrm{HF}$ for 1 hour at $0^{\circ} \mathrm{C}$ with $4 \% \mathrm{p}$-cresol (v/v) as scavenger. Peptides were precipitated in ice-cold diethylether, dissolved in 50\% acetonitrile in water $+0.1 \%$ TFA and lyophilized. The crude mixture was subjected to semipreparative HPLC and fractions containing the desired product were identified by ESI-MS, pooled and lyophilized.

LYRAK model peptide

sequence: $\mathrm{H}_{2} \mathrm{~N}$-Leu-Tyr-Arg-Ala-Lys-CONH${ }_{2}$

VIPF model peptide

sequence: $\mathrm{H}_{2} \mathrm{~N}$-(Aminooxy)acetic acid-Val-Ile-Pro-Phe- $\mathrm{CONH}_{2}$

M urine RANTES C-terminus

sequence: $\mathrm{H}_{2} \mathrm{~N}$-Cys-Ser-Asn-Leu-Ala-Val-Val-Phe-Val-Thr-Arg-Arg-Asn-Arg-Gln-Val-CysAla-Asn-Pro-Glu-Lys-Lys-Trp-Val-GIn-Glu-Tyr-Ile-Asn-Tyr-Leu-Glu-M et-Ser-Lys(Fmoc)$\mathrm{CONH}_{2}$

Murine RANTES N-terminus

sequence: $\mathrm{H}_{2} \mathrm{~N}$-Ser-Pro-Tyr-Gly-Ser-Asp-Thr-Thr-Pro-Cys-Cys-Phe-Ala-Tyr-Leu-Ser-LeuAla-Leu-Pro-Arg-Ala-His-Val-Lys-Glu-Tyr-Phe-Tyr-Thr-Ser-Ser-Lys-M PA-Leu-CONH${ }_{2}$

Synthesis of Rhodamine B DTPA dual label. A dipeptide Cys-Lys(Fmoc) was prepared via solid phase peptide synthesis as described above. The N-terminal Boc protection was removed with $2 \times 1$ min TFA treatment after which (Aminooxy)acetic acid (2.2 $\mathrm{mmol})$ was preactivated using DIC $(2.0 \mathrm{mmol})$ for 2 minutes after which NHS (2.0 $\mathrm{mmol})$ and DIPEA $(0.6 \mathrm{mmol})$ was added, directly followed by addition to the deprotected Cys-Lys $(0.25 \mathrm{mmol})$ and left to react for 1 hour. The Fmoc deprotection was achieved by $4 \times 3$ min $20 \%$ piperidine in DM F followed by a DM F and DCM wash to 
remove any residual piperidine. $0.5 \mathrm{~mL}$ rhodamine B-succinimide (AAT bioquest, Sunnyvale CA, USA) $(7.5 \mathrm{mg} / \mathrm{mL})$ was added to the resin and the mixture was left to react at $37{ }^{\circ} \mathrm{C}$ for 4 hours with occasional mixing. The resin was washed with DMF followed by N-terminal Boc protection. The dipeptide was cleaved from the resin using anhydrous $\mathrm{HF}$, precipitated in diethylether, dissolved in $50 \% \mathrm{M} \mathrm{eCN}$ in $\mathrm{H} 2 \mathrm{O}+0.1 \%$ TFA, purified and lyophilized. The dried peptide $(2.4 \mathrm{mg}$ ) was dissolved in $1 \mathrm{~mL} 0.1 \mathrm{M}$ $\mathrm{NH} 40 \mathrm{Ac}(\mathrm{pH} 5.7)+10 \% \mathrm{MeCN}$. M aleimide-DTPA was added in 1.5 times excess and left to react at $37^{\circ} \mathrm{C}$ for 2.5 hours. The resulting product was purified, analyzed with M ALDI mass spectrometry and lyophilized.

Ketone incorporation into chemokine RANTES C-terminus. After completion of the peptide chain, the Fmoc protective group on the C-terminal lysine was deprotected using $4 \times 3$ min treatments with $20 \%$ piperidine in DM F. Subsequently, keto-acids LA and OBA $(2.2 \mathrm{mmol})$ were preactivated using carbodiimide $(2 \mathrm{mmol})(\mathrm{DIC})$ for 2 minutes after which $\mathrm{N}$-hydroxysuccinimide (NHS) $(2.0 \mathrm{mmol})$ and $\mathrm{N}, \mathrm{N}$ diisopropyldiamine (DIPEA) $(0.6 \mathrm{mmol})$ was added, directly followed by addition to the deprotected RANTES $(0.25 \mathrm{mmol})$ and left to react for 1 hour. Finally the N-terminal Boc-protective group was removed by treatment with TFA as described above to result in RANTES(LA) and RANTES(OBA) after cleavage from the resin.

Native chemical ligation of RANTES C- and N-terminus. Both the C- and N-terminus were purified before ligation. Equimolar amounts of both parts were mixed in $6 \mathrm{M}$ Guanidine (Gdn)-HCl, $0.1 \mathrm{M}$ Tris- $\mathrm{HCl},(\mathrm{pH} 8)$ at a concentration of $10 \mathrm{mg} / \mathrm{mL}$. Benzylmercaptan and thiophenol were added ( $1 \mathrm{v}-\%$ each). The $\mathrm{pH}$ was adjusted to 7 before the reaction was left to react at $37^{\circ} \mathrm{C}$ for $24 \mathrm{~h}$ with mixing every hour.

Oxidative folding of RANTES. The ligated peptide was purified using HPLC, desired fractions were pooled and lyophilized. The peptide was dissolved in $3 \mathrm{M} \mathrm{Gdn-HCl}, 0.1$ $\mathrm{M}$ Tris- $\mathrm{HCl} \mathrm{pH} 8$ at a concentration of $0.2 \mathrm{mg} / \mathrm{mL}$. Cysteine $(8 \mathrm{mM})$ and Cystine $(1 \mathrm{mM})$ were added and the protein was left to fold at $4{ }^{\circ} \mathrm{C}$ for $24 \mathrm{~h}$ with continuous mixing. The folded protein was purified using HPLC, desired fractions were pooled and lyophilized.

HPLC Analysis and Purification. Analytical HPLC was performed using a Vydac $\mathrm{C} 18$ HPLC column (4.6 mm x $150 \mathrm{~mm}, 1 \mathrm{~mL} / \mathrm{min}$ flow rate) connected to a Varian Prostar system consisting of two Varian Prostar 215 delivery modules and a Varian Prostar $320 \mathrm{UV} / \mathrm{Vis}$ detector $(\lambda=214 \mathrm{~nm})$. A linear gradient of 0-67\% buffer $B$ in buffer $A$ over 30 minutes was used, where buffer $A=0.1 \mathrm{v}-\%$ TFA in $\mathrm{H} 2 \mathrm{O}$ and buffer $B=0.1 \mathrm{v}-\%$ TFA, $10 \mathrm{v}-\% \mathrm{H}_{2} \mathrm{O}$ in $\mathrm{CH}_{3} \mathrm{CN}$.

Semi-preparative HPLC was performed using Vydac C18 HPLC columns (10 mm x 250 $\mathrm{mm}, 5 \mathrm{~mL} / \mathrm{min}$ flow rate or $22 \mathrm{~mm} \times 250 \mathrm{~mm}, 15 \mathrm{~mL} / \mathrm{min}$ flow rate) connected to a Waters Deltaprep System consisting of a Waters Prep LC Controller and a Waters 2487 
Dual wavelength Absorbance Detector $(\lambda=214 \mathrm{~nm})$. Peptides were eluted using a gradient of $B$ in $A$, based on an analytical HPLC run. Fractions were analyzed by Electrospray Ionization Mass Spectrometry (ESI-MS), desired fractions were pooled and lyophilized.

Mass Spectrometry. ESI-M S was performed on an Applied Biosystems SCIEX API 150 EX electrospray ionization quadrupole (ESI-Q) mass spectrometer. UPLC ESI-MS was performed on a Waters UHPLC XEVO-G2QTOF system Peptide masses were calculated from the experimental mass to charge $(\mathrm{m} / \mathrm{z})$ ratios of all the protonation states observed in the ESI-MS spectrum of a peptide using MaxEnt 3. Monoisotopic and average theoretical masses of compounds were calculated using Chemdraw 12.0.2.

UPLC Mass spectrometry. Oxime ligation was monitored on a Waters UHPLC XEVOG2QTOF system. Sample (1-10 $\mu \mathrm{L})$ was introduced to a PST C18 column (130A; $1.7 \mu \mathrm{m}$ particles; column dimension $2.1 \times 50 \mathrm{~mm}, 35^{\circ} \mathrm{C}$ ) by an FTN-autosampler, using $5 \%$ acetonitrile and $0.1 \%$ formic acid (FA) in water as purge-solvent/diluent. A wateracetonitrile gradient containing $0.1 \%$ FA (flowrate $250 \mu \mathrm{L} / \mathrm{min}$ ) was used to separate starting peptides and oxime bound product at baseline level in $25 \mathrm{~min}$. Exact mass measurement was performed in resolution mode using ESI-ionisation in positive mode (NaFormate-calibrated). Both quad profile and probe settings were optimized for small peptide measurement.

Keto-acid ligation to LYRAK. The Fmoc protective group on the lysine sidechain was deprotected by treatment with $20 \%$ piperidine in DMF for three minutes repeated four times. The different keto-acids $(2.2 \mathrm{mmol})$ were preactivated using carbodiimide ( $2 \mathrm{mmol}$ ) (DIC) for 2 minutes after which $\mathrm{N}$-hydroxysuccinimide ( $\mathrm{NHS})(2.0 \mathrm{mmol})$ and $\mathrm{N}, \mathrm{N}$-diisopropyldiamine (DIPEA) $(0.6 \mathrm{mmol})$ was added, directly followed by addition to the deprotected LYRAK $(0.25 \mathrm{mmol})$ and left to react for 1 hour. Finally the $\mathrm{N}$-terminal Boc-protective group was removed by treatment with TFA as described above.

Aminooxy acetic acid ligation to VIPF. The Boc deprotection of the last amino acid was performed by treatment with TFA as described above. (Aminooxy)acetic acid (2.2 mmol) was preactivated using DIC $(2.0 \mathrm{mmol})$ for 2 minutes after which NHS (2.0 $\mathrm{mmol})$ and DIPEA ( $0.6 \mathrm{mmol}$ ) was added, directly followed by addition to deprotected VIPF (0.25 mmol) and left to react for 1 hour.

Oxime ligations between LYRAK-ketone and aminooxy-VIPF. Peptide stocks were prepared fresh in $0.1 \mathrm{M}$ ammonium acetate ( $\mathrm{pH} 4.5)$. One equivalent of LYRAK-ketone was reacted with 2 equivalents of aminooxy-VIPF at 7, 70 and $700 \mu \mathrm{M}$ of ketone in a total reaction volume of $1 \mathrm{~mL}$. In the case of $7 \mu \mathrm{M}$ reactions, oxime formation was monitored in presence of 0,10 and $100 \mathrm{mM}$ aniline. An aniline stock solution (200 $\mathrm{mM}$ ) was prepared fresh in $0.1 \mathrm{M}$ ammonium acetate ( $\mathrm{pH} 4.5)$ after which the $\mathrm{pH}$ was 
adjusted to 4.5. Reactions were followed on a Xevo Waters UPLC system at 220 and $280 \mathrm{~nm}$ with M S detection. Product formation was followed by absorbance at $280 \mathrm{~nm}$. Integration of peaks was used to determine concentration of product formed. Product peak area was divided by the total peak area to obtain product concentration. Reactions were monitored for $48 \mathrm{~h}$ with time points every $2.5 \mathrm{~h}$. Reaction constants were calculated by fitting the data points to equation 3 (see below).

Oxime hydrolysis of LYRAK-OBA and aminooxy-VIPF. The mixture of oxime and residual aminooxy-VIPF was prepared at $700 \mu \mathrm{M}$ as above and diluted to 70 and $7 \mu \mathrm{M}$ final concentration of oxime. Oxime hydrolysis was monitored in presence of 0,10 and $100 \mathrm{mM}$ aniline for both concentrations. Product degradation was followed on a Xevo Waters UPLC system at 220 and $280 \mathrm{~nm}$ with M S detection. Peak surface at 280 $\mathrm{nm}$ was integrated to determine the concentration of product disappearing. Reactions were initially monitored with time points every 3 hours, with the addition of time points after 1, 2, 3 and 7 days. Reaction constants were calculated by fitting the data points to equation 3 (see below).

Intramolecular cyclization of LYRAK-LA. Peptide stocks were prepared in fresh $0.1 \mathrm{M}$ ammonium acetate ( $\mathrm{pH} \mathrm{4.5)}$ at 700,70 and $7 \mu \mathrm{M}$. Levulinoyl product forming was monitored on a Xevo Waters UPLC system at 220 and $280 \mathrm{~nm}$ with M S detection. Peak surface at $220 \mathrm{~nm}$ was integrated to determine the concentration of product formation. Reactions were monitored every 75 minutes for 17 hours. Reaction constants were calculated by fitting the data points to equation 6 (see below). The cyclization was proven to be concentration independent with rate constants of $3.68 \mathrm{E}$ $05 \mathrm{~s}^{-1}$ and 1.22E-05 for $\mathrm{k}^{1}$ and $\mathrm{k}^{-1}$ respectively.

RANTES labeling. RANTES(OBA) and RANTES(LA) were prepared as described above. RANTES(OBA)/RANTES(LA) (1 equivalent, $280 \mu \mathrm{g}$ ) and $98 \mu \mathrm{g}$ label ( 2 equivalents) were dissolved in $6 \mathrm{M} \mathrm{Gdn-HCl} 0.1 \mathrm{M}$ acetate $\mathrm{pH} 4.5$. Oxime formation was monitored on a Xevo Waters UPLC system at 220 and $540 \mathrm{~nm}$ with M S detection. Peak surface at 220 $\mathrm{nm}$ was integrated to determine the concentration of product formation. Reactions were monitored for 36 hours with addition of time points at 65 (OBA) and 85 (LA) hours. RANTES-OBA-label was purified, analyzed with MALDI mass spectrometry and lyophilized.

Analytical

Second order reversible rate equation. The analytical solution for this reaction has been derived by Korobov[2]. In short, in a second order reversible reaction $A 1+A 2 \leftrightarrow$ $B$, the change in product $(x)$ is given by the differential equation 1 .

$$
\frac{d x(t)}{d t}=k_{1}\left(A_{10}-x(t)\right)\left(A_{20}-x(t)\right)-k_{2}\left(B_{0}+x(t)\right)
$$


The analytical solution for equation 1 is given by equation 2

$$
x(t)=\left(\frac{e^{\left(t \beta-2 k_{1} x_{e q}\right)} \beta-e^{\left(t \beta-2 k_{1} x_{e q}\right)} k_{1} x_{e q}-\beta+k_{1} x_{e q}}{e^{\left(i \beta-2 k_{1} x_{e q}\right)} \beta-e^{\left(i \beta-2 k_{1} x_{e q}\right)} k_{1} x_{e q}-k_{1} x_{e q}} x_{e q}\right.
$$

This leads to the following expression for the concentration of product, [P].

$$
[P]=B_{0}+\left(\frac{e^{\left(i \beta-2 k_{1} x_{e q}\right)} \beta-e^{\left(t \beta-2 k_{1} x_{e q}\right)} k_{1} x_{e q}-\beta+k_{1} x_{e q}}{e^{\left(t \beta-2 k_{1} x_{e q}\right)} \beta-e^{\left(t \beta-2 k_{1} x_{e q}\right)} k_{1} x_{e q}-k_{1} x_{e q}}\right) x_{e q}
$$

With

$$
\begin{aligned}
& x_{e q}=\frac{1}{2 k_{1}}\left(k_{1} A_{10}+k_{1} A_{20}+k_{2}-\right. \\
& \left.\sqrt{k_{1}^{2} A_{10}^{2}-2 k_{1}^{2} A_{10} A_{20}+2 k_{1} A_{10} k_{2}+k_{1}^{2} A_{20}^{2}+2 k_{1} A_{20} k_{2}+k_{2}^{2}+4 k_{1} k_{2} B_{0}}\right)
\end{aligned}
$$

and

$$
\beta=k_{1} A_{10}+k_{1} A_{20}+k_{2}
$$

In which $[P]$ is the concentration $(M)$ of measured product formation, $A 10$ is the initial concentration of ketone (M), A20 is the initial concentration of aminooxy (M), B0 is the initial concentration of oxime $(M), k 1$ is the reaction constant in $M-1 s-1, k 2$ is the rate constant in $\mathrm{s}-1$ and $\mathrm{t}$ is the time in seconds.

First order reversible rate equation. The analytical solution for this reaction has been derived by Korobov[2]. In short, in a first order reversible reaction $A \leftrightarrow B$, the change in product $(\mathrm{x})$ is given by the differential equation 4 .

$$
\frac{d x(t)}{d t}=k_{1}\left(A_{0}-x(t)\right)-k_{2}\left(B_{0}+x(t)\right)
$$

The analytical solution for equation 4 is given by equation 5 .

$$
x(t)=x_{e q}\left(1-e^{-\left(k_{1}+k_{2}\right) t}\right)
$$

This leads to the following expression for the concentration of product, [P]

$$
[P]=B_{0}+x_{e q}\left(1-e^{-\left(k_{1}+k_{2}\right) t}\right)
$$

With $_{x_{e q}}=\frac{k_{1} \cdot A_{0}-k_{2} \cdot B_{0}}{k_{1}+k_{2}}$

In which $[P]$ is the concentration $(M)$ of measured product formation, $A 0$ is the initial concentration of $A(M), B 0$ is the initial concentration of $B(M), k 1$ is the reaction constant in $\mathrm{s}-1, \mathrm{k} 2$ is the rate constant in $\mathrm{s}-1$ and $\mathrm{t}$ is the time in seconds. 
Nuclear magnetic resonance

Instrumentation. NM R experiments on the LYRAK and VIPF peptides were carried on Bruker Avance III 600, 700 HD, 750 and $900 \mathrm{M} \mathrm{Hz}$ spectrometers. With the exception of the $750 \mathrm{MHz}$ all other three spectrometers were equipped with $\mathrm{TCl}$ cryo probes. Proton spectra were recorded at $25{ }^{\circ} \mathrm{C}, 30{ }^{\circ} \mathrm{C}$ or $37{ }^{\circ} \mathrm{C}$, with the temperature calibrated using an external ethylene glycol-DM SO- $\mathrm{d}_{6}$ (80\%:20\% v/v) NMR sample [3] and/or by means of an internal T1 temperature sensor that was placed in water at the center height of the magnetic coil of the spectrometer.

Data acquisition and assignments. Chemical shifts of peptides in water are referenced to internal DSS samples in DMSO- $d_{6}$, in particular to the residual proton (2.50 ppm) and carbon signal (39.54 ppm) of (partially) protonated DMSO. Chemical shift assignments of the levulinoyl peptides were made based on natural abundance gradient enhanced $15 \mathrm{~N}-1 \mathrm{H}$ HSQC, $13 \mathrm{C}-1 \mathrm{H} \mathrm{HSQC},{ }^{15} \mathrm{~N}-{ }^{1} \mathrm{H}$ HMBC and ${ }^{13} \mathrm{C}-{ }^{1} \mathrm{H}$ HMBC heteronuclear 2D experiments in combination with sequential assignments 2D ROESY (200 ms mixing time), 2D NOESY (400 ms mixing time), 2D DIPSI (70 ms mixing time) spectra in water. Water suppression of NMR samples containing water-based buffer was carried by excitation sculpting techniques [4] or in the case of $13 \mathrm{C}-1 \mathrm{H} \mathrm{HMBC}$ spectra by presaturation of the residual water line. Similar procedures were carried out for the assignment of LYRAK(AB), aminooxy-VIPF and its reaction product. Pulse sequences were taken from the standard Bruker pulse library, analysis of the NMR spectra was done in Sparky 3.114 [5].

Cyclization of LYRAK(LA). To follow the spontaneous cyclization of LYRAK(LA) by means of NMR, the freeze-dried peptide material, stored at $-20{ }^{\circ} \mathrm{C}$, was dissolved in $500 \mu \mathrm{L} \mathrm{D}_{2} \mathrm{O}$ or DM SO- $\mathrm{d}_{6}$ and immediately put in a Wilmad $5 \mathrm{~mm}$ NM R tube for quick data collection in the spectrometer. No water-based buffer has been used to prepare these LYRAK samples, the $\mathrm{pH}^{*}$ (uncorrected for isotope effects) was measured 3.0-3.3 after dissolution in $\mathrm{D}_{2} \mathrm{O}$. Figure $\mathrm{S} 1$ shows the conversion of LYRAK(LA) to cyclic (6) in $\mathrm{D}_{2} \mathrm{O}$ followed by proton NM R spectroscopy.

Characterization of the cyclic LYRAK(LA) species. Chemical shift assignments for the reference LYRAK peptide, LYRAK(LA) (4) and various isomers of rearranged, Lev$\operatorname{LYRAK}(\operatorname{LA})(6,7,8)$ are summarized in Figure S2. More structural details on the rearranged Lev-LYRAK(LA) isomers will be presented in a separate article (to be published).

Characterization of the reaction between LYRAK(AB) and aminooxy-VIPF. The reaction between $L Y R A K(A B)$ and aminooxy-VIPF was followed in real-time by NMR after dissolving lyophilized LYRAK(AB) peptide in $500 \mu \mathrm{L} 100 \mathrm{mM}$ sodium acetate- $\mathrm{d}_{3}$ buffer ( $\mathrm{pH} 4.5$ ) with added $5 \%(\mathrm{v} / \mathrm{v}) \mathrm{D}_{2} \mathrm{O}$. Two peptide concentration ranges were tested: $70 \mu \mathrm{M}$ and $700 \mu \mathrm{M}$ LYRAK(AB) with two-fold molar excess of aminooxy-VIPF 
reactant ( $140 \mu \mathrm{M}$ and $1.4 \mathrm{mM}$, respectively). Reactions were monitored at $37^{\circ} \mathrm{C}$ in the NM R spectrometer over the time course of 24 hour for the $700 \mu \mathrm{M}$ series and up to 7 days for the $70 \mu \mathrm{M}$ sample. The initial time point zero of the reaction coordinate was taken as the moment that the NMR tube, containing the freshly mixed solution of LYRAK(AB) and aminooxy-VIPF, entered the spectrometer probe preset at a controlled temperature of $37{ }^{\circ} \mathrm{C}$. For the $70 \mu \mathrm{M}$ time series, a new 1D spectrum was started approximately every 15 minutes, for the $700 \mu \mathrm{M}$ series a $1 \mathrm{D}$ spectrum was collected every 2 minutes. Relaxation delay between successive scans was set to 3 seconds. The 1D spectra were stored in a pseudo 2D matrix to get identical phase-correction and base-line correction of all subspectra. All NMR processing was performed in Bruker Topspin 3.2 (Rheinstetten, Germany). Integration of proton signals was done by first exporting the data points to ASCll format in MestReC (version 4.9.9.6) [6] and summing the intensities of all points that fell in the appropriate chemical shift interval of the selected peak to integrate. Figure $\mathrm{S} 5$ displays $1 \mathrm{H}$ spectra taken at selected time points during 20 hour for the oxime reaction between LYRAK(AB) $(700 \mu \mathrm{M})$ and aminooxy-VIPF (1.4 mM) that have been used to determine rate constants.

In order to characterize the final adduct formed between LYRAK(AB) and aminooxyVIPF more easily by NMR, the reaction was also carried out at $37{ }^{\circ} \mathrm{C}$ at a nearequimolar ratio of 1:1.05. This prevents the presence of excess non-reacted aminooxy-VIPF in the reaction mixture that would otherwise interfere with the resonance assignment of the final adduct. More details on the structural characterization of the oxime adduct will be presented in a separate article (to be published).

Validation of peak integration method using NMR. The peak integration method used to calculate the amount of oxime product formed was validated by following the reaction of LYRAK-AB with aminooxy-VIPF using NMR. $700 \mu \mathrm{M}$ LYRAK-AB and $1400 \mu \mathrm{M}$ aminooxy-VIPF were dissolved in $100 \mathrm{mM} \mathrm{NaOAc-d_{3 }}(\mathrm{pH} 4.5)$. Decrease in proton signal of the neighboring $\mathrm{CH}_{2}$ or increase in signal of the valine $\mathrm{NH}$ was monitored. The resulting graphs were fitted to eq (3) and compared to the graphs obtained from the UPLC data as described above (Figure S10).

Biology

Cell isolation and culture. Murine bone marrow-derived macrophages (BMDM $\varphi$ ) were isolated from the femurs of apolipoprotein E-deficient C57BI/6 mice according to Davies and Gordon[7]. After flushing the marrow from the femurs, the cells were dispersed using a 70- $\mu \mathrm{m}$ cell strainer. Macrophages were cultured in bacteriological plastic plates in RPMI 1640 containing 10mM HEPES, 10\% fetal calf serum and 1.5 $\mathrm{ng} / \mathrm{mL}$ macrophage colony stimulating factor. M urine $3 \mathrm{~T} 3$ fibroblasts were cultured in DM EM containing $10 \%$ fetal calf serum. 
Microscopic imaging using RANTES and SYTO-13. One day prior to confocal microscopy imaging, the cells were transferred into 4- or 8-chamber IBIDI slides. After overnight culture, the cells were washed with PBS and fresh serum-free DMEM or RPMI-1640 was added. Cells were incubated with $0,500,1000$ or 1500 nM RANTES and $2 \mu \mathrm{M}$ SYTO- 13 for 1 hour at $37^{\circ} \mathrm{C}$. Visualization of macrophages and $3 \mathrm{T3}$ fibroblasts was performed using a Zeiss LSM Life-7 confocal microscope system.

a<smiles>[R][14CH2][14CH2]NC(=O)[14CH]([14CH2])C(C)=O</smiles>

b

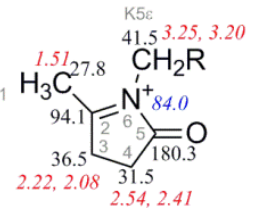

$\mathrm{D}_{2} \mathrm{O}$
C

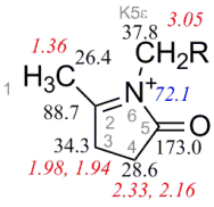

d

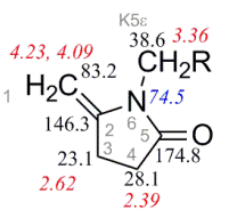

e

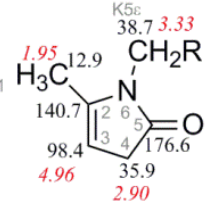

DMSO- $\mathrm{d}_{6}$

Figure S1: Numbering scheme of levulinic derivatives of the LYRAK peptide, together with a summary of experimental observed chemical shifts of various characterized isomers of LYRAK(LA):

a: Unstable linear form (4) in $\mathrm{D}_{2} \mathrm{O}$; b: Rearranged cyclic isomer (6) in $\mathrm{D}_{2} \mathrm{O}$; $\mathrm{c}$ : Cyclic isomer (6) in DMSO- $d_{6}$; $d$ : Rearranged cyclic isomer (7) in DM SO- $d_{6}$ formed after $24 \mathrm{hr}$; e: Minor cyclic form (8) formed after three months in DM SO- $\mathrm{d}_{6}$. Grey numbers indicate atom numbers. ${ }^{1} \mathrm{H},{ }^{15} \mathrm{~N}$, and ${ }^{13} \mathrm{C}$ chemical shift values are color-coded in red, blue or black, respectively. 


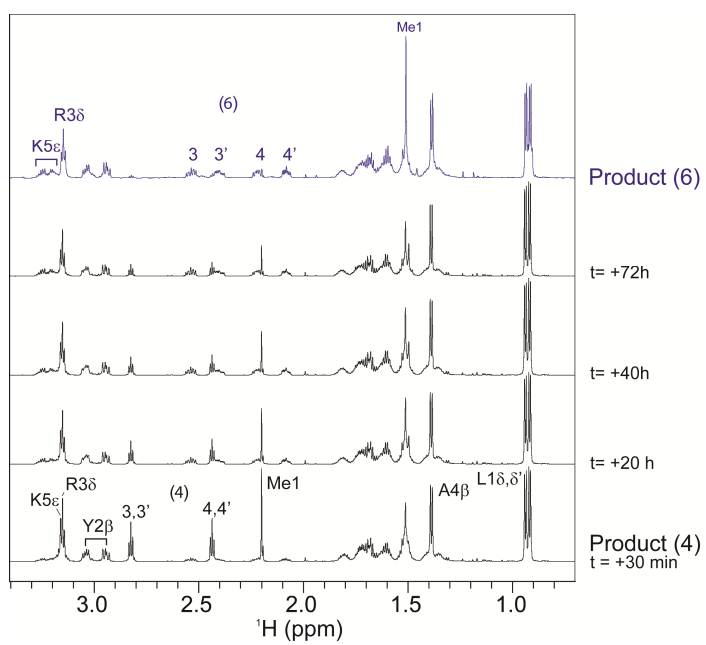

Figure S2: ${ }^{1} \mathrm{H} 750 \mathrm{MHz}$ spectra of the time profile of spontaneous cyclization of LYRAK(LA) (4) to (6) after freshly dissolving freeze-dried peptide (4) in $\mathrm{D}_{2} \mathrm{O}$. Already after 30 minutes of data collection significant formation of the cyclic isomer (6) has taken place $(1.8 \mathrm{mg} / \mathrm{ml}$ peptide incubated at $25^{\circ} \mathrm{C}$ ). The top spectrum of (6) is taken after prolonged pre-incubation (over several weeks) on a separate NMR sample. Note that approximately $5 \%$ of the original population of linear LYRAK(LA) (4) still survives after long incubation times.

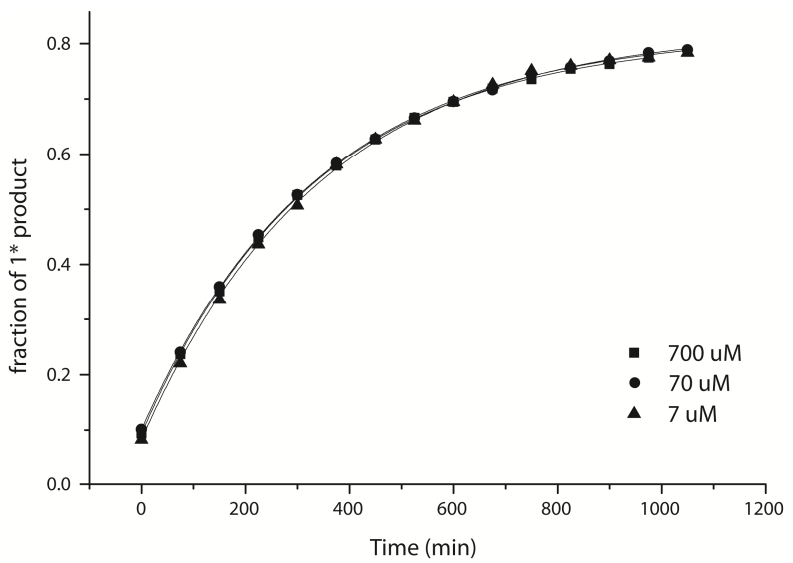

Figure S3: Measured concentration of levulinoyl side product ( $\left.1^{*}\right)$ formed at 700,70 or $7 \mu \mathrm{M}$. Curves were fitted according to a first order reversible reaction as described above. 


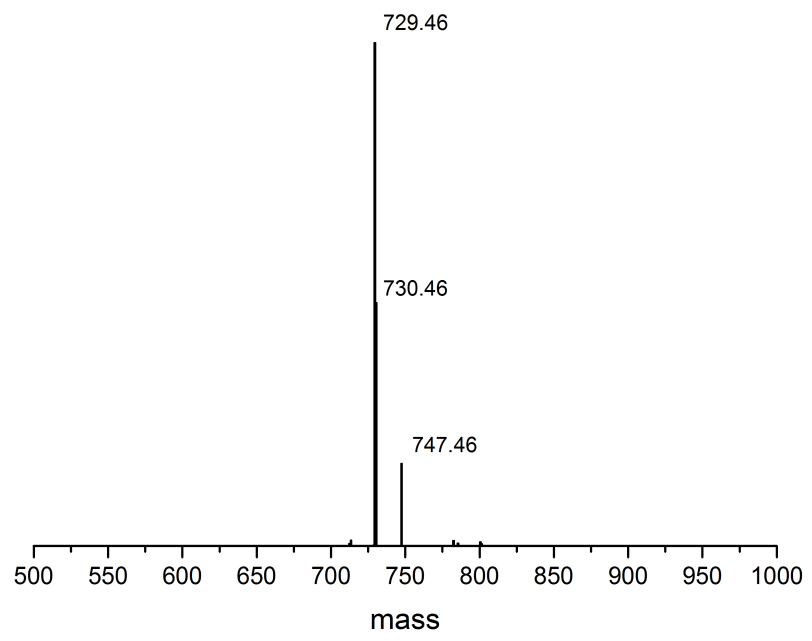

Figure S4: Deconvoluted spectrum of $1^{*}$ side product. 747.46 corresponds to the linear form of levulinic acid. 729.46 corresponds to the cyclic pyrrolidone species with a mass difference of -18 $\mathrm{Da} .730 .46$ corresponds to the iminium species with a mass difference of $-17 \mathrm{Da}$.

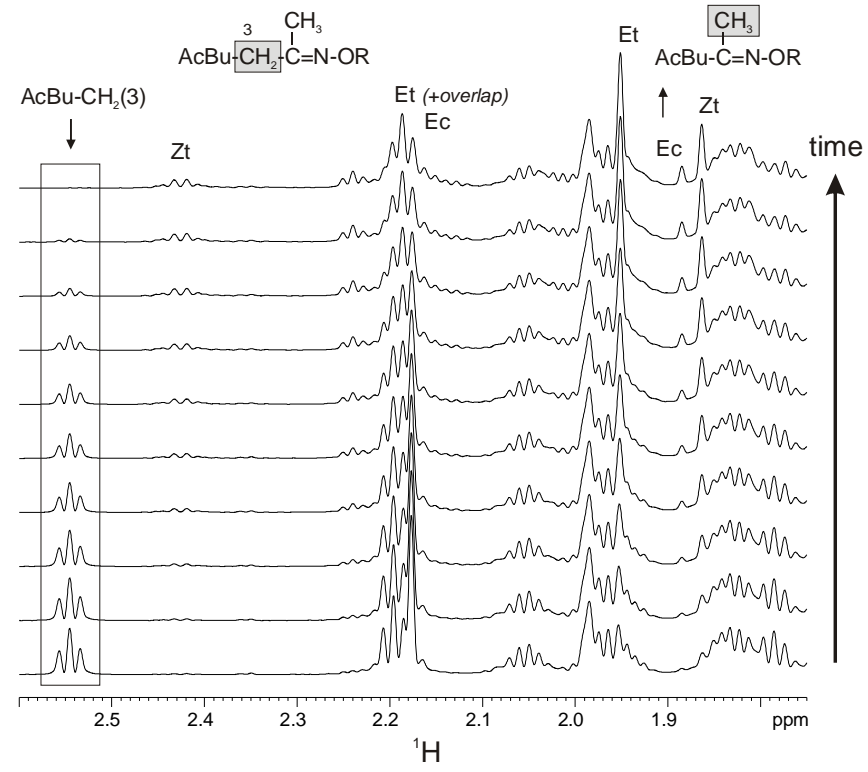

Figure S5: Selected ID NM R spectra taken during the reaction between LYRAK(AB) and AO-VIPF at $700 \mu \mathrm{M}$ concentration LYRAK(AB) (with two-fold excess of AO-VIPF) and $37^{\circ} \mathrm{C}$. Spectral changes over time are indicated. The original $A B-C_{2}-(3)$ methylene (at $2.55 \mathrm{ppm}$ ) and $\mathrm{AB}-\mathrm{CH}_{3}$ methyl in LYRAK(AB) (at $2.18 \mathrm{ppm}$ ) slowly disappeared and transformed into new signals that are contributed to the two possible $\mathrm{C}=\mathrm{N}$ double bond conformational states ( $\mathrm{E}$ or $\mathrm{Z}$ ) of the 
ligation adduct. The ratio of $E / Z$ is approx. 2:1 with $E$ being the conformer having its methyl group cis relative to the $\mathrm{N}-\mathrm{O}$ oxygen atom, while the $\mathrm{Z}$ conformer has the methyl group placed in a trans configuration relative to the $\mathrm{N}-\mathrm{O}$ oxygen atom. However, because the VIPF peptide part contains a proline that exists in a slow equilibrium between a major trans and cis conformer, four non-equivalent states can be discerned in the NMR spectra of the adduct. Et corresponds to $\mathrm{R}-\mathrm{C}=\mathrm{N}-\mathrm{O}(\mathrm{E})$ with a trans-proline; $\mathrm{Ec}$ to $\mathrm{R}-\mathrm{C}=\mathrm{N}-\mathrm{O}(\mathrm{Z})$ with a cis-proline; $\mathrm{Zt}$ to $\mathrm{R}$ $\mathrm{C}=\mathrm{N}-\mathrm{O}(\mathrm{Z})$ with a trans-proline and $\mathrm{Zc}$ to $\mathrm{R}-\mathrm{C}=\mathrm{N}-\mathrm{O}(\mathrm{E})$ with a cis-proline. Peaks belonging to the Zc conformer are weak and are not visible in these 1D plots due to spectrum overlap and low intensity. More details will be presented in a separate article (to be published).

a

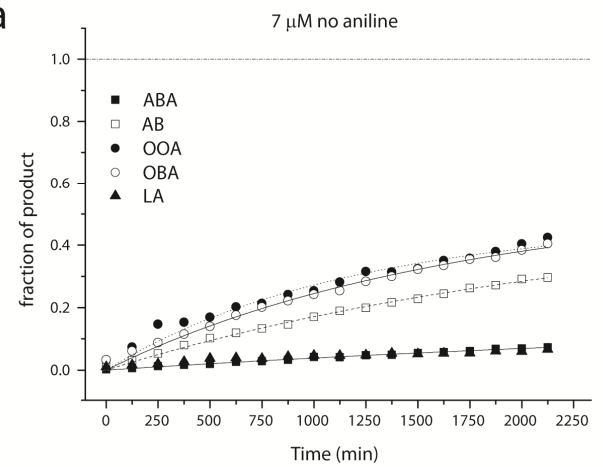

C

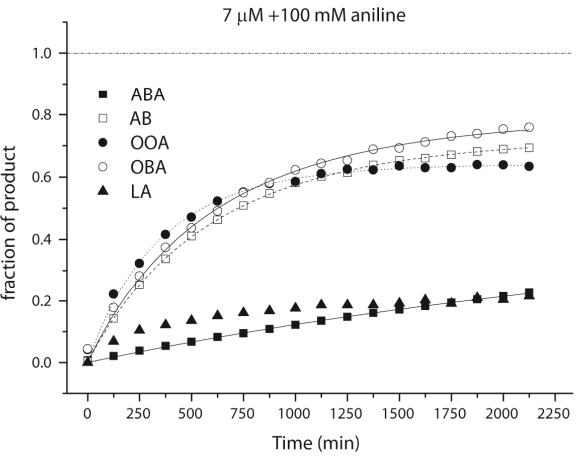

b

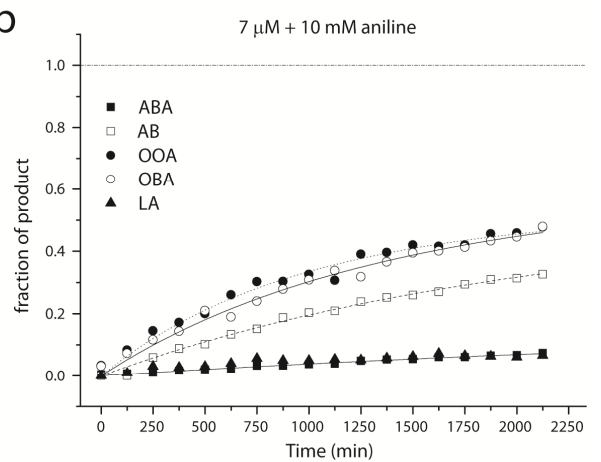

Figure S6: Measured concentration of oxime formed in a reaction of $7 \mu \mathrm{M}$ ketone with $14 \mu \mathrm{M}$ aminooxy in the absence (a) or presence of $10 \mathrm{mM}$ (b) or $100 \mathrm{mM}$ aniline (c) fitted to a second order reversible reaction as described above. Dotted line represents theoretical maximum of product. 
a

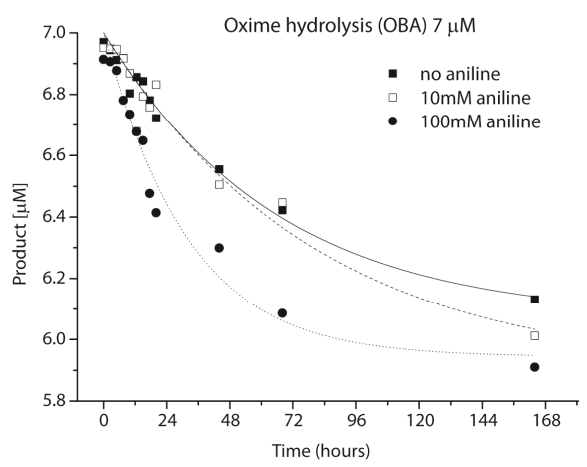

b

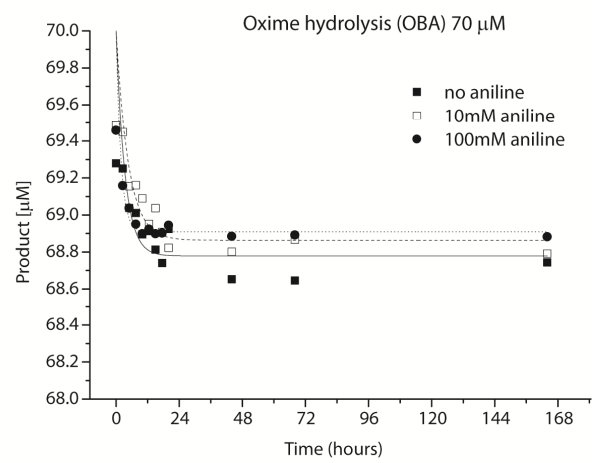

Figure S7: Measured concentration of oxime hydrolyzed in a reaction of $70 \mu \mathrm{M}$ (a) or $7 \mu \mathrm{M}$ (b) oxime with $7 \mu \mathrm{M}$ aminooxy in absence and presence of aniline fitted to a second order reversible reaction as described above

a

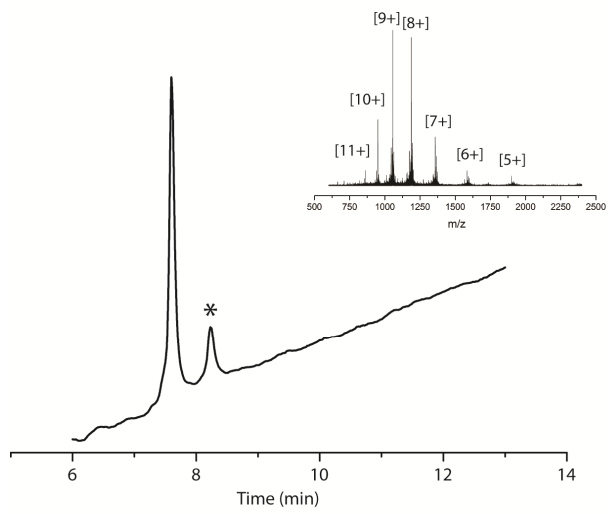

b

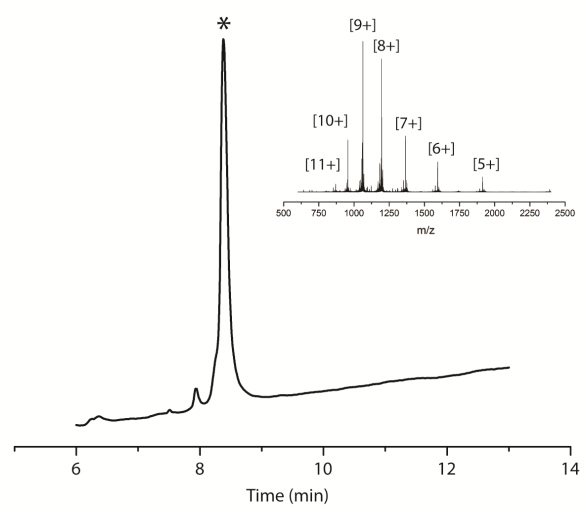

Figure S8: UV spectrum of RANTES(LA) (a) or RANTES(OBA) (b) labeling with Rhodamine B DTPA dual label after $36 \mathrm{~h}$. Desired product is labeled with *. Inserts show charge envelopes of purified RANTES-LA-label (exact mass: 9491.5, observed mass: 9491.8) and purified RANTESOBA-label (exact mass: 9553.5, observed mass: 9552.9).<smiles>CC(CCCC(=O)NCCCC(N)C(=O)NOC(=O)OCc1ccccc1)=NOCC(=O)NPC(=O)O</smiles>

Figure S9: Oxime bond formed by reaction of LYRAK(AB) with aminooxy-VIPF. Signals of protons highlighted in bold have been integrated over time using NM R spectroscopy and used for the fit in Figure S10. 


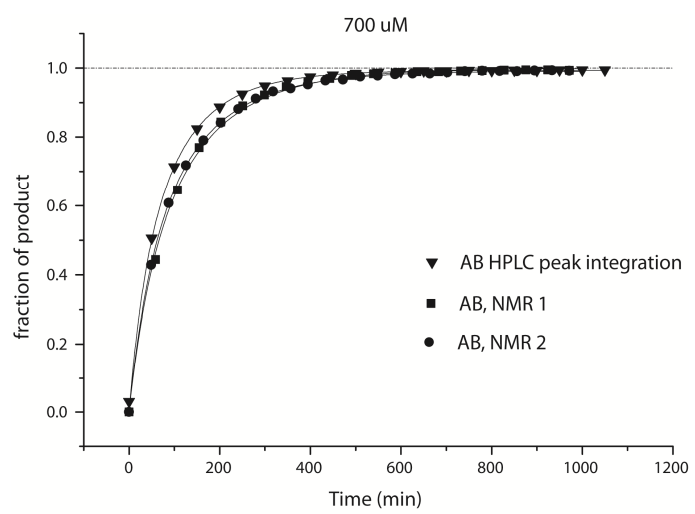

Figure S10: Comparison of measured concentration of oxime formed in a reaction of $700 \mu \mathrm{M}$ ketone with $1400 \mu \mathrm{M}$ aminooxy fitted to a second order reversible reaction as described above, either obtained by HPLC peak integration or NMR. NMR 1 represents the data obtained when following decrease of $\mathrm{CH}_{2}$ signal upon oxime formation, whereas NMR 2 represents the data when following the signal increase of $\mathrm{NH}$ upon oxime formation. Dotted line represents theoretical maximum of product.
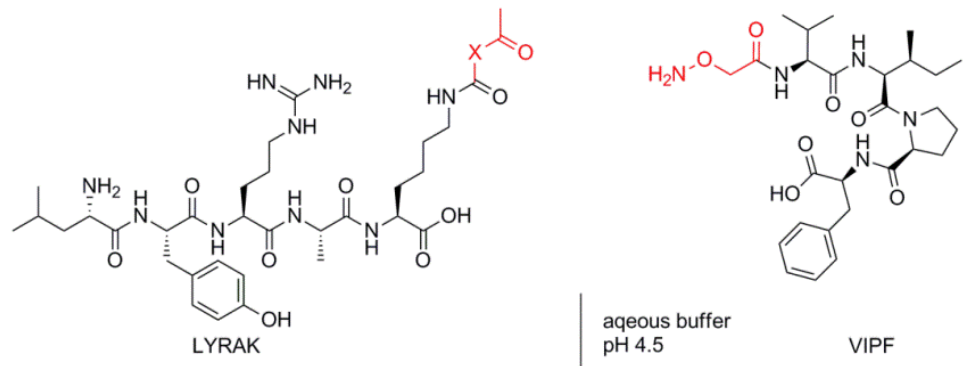

VIPF

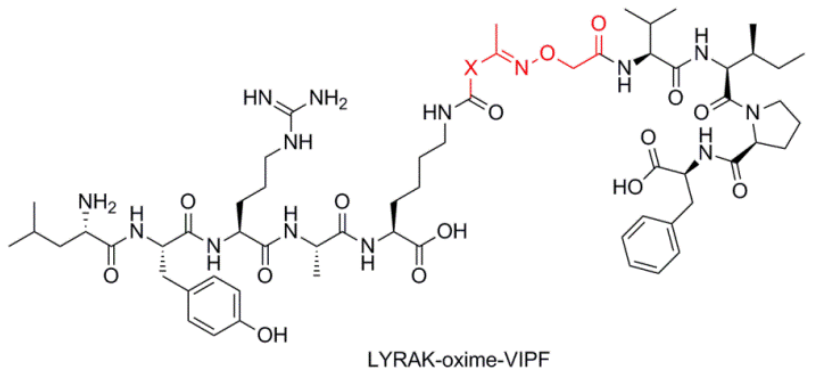

Figure S11: Schematic representation of the peptide model system. Peptides LYRAK, modified with a ketone ( $X$ denotes the different ketones used), and peptide VIPF, modified with an aminooxy, were reacted in aqueous buffer $\mathrm{pH} 4.5$ to form an oxime bond 


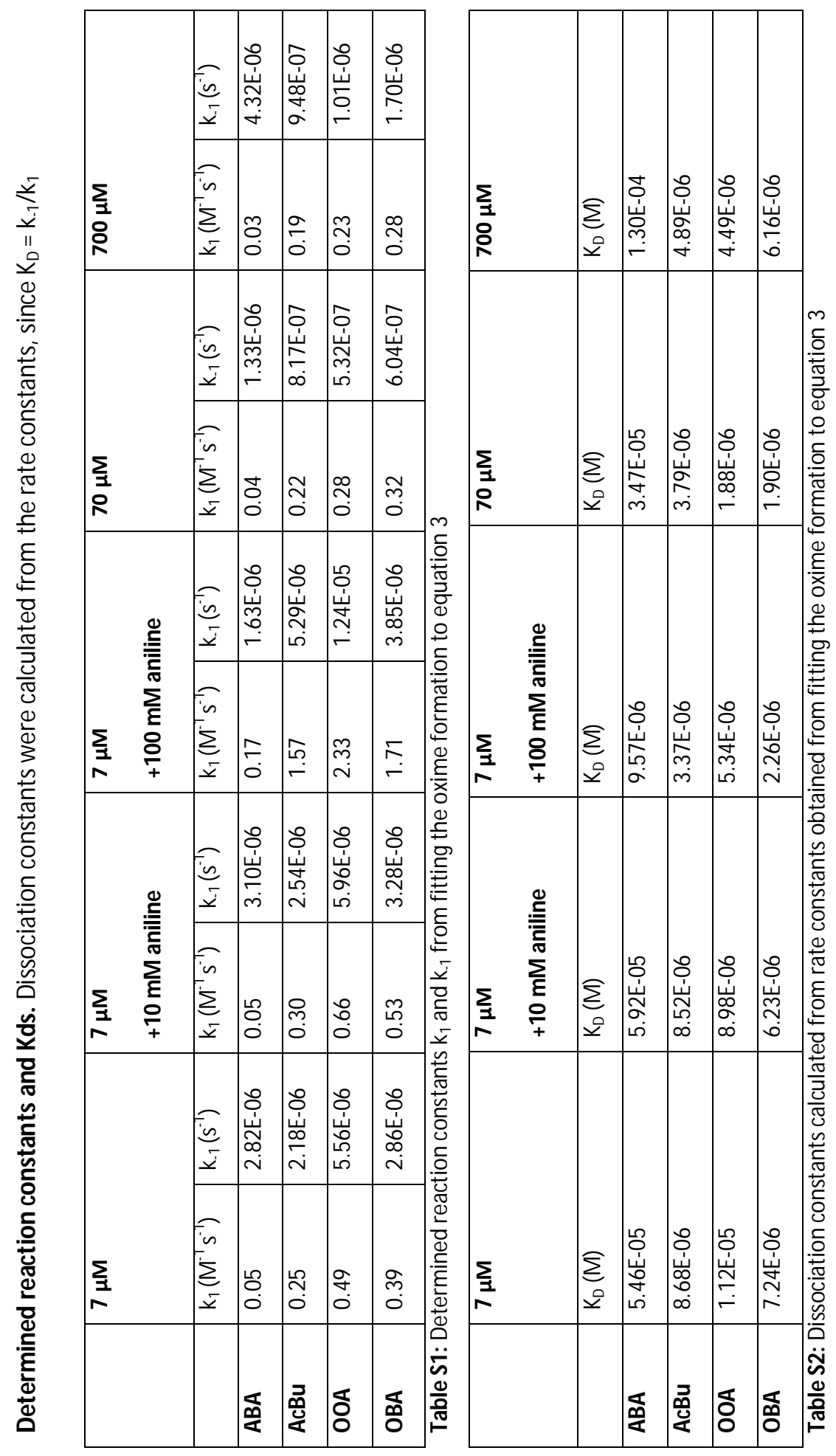



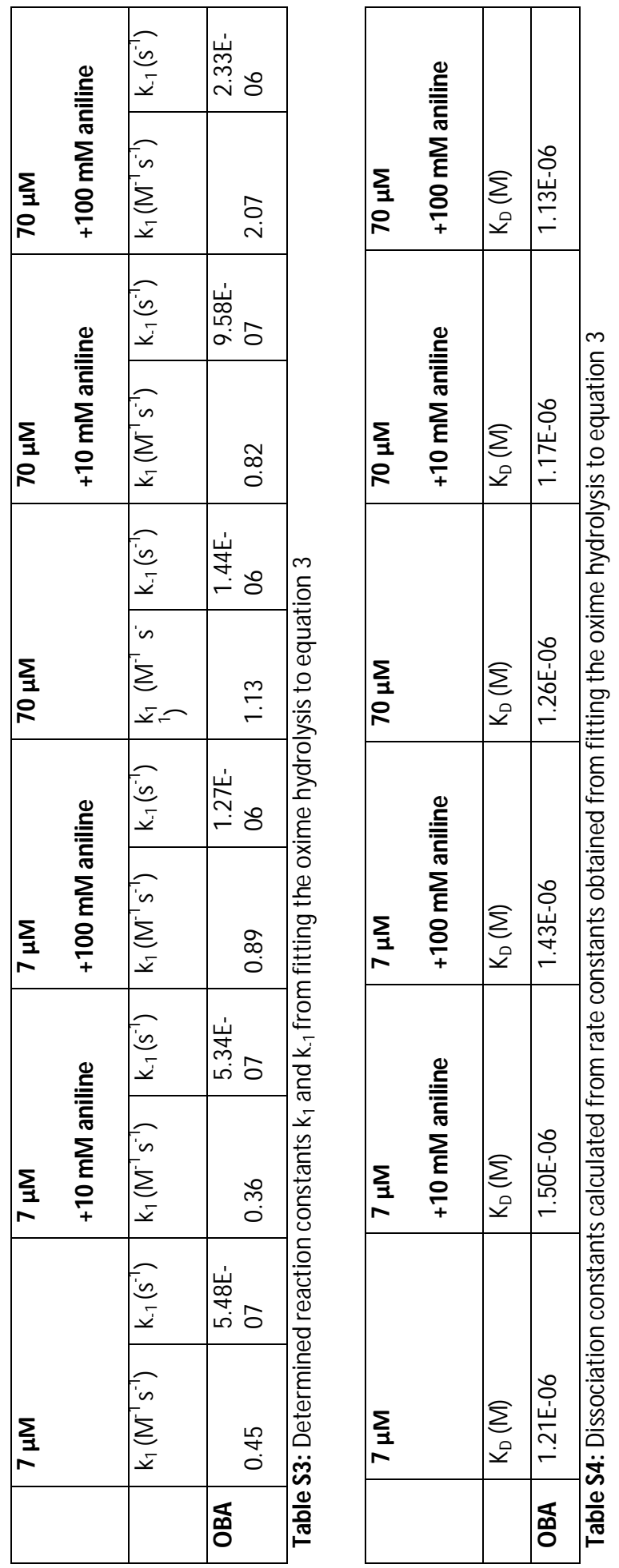


\section{Supplementary References}

1. M. Schnolzer, P. Alewood, A. Jones, D. Alewood, S. B. Kent, Int J Pept Protein Res 1992, 40, 180-193.

2. V. K. Korobov, E.; Ochkov, V., Chemical Kinetics tasks on the MAS.

3. //staff.ustc.edu.cn/ -liuyz/ methods/NMR_VT_calibration.htm

4. T. L. Hwang, A. J. Shaka, Journal of Magnetic Resonance, Series A 1995, 112, 275-279.

5. T. D. Goddard, D. G. Kneller, University of California, San Francisco.

6. J. C. Cobas, F. J. Sardina, Concepts in Magnetic Resonance Part A 2003, 19A, 80-96.

7. J. Davies, S. Gordon, in Basic Cell Culture Protocols, Vol. 290 (Eds.: C. Helgason, C. Miller), Humana Press, 2005, pp. 91-103. 



\section{Chapter 4}

\section{Oxime catalysis by freezing}

Agten SM, Suylen DP, Hackeng TM

Bioconjug Chem 2016; 27(1): 42-6 


\section{Abstract}

Chemical reaction rates are generally decreased at lower temperatures. Here, we report that an oxime ligation reaction in water at neutral $\mathrm{pH}$ is accelerated by freezing. The freezing method and its rate effect on oxime ligation are systematically studied on a peptide model system, and applied to a larger chemokine protein, containing a single acetyl butyrate group, which is conjugated to an aminooxy-labeled ligand. Our improved ligation protocol now makes it possible to efficiently introduce oxime-bond coupled ligands into proteins under aqueous conditions at low concentrations and neutral $\mathrm{pH}$.

\section{Introduction}

Oxime ligations have unique properties and provide various linkage possibilities due to their orthogonal chemical nature. However, this chemical reaction is not routinely employed in bioconjugation strategies, primarily due to the slow rate of oxime formation. The reaction between a ketone or aldehyde with an aminooxy moiety forming an oxime bond is known to be sluggish especially at neutral $\mathrm{pH}$, but can be accelerated by addition of the catalyst aniline or derivatives thereof.[1-5] Although the oxime ligation is becoming more popular, other strategies such as the (copper catalyzed) click reaction, the Staudinger ligation or Diels-Alder reactions are the preferred methods in most laboratories. [6-8]

Typically, chemical reaction rates gradually decrease with decreasing temperatures, an observation which also holds true for the oxime reaction. Here, we show that by slowly freezing the reaction mixture in water at $-20^{\circ} \mathrm{C}$, the oxime reaction rate can be increased up to two orders of magnitude, an enhancement greater than that achieved with the usual catalyst aniline. To demonstrate the feasibility and characteristics of the freeze-induced oxime ligation method, we show examples of bioconjugation on a model peptide system and a larger chemokine protein. 
<smiles>CC(=O)CCCC(=O)NCCCC[C@H](NC(=O)[C@H](C)NC(=O)[C@H](CCCNC(=N)N)NC(=O)[C@H](Cc1ccc(O)cc1)NC(=O)[C@H](N)CC(C)C)C(N)=O</smiles>

LYRAK(ACBu)

1<smiles>CC(C)CC(N)C(=O)N[C@H](Cc1ccc(O)cc1)C(=O)N[C@@H](CCCCNC(=N)N)C(=O)N[C@@H](C)C(=O)O</smiles>

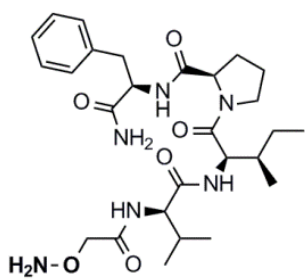

AO-VIPF

2

Scheme 1: M odel peptide LYRAK(ACBu) and AO-VIPF oxime ligation scheme

\section{Results}

To investigate the freezing effect on the oxime reaction, a model system was used that consisted of two modified peptide sequences, LYRAK and VIPF. The lysine side chain in the LYRAK peptide was modified with 4-acetylbutyric acid to yield LYRAK(AcBu), one of the fastest reacting ketones. [9] Peptide VIPF was modified with an aminooxy group on the $\mathrm{N}$-terminal $\mathrm{NH}_{2}$ group to result in AO-VIPF (Scheme 1). The choice for a ketone instead of an aldehyde functionality on LYRAK was made because ketones are more widely used in bioconjugation but suffer from lower reactivity as compared to aldehydes, thus making it an optimal target for improvement. [3, 10-13] In previous studies, catalysis with aniline (or its derivatives) still exhibit relatively long reaction times. [2-4] For example, PEGylation of a ketone-containing protein at low concentration $(7 \mu \mathrm{M})$ was performed at $\mathrm{pH} 7$ using a 700 -fold excess of aminooxyPEG.[3] Even in the presence of $500 \mathrm{mM} \mathrm{m}$-phenylenediamine as catalyst, the reaction yield was only $-60 \%$ after 20 hours, thus providing impetus for improving ketonemediated oxime reactions.[3] 

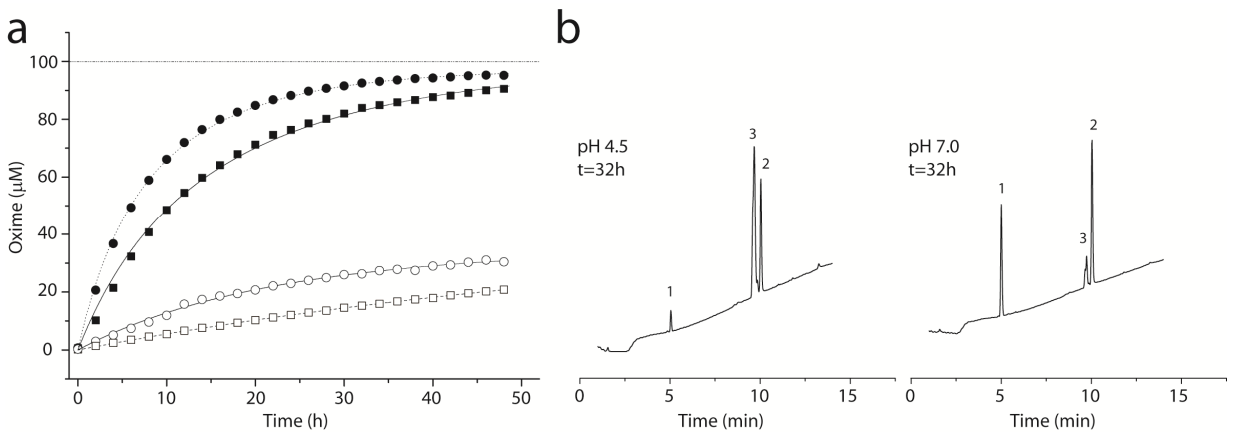

Figure 1: a: Oxime ligation progression curve of peptides LYRAK(ACBu) and AO-VIPF at $37{ }^{\circ} \mathrm{C}$. Conditions - $\mathrm{pH} 4.5 \square \mathrm{pH} 7.0 \bullet \mathrm{pH} 4.5+10 \mathrm{mM}$ aniline $\circ \mathrm{pH} 7.0+10 \mathrm{mM}$ pheneylenediamine, b: HPLC chromatogram of the reaction taken after $32 \mathrm{~h}$ at $\mathrm{pH} 4.5$ or $\mathrm{pH} 7.0$ in absence of aniline. LYRAK(ACBu) 1, AO-VIPF $\mathbf{2}$ and oxime product $\mathbf{3}$ are denoted.

The oxime reaction involving two test peptides LYRAK(ACBu) and AO-VIPF was followed under various experimental conditions (Figure 1,2). All reactions with the model system were performed at a concentration of $100 \mu \mathrm{M}$ LYRAK(ACBu) and a twofold excess of AO-VIPF $(200 \mu M)$.

In the absence of catalyst, the oxime reaction at the optimal pH of 4.5 was completed only after 48 hours $\left(k_{1} 0.11 \mathrm{M}^{-1} \mathrm{~s}^{-1}\right)$. At neutral $\mathrm{pH}$ the reaction was much slower and did not exceed $20 \%$ of maximal product formation over the same period of time ( $k_{1}$ $0.01 \mathrm{M}^{-1} \mathrm{~s}^{-1}$ ). Catalysis with $10 \mathrm{mM}$ aniline at $\mathrm{pH} 4.5$ resulted in a two fold increase in reaction rate $\left(\mathrm{k}_{1} 0.19 \mathrm{M}^{-1} \mathrm{~s}^{-1}\right)$ (Figure 1$)$. At neutral $\mathrm{pH}$ the reaction was catalyzed with p-pheneylenediamine, which was shown to have increased activity as compared to aniline at neutral $\mathrm{pH}$, yielding a two fold increase in reaction rate $\left(k_{1} 0.02 \mathrm{M}^{-1} \mathrm{~s}^{-1}\right)$. [4] These results show that slow reaction rates for oxime bond formation remain $a$ problem especially at neutral $\mathrm{pH}$ and prompted us to examine experimental conditions that would lead to increased oxime reaction rates for more effective protein bioconjugation, which ideally requires reactions to be performed at low concentration and neutral $\mathrm{pH}$.

In studying the thermodynamics of the oxime reaction, we observed that upon freezing our sample at $-20{ }^{\circ} \mathrm{C}$ the reaction unexpectedly reached completion. To investigate this effect on oxime formation, peptides LYRAK(ACBu) and AO-VIPF were ligated under freezing conditions. To ensure a homogenous freezing of the mixture, the samples were frozen in an isopropanol bath at temperatures -20 and $-80^{\circ} \mathrm{C}$, or alternatively in liquid nitrogen at $-196{ }^{\circ} \mathrm{C}$. The effects of freezing on ligation yields were first studied by maintaining the frozen reaction vessel 1,2 or 3 hours at a constant low temperature (Figure $2 \mathrm{~A}$ ). At optimal pH of 4.5 and freezing at $-20{ }^{\circ} \mathrm{C}$, the reaction reached $85 \%$ of oxime product after 1 hour. Prolongation of incubation time to 2 and 3 hours resulted in a slight increase in formation of oxime product, likely due 
to continuation of normal reaction kinetics. Therefore we concluded that a freezing time of 1 hour is sufficient to reach a desirable yield. Addition of $100 \mathrm{mM}$ aniline to the reaction increased the yield to near completion within 1 hour (Figure 2A). To unambiguously prove that freezing of the sample is responsible for the observed effect, a sample was measured under similar conditions in presence of $30 \%$ methanol, to decrease the freezing point to $-26{ }^{\circ} \mathrm{C}$. Addition of methanol only mildly reduced $\mathrm{k}_{1}$ from $0.17 \mathrm{M}^{-1} \mathrm{~s}^{-1}$ to $0.10 \mathrm{M}^{-1} \mathrm{~s}^{-1}$ (Figure S1). Presence of $30 \%$ methanol at $-20{ }^{\circ} \mathrm{C}$ for 1,2 or 3 hours showed no effect on the reaction rate, indicating that the process of freezing caused the observed increase in reaction rate (Figure 2A).

a

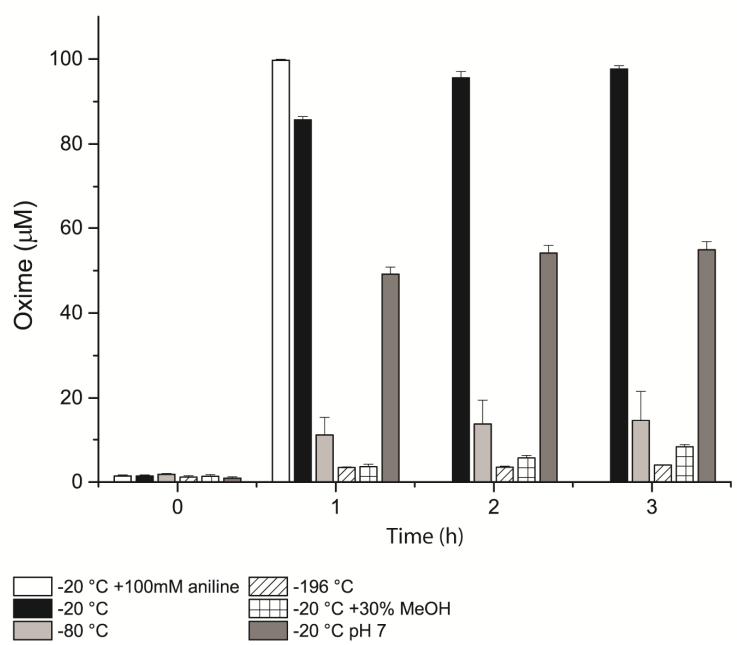

b

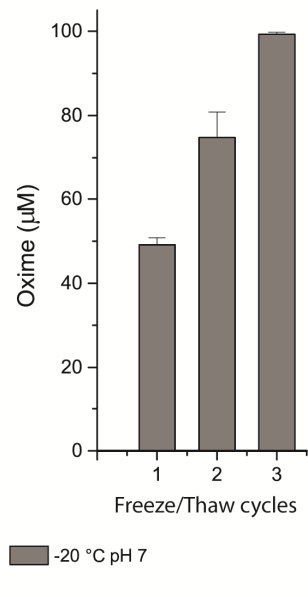

Figure 2: a: Yield of oxime formation between LYRAK(AcBu) $(100 \mu \mathrm{M})$ and AO-VIPF $(200 \mu \mathrm{M})$ as a function of freezing time at different temperature and solution conditions. Maximum theoretical yield is $100 \mu \mathrm{M}$. b: Effect of the number of freeze/ thaw cycles (duration of one hour) on the final yield of the oxime product formed between LYRAK(AcBu) $(100 \mu \mathrm{M})$ and AO-VIPF $(200 \mu \mathrm{M})$ in sodium phosphate buffer $\mathrm{pH} 7$.

In our experimental setup the time for complete freezing of the sample at $-20^{\circ} \mathrm{C}$ was $\sim 1$ hour. To study the influence of freezing rate on oxime formation, the reaction mixture was frozen at lower temperatures of -80 or $-196{ }^{\circ} \mathrm{C}$, respectively, to decrease the time until a fully frozen state was reached. Notably, the fast freezing procedure barely increased oxime reaction rates or yields (Figure $2 \mathrm{~A}$ ). This indicated that $-20^{\circ} \mathrm{C}$ is an optimal temperature and suggested that slow growing ice crystals likely produce locally high concentrations of reactants favoring more rapid oxime bond formation. In the case of freezing at -80 or $-196{ }^{\circ} \mathrm{C}$ the short freezing time likely prevents reactant exclusion and therefore will not influence oxime formation to a large extent.

Even though freezing at $\mathrm{pH} 4.5$ was promising, it provided no great advantage compared to reaction catalysis with aniline (Figures $1 \mathrm{~A} ; 2 \mathrm{~A}$ ). For this reason, we decided to assess effects on the reaction at neutral $\mathrm{pH}$ where oxime reactions occur 
very slowly even in the presence of catalysts. Freezing of the sample at $\mathrm{pH} 7$ saw an oxime yield of approximately $50 \%$, which is a 25 fold increase in comparison to the control reaction at $37{ }^{\circ} \mathrm{C}$ that reaches $2 \%$ in 1 (Figure $1 \mathrm{~A}$ ). In an attempt to increase the oxime formation yield above $50 \%$ under these conditions, repeated freeze/thaw cycles were performed. In each cycle the samples were slowly frozen at $-20^{\circ} \mathrm{C}$ for 55 minutes and subsequently thawed. After one thermal cycle, the oxime yield was $50 \%$ (Figure 2B). A second cycle increased the yield to $75 \%$, and the maximum yield was obtained after a third cycle.

To put these results in a more biological and practical context, we applied our freezing protocol to protein labeling, at low concentrations and neutral pH. For this purpose, the 68 amino acid chemokine CCL5 obtained by chemical synthesis and derivatized with a ketone moiety on Lys69 was conjugated with a bimodal label containing diethylenetriamine pentaacetic acid (DTPA) and tetramethyl rhodamine (TAM RA) and an aminooxy group (Figure 3A). The protein concentration was lowered to $10 \mu \mathrm{M}$ to mimic a more realistic protein bioconjugation situation, with the aminooxy label present in three-fold excess. As a control the reaction was followed at $37{ }^{\circ} \mathrm{C}$ which showed slow progression of the oxime reaction at neutral $\mathrm{pH}$ with a yield of $10 \%$ reached after $48 \mathrm{~h}$. In contrast, after a single freeze/thaw cycle the same reaction reached a $77 \%$ yield and conversion was near complete after 3 cycles (Figure 3C). To compare the freezing procedure with the continuous reaction at $37{ }^{\circ} \mathrm{C}$, data are presented as three successive freeze cycles of 1 hour each (Figure 3C). 

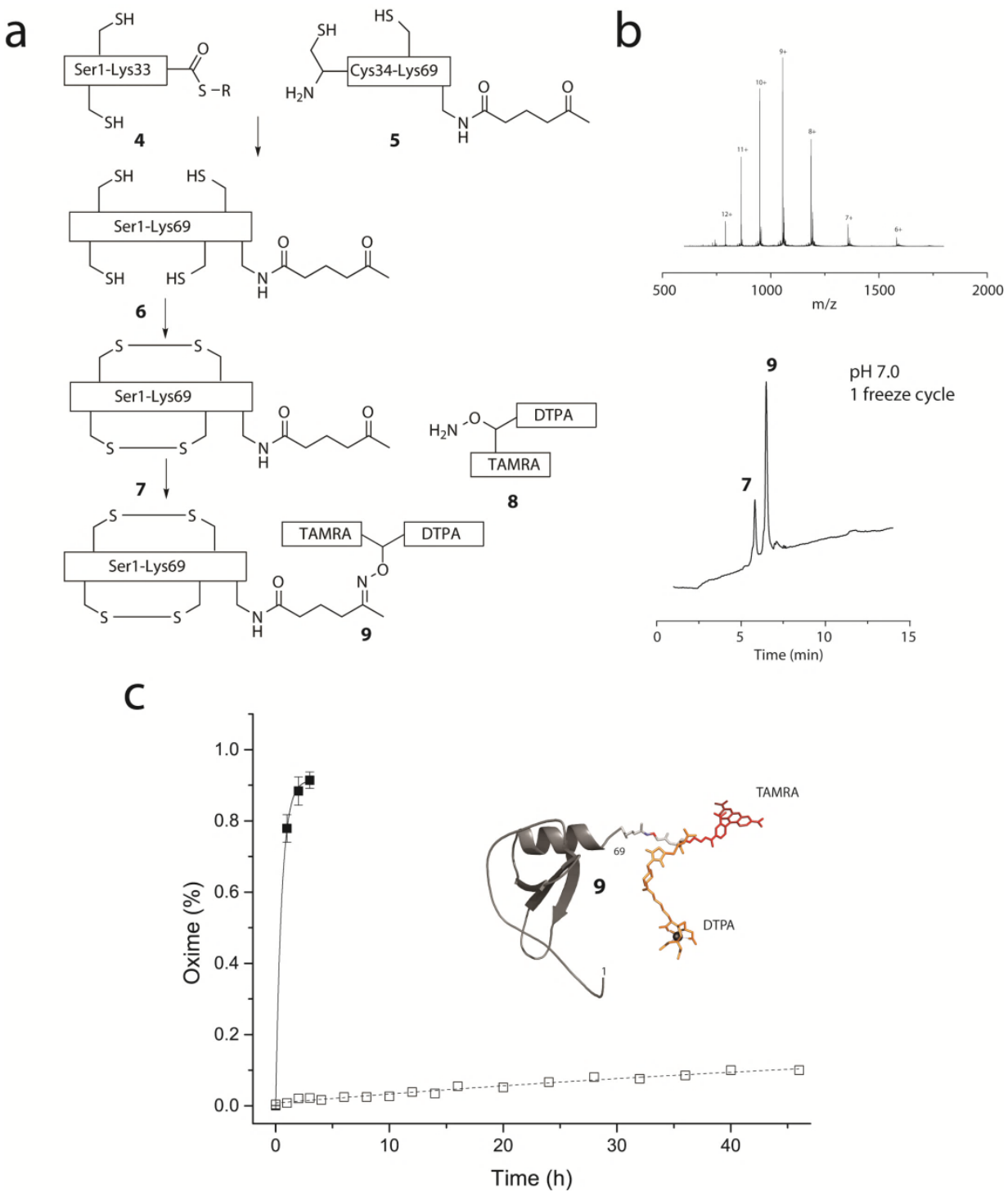

Figure 3: a: Schematic representation of the RANTES synthesis and subsequent labelling with a bimodal label. b: M ass spectrum of 9, HPLC graph after a single freeze/thaw cycle of reaction of 7 and 8 to yield $9 \mathrm{c}$ : Labelling of CCL5 with an aminooxy label. Reaction followed over time. Freeze/thaw cycles $-20^{\circ} \mathrm{C} \square$ reaction progression at $37^{\circ} \mathrm{C}$. Insert shows a ribbon representation of 9

Here, we demonstrated that under aqueous conditions, the oxime reaction between a ketone and aminooxy group can be readily catalyzed by freezing of the reaction mixture. The effects are largest at neutral pH, at which uncatalyzed oxime ligations are usually unreactive. The observation that chemical reactions are accelerated by freezing was first observed in the '60s.[14-16] The explanation for this interesting phenomenon rests in several factors.[17] First, freezing induces a concentration effect 
that can account for most reaction rate accelerations. In addition, a catalytic effect of the fine-structured growing ice crystals might play a role. Finally, the increase in salt concentration and associated change in $\mathrm{pH}$ and ionic strength were mentioned as reasons for rate acceleration. The basis for the observed effect in case of the oxime reaction most likely lies in the concentration effect, which supports our reactantexclusion theory. However, since the effect seen at pH 7.0 is larger than at pH 4.5, we cannot exclude that one of the other freezing effects might play a role in rate acceleration at neutral $\mathrm{pH}$.

Overall, we have presented a simple procedure to significantly enhance oxime reaction rates without the addition of catalyst. One limitation of our study might lie in the repetitive freezing protocol, which would make the procedure less attractive for proteins that destabilize and aggregate during freezing. However, in comparison to catalysis of the oxime reaction with aniline (or derivatives) the presented increase in reaction rate by freezing has a number of advantages. Firstly, the catalysis with aniline will also accelerate the backward hydrolysis reaction.[9] Secondly, catalysis with aniline requires a purification step following conjugation to remove the catalyst. Finally, in comparison to protein labeling reactions catalyzed by anilines, reaction times can be even further reduced. For example, the latest reported derivative of aniline, $\mathrm{p}$-phenylenediamine, requires $20 \mathrm{~h}$ reaction time to reach $90 \%$ conversion (conditions: $91 \mu \mathrm{M}$ protein 5 -fold excess label, $10 \mathrm{mM}$ catalyst, $4{ }^{\circ} \mathrm{C}$ ) whereas our method saw similar yields after only 3 hours with 10 fold lower protein concentrations.[4]

This procedure offers a quick and facile procedure to label proteins via oxime chemistry without the need to use large excesses of label, catalysts, or purification. 


\section{References}

1. Dirksen, A. and P.E. Dawson, Rapid oxime and hydrazone ligations with aromatic aldehydes for biomolecular labeling. Bioconjug Chem, 2008. 19(12): 2543-2548.

2. Dirksen, A., T.M. Hackeng, and P.E. Dawson, Nucleophilic catalysis of oxime ligation. Angew Chem Int Ed Engl, 2006. 45(45): 7581-7584.

3. Rashidian, M., M.M. Mahmoodi, R. Shah, J.K. Dozier, C.R. Wagner, and M.D. Distefano, A highly efficient catalyst for oxime ligation and hydrazone-oxime exchange suitable for bioconjugation. Bioconjug Chem, 2013. 24(3): 333-342.

4. Wendeler, M., L. Grinberg, X. Wang, P.E. Dawson, and M. Baca, Enhanced catalysis of oxime-based bioconjugations by substituted anilines. Bioconjug Chem, 2014. 25(1): 93-101.

5. Crisalli, P. and E.T. Kool, Water-soluble organocatalysts for hydrazone and oxime formation. J Org Chem, 2013. 78(3): 1184-1189.

6. Kolb, H.C., M.G. Finn, and K.B. Sharpless, Click Chemistry: Diverse Chemical Function from a Few Good Reactions. Angew Chem Int Ed Engl, 2001. 40(11): 2004-2021.

7. Saxon, E. and C.R. Bertozzi, Cell surface engineering by a modified Staudinger reaction. Science, 2000. 287(5460): 2007-2010.

8. Kalia, J. and R.T. Raines, Advances in Bioconjugation. Curr Org Chem, 2010. 14(2): 138147.

9. Agten, S.M., D. Suylen, H. Ippel, M. Kokozidou, G. Tans, P. van de Vijver, R.R. Koenen, and T.M. Hackeng, Chemoselective oxime reactions in proteins and peptides by using an optimized oxime strategy: the demise of levulinic acid. Chembiochem, 2013. 14(18): 2431-2434.

10. Fleissner, M.R., E.M. Brustad, T. Kalai, C. Altenbach, D. Cascio, F.B. Peters, K. Hideg, S. Peuker, P.G. Schultz, and W.L. Hubbell, Site-directed spin labeling of a genetically encoded unnatural amino acid. Proc Natl Acad Sci U SA, 2009. 106(51): 21637-21642.

11. Kim, C.H., J.Y. Axup, A. Dubrovska, S.A. Kazane, B.A. Hutchins, E.D. Wold, V.V. Smider, and P.G. Schultz, Synthesis of bispecific antibodies using genetically encoded unnatural amino acids. J Am Chem Soc, 2012. 134(24): 9918-9921.

12. Scheck, R.A., M.T. Dedeo, A.T. lavarone, and M.B. Francis, Optimization of a biomimetic transamination reaction. J Am Chem Soc, 2008. 130(35): 11762-11770.

13. Yi, L., H. Sun, Y.W. Wu, G. Triola, H. Waldmann, and R.S. Goody, A highly efficient strategy for modification of proteins at the C terminus. Angew Chem Int Ed Engl, 2010. 49(49): 9417-9421.

14. Bruice, T.C., Catalysis in Water and Ice. A Comparison of the Kinetics of Hydrolysis of Acetic Anhydride, $\beta$-Propiolactone, and $p$-Nitrophenyl Acetate and the Dehydration of 5-Hydro-6-hydroxydeoxyuridine in Water and Ice. Journal of the American Chemical Society, 1964. 86(3): 313-319.

15. Grant, N.H. and H.E. Alburn, Fast Reactions of Ascorbic Acid and Hydrogen Peroxide in Ice, a Presumptive Early Environment. Science, 1965. 150(3703): 1589-1590.

16. Takenaka, N., A. Ueda, T. Daimon, H. Bandow, T. Dohmaru, and Y. Maeda, Acceleration mechanism of chemical reaction by freezing: The reaction of nitrous acid with dissolved oxygen. J Phys Chem-Us, 1996. 100(32): 13874-13884.

17. Fennema, O., Reaction Kinetics in Partially Frozen Aqueous Systems, in Water Relations of Foods, R.B. Duckworth, Editor 1975, Academic Press. p. 539-556. 


\section{Supporting Information}

Peptide synthesis. Peptides were synthesized manually by SPPS on a $0.25 \mathrm{mmol}$ scale on a M BHA or PAM resin. An in situ neutralization/HCTU activation for Boc chemistry was used. Each synthetic cycle consisted of 1. removal of the Boc protective group by two 1-minute treatments with TFA, followed by a DMF wash; 2. addition of the preactivated amino acid in the presence of excess DIPEA, followed by another DM $F$ wash. The Boc-protected amino acids ( $1.1 \mathrm{mmol}$ ) were activated with $1 \mathrm{mmol}$ of HCTU and $3 \mathrm{mmol}$ DIPEA. Coupling of GIn residues was followed by a DCM wash, before and after TFA deprotection, to prevent intramolecular pyrrolidone formation. After coupling of the final amino acid, the resin was dried by wash steps with DCM and $\mathrm{DCM} / \mathrm{MeOH}$.

After completion of the peptide chain, the peptides were deprotected and cleaved from the resin by treatment with anhydrous $\mathrm{HF}$ for 1 hour at $0^{\circ} \mathrm{C}$, using $4 \% \mathrm{p}$-cresol $(\mathrm{v} / \mathrm{v})$ as scavenger Peptides were precipitated in ice-cold diethylether, dissolved in $50 \%$ acetonitrile in water containing $0.1 \%$ TFA, and lyophilized. The crude mixture was subjected to preparative HPLC and fractions containing the desired product were identified by ESI-M S, pooled and lyophilized.

LYRAK model peptide

sequence: $\mathrm{H}_{2} \mathrm{~N}$-Leu-Tyr-Arg-Ala-Lys(Fmoc)-CONH

VIPF model peptide

sequence: $\mathrm{H}_{2} \mathrm{~N}$-(Aminooxy)acetic acid-Val-Ile-Pro-Phe- $\mathrm{CONH}_{2}$

RANTES C-terminus peptide

sequence: $\mathrm{H}_{2} \mathrm{~N}$-Cys-Ser-Asn-Pro-Ala-Val-Val-Phe-Val-Thr-Arg-Lys-Asn-Arg-Gln-Val-CysAla-Asn-Pro-Glu-Lys-Lys-Trp-Val-Arg-Glu-Tyr-Ile-Asn-Ser-Leu-Glu-M et-Ser-Lys(Fmoc)$\mathrm{COOH}$

RANTES N-terminus peptide

sequence: $\quad \mathrm{H}_{2} \mathrm{~N}$-Ser-Pro-Tyr-Ser-Ser-Asp-Thr-Thr-Pro-Cys-Cys-Phe-Ala-Tyr-Ile-Ala-ArgPro-Leu-Pro-Arg-Ala-His-Ile-Lys-Glu-Tyr-Phe-Tyr-Thr-Ser-Gly-Lys-M PAL-COOH

Synthesis of Rhodamine B DTPA dual label. A dipeptide Cys-Lys(Fmoc) was prepared via solid phase peptide synthesis as described above. The N-terminal Boc protection was removed with $2 \times 1$ min TFA treatment after which (Aminooxy)acetic acid (2.2 mmol) was preactivated using DIC $(2.0 \mathrm{mmol})$ for 2 minutes. NHS $(2.0 \mathrm{mmol})$ and DIPEA $(0.6 \mathrm{mmol})$ was added to the mixture, directly followed by addition to the deprotected Cys-Lys $(0.25 \mathrm{mmol})$ and left to react for 1 hour. The Fmoc deprotection was achieved by $4 \times 3$ min $20 \%$ piperidine in DMF. Any unreacted, residual piperidine 
were removed by a DMF and DCM wash step. $0.5 \mathrm{~mL}$ rhodamine B-succinimide (AAT Bioquest, Sunnyvale CA, USA) $(7.5 \mathrm{mg} / \mathrm{mL})$ was added to the resin and the mixture was left to react at $37{ }^{\circ} \mathrm{C}$ for 4 hours with occasional mixing. The resin was washed with DM F followed by N-terminal Boc deprotection. The dipeptide was cleaved from the resin using anhydrous $\mathrm{HF}$, precipitated in diethylether, dissolved in $50 \% \mathrm{MeCN}$ in $\mathrm{H} 2 \mathrm{O}+0.1 \%$ TFA, purified and lyophilized. The dried peptide $(2.4 \mathrm{mg})$ was dissolved in $1 \mathrm{~mL} 0.1 \mathrm{M} \mathrm{NH} 4 \mathrm{OAc}$ (pH 5.7) $+10 \%$ MeCN. Maleimide-DTPA was added in 1.5 times excess and left to react at $37{ }^{\circ} \mathrm{C}$ for 2.5 hours. The resulting product was purified, analyzed by M ALDI mass spectrometry and lyophilized.

Ketone incorporation into chemokine RANTES C-terminus peptide. After completion of the peptide chain, the Fmoc protective group on the C-terminal lysine was deprotected using $4 \times 3$ min treatments with $20 \%$ piperidine in DMF. Subsequently, keto-acid 4-acetylbutyric acid $(2.2 \mathrm{mmol})$ was preactivated using carbodiimide (2 $\mathrm{mmol})$ (DIC) for 2 minutes after which $\mathrm{N}$-hydroxysuccinimide (NHS) $(2.0 \mathrm{mmol})$ and $\mathrm{N}, \mathrm{N}$-diisopropyldiamine (DIPEA) $(0.6 \mathrm{mmol})$ was added. This mixture was directly added to the deprotected RANTES $(0.25 \mathrm{mmol})$ and left to react for 1 hour. Finally the $\mathrm{N}$-terminal Boc-protective group was removed by treatment with TFA as described above to result in RANTES(AcBu) C-terminal peptide after cleavage from the resin.

Native chemical ligation of RANTES C- and N-terminus peptides. Both the C- and Nterminal peptides were purified using HPLC before ligation. Equimolar amounts of both peptides were mixed in $6 \mathrm{M}$ Guanidine (Gdn)-HCl, $0.1 \mathrm{M}$ Tris- $\mathrm{HCl},(\mathrm{pH} 8)$ at a concentration of $10 \mathrm{mg} / \mathrm{mL}$ each, and thiophenol was added (2 vol-\%). The $\mathrm{pH}$ was adjusted to 7 before the reaction was left to react at $37{ }^{\circ} \mathrm{C}$ for $4 \mathrm{~h}$ with occasional mixing.

Oxidative folding of RANTES. After native chemical ligation RANTES was purified using HPLC, desired fractions were pooled and lyophilized. The peptide was dissolved in $3 \mathrm{M}$ $\mathrm{Gdn}-\mathrm{HCl}, 0.1 \mathrm{M}$ Tris- $\mathrm{HCl} \mathrm{pH} 8$ at a concentration of $0.2 \mathrm{mg} / \mathrm{mL}$. Cysteine $(8 \mathrm{mM})$ and Cystine $(1 \mathrm{mM})$ were added and the protein was left to fold at $4{ }^{\circ} \mathrm{C}$ for $24 \mathrm{~h}$ with continuous stirring. The folded protein was purified using HPLC, and desired fractions were pooled and lyophilized.

UPLC Mass spectrometry. Analysis of oxime reactions and HPLC fraction analysis were performed on a Waters UHPLC XEVO-G2QTOF system. Samples (1-10 $\mu \mathrm{L}$ ) were loaded using a FTN-autosampler on a PST C18 column (130A; $1.7 \mu \mathrm{m}$ particles; column dimension $2.1 \times 50 \mathrm{~mm}, 35^{\circ} \mathrm{C}$ ). $5 \%$ acetonitrile and $0.1 \%$ formic acid (FA) in water was applied as purge-solvent. A water-acetonitrile gradient containing $0.1 \%$ FA (flowrate $250 \mathrm{LL} / \mathrm{min}$ ) was used to separate starting peptides and oxime bound product at baseline level in 14 min Exact mass measurement was performed in resolution mode using ESI-ionisation in positive mode detection (NaFormate-calibrated). Both quad 
profile and probe settings were optimized for small peptide measurementin the case of analysis of the model system reactions or optimized for large peptide measurements in the case of analysis of RANTES fragments.

HPLC Purification. (Semi-)preparative HPLC was performed using Vydac C18 HPLC columns $(10 \mathrm{~mm} \times 250 \mathrm{~mm}, 10 \mathrm{~mL} / \mathrm{min}$ flow rate or $22 \mathrm{~mm} \times 250 \mathrm{~mm}, 20 \mathrm{~mL} / \mathrm{min}$ flow rate) connected to a Waters Deltaprep System consisting of a Waters Prep LC Controller and a Waters 2487 Dual wavelength Absorbance Detector $(\lambda=214 \mathrm{~nm})$. Peptides were eluted using a gradient of $\mathrm{B}(90 \% \mathrm{MeCN}$ in $\mathrm{H} 20$ with $0.1 \%$ TFA) in $\mathrm{A}(100 \%$ $\mathrm{H} 2 \mathrm{O}$ with $0.1 \%$ TFA) based on an analytical UPLC run. Fractions were analyzed by UPLC-MS, desired fractions were pooled and lyophilized.

Keto-acid ligation to LYRAK. The Fmoc protective group on the lysine sidechain was deprotected by treatment with $20 \%$ piperidine in DMF for three minutes, and repeated four times. 4-acetylbutyric acid ( $\mathrm{ACBu})(2.2 \mathrm{mmol})$ was preactivated for 2 minutes using carbodiimide ( $2.0 \mathrm{mmol}$ ) (DIC) after which $\mathrm{N}$-hydroxysuccinimide (NHS) $(2.0 \mathrm{mmol})$ and $\mathrm{N}, \mathrm{N}$-diisopropyldiamine (DIPEA) $(0.6 \mathrm{mmol})$ were added. This mixture was directly added to deprotected LYRAK $(0.25 \mathrm{mmol})$ and left to react for 1 hour. Finally, the N-terminal Boc-protective group was removed by treatment with TFA as described above.

Aminooxy acetic acid ligation to VIPF. The Boc deprotection of the first amino acid (Valine) was performed by treatment with TFA as described above. Boc(Aminooxy)acetic acid (2.2 mmol) was preactivated for 2 minutes using DIC ( $2.0 \mathrm{mmol}$ ) after which NHS $(2.0 \mathrm{mmol})$ and DIPEA $(0.6 \mathrm{mmol})$ was added. this mixture was directly added to deprotected VIPF $(0.25 \mathrm{mmol})$ and left to react for 1 hour.

Control oxime ligation experiments. Peptides LYRAK(AcBu) and AO-VIPF were dissolved in freshly made buffer to a final concentration of respectively $100 \mu \mathrm{M}$ and $200 \mu \mathrm{M}$. Experiments done at $\mathrm{pH} 4.5$ were performed in $100 \mathrm{mM}$ sodium acetate buffer, experiments at pH 7.0 were carried out in $100 \mathrm{mM}$ sodium phosphate buffer. An additional control reaction, where $30 \% \mathrm{v} / \mathrm{v}$ methanol was added to the $\mathrm{pH} 4.5$ buffer, was also studied (supplemental Figure 1). Oxime formation was monitored by integration of the two HPLC chromatogram peaks, absorbing at $280 \mathrm{~nm}$, that correspond to starting material and peptide end product. The integrated peaks as a function of reaction time were fitted to an kinetic equation describing a 2 nd order reversible reaction.

Freeze-induced oxime ligation experiments. Peptides LYRAK(ACBu) and AO-VIPF were dissolved in freshly made buffer to a final concentration of respectively $100 \mu \mathrm{M}$ and $200 \mu \mathrm{M}$. Experiments done at $\mathrm{pH} 4.5$ were performed in $100 \mathrm{mM}$ sodium acetate buffer, experiments at pH 7.0 were carried out in $100 \mathrm{mM}$ Sodium phosphate buffer. 
All freeze experiments were performed in triplicate. Samples were frozen in a bath of isopropanol at temperatures $-20^{\circ} \mathrm{C}$ and $-80^{\circ} \mathrm{C}$, or in liquid nitrogen at $-196{ }^{\circ} \mathrm{C}$. Oxime conversion yields were determined by integration of HPLC chromatogram peaks, absorbing at $280 \mathrm{~nm}$, that correspond to starting material and peptide end product.

RANTES(AcBu) conjugation with A0-dual label. $10 \mu \mathrm{g}$ RANTES(AcBu) was dissolved in $95 \mu \mathrm{L}$ buffer ( $100 \mathrm{mM}$ sodium phosphate $\mathrm{pH}$ 7.0), $5 \mu \mathrm{L}$ AO-dual label was added from a $705 \mu \mathrm{M}$ stock solution to reach final concentrations of $12 \mu \mathrm{M}$ and $35 \mu \mathrm{M}$ for respectively RANTES(ACBu) and AO-dual label. The reaction mixture was slowly frozen at $-20{ }^{\circ} \mathrm{C}$ in an isopropanol bath, kept at constant temperature for 55 minutes and subsequently thawed. After thawing the reaction mixture was placed back in the isopropanol bath for a second freeze/ thaw cycle, etc. In total 3 freeze/thaw cycles were applied. The experiments were repeated four times and the final results were averaged.

The control experiment without freezing was performed at the same concentration and in the same buffer. The samples were placed at $37^{\circ} \mathrm{C}$ and measured for $48 \mathrm{~h}$. Oxime yield was determined by integration of peaks in the HPLC spectrum at $220 \mathrm{~nm}$.

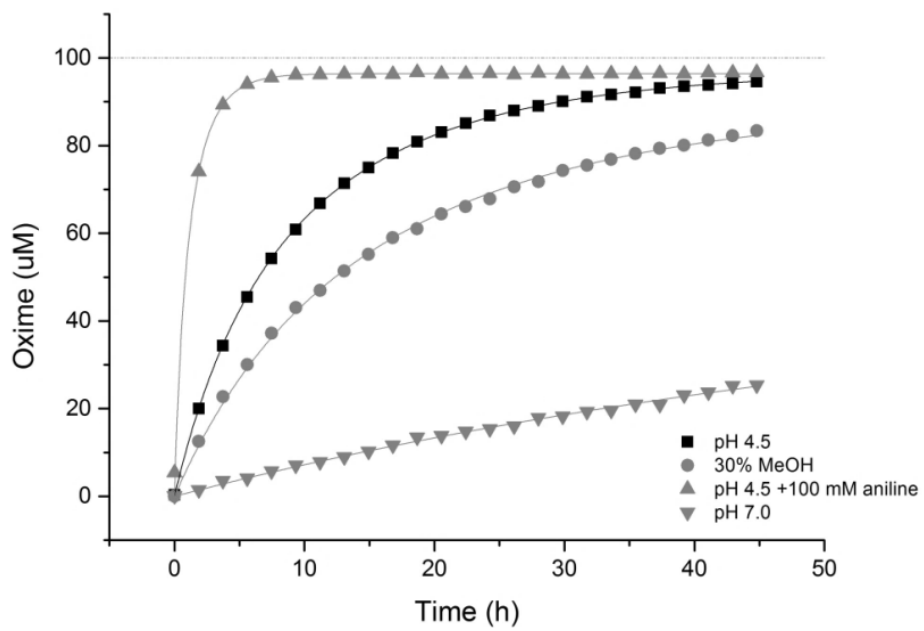

Figure S1: Reaction of LYRAK(AcBu) and AO-VIPF followed over time. Solution conditions used were: $100 \mathrm{mM}$ sodium acetate buffer $\mathrm{pH} 4.5$ (-), $100 \mathrm{mM}$ sodium acetate buffer $+100 \mathrm{mM}$ aniline $\mathrm{pH} 4.5(\Delta), 100 \mathrm{mM}$ sodium phosphate buffer $\mathrm{pH} 7(\nabla)$ and in $30 \%(\mathrm{v} / \mathrm{v}) \mathrm{MeOH}$ plus $70 \%$ $100 \mathrm{mM}$ sodium acetate water buffer $\mathrm{pH} 4.5$ (•). The addition of $30 \% \mathrm{MeOH}$ to the buffer lowers the freezing temperature to $-26^{\circ} \mathrm{C}$ and consequently does not freeze in the model system at $-20^{\circ} \mathrm{C}$ 



\section{Chapter 5}

Probing Functional Heteromeric Chemokine Protein-Protein Interactions through Conformation-assisted Oxime Ligation

Agten SM , Koenen RR, Ippel H, Eckardt V, von Hundelshausen P, Mayo KH, Weber C, Hackeng TM Angew Chem Int Ed 2016; in press 


\section{Abstract}

Protein-protein interactions (PPIs) govern most processes in living cells. Current drug development strategies are aimed at disrupting or stabilizing PPIs, which require thorough understanding of PPI mechanisms. Examples of such PPIs are heteromericchemokine interactions that are potentially involved in pathological disorders such as cancer, atherosclerosis and HIV. It remains unclear whether this functional modulation is mediated by heterodimer formation or by additive effects of mixed chemokines on their respective receptors. To address this issue, we report the synthesis of a covalent RANTES-PF4 heterodimer (termed OPRAH) by total chemical synthesis and oxime ligation, with an acceleration of the final ligation step driven by PPIs between RANTES and PF4. Compared to mixed separate chemokines, OPRAH exhibited increased biological activity, thus providing evidence that physical formation of the heterodimer indeed mediates enhanced function.

\section{Introduction}

Chemokines are small chemotactic cytokines that mediate leukocyte trafficking, which makes them interesting pharmaceutical targets to antagonize inflammatory diseases such as rheumatoid arthritis, Crohn's disease and atherosclerosis.[1, 2] By binding to their cognate $G$ protein-coupled receptors, they can rapidly trigger leukocyte chemotaxis and adhesion, and thus regulate a variety of cellular processes e.g. angiogenesis, embryonic development and cell homeostasis.[3]

The structure of chemokine monomers is characterized by a disordered $\mathrm{N}$-terminus and three-stranded antiparallel $\beta$-sheets onto which a C-terminal $\alpha$-helix is folded. Based on the spacing between conserved $\mathrm{N}$-terminal cysteine residues, chemokines are divided into 4 groups, with the major ones being CC- and CXC-type. Although being small $(<10 \mathrm{kDa})$, most chemokines have the propensity to form homodimers or higher-order multimeric structures (>200 kDa). [4] While the monomeric structures of all chemokines are highly conserved, there are notable differences between their (oligomeric) quaternary structures. For example, CC-type chemokine dimers, formed by interactions between their $\mathrm{N}$-termini, are elongated and dumbbell shaped, whereas CXC-type chemokine dimers are formed by interactions between their central $\beta$-sheets making them more globular in structure.

The chemokines RANTES (CCL5) and platelet factor 4 (PF4, CXCL4) are stored in the $\alpha$ granules of platelets. While RANTES is a potent attractant of mononuclear cells, PF4 lacks classical chemo-attractant functions.[5] However, the presence of PF4 can synergistically enhance RANTES-mediated cell-recruitment mediated by heterophilic interactions between chemokines.[5] In fact, pharmacologic inhibition of RANTES and PF4 heterodimer formation inhibits monocyte recruitment and attenuates progression of atherosclerosis, lung injury and aneurysm formation in mice.[6-8] 
Heterophilic chemokine interactions have also been reported for CXCL4 and CXCL8[9], CCL19 and CCL22[10], CCL2 and CCL8[11], as well as other chemokines.[12] These studies support the proposal that heterophilic interactions between different chemokines are relevant for many physiological and pathological processes.

Although current evidence suggests that physical formation of chemokine heterodimers mediates their observed functional modulation, the possibility remains that this could simply be due to combined receptor stimulation by the respective chemokines. Therefore, the aim of the present study is to generate an obligate RANTES-PF4 heterodimer by means of total chemical synthesis in order to address this crucial mechanistic question.

\section{Results}

Based on the observation that RANTES and PF4 interact via their N-termini as a CCtype dimer,[6] we used this model as a starting point to assess optimal coupling strategies for the protein pair (Figure 1). Because oxime ligation can be performed with folded proteins in aqueous buffer at neutral $\mathrm{pH}$, we chose it to be a suitable reaction to covalently link the two proteins. Oxime ligation requires the incorporation of a ketone in one protein and an aminooxy moiety in the other. Due to limitations in the ketone functionality of the widely-used levulinic acid, we used 5-ketohexanoic acid because of its high reactivity and conformational flexibility.[13]

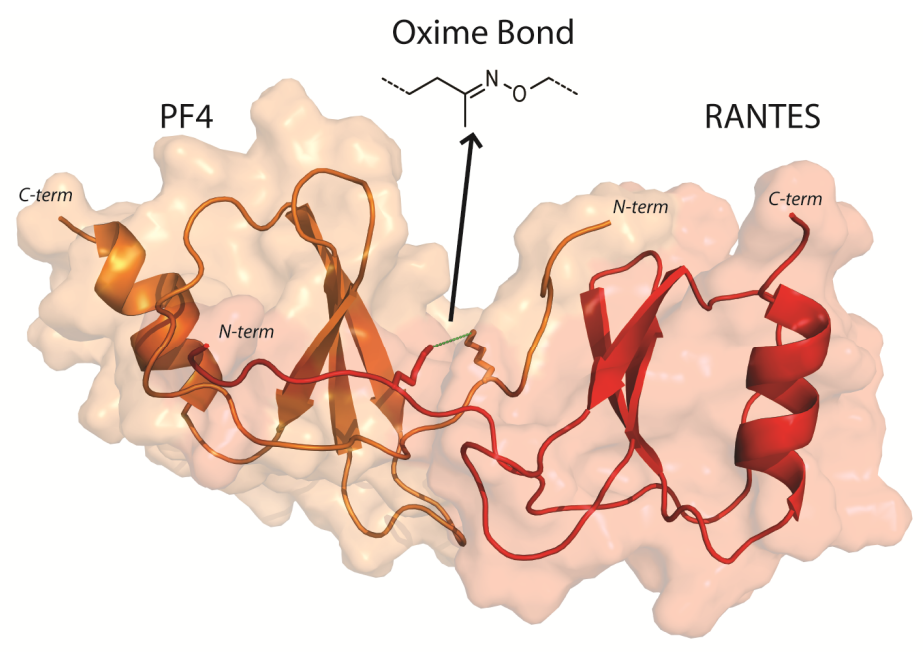

Figure 1: Schematic representation of a covalently linked dimer of PF4 (left) and RANTES (right). The termini of the two chemokines are labeled. The oxime connection between the two proteins is shown. 
The proposed heterodimer consists of a RANTES monomer (68 aa) that is covalently linked to a PF4 monomer (76 aa) (Figure 3). The chemokines were each assembled by two subsequent native chemical ligations (NCL)[14], followed by oxidative folding, and joined by oxime ligation. Positions suitable for covalent linkage of the two proteins were based on the proposed heterodimer structure observed by NMR.[6] Furthermore, the N-terminus of RANTES was required to remain unrestricted to allow interactions with its receptor (CCR5).[15] In addition, amino acids crucial for RANTESPF4 interaction were left untouched, leaving Thr7 in RANTES and Leu8 in PF4 as a site for crosslinking (Figure 1). Therefore, Thr7 and Leu8 were replaced by orthogonal protected lysines to provide a handle for introducing the ketone or aminooxy moiety. All reactions were followed by HPLC-MS. After oxidative folding of the chemokines to obtain modified RANTES (16) and PF4 (8), oxime linkage between the two proteins was obtained by reacting equimolar quantities of the two modified chemokines (200 $\mu \mathrm{M})$ in aqueous buffer at $\mathrm{pH}$ 4.5. This led to the desired Obligate PF4-RANTES Heterodimer (OPRAH: 17) with a $60 \%$ yield after 12 hours (Figure 3; SI1; SI2). A functional negative control (nOPRAH) was established by linking Ser 1 of RANTES to Glul of PF4 through an identical oxime linker by which the N-terminal interaction of RANTES with its receptor CCR5 was blocked.

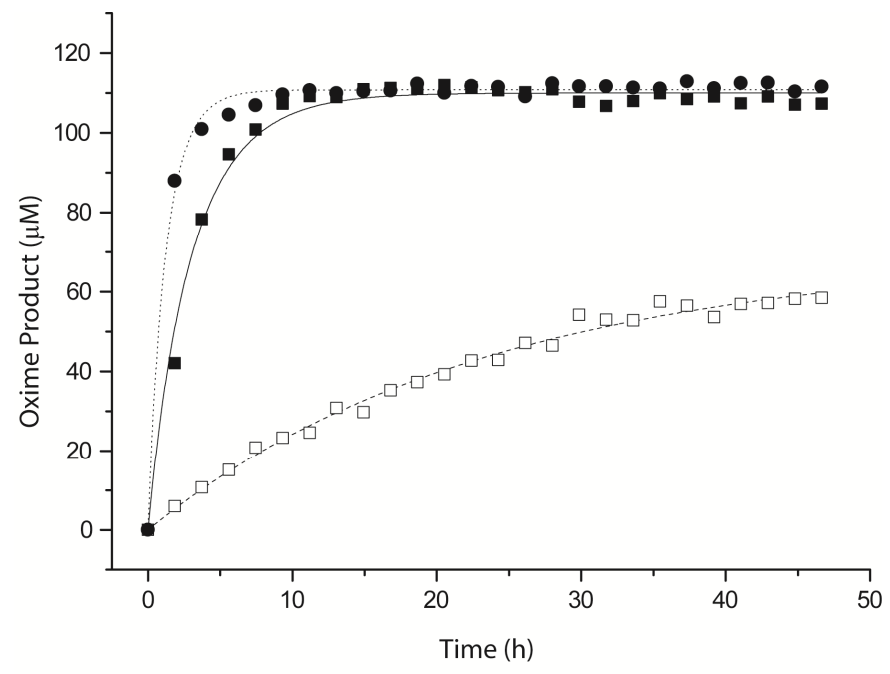

Figure 2: Oxime formation between $\mathbf{8}$ and $\mathbf{1 6}$ followed over time in $0.1 \mathrm{M} \mathrm{NaOAc}$ without

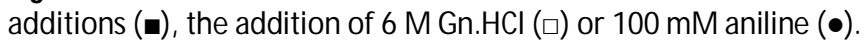

In an effort to improve the reaction rate we observed only minor enhancement by addition of aniline as catalyst.[16] To rule out that homomeric interactions between folded chemokines would impair heteromeric oxime formation, we performed oxime ligation in the presence of a denaturing agent ( $6 \mathrm{M} \mathrm{Gn} . \mathrm{HCl})$. Surprisingly, in contrast to accelerating heteromeric oxime formation, the presence of $\mathrm{Gn} . \mathrm{HCl}$ slowed down 
oxime ligation 5 -fold, while it only had a minor effect on the reaction rate in a model system (Figure 2; $\mathrm{SI} 3$ ). This observation indicated that the rate of formation of the oxime bond between RANTES and PF4 was accelerated by heterophilic chemokine interactions which bring the two reactive species into close proximity (Figure 2). In retrospect, the proposed conformation-assisted ligation was supported by the lowerthan-expected catalytic effect by aniline. Eventually, using slow freezing catalysis,[17] we were able to achieve complete oxime reaction within 2 hours.

To assess the folded states of modified PF4 and RANTES, as well as OPRAH we applied NM R spectrometry. NM R spectra show that modified PF4 and RANTES are well folded. However, modified PF4 could still form tetramers like wild type PF4, whereas modified RANTES with its N-terminally positioned lysyl-linker showed markedly attenuated dimer formation. Compared to NMR spectra of the non-ligated proteins, OPRAH appears to contain two correctly folded domains of the respective chemokines (Figure 4, Figure SI4). The resolved Trp57 $\mathrm{H} \varepsilon$ resonance in the spectrum of $\mathbf{1 6}$ is a good indicator of the folding preference of the RANTES subunit in OPRAH. In nonligated RANTES, Trp57 $\mathrm{H} \varepsilon$ resonances are observed for monomer $(\mathrm{m})$ and homodimer (d) states (insert to Figure 4). Upon covalent dimerization of $\mathbf{1 6}$ and $\mathbf{8}$ to form OPRAH (17), the RANTES homodimer " $d$ " state peak is reduced in intensity, whereas the " $m$ " peak is increased in intensity and slightly chemically shifted consistent with a change in chemical environment likely due to formation of the linked heterodimer. The remaining RANTES " $d$ " peak intensity in $\mathbf{1 7}$ may arise from some homodimerization of two RANTES domains in OPRAH.

We also followed real time oxime formation between $\mathbf{8}$ and $\mathbf{1 6}$ using NM R analysis (Figure SI4-6). These NMR spectra show overall resonance broadening, which we attribute to transient formation of the OPRAH heterodimer. This is supported by our observations with the $\mathrm{H} \varepsilon$ resonances of Trp57 which is an indirect structural probe due to its distance from the modified $\mathrm{N}$-terminus of $\mathbf{1 6}$. Overall, we conclude that the general folds of the two protein domains, PF4 and RANTES, are maintained in OPRAH, and resonance broadening of residues at the oxime ligation site suggests dynamic interactions between the two covalently-linked domains. 

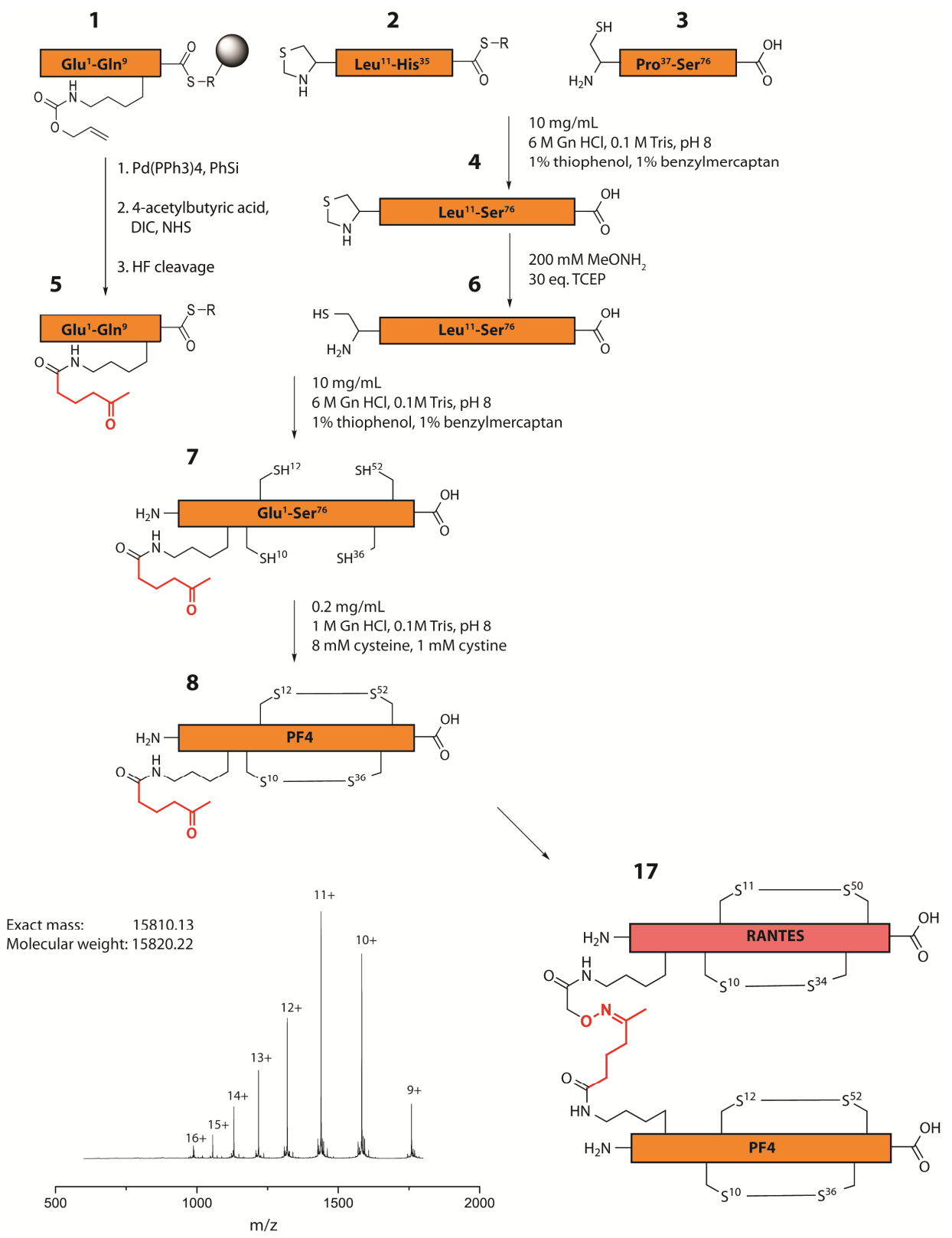

Figure 3: Schematic representation of the obligate PF4-RANTES heterodimer (OPRAH) synthesis route. Insert showing the mass-to-charge distribution of $\mathbf{1 7}$ (left) and the UV detected LC chromatogram of $\mathbf{1 7}$ (right). Both C-terminal peptides (3 and $\mathbf{1 1}$ ) were synthesized using standard tBoc solid phase peptide chemistry protocols.[18] Sequential NCL required N-terminal encrypted cysteines (thiaprolines) to be used in the middle fragments ( 2 and 10 ).[19] 

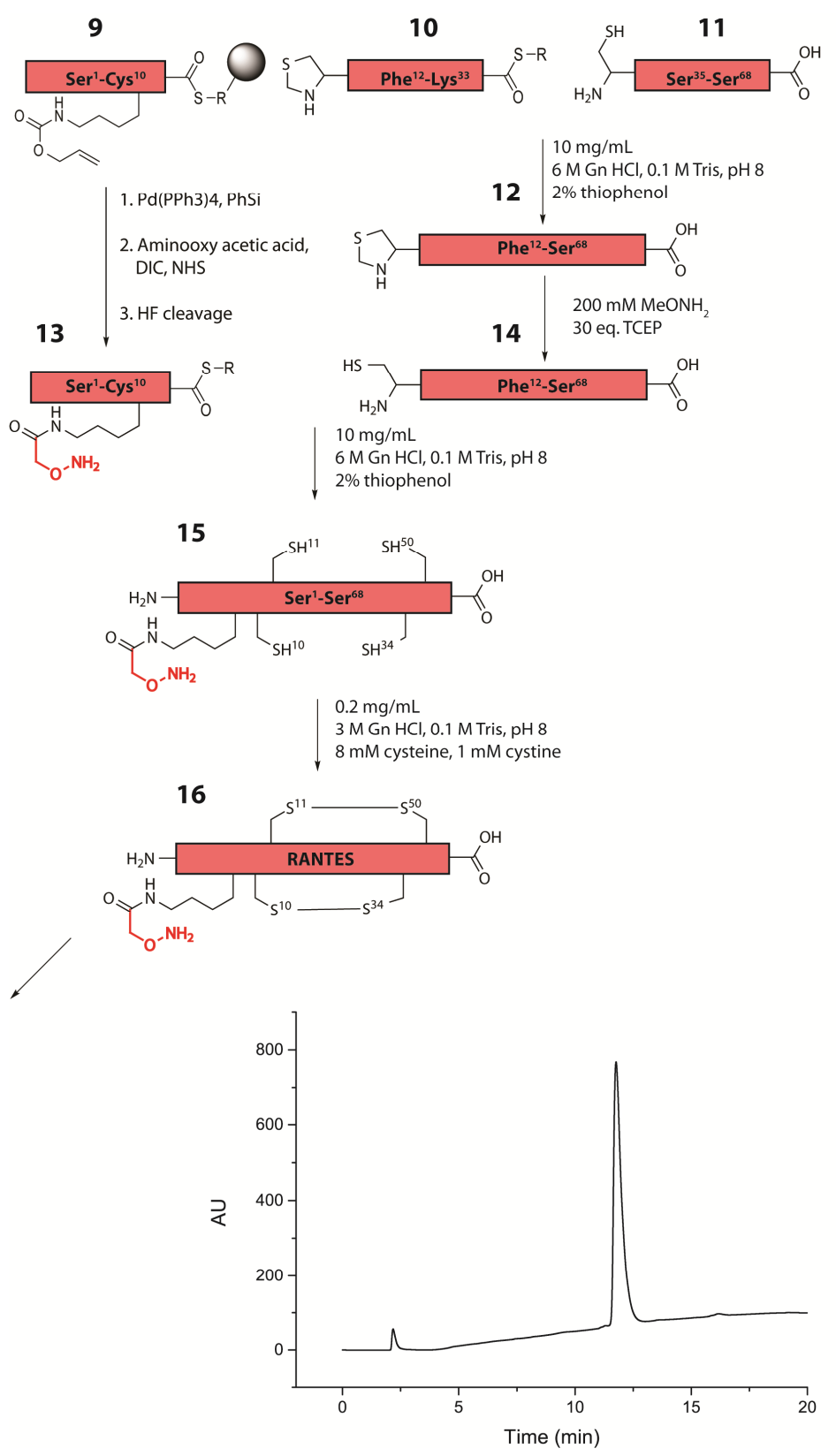

Figure 3 (continued): Both N-terminal fragments (1 and $\mathbf{9}$ ) contain a thioester for $\mathrm{NCL}$ and require an orthogonally protected ( $\mathrm{N} \varepsilon$-Alloc) lysine for incorporation of the ketone or aminooxy functional group. Deprotection of the Alloc group was performed on resin using $\mathrm{Pd}\left(\mathrm{PPh}_{3}\right)_{4}$, and the ketone (5-ketohexanoic acid) and aminooxy (Boc-(aminooxy)acetic acid) moieties were introduced to obtain $\mathbf{5}$ and $\mathbf{1 3}$, respectively. Following synthesis and purification, all peptide fragments were ligated sequentially with the use of $1-2 \%$ thiophenol and benzylmercaptan as catalysts. 


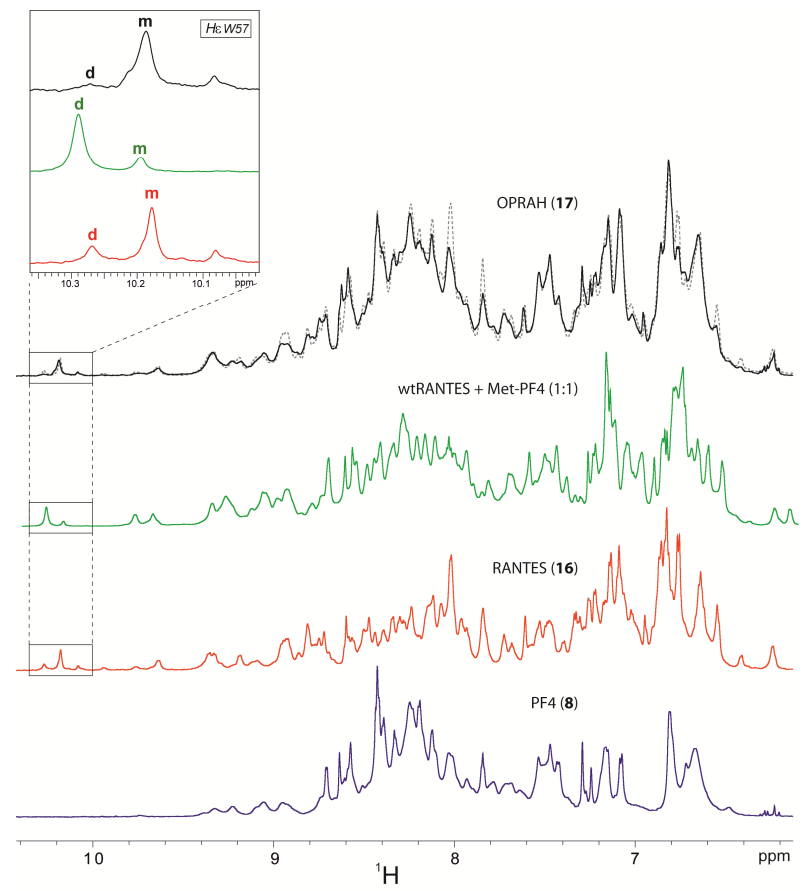

Figure 4: Comparison between $700 \mathrm{MHz} 1 \mathrm{D}$ proton spectra (amide region) of PF4 (8), RANTES (16), OPRAH (17) and a 1:1 complex of wtRANTES and M et-PF4, under similar conditions. Top spectrum: overlay of experimental proton spectrum of OPRAH (black) and the sum spectra of free RANTES (16) and PF4 (8) (broken line) The agreement between experimental spectrum 17 and the summed spectra $\mathbf{8 + 1 6}$ shows that globally OPRAH consists of two natively folded PF4 and RANTES protein domains. Local differences are however apparent and these regions correspond to sharp amide peaks in the N-terminus region (2-7) of free PF4 that seem to broaden out significantly in OPRAH. Insert: Trp57 He signal is indicated for free RANTES(16), the 1:1 complex and OPRAH(17).

We next investigated biological activity of OPRAH in a monocyte arrest assay. Here, a monolayer of endothelial cells was pre-treated with chemokines or heterodimers, after which monocytes were passed over the surface.[5] The presence of chemokines triggered monocyte arrest, and the number of arrested monocytes was recorded as measure of activity (Figure 5A). Three different conditions were tested; OPRAH, the negative control nOPRAH, in which the $\mathrm{N}$-termini were blocked by oxime linkage at positions 1 in RANTES and PF4, and a non-covalent dimer-mix of RANTES and PF4. OPRAH (17) recruited twice the amount of monocytes than the non-covalent mixed PF4 and RANTES chemokines (Figure 5B). Furthermore, the negative control nOPRAH showed a decrease in activity, proving the importance of the free $\mathrm{N}$-terminus of OPRAH for receptor-mediated monocyte recruitment.[15] Peptide CKEY, that was able to disrupt non-covalent PF4-RANTES heterodimers and that led to a decrease in atherosclerosis in a mouse model,[6] was able to reduce monocyte adhesion with non-covalent PF4-RANTES heterodimers, but not with OPRAH (Figure 5C). 


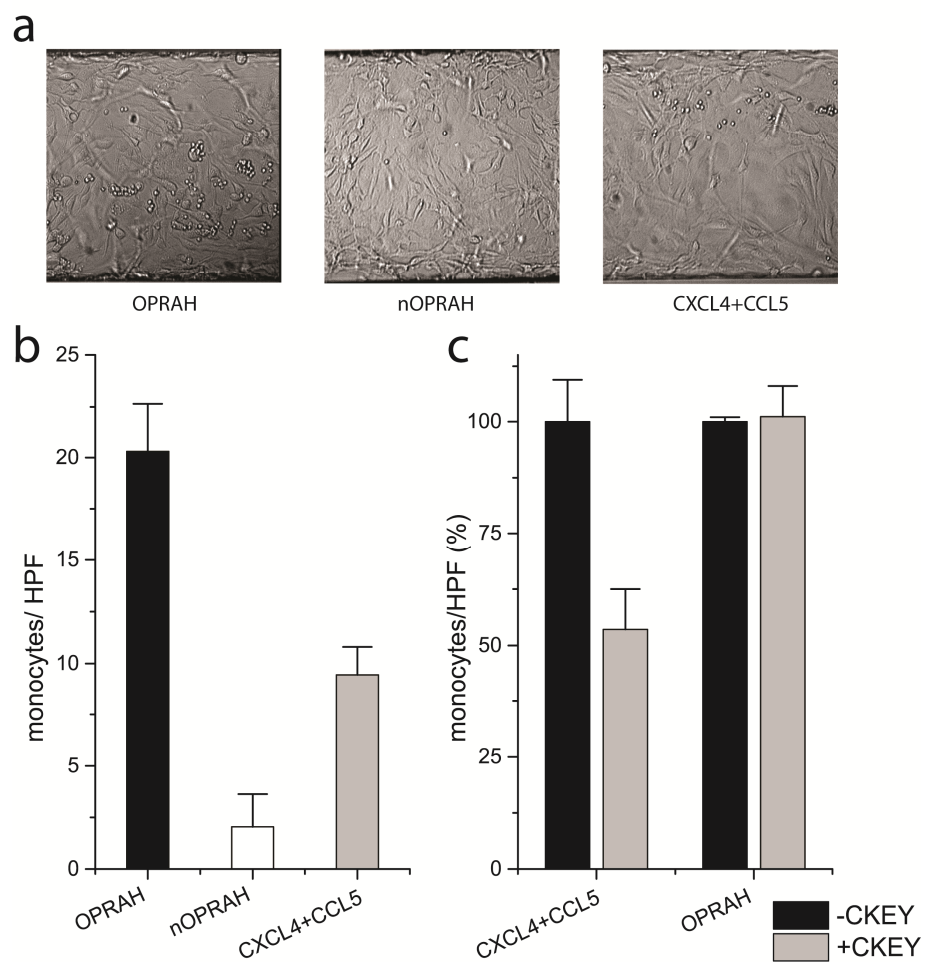

Figure 5: a: Microscopy images showing monocyte arrest by (n)OPRAH and non-covalent RANTES-PF4 mixtures on endothelial cells. b: Monocyte arrest by (n)OPRAH (1.9 nM; $n=6 \pm$ SEM ) and non-covalent RANTES-PF4 mixtures (3.8 nM each; $n=3 \pm$ SEM ). C Effect of CKEY on chemokine-mediated monocyte arrest $(n=6 \pm$ SEM).

In summary, we have provided strong evidence that synergism in monocyte recruitment by the PF4-RANTES complex proceeds through a 1:1 heterodimeric fashion. Proof of this concept through chemical synthesis of a covalent PF4-RANTES heterodimer (OPRAH) in addition offers synthetic access to multiple chemokine heteromers that can unambiguously prove functional enhancement through heteromerization within this novel area of chemokine biology. 


\section{References}

1. Schall, T.J. and A.E. Proudfoot, Overcoming hurdles in developing successful drugs targeting chemokine receptors. Nat Rev Immunol, 2011. 11(5): 355-363.

2. Koenen, R.R. and C. Weber, Therapeutic targeting of chemokine interactions in atherosclerosis. Nat Rev Drug Discov, 2010. 9(2): 141-153.

3. Raman, D., T. Sobolik-Delmaire, and A. Richmond, Chemokines in health and disease. Exp Cell Res, 2011. 317(5): 575-589.

4. Allen, S.J., S.E. Crown, and T.M. Handel, Chemokine: receptor structure, interactions, and antagonism. Annu Rev Immunol, 2007. 25: 787-820.

5. von Hundelshausen, P., R.R. Koenen, M. Sack, S.F. M ause, W. Adriaens, A.E. Proudfoot, T.M. Hackeng, and C. Weber, Heterophilic interactions of platelet factor 4 and RANTES promote monocyte arrest on endothelium. Blood, 2005. 105(3): 924-930.

6. Koenen, R.R., P. von Hundelshausen, I.V. Nesmelova, A. Zernecke, E.A. Liehn, A. Sarabi, B.K. Kramp, A.M. Piccinini, S.R. Paludan, M .A. Kowalska, A.J. Kungl, T.M. Hackeng, K.H. $M$ ayo, and $C$. Weber, Disrupting functional interactions between platelet chemokines inhibits atherosclerosis in hyperlipidemic mice. Nat M ed, 2009. 15(1): 97-103.

7. Grommes, J., J.E. Alard, M. Drechsler, S. Wantha, M. Morgelin, W.M. Kuebler, M. Jacobs, P. von Hundelshausen, P. M arkart, M. Wygrecka, K.T. Preissner, T.M . Hackeng, R.R. Koenen, C. Weber, and O. Soehnlein, Disruption of platelet-derived chemokine heteromers prevents neutrophil extravasation in acute lung injury. Am J Respir Crit Care Med, 2012. 185(6): 628-636.

8. Iida, Y., B. Xu, H. Xuan, K.J. Glover, H. Tanaka, X. Hu, N. Fujimura, W. Wang, J.R. Schultz, C.R. Turner, and R.L. Dalman, Peptide inhibitor of CXCL4-CCL5 heterodimer formation, MKEY, inhibits experimental aortic aneurysm initiation and progression. Arterioscler Thromb Vasc Biol, 2013. 33(4): 718-726.

9. Dudek, A.Z, I. Nesmelova, K. Mayo, C.M. Verfaillie, S. Pitchford, and A. Slungaard, Platelet factor 4 promotes adhesion of hematopoietic progenitor cells and binds IL-8: novel mechanisms for modulation of hematopoiesis. Blood, 2003. 101(12): 4687-4694.

10. Sebastiani, S., G. Danelon, B. Gerber, and M. Uguccioni, CCL22-induced responses are powerfully enhanced by synergy inducing chemokines via CCR4: evidence for the involvement of first beta-strand of chemokine. Eur J Immunol, 2005. 35(3): 746-756.

11. Crown, S.E., Y. Yu, M.D. Sweeney, J.A. Leary, and T.M. Handel, Heterodimerization of CCR2 chemokines and regulation by glycosaminoglycan binding. J Biol Chem, 2006. 281(35): 25438-25446.

12. Nesmelova, I.V., Y. Sham, J. Gao, and K.H. M ayo, CXC and CC chemokines form mixed heterodimers: association free energies from molecular dynamics simulations and experimental correlations. J Biol Chem, 2008. 283(35): 24155-24166.

13. Agten, S.M., D. Suylen, H. Ippel, M. Kokozidou, G. Tans, P. van de Vijver, R.R. Koenen, and T.M. Hackeng, Chemoselective oxime reactions in proteins and peptides by using an optimized oxime strategy: the demise of levulinic acid. Chembiochem, 2013. 14(18): 2431-2434.

14. Dawson, P.E., T.W. Muir, I. Clark-Lewis, and S.B. Kent, Synthesis of proteins by native chemical ligation. Science, 1994. 266(5186): 776-779.

15. Proudfoot, A.E., C.A. Power, A.J. Hoogewerf, M.O. Montjovent, F. Borlat, R.E. Offord, and T.N. Wells, Extension of recombinant human RANTES by the retention of the initiating methionine produces a potent antagonist. J Biol Chem, 1996. 271(5): 25992603.

16. Dirksen, A., T.M. Hackeng, and P.E. Dawson, Nucleophilic catalysis of oxime ligation. Angew Chem Int Ed Engl, 2006. 45(45): 7581-7584. 
17. Agten, S.M., D.P. Suylen, and T.M. Hackeng, Oxime Catalysis by Freezing. Bioconjug Chem, 2016. 27(1): 42-46.

18. Schnolzer, M., P. Alewood, A. Jones, D. Alewood, and S.B. Kent, In situ neutralization in Boc-chemistry solid phase peptide synthesis. Rapid, high yield assembly of difficult sequences. Int J Pept Protein Res, 1992. 40(3-4): 180-193.

19. Bang, D. and S.B. Kent, A one-pot total synthesis of crambin. Angew Chem Int Ed Engl, 2004. 43(19): 2534-2538.

20. Hackeng, T.M., J.H. Griffin, and P.E. Dawson, Protein synthesis by native chemical ligation: expanded scope by using straightforward methodology. Proc Natl Acad Sci U SA, 1999. 96(18): 10068-10073. 


\section{Supporting Information}

Peptide synthesis. Peptides were synthesized manually by SPPS on a $0.25 \mathrm{mmol}$ scale on a M BHA or PAM resin. An in situ neutralization/HCTU activation for Boc chemistry was used[18]. Each synthetic cycle consisted of the Boc protective group removal by two 1-minute treatments with TFA followed by a DMF wash, addition of the preactivated amino acid in presence of excess DIPEA, followed by another DM $F$ wash. The Boc-protected amino acids $(1.1 \mathrm{mmol})$ were activated with $1 \mathrm{mmol}$ of HCTU and 3 mmol DIPEA. Coupling of Gln residues was followed by a DCM wash before and after TFA deprotection to prevent intramolecular pyrrolidone formation. After coupling of the final amino acid, the resin was dried by wash steps with DCM and DCM / M eOH.

After completion of the peptide chain, the peptides were deprotected and cleaved from the resin by treatment with anhydrous $\mathrm{HF}$ for 1 hour at $0^{\circ} \mathrm{C}$ with $4 \% \mathrm{p}$-cresol $(\mathrm{v} / \mathrm{v})$ as scavenger. Peptides were precipitated in ice-cold diethylether, dissolved in $50 \%$ acetonitrile in water $+0.1 \%$ TFA and lyophilized. The crude mixture was subjected to preparative HPLC and fractions containing the desired product were identified by ESIMS, pooled and lyophilized.

Human RANTES C-term

sequence: $\mathrm{H}_{2} \mathrm{~N}$-Cys-Ser-Asn-Pro-Ala-Val-Val-Phe-Val-Thr-Arg-Lys-Asn-Arg-Gln-Val-CysAla-Asn-Pro-Glu-Lys-Lys-Trp-Val-Arg-Glu-Tyr-Ile-Asn-Ser-Leu-Glu-M et-Ser-COOH

Human RANTES middle (M) fragment

sequence: $\quad \mathrm{H}_{2} \mathrm{~N}$-Thz-Phe-Ala-Tyr-Ile-Ala-Arg-Pro-Leu-Pro-Arg-Ala-His-Ile-Lys-Glu-TyrPhe-Tyr-Thr-Ser-Gly-Lys-M PAL-COOH

Human RANTES N-term

sequence: $\mathrm{H}_{2} \mathrm{~N}$-Ser-Pro-Tyr-Ser-Ser-Asp-Thr-Thr-Pro-Cys-M PAL-COOH

Human PF4 C-term

sequence: $\quad \mathrm{H}_{2} \mathrm{~N}$-Cys-Pro-Thr-Ala-Gln-Leu-Ile-Ala-Thr-Leu-Lys-Asn-Gly-Arg-Lys-Ile-CysLeu-Asp-Leu-GIn-Ala-Pro-Leu-Tyr-Lys-Lys-Ile-Ile-Lys-Lys-Leu-Leu-Glu-Ser-COOH

Human PF4 middle (M) fragment

sequence: $\quad \mathrm{H}_{2} \mathrm{~N}$-Thz-Leu-Cys-Val-Lys-Thr-Thr-Ser-Gln-Val-Arg-Pro-Arg-His-lle-Thr-SerLeu-Glu-Val-Ile-Lys-Ala-Gly-Pro-His-M PAL-COOH

Human PF4 N-term

sequence: $\mathrm{H}_{2} \mathrm{~N}$-Glu-Ala-Glu-Glu-Asp-Gly-Asp-Leu-Gln-M PAL-COOH

Residues in bold were changed into Boc-Lys(alloc) to accommodate for ketone or aminooxy incorporations in the different constructs. Thz denotes a cysteine protected 
as a thiazolidine. M PAL denotes a leucine to which a mercaptopropionic is coupled after which the sequence is continued as normal.[20]

Ketone or aminooxy incorporation into chemokine $\mathbf{N}$-termini. After completion of the peptide chain, the Alloc protective group on the $\mathrm{N}$-terminal lysine was deprotected using $2 \times 30$ min treatments with 0.25 eq. $\mathrm{Pd}(\mathrm{PPh} 3) 4$ in $\mathrm{DCM}$ using $\mathrm{PhSiH} 3$ (24 eq.) as a scavenger. Subsequently, the keto-acid (4-acetyl butyric acid) or Boc (aminooxy)acetic acid $(2.2 \mathrm{mmol}$ ) were preactivated using carbodiimide $(2 \mathrm{mmol})$ (DIC) for 2 minutes after which $\mathrm{N}$-hydroxysuccinimide (NHS) $(2.0 \mathrm{mmol})$ and $\mathrm{N}, \mathrm{N}$ diisopropyldiamine (DIPEA) $(0.6 \mathrm{mmol})$ was added, directly followed by addition to the deprotected peptide chain $(0.25 \mathrm{mmol})$ and left to react for 1 hour. Finally the $\mathrm{N}$ terminal Boc-protective group was removed by treatment with TFA as described above to result in the peptide chain modified with a ketone or aminooxy after cleavage from the resin. Alternative orthogonal protection using Fmoc was unsuccessful because of low yields obtained by deprotection with $20 \%$ piperidine (nucleophilic attack on thioester moiety) or with DBU/HOBt.

Native chemical ligation of RANTES C-terminus and middle fragment $(\mathbf{1 0}+11)$. Both the $\mathrm{C}$-terminus and middle fragment (M) were purified before ligation. Equimolar amounts of both parts were mixed at a concentration of $10 \mathrm{mg} / \mathrm{mL}$ in $0.1 \mathrm{M}$ Tris-HCl $\mathrm{pH} 8$, containing $6 \mathrm{M}$ Guanidine (Gdn) $-\mathrm{HCl}$. . Thiophenol was added $(2 \% \mathrm{v} / \mathrm{v})$. The $\mathrm{pH}$ was adjusted to 7 before the reaction was left to react at $37{ }^{\circ} \mathrm{C}$ for $7 \mathrm{~h}$ with mixing every 30 minutes.

Thiazolidine deprotection RANTES CM ligation product (12 $\rightarrow$ 14). After ligation of the $\mathrm{C}$ and $\mathrm{M}$ fragments the $\mathrm{N}$-terminal thiazolidine was deprotected. The ligation mixture was diluted 5 times in $0.1 \mathrm{M}$ Acetate $\mathrm{pH} 4$ containing $6 \mathrm{M}$ Guanidine (Gdn)-HCl,. $\mathrm{MeONH} 2(0.2 \mathrm{M})$ and TCEP (30 eq.) were added and the deprotection reaction was left at RT for $12 \mathrm{~h}$.

Native chemical ligation of RANTES CM- and N-terminus (13+14). Both the CM and $\mathrm{N}$-terminus were purified before ligation. The $\mathrm{N}$-terminus was taken in 2 times excess, both parts were mixed at a concentration of $10 \mathrm{mg} / \mathrm{mL}$ in $0.1 \mathrm{M} \mathrm{Tris-} \mathrm{HCl} \mathrm{pH} 8$, containing $6 \mathrm{M}$ Guanidine (Gdn)- $\mathrm{HCl}$, . Thiophenol was added ( $2 \% \mathrm{v} / \mathrm{v})$. The $\mathrm{pH}$ was adjusted to 7 before the reaction was left to react at $37^{\circ} \mathrm{C}$ for $1 \mathrm{~h}$ with mixing every 5 minutes.

Oxidative folding of RANTES $(\mathbf{1 5} \rightarrow \mathbf{1 6})$. The ligated peptide was purified using HPLC, desired fractions were pooled and lyophilized. The peptide was dissolved at a concentration of $0.2 \mathrm{mg} / \mathrm{mL}$ in $0.1 \mathrm{M}$ Tris- $\mathrm{HCl}$ pH 8 containing $3 \mathrm{M} \mathrm{Gdn}-\mathrm{HCl}$. Cysteine $(8 \mathrm{mM})$ and cystine $(1 \mathrm{mM})$ were added and the protein was left to fold at $4{ }^{\circ} \mathrm{C}$ for $24 \mathrm{~h}$ with continuous mixing. The folded protein was purified using HPLC, desired fractions were pooled and lyophilized. 
Native chemical ligation of PF4 C-terminus and middle fragment (2+3).Both the Cand $M$ iddle $(M)$ fragments were purified before ligation. Equimolar amounts of both parts were mixed at a concentration of $10 \mathrm{mg} / \mathrm{mL}$ in $0.1 \mathrm{M}$ Tris- $\mathrm{HCl}, \mathrm{pH} 8$ containing 6 M Guanidine (Gdn)- $\mathrm{HCl}$, . Thiophenol and benzylmercaptan were added ( $1 \% \mathrm{v} / \mathrm{v}$ each). The $\mathrm{pH}$ was adjusted to 7 before the reaction was left to react at $37^{\circ} \mathrm{C}$ for $6 \mathrm{~h}$ with mixing every 30 minutes.

Thiazolidine deprotection PF4 CM ligation product $(\mathbf{4} \rightarrow \mathbf{6})$. After ligation of the $\mathrm{C}$ and Middle $(\mathrm{M})$ fragments the $\mathrm{N}$-terminal thiazolidine was deprotected. The ligation mixture was diluted 5 times using $0.1 \mathrm{M}$ Acetate, pH 4 containing $6 \mathrm{M}$ Guanidine (Gdn)-HCl, $0.2 \mathrm{M} \mathrm{MeONH2}$ and TCEP (30 eq.) The deprotection reaction was left at $\mathrm{RT}$ for $12 \mathrm{~h}$.

Native chemical ligation of PF4 CM- and N-terminus $(5+6)$. Both the $\mathrm{CM}$ and $\mathrm{N}$ terminus were purified before ligation. The $\mathrm{N}$-terminus was taken in 2 times excess, both parts were mixed at a concentration of $10 \mathrm{mg} / \mathrm{mL}$ in $0.1 \mathrm{M} \mathrm{Tris-HCl}$, pH 8 containing $6 \mathrm{M}$ Guanidine (Gdn)-HCl, . Thiophenol and benzylmercaptan were added (1\% $\mathrm{v} / \mathrm{v}$ each). The $\mathrm{pH}$ was adjusted to 7 before the reaction was left to react at $37^{\circ} \mathrm{C}$ for $8 \mathrm{~h}$ with mixing every 30 minutes.

Oxidative folding of PF4 (7 $\rightarrow \mathbf{8})$. The ligated peptide was purified using HPLC, desired fractions were pooled and lyophilized. The peptide was dissolved at a concentration of $0.2 \mathrm{mg} / \mathrm{mL}$ in $0.1 \mathrm{M}$ Tris- $\mathrm{HCl} \mathrm{pH} 8$ containing $1 \mathrm{M} \mathrm{Gdn}-\mathrm{HCl}$, . Cysteine (8 mM) and cystine $(1 \mathrm{mM})$ were added and the protein was left to fold at $4{ }^{\circ} \mathrm{C}$ for $24 \mathrm{~h}$ with continuous mixing. The folded protein was purified using HPLC, desired fractions were pooled and lyophilized.

HPLC analysis and purification. Analytical HPLC was performed using a Vydac $\mathrm{Cl}$ HPLC column (4.6 mm x $150 \mathrm{~mm}, 1 \mathrm{~mL} / \mathrm{min}$ flow rate) connected to a Varian Prostar system consisting of two Varian Prostar 215 delivery modules and a Varian Prostar $320 \mathrm{UV} / \mathrm{Vis}$ detector $(\lambda=214 \mathrm{~nm})$. A linear gradient of 0-67 \% buffer $B$ in buffer $A$ over 30 minutes was used, where buffer $A=0.1 \mathrm{v}-\%$ TFA in $\mathrm{H} 2 \mathrm{O}$ and buffer $\mathrm{B}=0.1 \mathrm{v}-\%$ TFA, $10 \mathrm{v}-\% \mathrm{H} 2 \mathrm{O}$ in $\mathrm{CH} 3 \mathrm{CN}$.

Semi-preparative HPLC was performed using Vydac C18 HPLC columns (10 mm x 250 $\mathrm{mm}, 10 \mathrm{~mL} / \mathrm{min}$ flow rate or $22 \mathrm{~mm} \times 250 \mathrm{~mm}, 20 \mathrm{~mL} / \mathrm{min}$ flow rate) connected to a Waters Deltaprep System consisting of a Waters Prep LC Controller and a Waters 2487 Dual wavelength Absorbance Detector $(\lambda=214 \mathrm{~nm})$. Peptides were eluted using a gradient of $B$ in $A$, based on an analytical HPLC run. Fractions were analyzed by Electrospray Ionization Mass Spectrometry (ESI-MS), desired fractions were pooled and lyophilized. 
Mass spectrometry. UPLC ESI-M S was performed on a Waters UHPLC XEVO-G2QTOF system. Peptide masses were calculated from the experimental mass to charge $(\mathrm{m} / \mathrm{z})$ ratios of all the protonation states observed in the ESI-M S spectrum of a peptide using MaxEnt 3. Monoisotopic and average theoretical masses of compounds were calculated using Chemdraw 12.0.2.

UPLC mass spectrometry. Ligation reactions and preparative HPLC fractions were monitored on a Waters UHPLC XEVO-G2QTOF system. Sample (1-10 $\mu \mathrm{L})$ was introduced to a PST C18 column (130A; $1.7 \mu \mathrm{m}$ particles; column dimension $2.1 \times 50 \mathrm{~mm}, 40^{\circ} \mathrm{C}$ ) by an FTN-autosampler, using $5 \%$ acetonitrile and $0.1 \%$ formic acid (FA) in water as purge-solvent/diluent. A water-acetonitrile gradient containing $0.1 \%$ FA (flowrate $250 \mu \mathrm{L} / \mathrm{min}$ ) was used to separate peptides and ligation products at baseline level in 14 min. Exact mass measurement was performed in resolution mode using ESI-ionisation in positive mode (sodium formate-calibrated). Both quad profile and probe settings were optimized for large peptide measurement.

Oxime ligation of PF4 and RANTES. The chemokines were dissolved in $100 \mathrm{mM}$ $\mathrm{NaOAc}(\mathrm{pH} 4.5)$ in equimolar amounts $(200 \mu \mathrm{M})$ and left to react for $48 \mathrm{~h}$ at $37^{\circ} \mathrm{C}$. Reactions were followed using UPLC-MS. Freeze catalysis was performed in identical conditions; proteins were mixed, frozen at $-20^{\circ} \mathrm{C}$ for 1 hour and subsequently thawed. This procedure was repeated twice. 

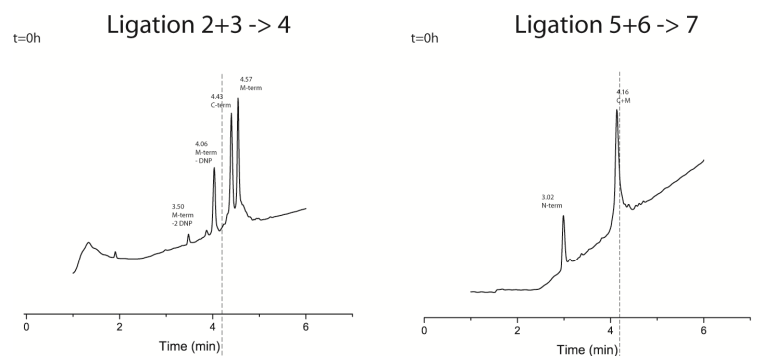

$\mathrm{t}=\mathrm{oh} \quad$ Folding $7->8$
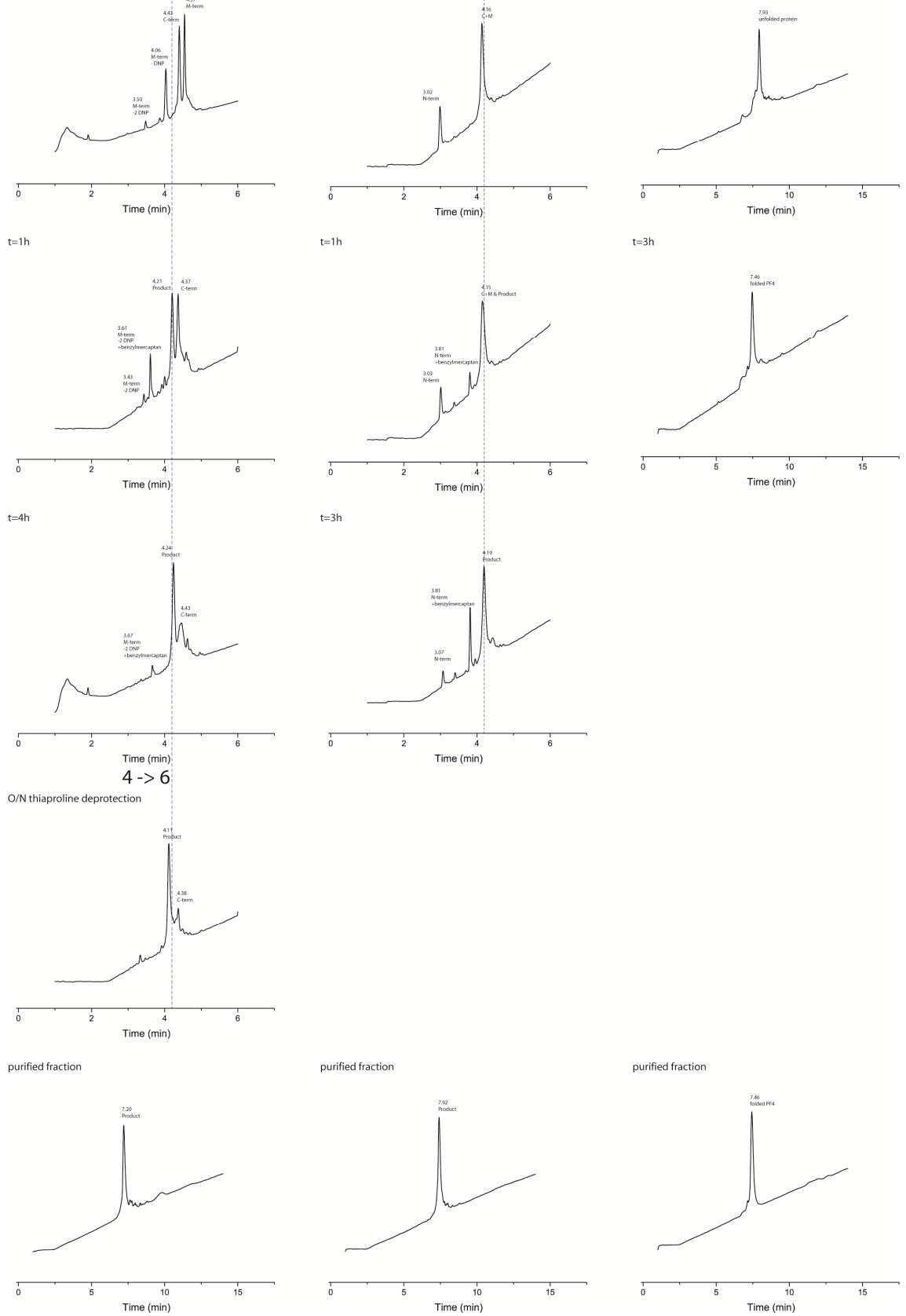

purified fraction

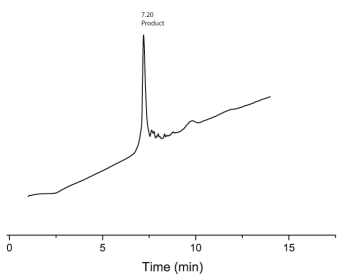

Figure SI 1: Overview of PF4 synthesis: first column shows ligation of the C-terminal with the middle fragment followed over time, with subsequent thiaproline deprotection and purification. Middle column shows NCL of the ligated product with the N-terminal fragment. The final column shows oxidative folding of PF4 

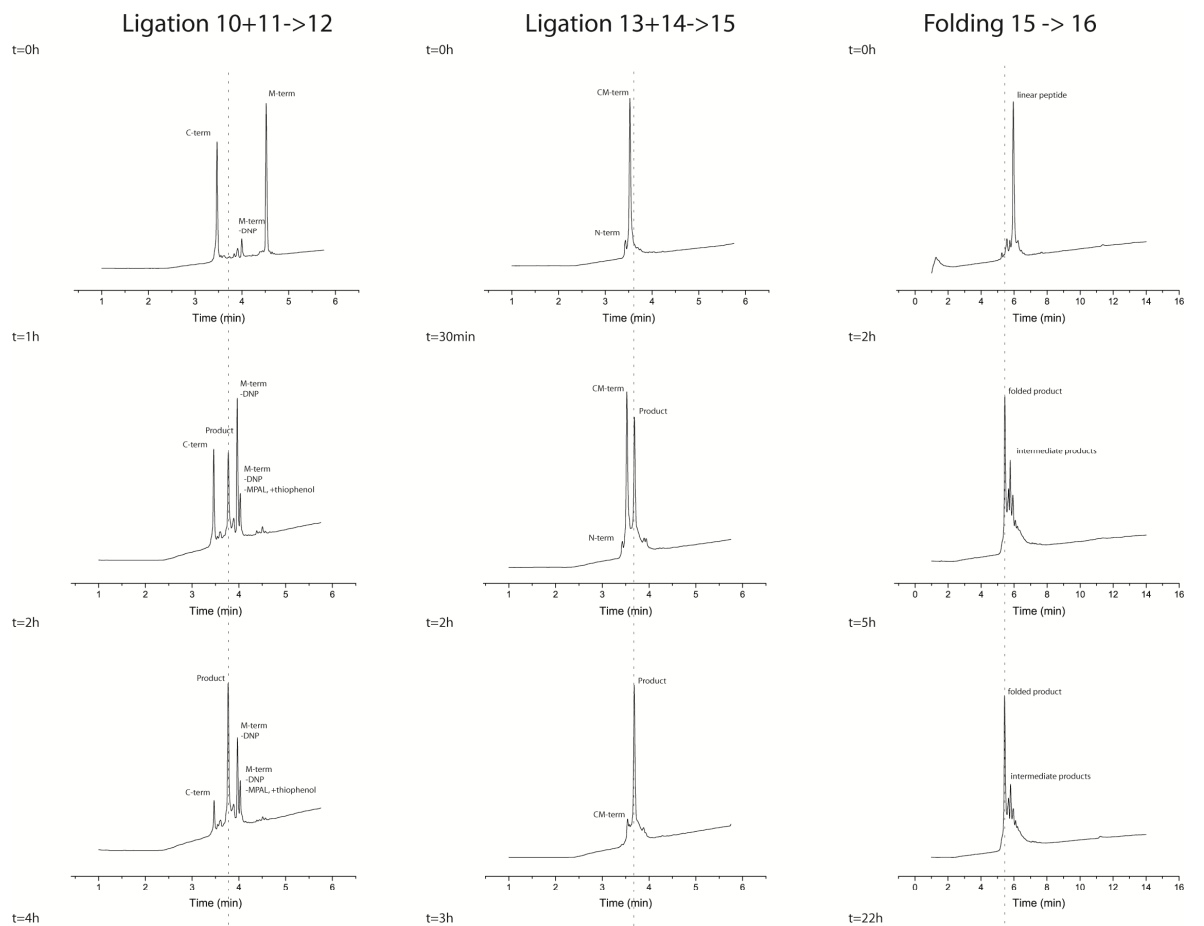

$t=5 h$
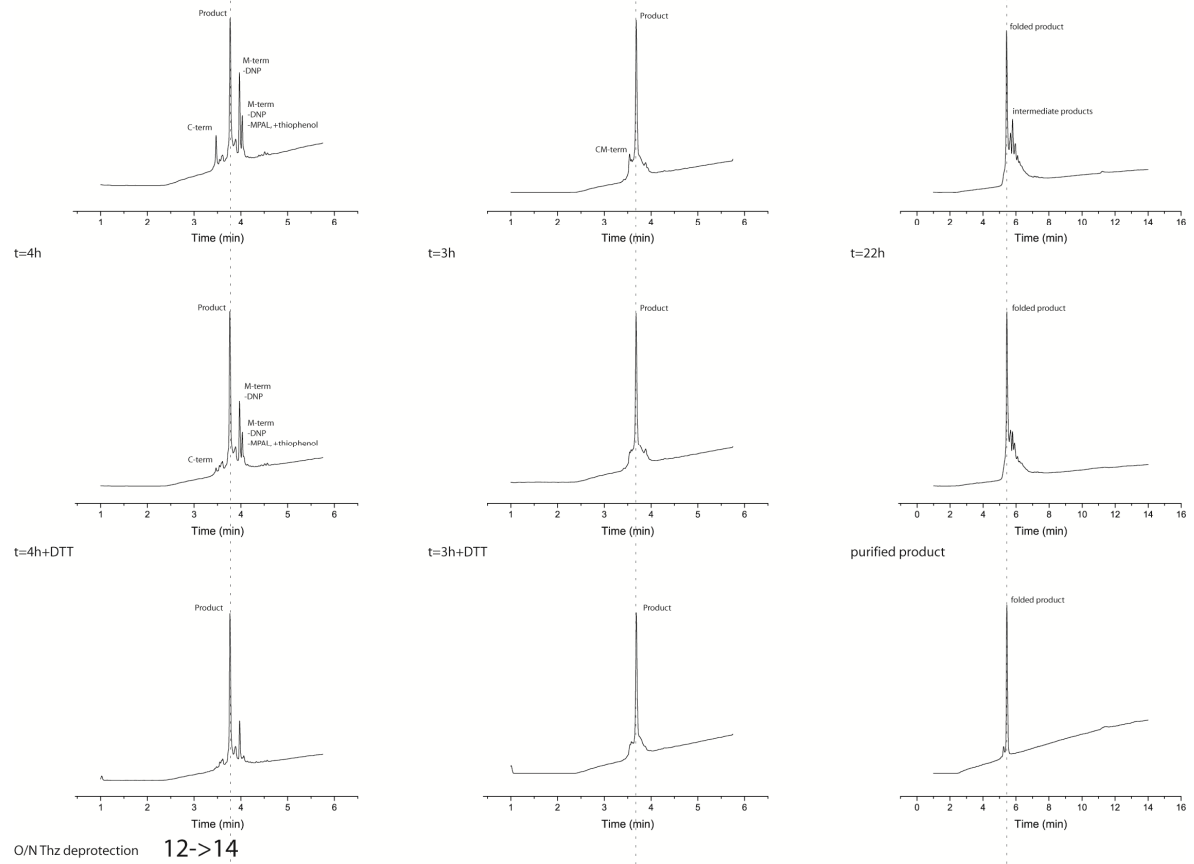

purified product
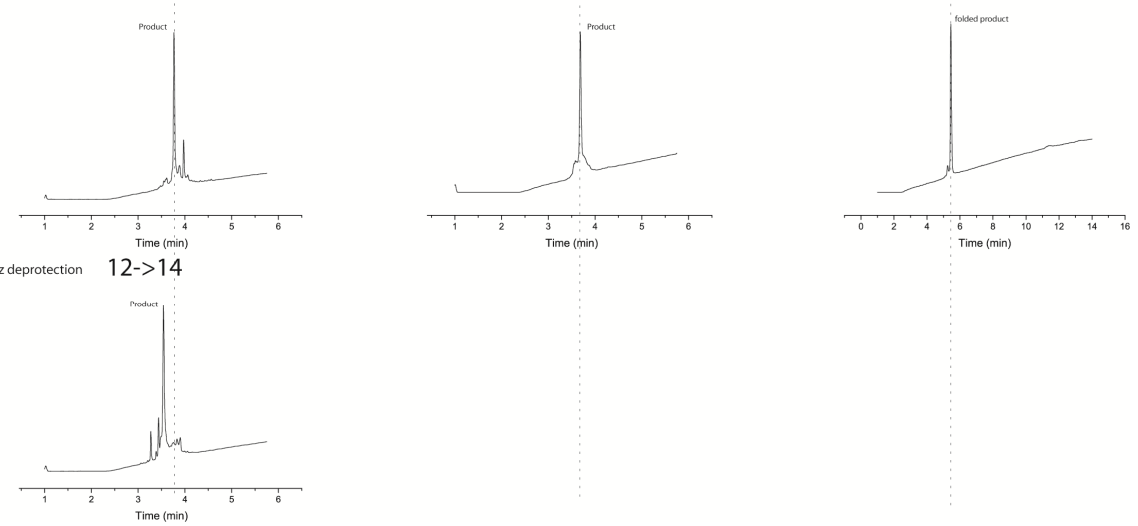

Figure SI 2: Overview of RANTES synthesis: first column shows ligation of the C-terminal with the middle fragment followed over time, with subsequent thiaproline deprotection and purification. Middle column shows NCL of the ligated product with the N-terminal fragment. The final column shows oxidative folding of RANTES 


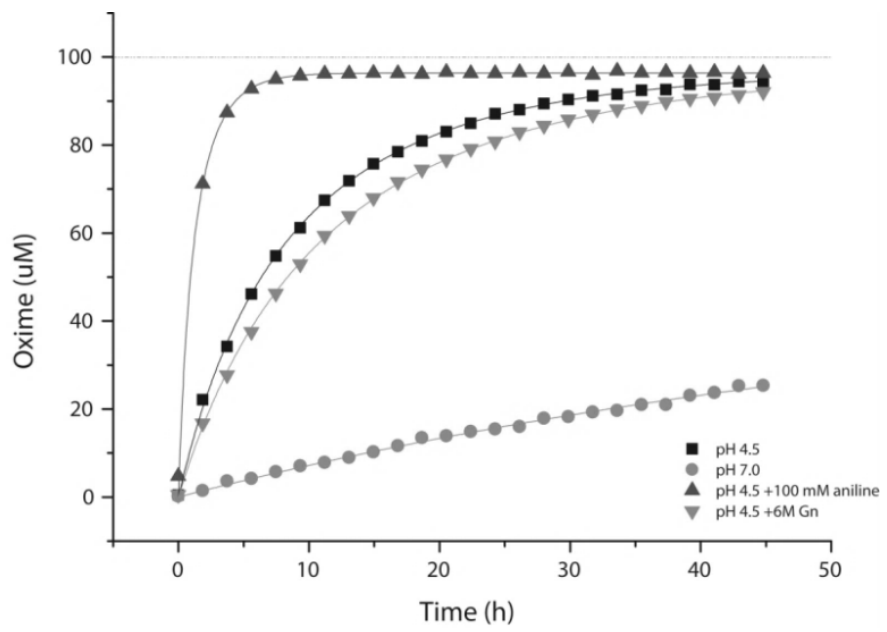

Figure SI 3: Oxime forming reaction of LYRAK(ACBu) and AO-VIPF followed over time in different conditions. All reaction were performed in $100 \mathrm{mM} \mathrm{NaOAc} \mathrm{pH} 4.5$ or in $100 \mathrm{mM} \mathrm{NaPhos} \mathrm{pH} \mathrm{7.0,}$ concentrations were $100 \mu \mathrm{M}$ for LYRAK(AcBu) and $200 \mu \mathrm{M}$ for AO-VIPF. Conditions: apH 4.5 - pH $7.0 \Delta \mathrm{pH} 4.5+100 \mathrm{mM}$ aniline $\nabla \mathrm{pH} 4.5+6 \mathrm{M} \mathrm{Gdn-HCl}$

NMR spectroscopy. NMR samples of OPRAH, modified RANTES and modified PF4, were prepared as $0.2 \mathrm{mM}$ solutions made from freeze-dried protein buffer exchanged into $25 \mathrm{mM}$ deuterated $\mathrm{NaAc}_{3} \mathrm{~d}_{3}$ buffer ( $\mathrm{pH}$ 3.60) containing $0.1 \mathrm{mM}$ EDTA, $0.2 \mathrm{mM}$ sodium azide. $5 \%(v / v) D_{2} \mathrm{O}$ was added for deuterium lock. Initial buffer exchange steps were carried out by ultracentrifugation (in four to five steps) using pre-washed Amicon Ultra-4 ultra-centrifugaton devices with a filter cutoff of $3 \mathrm{kDa}$. Final NMR solutions were prepared in Wilmad $3 \mathrm{~mm}$ NMR tubes (160 $\mu$ l volume), containing a tiny trace of DSS for internal chemical shift calibration $\left(0 \mathrm{ppm}{ }^{1} \mathrm{H}\right)$.

NMR spectra were recorded on a Bruker Avance III HD $700 \mathrm{MHz}$ spectrometer, equipped with a cryogenically cooled TCl probe. Internal temperature was set to $37^{\circ} \mathrm{C}$, with the probe temperature calibrated using a thermocouple inside a NMR tube that was inserted into the probe. One dimensional proton spectra were recorded using excitation sculpting to suppress residual water. Two-dimensional DIPSI (70 ms mixing time) and 2D NOESY spectra (150 ms mixing time) were recorded using the same water suppression technique. Typically 32 scans over 600 increments were collected per spectrum. In addition, natural abundance heteronuclear ${ }^{13} \mathrm{C}-{ }^{1} \mathrm{H} \mathrm{HSQC}$ spectra were acquired for better comparison to known assignments of free RANTES and PF4.

The oxime reaction between RANTES and RANTES to form OPRAH was followed in real-time by $1 D N M R$ inside the NMR tube at $50{ }^{\circ} \mathrm{C}$. The reaction proceeds relatively slowly, so for that reason the reaction was also studied by freezing the NM R sample at $-20{ }^{\circ} \mathrm{C}$ for one hour in the freezer, and slowly warm up the sample back to room temperature. Spectra processing was performed by Bruker Topspin3.2 and Sparky 3.114 software. 

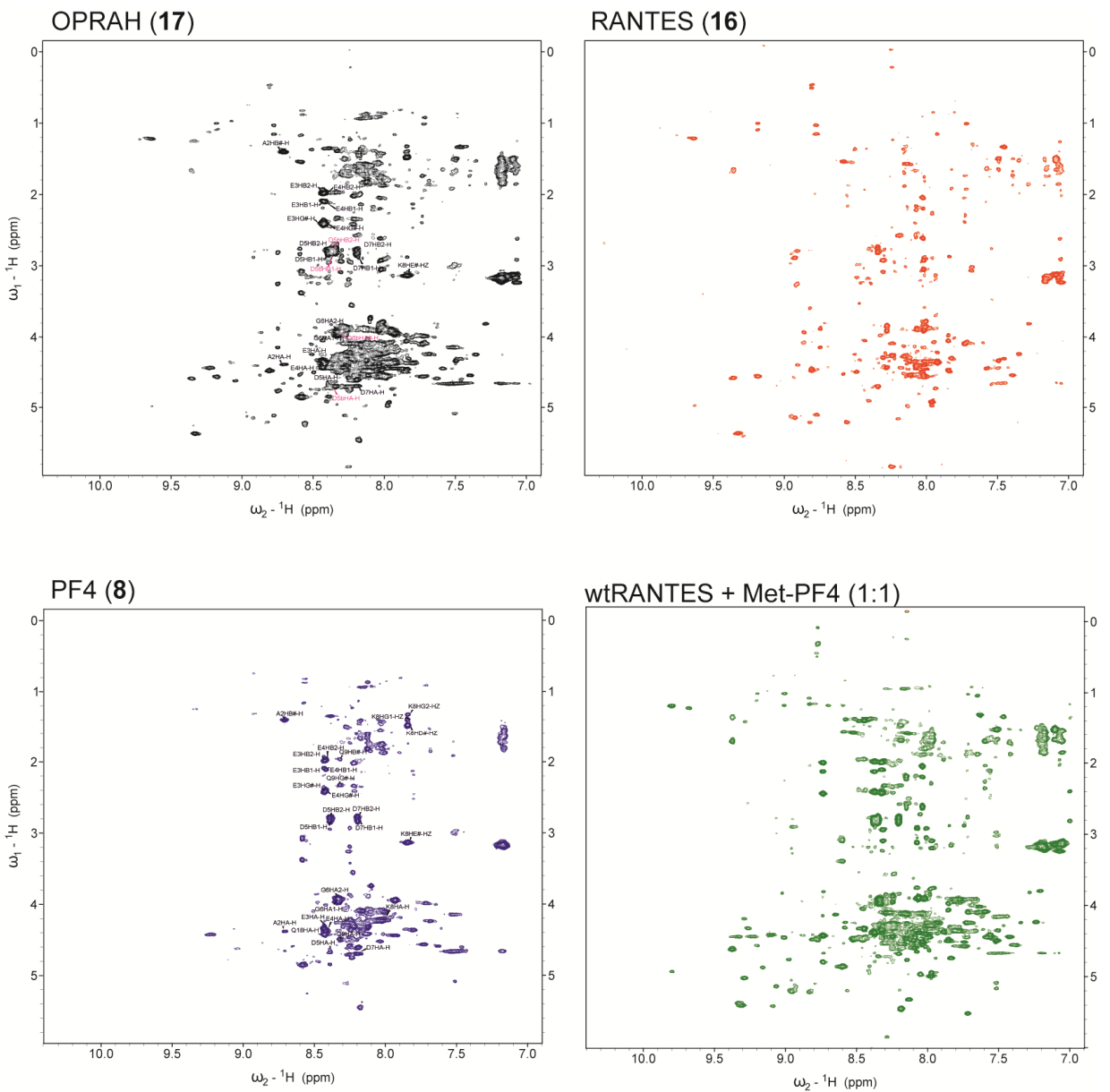

Figure SI 4: Comparison between the DIPSI spectra (70 msec mixing time) of $0.2 \mathrm{mM}$ OPRAH (17), RANTES(16) PF(8) and a 1:1 complex of wtRANTES + Met-PF4 measured under the same conditions ( $700 \mathrm{MHz}, 37^{\circ} \mathrm{C}$ in $25 \mathrm{mM} \mathrm{NaAc}-\mathrm{d}_{3}$ buffer (pH 3.60), $0.1 \mathrm{mM}$ EDTA, and $0.2 \mathrm{mM}$ sodium azide). Assignments for native tetrameric PF4 are incomplete, mostly due to severe dynamic chemical shift broadening of proton resonances, N-terminal amide resonances of PF4(2-7) are however sharp and sequentially assigned from NOESY spectra. Analysis show that the DIPSI spectrum of OPRAH (black) mostly corresponds to a superposition of the spectra of two separately folded domains. Signals for important residues connected just around the linker region are however missing in OPRAH, most likely due to dynamic repositioning between the two domains on an intermediate millisecond time scale. 


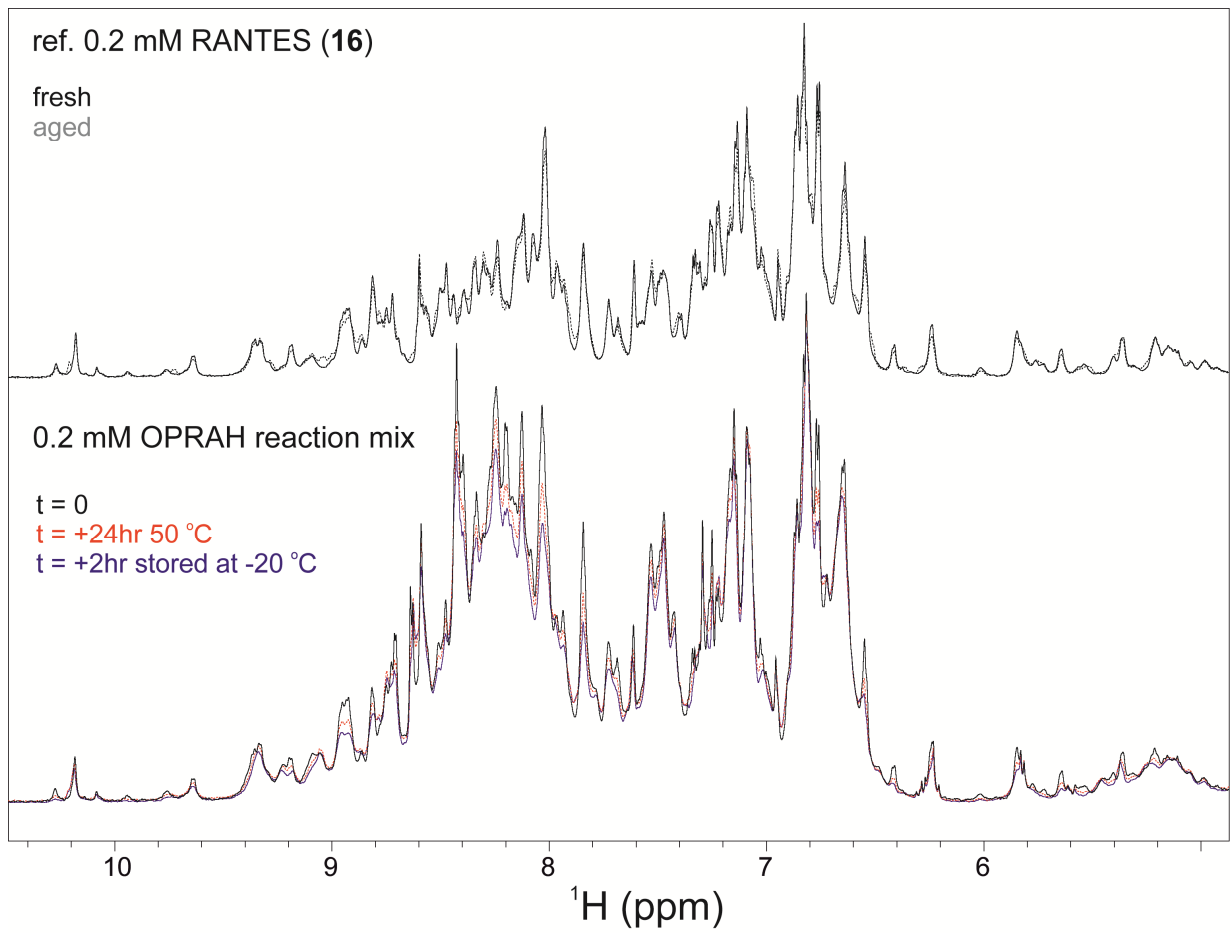

Figure SI 5: Bottom spectrum: Comparison of ${ }^{1} \mathrm{H}$ NMR $700 \mathrm{MHz}$ spectra (amide region) monitoring the oxime reaction between $0.2 \mathrm{mM}$ RANTES (16) and $0.2 \mathrm{mM}$ PF4 (8) yielding OPRAH. Reaction times were +24 hour at $50{ }^{\circ} \mathrm{C}(\mathrm{red})$, and $+2 \mathrm{hr}$ at $-20^{\circ} \mathrm{C}$, followed by thawing and a warm up of the frozen NM R sample (blue). Top spectrum: reference spectrum of free 0.2 mM RANTES (16) taken at time zero (black) and +24 hours at $50^{\circ} \mathrm{C}$ (broken line). Changes have been contributed to side reactions of the aminooxy group in free RANTES (16) and gradually appear in both the spectrum of RANTES and OPRAH after keeping the sample for several hours at $50^{\circ} \mathrm{C}$ (broken line). 
a

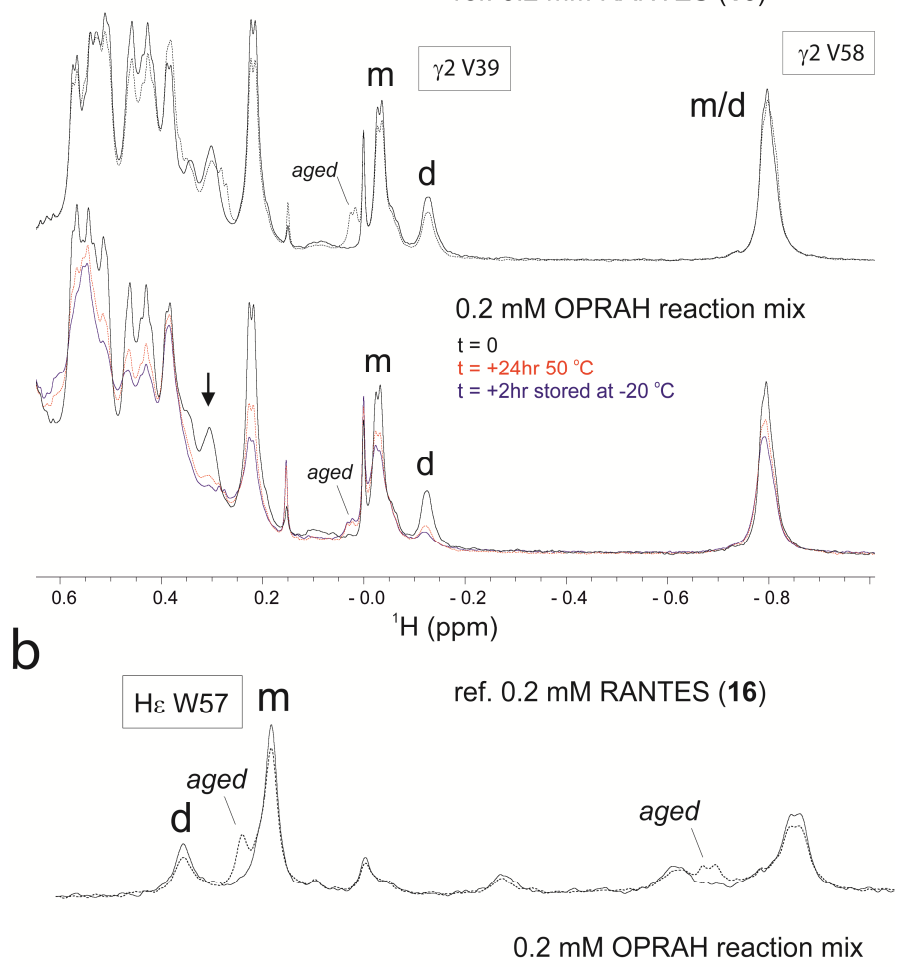

ref. 0.2 mM RANTES (16)

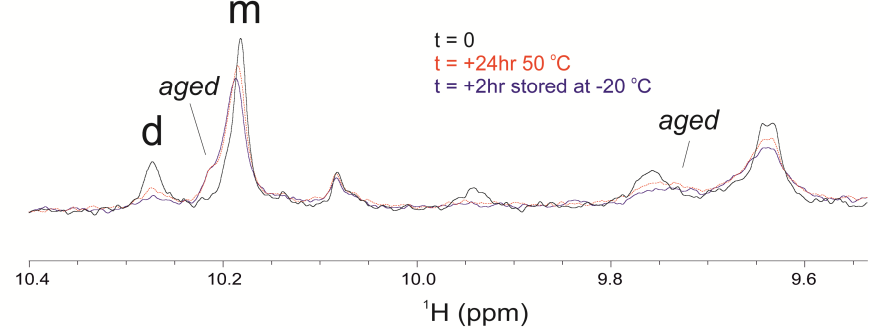

Figure SI 6: a: Top spectrum: methyl groups in the reference RANTES (16) protein. Two different conformational states of the RANTES domain are present: $m=$ monomeric; $d=$ dimeric (top) in both RANTES and OPRAH. Peaks denoted "aged" have been contributed to side reactions of the aminooxy group of free RANTES (16) and gradually appear in both the spectrum of RANTES and OPRAH after keeping the sample for several hours at $50{ }^{\circ} \mathrm{C}$ (broken line). Most prominent change of conformational state in RANTES (16) is the diminished dimer population compared to native RANTES, due to steric hindrance of the introduced oxime bridge involving lysine sidechain at RANTES position T7K. Bottom spectrum: Comparison of ${ }^{1} \mathrm{H}$ NMR $700 \mathrm{MHz}$ spectra (methyl region) monitoring the oxime reaction between $0.2 \mathrm{mM}$ RANTES (16) and $0.2 \mathrm{mM}$ PF4 (8) yielding OPRAH. Reaction times were +24 hour at $50{ }^{\circ} \mathrm{C}$ (red), and $+2 \mathrm{hr}$ at $-20^{\circ} \mathrm{C}$, followed by thawing and a warm up of the frozen NMR sample (blue). After freezing the reaction NMR mixture for an additional +2 hours at $-20^{\circ} \mathrm{C}$, mass spectra indicate near-complete conversion to OPRAH, and the population of homodimer RANTES states decrease even more compared to free RANTES (16), in agreement with competitive formation of heterodimers formed between RANTES and PF4 in OPRAH. b: Enlarged section of Figure SI5 showing the comparison of ${ }^{1} \mathrm{H}$ NMR 
$700 \mathrm{MHz}$ spectra (Trp sidechain amino region) monitoring the oxime reaction between $0.2 \mathrm{mM}$ RANTES (16) and $0.2 \mathrm{mM} \mathrm{PF4} \mathrm{(8)} \mathrm{yielding} \mathrm{OPRAH.} \mathrm{Reaction} \mathrm{times} \mathrm{were}+24$ hour at $50{ }^{\circ} \mathrm{C}$ (red), and $+2 \mathrm{hr}$ at $-20^{\circ} \mathrm{C}$, followed by thawing and a warm up of the frozen NMR sample (blue). Top spectrum: Peaks of RANTES Trp57 $\mathrm{H} \varepsilon$ in the reference RANTES (16) protein. Two different conformational states of the RANTES domain are present: $m=$ monomeric; $d=$ dimeric (top) in both RANTES and OPRAH. Peaks denoted "aged" have been contributed to side reactions of the aminooxy group of free RANTES (16) and gradually appear in both the spectrum of RANTES and OPRAH after keeping the sample for several hours at $50{ }^{\circ} \mathrm{C}$ (broken line). Bottom spectrum: Comparison of ${ }^{1} \mathrm{H}$ NMR $700 \mathrm{MHz}$ spectra (aromatic region) monitoring the oxime reaction between $0.2 \mathrm{mM}$ RANTES (16) and $0.2 \mathrm{mM}$ PF4 (8) yielding OPRAH. Reaction times were +24 hour at $50{ }^{\circ} \mathrm{C}(\mathrm{red})$, and $+2 \mathrm{hr}$ at $-20^{\circ} \mathrm{C}$, followed by thawing and a warm up of the frozen NMR sample (blue)

Monocyte arrest assay. $\mathrm{CD} 14^{+}$human monocytes were isolated from peripheral blood mononuclear cells (PBMC), which were separated from human whole blood (see above), and purified by negative selection using the "Monocyte Isolation Kit II" according to the manufacturers protocol (M iltenyi Biotec $\mathrm{GmbH}$, Bergisch Gladbach, Germany). Human aortic endothelial cells (HAOEC) were cultured and activated with IL-1ß for 4 hours prior to incubation for 30 minutes with chemokines (CXCL4+CCL5 3.8 $\mathrm{nM})$ or synthetic obligate chemokine $(1.9 \mathrm{nM})$ heterodimers and peptide interfering with heterodimerization inhibitor (CKEY). Monocytes $\left(0.7 \times 10^{6} / \mathrm{ml}\right)$ were applied onto the activated endothelium shear stress $\left(1.5 \mathrm{dyn} / \mathrm{cm}^{2}\right)$ using a syringe pump (WPI, Berlin, Germany) in a laminar flow chamber for $2 \mathrm{~min}$ and flushed with assay medium thereafter. Cells were visualized and recorded using a phase contrast microscope (Olympus IX 50, Shinjuku, Japan) connected to a CMOS camera (ids, Obersulm, Germany). For quantification, tightly adherent leukocytes were manually counted in 10 fields of view per dish. Experiments were performed $n=3$ for (CXCL4+CCL5) or $n=6$ for OPRAH and nOPRAH. Presented data were subtracted with monocyte adherence in absence of chemokines. Data are presented as mean +SEM . 


\section{Chapter 6}

Chemokine interactome mapping enables tailored intervention in acute and chronic inflammation

von Hundelshausen P, Agten SM, Eckardt V, Schmitt

M, Blanchet X, Ippel H, Neideck C, Bidzhekov K, Wichapong K, Faussner A, Drechsler M, Grommes J, Li

H, Dijkgraaf I, Nicolaes G, Döring Y, Soehnlein O, Lutgens E, Heemskerk J, Koenen RR, M ayo KH, Hackeng TM , Weber $\mathrm{C}$

under revision 


\section{Abstract}

Chemokines orchestrate leukocyte trafficking and function in health and disease. Heterophilic interactions between chemokines in a given microenvironment may amplify, inhibit or fine-tune their activity; however, a systematic evaluation of the chemokine interactome has not been achieved. We used immuno-ligand blotting and surface plasmon resonance to obtain a comprehensive map of chemokine-chemokine interactions and confirm their specificity. Structure-function analyses revealed that chemokine activity was enhanced by CC-type heterodimers but inhibited by CXC-type heterodimers. Functional synergy was achieved through receptor heteromerization (for CCL5-CCL17) or receptor retention by auxiliary proteoglycan binding (for CCL5CXCL4), whereas inhibition was due to conformational changes affecting receptor activation. Obligate CC-type heterodimers showed high efficacy/potency and drove acute lung injury and atherosclerosis, processes abrogated by specific CCL5-derived peptide inhibitors or knock-in of an interaction-deficient CXCL4 variant. Atheroprotective effects of CCL17 deficiency were pheno-copied by a CCL5-derived peptide disrupting CCL5-CCL17 heterodimers, whereas a CCL5 $\alpha$-helix-peptide mimicked inhibitory effects on CXCL12-driven platelet aggregation. Thus, formation of specific chemokine heterodimers differentially dictates functional activity and can be exploited for therapeutic targeting.

\section{Introduction}

Chemokines regulate leukocyte activation and coordinate their trafficking to sites of inflammation or during immune surveillance. The G-protein-coupled receptor-binding and function of chemokines are governed by their interaction with cell surface proteoglycans, oligomer formation, naturally occurring antagonists, and proteolytic processing. [1,2] Recent studies unveiled that heteromeric interactions between chemokines modify their biological activities and provide structural insight into underlying mechanisms. Consequently, we hypothesized that a functional chemokine interactome comprised of pairwise heteromeric interactions explains how signals conferred by individual chemokines can be integrated to control leukocyte responses. $[3,4]$

Many chemokines form homodimers or oligomers based on two modes to support interfaces: CC-type or CXC-type. [5] Dimerization in a CC-type occurs via interaction of the flexible $\mathrm{N}$-termini to form a two-stranded anti-parallel $\beta$-sheet, whereas in a CXCtype chemokines interact by anti-parallel extension of preformed $\beta$-strands. [5] In addition, their structural similarity allows chemokines to form unique hetero-dimers to shape the overall signaling response of their receptors, and homo- and heteromerization of some chemokines is linked to glycosaminoglycan (GAG) binding. [4-7] Molecular dynamics simulations (MDS) for selected chemokine homo- and 
hetero-dimer pairs predict that association free energies depend upon the particular chemokine combination and dimer-type (CC or CXC), some of which are energetically favored over others. [8] M DS suggests that CC chemokines preferably engage in CCtype interactions, CXC chemokines favor a CXC-type, while both interactions can occur in mixed CC-CXC heteromers. Preferred modes of interaction have been validated experimentally for some chemokine pairs, but have not been extensively explored or linked to differential functions. Nuclear magnetic resonance (NMR) analyses revealed that CC chemokine receptor 2 (CCR2) ligands form CC-type heteromers, and that CCL5 forms a mixed CC-type heteromer with the CXC chemokine CXCL4. [6, 7] The CXC-type heterodimer CXCL4-CXCL8 inhibits CXCL8-mediated endothelial cell activation and proliferation, binding CXCR2 less strongly than CXCL8 alone. [9, 10] Peptide-mediated disruption of the CCL5-CXCL4 heteromer revealed that this interaction enhances CCL5mediated leukocyte recruitment, acute lung injury and atherosclerosis [7, 11]; however, other heteromers have not been evaluated in disease models.

Among the interactions between platelet-derived chemokines identified by mass spectrometry, M DS revealed that CXCL4 can undergo conformational changes to align its $\alpha$-helix with that of CXCL12 to form a CXC-type dimer. [12] Without providing clues towards the type of interaction, screening for synergistic effects on leukocytes showed that combinations of CCR7 agonists with some non-agonist chemokines led to formation of heteromers that enhance T-cell migration and CCR2 ligand activity in monocytes. $[13,14]$ Such evidence of functional synergy implied that heteromers may act as amplifiers in chemokine-rich tissues; however, a systematic and in-depth approach to map interactions between chemokines and to verify their functional specificity has not been undertaken. 


\section{Results}

Mapping the chemokine interactome

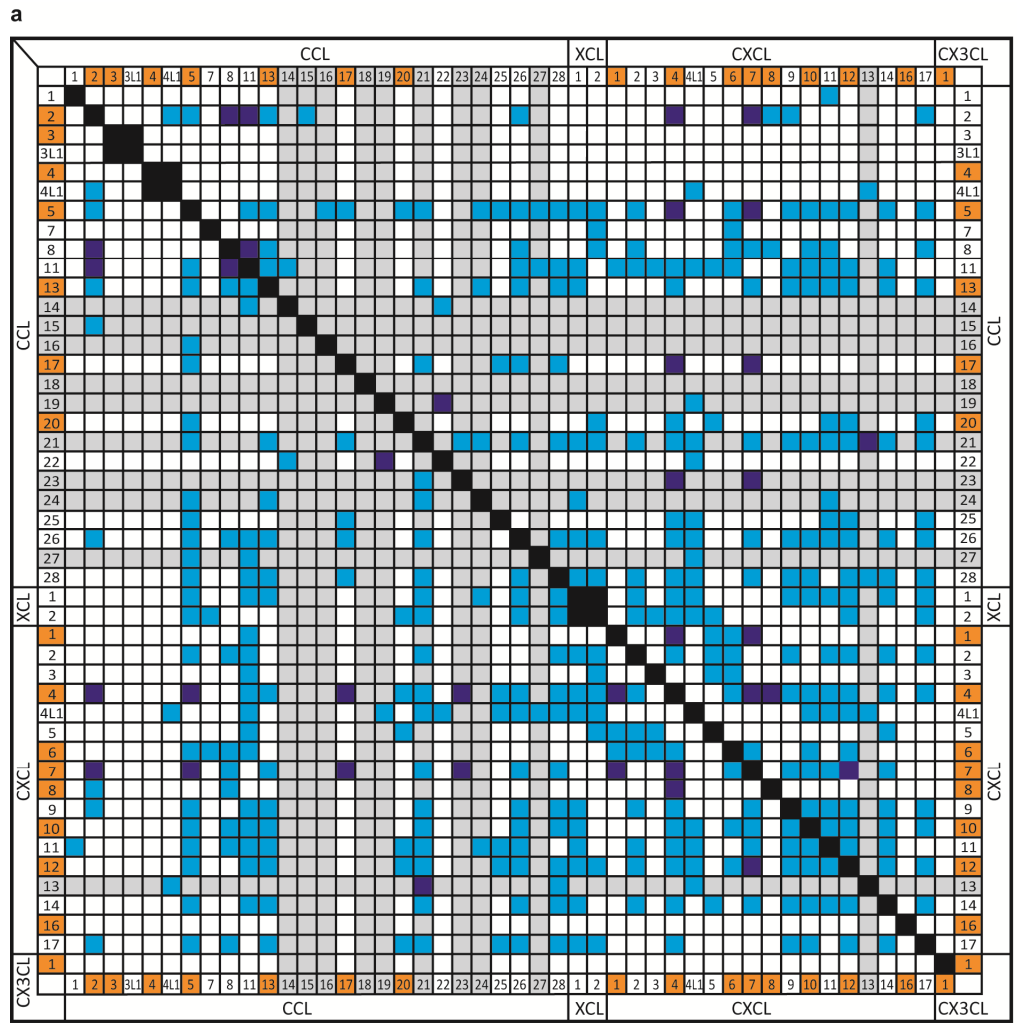

b

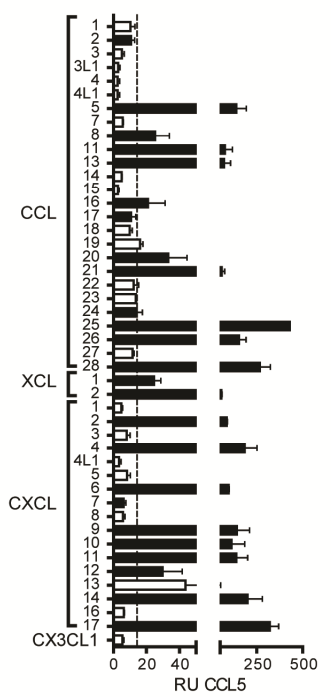

c

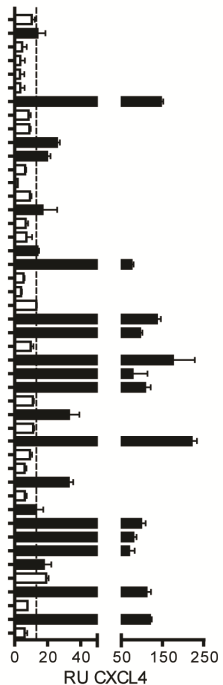

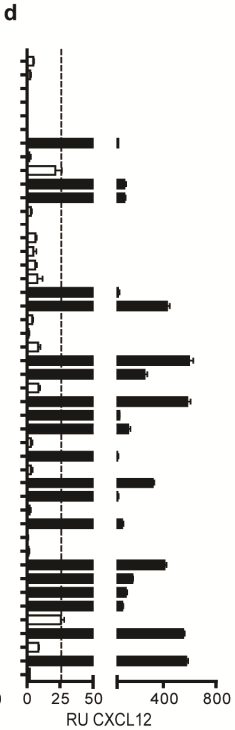

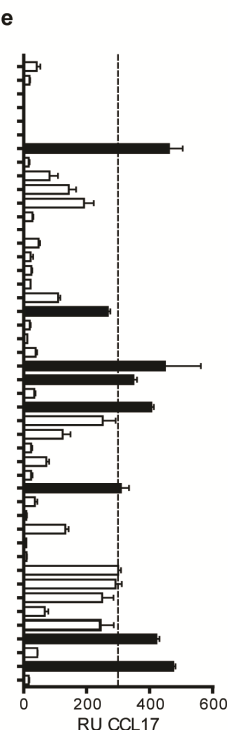


An unbiased, bidirectional immunoblot chemokine screening in which one partner was immobilized on a nitrocellulose membrane and the other remained in solution (Fig. S1) identified heteromeric interactions between pairwise combinations of all known human chemokines. Interactions were considered positive when they exceeded a densitometry threshold of $5 \%$ (on average) relative to positive controls in either direction (Fig. 1A, Table S1). The full interactome matrix revealed hotspots of heteromeric interactions (mostly for inflammatory pairs) and large areas devoid of interactions (Fig. 1A). Neither CC chemokines that adopt unusual polymeric or unique monomeric states (CCL3, CCL4, CCL18) $[15,16]$ nor transmembrane chemokines (CX3CL1, CXCL16) formed heteromers. Only few plasma chemokines activated by $\mathrm{N}$ terminal cleavage or non-mucosal homeostatic chemokines [1] engaged in interactions, with the exception of CCR7 ligands.

Aiming at the design of disease-specific peptide therapeutics, we focused on chemokines involved in atherosclerosis. CCL2 interacted with CCL5, CXCL8 and other CCR2 ligands (Fig. 1A). The atherogenic CCR1/3/5 agonist CCL5 was the most promiscuous chemokine, forming heteromers with 24 partners (Fig. 1A). Various CXCR2 and CXCR3 ligands [2] interacted with each other, with CCL2, CCL5 or CCL11. We did not consider CCR7 ligands, because of their inconclusive role in atherosclerosis models. [17] The atypical chemokine CXCL4 interacted with CXCL12 and many atherogenic chemokines. CXCL4L1, a CXCL4 variant that differs at three C-terminal residues [18], primarily interacted with CCL19/21/25/27 and CXCL12, thus displaying a more homeostatic profile.

The multiple interactions observed for CCL5 and CXCL4 were validated by surface plasmon resonance (SPR), which also confirmed the interactions of atheroprotective CXCL12, e.g. with CCL5 and CXCL4, and a more selective interaction pattern of CCL17 (Fig. 1B-E). Thresholds for SPR and densitometry were defined so as to minimize the number of non-validated interactions. In addition to positive signals in ligand blots and/or in previous assays, interactions were considered bona fide when they passed these thresholds or had good affinity $\left(K_{d}<10^{-6} \mathrm{M}\right)$ despite sub-threshold SPR responses (Fig. 1A-E, Table S2).

Figure 1: Mapping of the chemokine interactome. a: Chemokine-chemokine interactions were detected by bidirectional immuno-ligand blotting. Known atherogenic chemokines are highlighted in orange and non-mucosal homeostatic chemokines are shaded in grey. Chemokine interactions were considered positive (cyan) if the densitometric signal exceeded that of the positive control by $5 \%$ (on average) on either side of the blot ( $n=2-4$ independent experiments). Chemokine interactions previously identified and experimentally confirmed by other techniques are indicated in dark blue. b-e: Binding of soluble chemokines ( $100 \mathrm{nM})$ to immobilized CCL5 (b), CXCL4 (c), CXCL12 (d) and CCL17 (e) was assessed by surface plasmon resonance (SPR). Response units (RU) were compared after the association phase. SPR thresholds optimally delineating binders (black bars) and non-binders (white bars) were based on median values derived from all tested interactions of CCL5, CXCL4 and CXCL12 (b-d), or were set at 300 RU by interpolation with immuno-blotting for CCL17. Data represent mean \pm SEM ( $n=3-5$ experiments). 
To elaborate interactions of interest, we performed kinetics analyses (Fig. S2). Dissociation constants revealed that CCL5 had high affinity for CCL17 and CXCL4 $\left(K_{D}<10^{-8} \mathrm{M}\right)$, intermediate affinity for $C C L 2$ and $C X C L 7\left(K_{D}<10^{-7} \mathrm{M}\right)$, and lower affinity for CXCL12 (Table S2). The affinities of CCL5 for CXCL4 and CXCL4 ${ }^{\mathrm{R}>}$ mutant (with attenuated heparin binding [19]) were similar, whereas CXCL4L1 did not bind CCL5 but retained affinity for CXCL12. Conversely, CCL5 and the mutant CCL5 $5^{\mathrm{E} 65 \mathrm{~S}}$ had high affinity for CXCL4, whereas mutation of the basic BBXB cluster (CCL5 ${ }^{44 A A A 47}$ ) or E26 $\left(C C L 5^{\mathrm{E} 26 \mathrm{~A}}\right)$ resulted in no or impaired binding, identifying residues critical for the interaction. CCL5 and CCL5 ${ }^{\mathrm{E} 665}$ showed similar affinities for CCL17 and CXCL12. Monomeric CCL5 ${ }^{\mathrm{MT7}}$ (N-methylated T7) did not bind CXCL4 and bound CCL17 with 17fold lower affinity, consistent with a role of the CCL5 N-terminus in CC-type interactions. CCL5 ${ }^{\mathrm{E} 26 \mathrm{~A}}$ but not $\mathrm{CCL} 5^{44 A A N A 47}$ had high affinity for CCL17, implying a specific role of E26 in binding to CXCL4, with the BBXB motif also involved in binding to CCL17.

\section{Formation of different types of chemokine heterodimers}

We focused our NM R structural studies on CCL5 and partners selected for their range of interactions and inflammatory relevance. To avoid higher-order aggregation [20] and poor spectral characteristics of native CCL5 [21], we used CCL5 ${ }^{\mathrm{E66S}}$. The CXCL4 ${ }^{\mathrm{K} 50 \mathrm{E}}$ mutant was applied to attenuate CXCL4 tetramer formation and to allay concerns about broadening of NMR spectra due to chemical exchange. [22] Heteronuclear single quantum coherence with ${ }^{15} \mathrm{~N}$-enriched $\mathrm{CCL}^{\mathrm{E} 66 \mathrm{~S}}$ is exemplified by $\mathrm{CXCL}{ }^{\mathrm{K} 50 \mathrm{E}}$ and CCL17 (Fig. 2A,B, full spectra in Fig. S3). Significant resonance broadening and minimal chemical shift $(\Delta \delta)$ changes indicated heteromeric interactions in the intermediate exchange regime. Changes in resonance intensity ( $\Delta$ Intensity) and $\Delta \delta$ of the CCL5 ${ }^{\mathrm{E} 665}$ monomer were plotted versus its sequence (Fig. 2C-F). Because CCL5 ${ }^{\mathrm{E} 665}$ dimer resonances were much less perturbed (Fig. S4A-D), we concluded that heteromeric interactions occur between monomers and not dimers. This was supported by comparing $\Delta \delta$ and $\Delta$ Intensity changes for native CXCL4 interactions with monomeric and dimeric CCL5 ${ }^{\mathrm{E} 665}$ (Fig. S4E-H).

The type of heterodimer formed (CC or CXC) was elucidated by analyzing spectral changes ( $\Delta \delta$; $\Delta$ intensity). The most perturbed $C C L 5^{\mathrm{E}}{ }^{66 \mathrm{~S}}$ monomer resonances belong to residues (7-14, 30-33, 47-50) involved in CC-type dimers (Fig. 2C-F, Fig. S4E,F). In both hetero-pairs, residues 7-11 at the primary CC-type dimer interface displayed relatively large changes. In $\mathrm{CCL}^{\mathrm{E} 66 \mathrm{~S}}$, residues 47-50 (corresponding to $\beta$-strand 3 ) were more perturbed by interactions with CCL17, whereas residues 30-33 were more affected by interactions with $C X C L{ }^{K 50 E}$ or CXCL4. As compared to CCL17, smaller spectral effects observed for CXCL4 indicate slightly weaker interactions with CCL5 ${ }^{\mathrm{E} 665}$, confirming that heterodimer stability depends on residue composition and inter-subunit orientation at the interface. [8] Although formation of both heterodimer types is possible with 
varying molar ratios (Fig. S5), our data show that these two chemokine pairs prefer to form CC-type heterodimers (Fig. 2G,H).

As evidenced by $\mathrm{CCL} 5{ }^{\mathrm{E} 665}$-induced ${ }^{15} \mathrm{~N}-\mathrm{CXCL} 12$ spectral changes that reflect intermediate exchange, CXCL12 and CCL5 also form heterodimers (Fig. S6A,B). The most perturbed ${ }^{15} \mathrm{~N}$-CXCL12 resonances belong to residues in $\beta$-strand- 1 and the $\mathrm{C}$ terminal helix, which are involved in the CXC-type dimer interface. Combining ${ }^{15} \mathrm{~N}$ $\mathrm{CCL}^{5665}$ and unlabeled CXCL12 was also indicative of an interaction but inconclusive in terms of heterodimer-type formed (Fig. S6C,D). Other chemokines, e.g. CXCL10, induced relatively non-specific and moderate spectral changes that are likely attributable to their propensity for homo-aggregation (as seen for CXCL10 tetramers [23]) and increased viscosity at higher concentrations (Fig. S6E). Weighted averaging of $\Delta$ Intensity changes and MDS-based in silico modeling supported that CXCL12 prefers to form CXC-type interactions with CCL5 and CXCL4, whereas CCL2, CCL17 and CXCL4 favor formation of CC-type hetero-dimers with CCL5 (Table S3).

To exploit our structural models for the design of peptide-based inhibitors, we next generated three CCL5-derived peptides (CKEY, CAN, VREY), which form part of the heterodimer interfaces with CXCL4, CCL17, and CXCL12, respectively (Table S4). Modeled CCL5-CCL17 (CC-type) and CCL5-CXCL12 (CXC-type) heterodimers are illustrated in Fig. S7A,B. Cyclic CKEY (containing N-loop and $\beta$-sheet 2, residues K25R44 [7]) partially reversed CXCL4-induced changes in $\Delta \delta$ and broadening of ${ }^{15} \mathrm{~N}$ $\mathrm{CCL}^{5665}$ monomer (but not homodimer) resonances (Fig. S7C). Cyclic CAN comprising CCL5 $\beta$-sheet 3 (residues K33-N52) partially reversed CCL17-induced changes in $\Delta \delta$ and broadening of ${ }^{15} \mathrm{~N}-\mathrm{CCL}^{5665}$ monomer resonances (Fig. S7D). Perturbations at their binding interfaces reflect a specific disruption of both CC-type heterodimers (Fig. S7C,D). Linear VREY ( $\alpha$-helix residues E54-S68) mimicked heterodimer interactions of CCL5 with ${ }^{15} \mathrm{~N}-\mathrm{CXCL} 12$, as similar resonances at the dimer interface were chemically shifted (data not shown). Owing to poor solubility of VREY at pH7 and to improve conformational stability [24], we generated a 4-helix bundle version of VREY (TASPVREY or [VREY] $]^{4}$ Fig. S8A). Spectral changes in $\Delta \delta$ and a structural perturbation plot (Fig. S8B-D) indicated that [VREY] ${ }^{4}$ interacts with ${ }^{15} \mathrm{~N}-\mathrm{CXCL} 12$ and can attenuate its homo- or heterodimer state, as evident by relevant shifts at the interface (Fig. S8E).

We validated these findings using SPR where CKEY inhibited the interaction of CCL5 with CXCL4, but not that with CCL17 or CXCL12; this effect was abrogated in the variant CKEY ${ }^{\mathrm{RE}}$ by substitutions at key residues R44/E26 crucial for heterodimerization (Table S5). Conversely, CAN inhibited the interaction of CCL5 with CCL17 but not that with CXCL4 or CXCL12, whereas the N-terminal peptide CCL5 ${ }^{1-33}$ blocked both CC-type interactions of CCL5 with CXCL4 or CCL17 (Table S5). Finally, [VREY] ${ }^{4}$ competed with CCL5 for binding to CXCL12, but not for that to CCL17 or CXCL4 (Table S5). These data evince that chemokine heterodimers can be specifically disrupted by small peptides. 


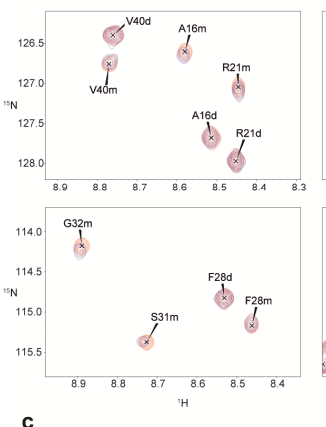

c

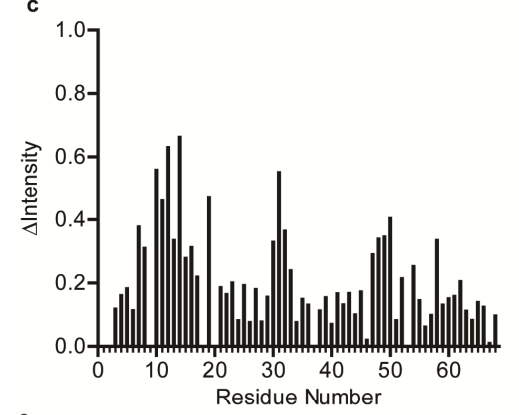

e

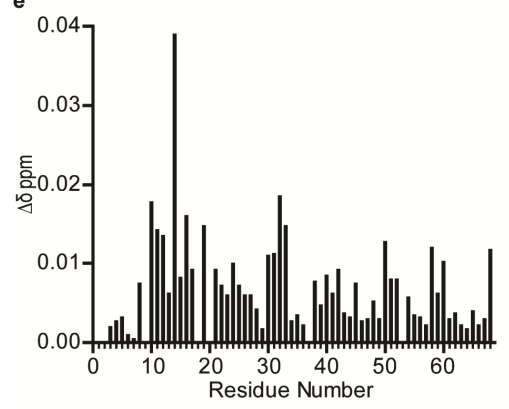

g
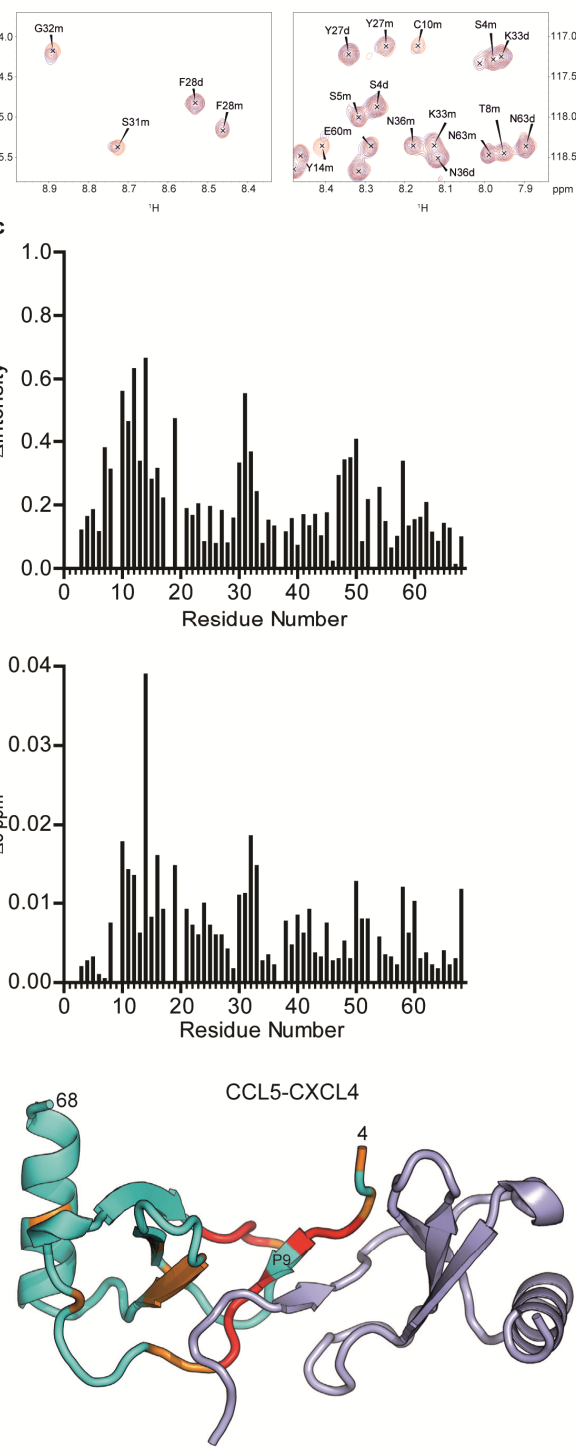

b
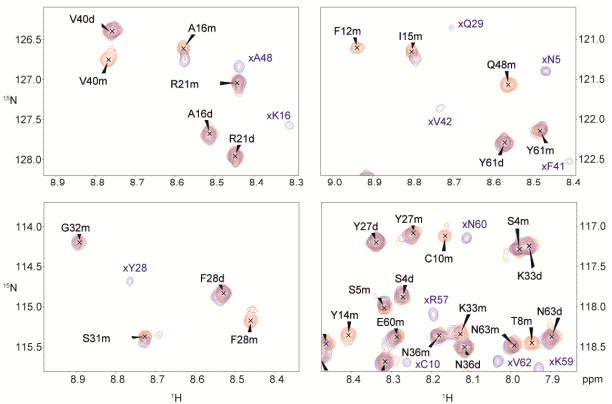

d

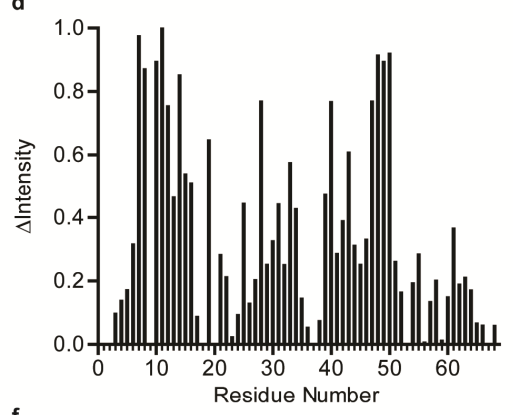

$\mathbf{f}$

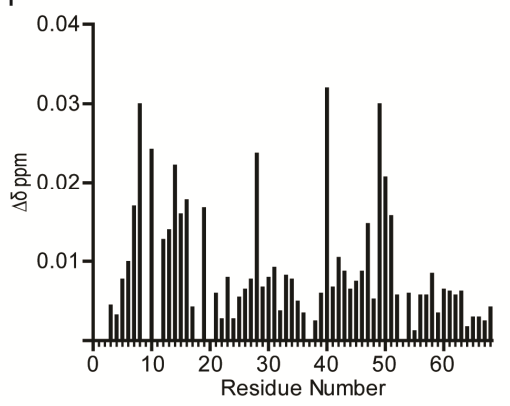

h

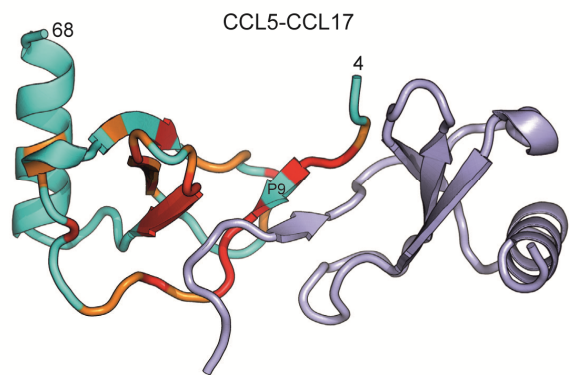

Figure 2: Characterization of chemokine interactions by NMR spectroscopy a-f: $1 \mathrm{H}-15 \mathrm{~N}$ Heteronuclear single quantum coherence (HSQC) spectra were acquired with 128 scans per transient and sweep widths of $16 \mathrm{ppm}$ in the $1 \mathrm{H}$ (2k points) dimension and $22 \mathrm{ppm}$ in the $15 \mathrm{~N}$ (200 points) dimension. Expansions are shown for $15 \mathrm{~N}-\mathrm{CCL}^{\mathrm{E} 66 \mathrm{~S}}$, either alone (red) or in the presence of unlabeled CXCL4 (blue) (a) or unlabeled CCL17 (blue) (b); the molar ratios of CCL17:CCL5 ${ }^{\mathrm{E} 66 \mathrm{~S}}(1 \mathrm{H} 850 \mathrm{M} \mathrm{Hz})$ and CXCL4:CCL5 ${ }^{\mathrm{E} 66 \mathrm{~S}}(1 \mathrm{H} 700 \mathrm{M} \mathrm{Hz})$ were 33:1 $\left(20 \mu \mathrm{M} \mathrm{CCL} 5^{\mathrm{E} 66 \mathrm{~S}}\right)$ and 20:1 (30 $\left.\mu \mathrm{M} \mathrm{CCL}^{\mathrm{E} 66 \mathrm{~S}}\right)$, respectively. Labels indicate monomers $(\mathrm{m})$, dimers $(\mathrm{d})$, and $15 \mathrm{~N}$ bleed- 
through from CCL17 (x). The solution contained $25 \mathrm{mM} \mathrm{Na}$-acetate- $\mathrm{d}_{3}$ buffer at $\mathrm{pH} 4.5$ and $37^{\circ} \mathrm{C}$. The changes in intensity and chemical shift $(\Delta \delta)$ for the $15 \mathrm{~N}-\mathrm{CCL} 5^{\mathrm{E} 665}$ monomer resonances upon binding to $\operatorname{CXCL} 4(\mathrm{c}, \mathrm{e})$ and $\operatorname{CCL} 17(\mathrm{~d}, \mathrm{f})$ versus those of $\mathrm{CCL}^{\mathrm{E} 66 \mathrm{~S}}$ are shown. Fractional changes in intensity ( $\Delta$ Intensity) were calculated as described in the methods section (48). g,h: Primary $C C L 55^{\mathrm{E} 66 \mathrm{~S}}$ residues binding CXCL4 $(\mathrm{g})$ and $\mathrm{CCL} 17 \mathrm{(h)}$ heterodimer subunits are indicated, based on the CCL5 homodimer structure (pdb 1U4L). The broadest resonances within a single subunit are in red (>2 SD above average), orange (between 2 SD and 1 SD), and blue (below 1 $\mathrm{SD})$. Full view HSQC spectra are displayed in Figure S3.

Differential function and disruption of heterodimers

To assess functional effects of chemokine heterodimers, we studied chemotaxis of activated $\mathrm{T}$ cells, which display a large chemokine-receptor repertoire and differentially respond to various chemokines (Fig. S9). Whereas CCL5 plus CCL17 or CXCL4 (CC-type), but not the interaction-deficient CXCL4L1 variant, acted synergistically to enhance chemotaxis (Fig. 3A-D, Fig. S10A-C), combination with CCL5, CXCL4 or CXCL4L1 (CXC-type) inhibited CXCL12-induced chemotaxis (Fig. S10D-F). Consistent with a lack of specific interactions, CCL5 plus CCL3 or CXCL10 resulted in functionally neutral, i.e. neither synergistic nor inhibitory, effects (Fig. S10G,H). Furthermore, combinations preferentially forming CC-type heterodimers (CCL5 plus CXCL4, CCL2 or CCL17) acted synergistically to increase monocyte and/or T-cell arrest (Fig. 3E,F, Fig. S11A). By contrast, combinations forming CXC-type heterodimers such as CXCL4 plus CXCL8 or CCL5 plus CXCL12 exerted inhibitory or less than additive effects (Fig. S11B,C). Overall, different types of heterodimeric interactions can have opposite functional consequences; namely, CC-type heterodimers are synergistic and CXC-type heterodimers are inhibitory.

In the chemotactic dose-response curve, a left-shift indicated that CCL5 increased the potency of CCL17 (Fig. 3A), indicative of increased affinity or receptor heteromerization. Synergistic effects of CCL5-CCL17 involved both the CCL17 receptor (CCR4) and CCL5 receptors (CCR1, CCR5), as shown by inhibition with the CCR4 antagonist $\mathrm{C021}$ and the CCL5 receptor antagonist Met-RANTES (Fig. S11D). By contrast, CXCL4 increased the efficacy of CCL5 over the entire dose range (Fig. 3B). This effect was blocked by Met-RANTES but not by an antibody to the low-affinity CXCL4 receptor CXCR3 (Fig. S11E). These data imply that different modes of synergy (affecting potency or efficacy) occur through distinct mechanisms. 

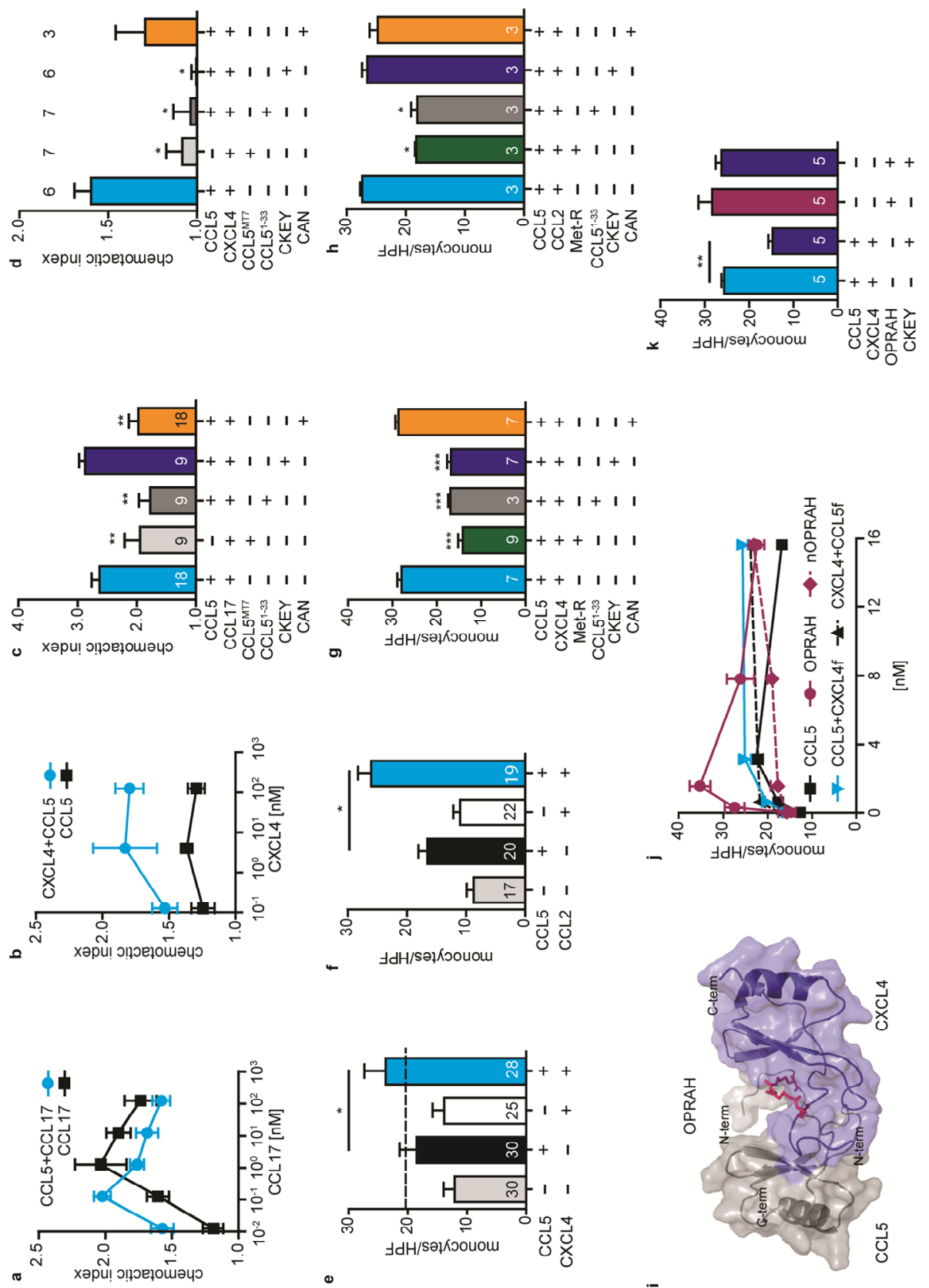
Figure 3: Differential function and specific inhibition of chemokine combinations. (a-d) Transwell-filter chemotaxis assays were performed using IL-2- and CD3/C28-activated human T cells. The chemotactic index was calculated as the ratio of chemokine-induced versus unstimulated migration, as determined by counting cells in the bottom chamber. Combinations of CCL5 (1 nM) plus CCL17 at indicated concentrations (a), CXCL4 (4 nM) plus CCL5 at indicated concentrations (b) ( $n=6-12$ independent experiments), CCL5 or CCL5 ${ }^{\mathrm{MT7}}$ (both $1 \mathrm{nM}$ ) plus CCL17 $(0.1 \mathrm{nM})$ (c) and CCL5 plus CXCL4 (both $4 \mathrm{nM}$ ) (d) were added to the bottom chamber. The CCL5-peptides $\mathrm{CCL}^{1-33}$ (N-terminal), CAN (CCL5-CCL17 interface), and CKEY (CCL5-CXCL4 interface) were added at 10-fold molar excess. (e-k) Isolated human blood monocytes were perfused over IL-1 $\beta$-activated human aortic endothelial cells (HAOECS) pre-incubated with chemokines and the number of adherent cells per high-power field (HPF) was counted. HAoECs were incubated with CCL5 and/ or CXCL4 (40 nM each) (e,g), CCL5 and/or CCL2 (4 nM each) (f,h). Dashed lines indicate a virtually calculated additive effect $(e, f)$. Monocytes were pre-incubated with the CCL5 receptor antagonist Met-RANTES (M et- $R, 40 \mathrm{nM}$ ), and the peptides $C C L 5^{1-33}$, CKEY, or CAN (40 nM each) were combined with CCL5 plus CXCL4, (g) or CCL5 plus CCL2 (h) for preincubation with HAoECs. (i) Energy-minimized structure model depicting the CC-type interaction of CCL5 (grey) and CXCL4 (blue) trapped via a covalent oxime linkage (magenta), resulting in an Obligate Platelet Factor 4-RANTES heterodimer (OPRAH). HAoECs were pre-incubated with indicated concentrations of CCL5 plus CXCL4 fixed at $4 \mathrm{nM}$ (CCL5+CXCL4f), indicated concentrations of CXCL4 plus CCL5 fixed at $4 \mathrm{nM}$ (CXCL4+CCL5f) or indicated concentrations of OPRAH or nOPRAH (N-terminally tethered OPRAH) (j). HAOECS were pre-incubated with CCL5 plus CXCL4 or OPRAH (4 nM each) with or without CKEY (40 nM) (k). Data represent mean \pm SEM from the indicated number of independent experiments. ${ }^{*} p \varangle 0.05, * * p \varangle 0.01, * * * p \varangle 0.001$ versus chemokine combinations (cyan), as analyzed by one-way ANOVA (c,e,f) or Kruskal-Wallis-test $(d, g, h, k)$.

Notably, monomeric CCL5 ${ }^{\mathrm{MT7}}$ neither formed heterodimers, nor did it support functional synergy with CCL17 or CXCL4; whereas the $\mathrm{N}$-terminal peptide $\mathrm{CCL}^{1-33}$ blocked synergistic effects of CCL5 with CXCL4, CCL17 or CCL2, indicating that $\mathrm{N}$ terminal motifs are required for CC-type heterodimer formation and activity (Fig. 3C,D,G,H). Consistent with SPR results (Table S5), CKEY (but not $\mathrm{CKEY}^{\mathrm{RE}}$ ) specifically inhibited CCL5-CXCL4 synergy, whereas CAN specifically inhibited CCL5-CCL17 (Fig. $3 C, D, G, H$, Fig. S11F). Thus, peptide-targeting of heterodimer interfaces encompassing $\beta$-strands 2 or 3 with adjacent loops confers specificity for functional inhibition. Mimicking effects of CCL5, [VREY] ${ }^{4}$ (but not the other peptides) inhibited CXCL12 activity in chemotaxis and arrest (Fig. S11C,H, data not shown). Along with the NMR data, this indicates that CCL5 and [VREY] ${ }^{4}$ induce structural changes in the CXCL12 dimer, thereby inhibiting CXCL12 activity.

Based on our modeling, we generated a covalently-linked CC-type CXCL4-CCL5 heterodimer termed OPRAH (obligate PF4-RANTES heterodimer, Fig.3I) by introducing an oxime linker between N-terminal residues of CCL5 (T7) and CXCL4 (L8). The efficacy and potency of OPRAH in triggering monocyte arrest were greater than for CCL5 alone and for synergistic effects of CCL5 and CXCL4 combined at concentrations that favor heterodimer formation (Fig. 3J). CKEY did not inhibit OPRAH-mediated effects (Fig. 3K). By contrast, OPRAH with N-termini tethered at the first residues (nOPRAH) failed to 
enhance function (Fig. 3J), indicating the importance of freely available N-termini. An obligate CCL5-CCL17 heterodimer induced T-cell arrest with higher potency and efficacy than a combination of CCL17 and CCL5 (Fig. S11I). These data establish that heterodimers are responsible for the synergistic effects observed.

To address underlying mechanisms for synergy, we used an in situ proximity ligation assay [25] reporting protein interactions that detect the presence of CCL5-CCL17 heterodimers formed on cytokine-stimulated endothelial cells after incubation with both chemokines (Fig. S12). This approach also allowed detection of endogenous heterodimers in mouse lymph nodes (Fig. S12). In dendritic cells, which express both CCR4 and CCR5, CCL5-CCL17 heterodimers assembled on the cell surface when adding both chemokines, whereas CCR5-CCR4 complexes were constitutively present (Fig. 4A). The increase in CCL5-CCL17 heterodimers was inhibited by CAN (Fig. 4B), revealing that heterodimers can be disrupted by peptides in a cellular context. Notably, the number of CCR5-CCR4 complexes and ligand-receptor cross-interactions were markedly increased by combining CCL5 and CCL17 but not by either alone (Fig. 4C, Fig. S13A-D). This effect was impaired by CAN, thus being mediated by CCL5-CCL17 heterodimers, and disrupted by CCR5-derived peptides spanning transmembrane 1 and 4 motifs (Fig. 4C), as observed for CCR5 homodimers [26]. Peptide-based disruption of CCL5-CCL17 or CCR5-CCR4 impeded synergy in T-cell chemotaxis (Fig. 4D, Fig. S13E), substantiating a role of ligand-induced receptor heteromer complexes. Binding competition assays further revealed that the affinity of CCL17 for CCR4 was higher when adding CCL5 to promote heterodimer formation (Fig. 4E).

To identify mechanisms underlying CXCL4-mediated synergy, we used the GAG binding-impaired mutant CXCL4 ${ }^{R>Q}$, which forms heterodimers with CCL5 (Table S2). This mutant did not enhance CCL5-induced monocyte arrest, suggesting that GAG binding through CXCL4 may improve presentation of CCL5 to its arrest-triggering receptors (Fig. 4F). Indeed, CXCL4 but not CXCL4 ${ }^{R>Q}$ increased surface binding of CCL5 to monocytes, indicating that this was mediated by GAG binding via CXCL4 (Fig. 4G). As a consequence, CXCL4 but not CXCL4 ${ }^{R>Q}$ prevented CCR1 internalization by CCL5 (Fig. 4H), without altering the affinity of CCL5 for CCR1 or CCR5 (Fig. S13F,G). Thus, CCL5-CXCL4 heterodimers limit rapid internalization of CCR1 from the cell surface, where it is retained for active signaling. 

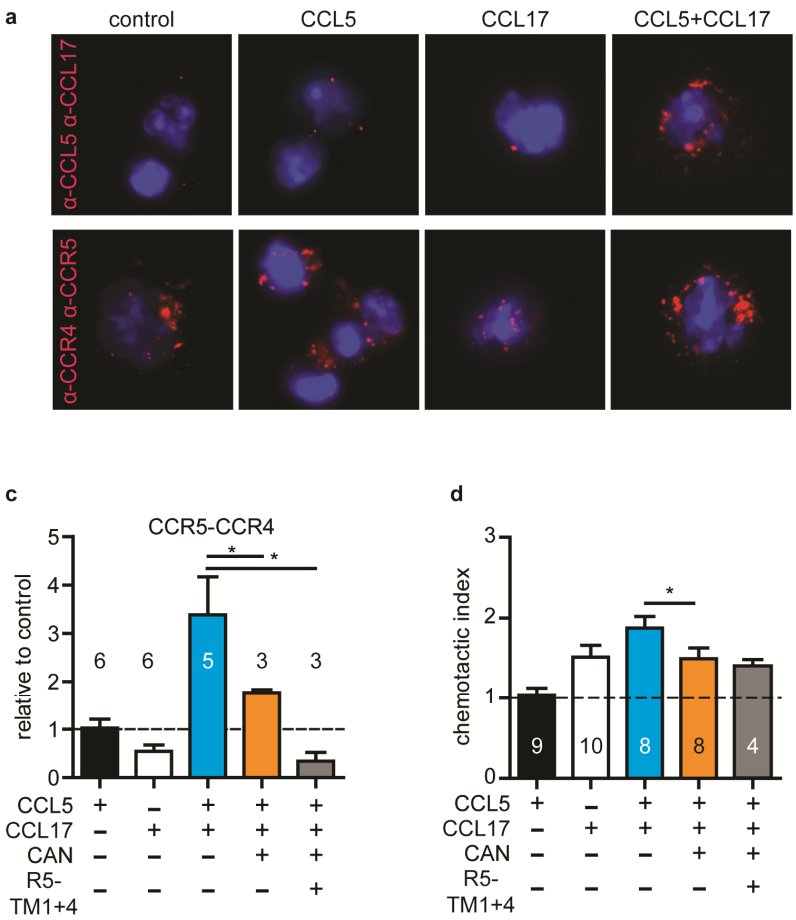

f

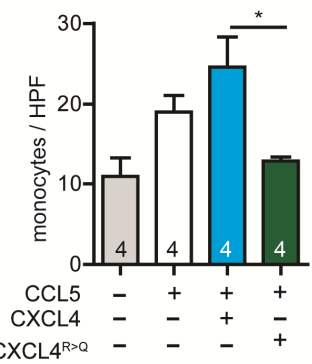

d

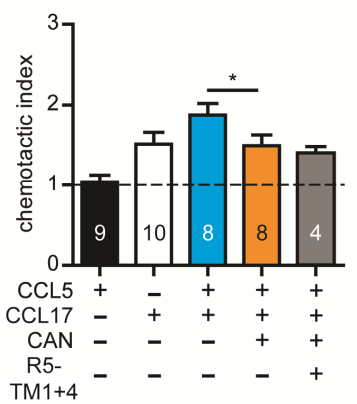

g

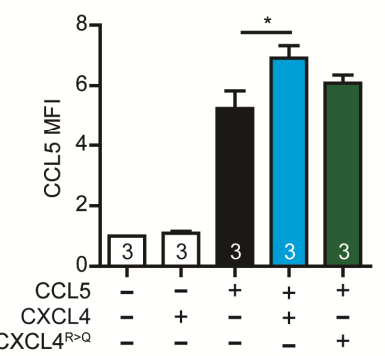

b
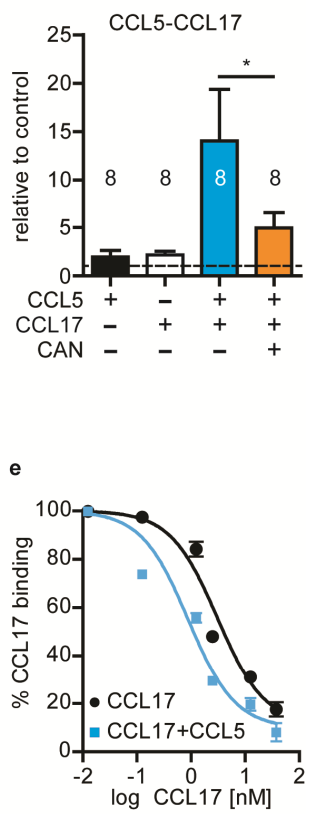

h

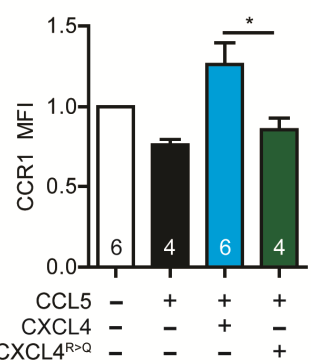

Figure 4: Mechanisms for synergistic effects of chemokine heterodimers. (a-c) Interactions between CCL5, CCL17, CCR4, and CCR5 were detected on the surface of adherent dendritic cells

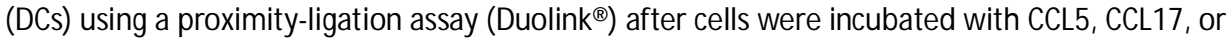
both (6 $\mathrm{nM}$ each) in the presence/absence of CAN (60 nM) or transmembrane (TM) 1+4 CCR5 peptides (50 $\mu \mathrm{g} / \mathrm{ml}$ ) known to inhibit CCR5 dimerization (26). Representative images depict the presence of CCL5-CCL17 and CCR4-CCR5 heteromers (red dots) on the DC surface (a). Proximity ligation signals generated by the interactions of CCL5-CCL17 (b) and CCL5-CCR4 (c) were quantified relative to CCL5 alone (control). (d) Transwell-filter chemotaxis assays were performed using CD3/CD28-activated primary mouse T cells. Chemotactic index was calculated as the ratio of chemokine-induced versus unstimulated migration, as determined by counting cells in the bottom chamber. Migration towards CCL5 and/or CCL17 (6 nM each) in the bottom chamber was analyzed in the presence/ absence of CAN $(60 \mathrm{nM})$ or TM $1+4$ peptides $(50 \mu \mathrm{g} / \mathrm{ml})$. Dashed lines indicate a virtually calculated additive effect (b-d). (e) Binding competition assay; CCL17-Alexa647 (2.5 nM) bound to CCR4-expressing HEK transfectants was displaced by unlabeled CCL17 in presence or absence of CQL5 (1 nM) ( $n=6-9$ independent experiments). (f) 
Isolated human monocytes were perfused over IL-1ß-HAoECs pre-incubated with CCL5 and CXCL4 or the GAG binding-deficient mutant $\mathrm{CXCL}^{\mathrm{R}>\mathrm{Q}}(4 \mathrm{nM}$ each), and the number of adherent cells per high power field (HPF) was counted. (g) Deposition of exogenous CCL5, either alone or in combination with CXCL4 or CXCL4R>Q (100 nM each) on the surface of primary human monocytes was detected by flow cytometry and given as specific mean fluorescence intensity (M FI). (h) CCR1 surface expression on human monocytes was detected by flow cytometry after treatment with CCL5 (4 nM), either alone or in combination with CXCL4 or CXCL4R>Q (each at $40 \mathrm{nM}$ ). Data represent mean $\pm S E M$ from the indicated number of independent experiments. $* p \varangle 0.05$ versus chemokine combinations (cyan), as analyzed by one-way ANOVA (b), MannWhitney-test $(c, f, g, h)$ or unpaired t-test (e).

Specific targeting of heterodimers in inflammatory disease models

To confirm the role of heterodimer formation in vivo, we first used the short-term model of LPS-induced acute lung injury (ALI), which relies on platelet chemokines for neutrophil recruitment. [11] Treatment with CKEY (but not with $\mathrm{CKEY}^{\mathrm{RE}}$ ) dosedependently reduced infiltration in the lung, as evidenced by lower intravascular, interstitial, bronchoalveolar and total neutrophil counts (Fig. 5A, FIG. S14A-C). Conversely, reconstitution of mice carrying $\mathrm{CCl}^{-1} \mathrm{CxCl}^{-1-}$ bone marrow (deficient in both heterodimer components) with OPRAH but not CCL5 exacerbated pulmonary infiltration, as reflected in higher intravascular neutrophil numbers and a trend towards higher total counts (Fig. 5B, FIG. S14D). 

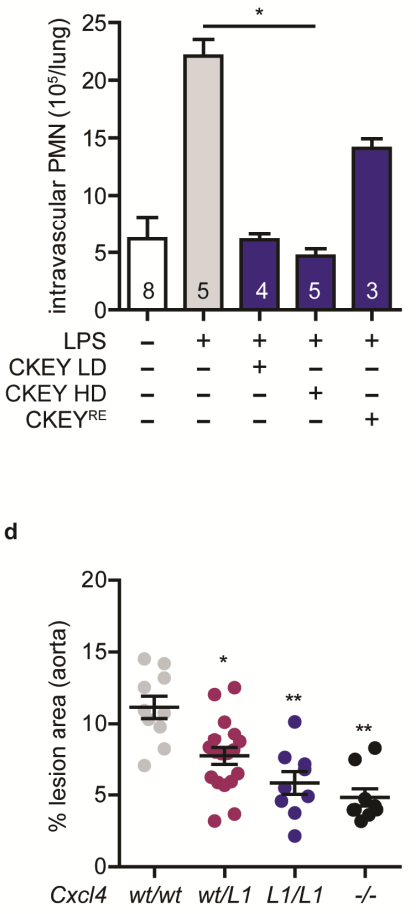

b

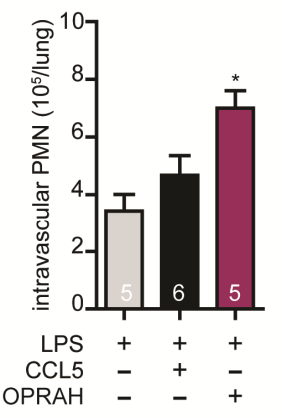

e
C

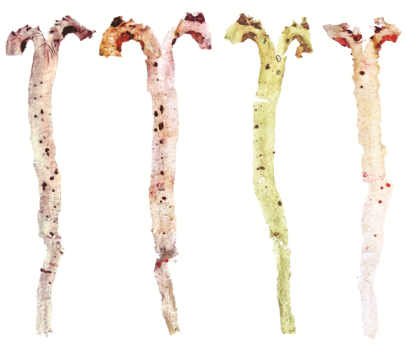

$w t / w t \quad w t / L 1 \quad L 1 / L 1 \quad-/$ g

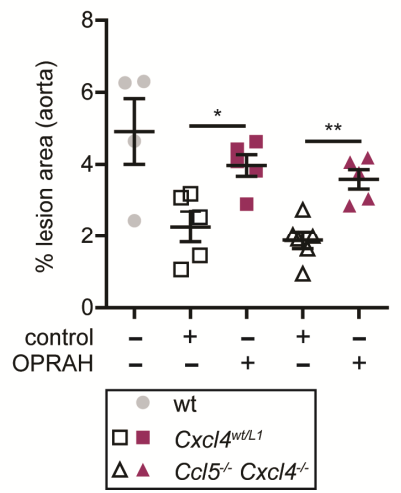

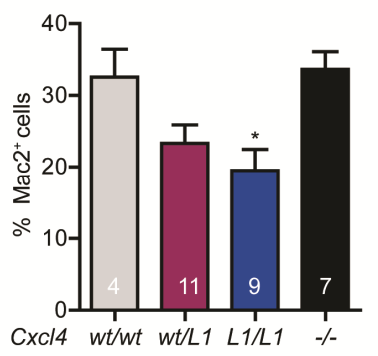

h

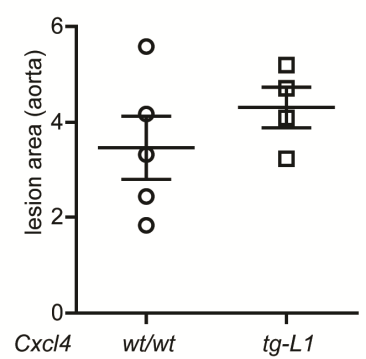

Figure 5: Inflammatory effects of CCL5-CXCL4 in vivo require heterodimer formation. $(a, b)$ Acute lung injury (AL) in C57/BI6 mice was induced by LPS inhalation. Intravascular neutrophil accumulation was detected by intravenous (i.v.) injection of a FITC-GR1 antibody before lung explantation. (a) Mice were injected intraperitoneally (i.p.) with CKEY at a low-dose (LD, 1 $\mathrm{mg} / \mathrm{kg}$ ) or a high-dose (HD, $10 \mathrm{mg} / \mathrm{kg}$ ), or with $\mathrm{CKEY}^{\mathrm{RE}}$ at a HD before LPS challenge. (b) $\mathrm{CCl}^{-1}$ $\mathrm{CxCl}^{-1-}$ bone marrow-chimeric mice were i.v. injected with CCL5 $(150 \mu \mathrm{g} / \mathrm{kg})$, OPRAH $(300$ $\mu \mathrm{g} / \mathrm{kg}$ ), or vehicle (ctrl) before LPS challenge. (c-e) Atherosclerosis was analyzed in wild-type $\mathrm{CxCl} 4^{\text {WT/WT }}$ mice, homozygous Cxcl $4^{\mathrm{LI} / L 1}$ mice with a Cxcl4 knock-out and a knock-in of a mouse variant of human CXCL4L1, heterozygous $\mathrm{CXCl} 4^{\mathrm{WT} / L 1}$ mice, and CXCL4-deficient $\mathrm{CXCl} 4^{-1-}$ mice on an $\mathrm{Apoe}^{-/-}$background after 12 weeks on a high-fat diet (HFD). Representative images of the 
aorta stained with oil-red-0 are shown (c). The area of the aorta showing oil-red-0-positive lesions (d) and the area of Mac2-positive cells in the aortic arch (e) were quantified and expressed as percentage of the total area. (f) The lesion area in the aorta of Apoe ${ }^{-/-}$mice expressing a human CXCL4L1 transgene (tg-L1) in addition to CXCL4 was analyzed after 12 weeks of HFD. $(\mathrm{g}, \mathrm{h}) \mathrm{CxCl} 4^{\mathrm{wt} / \mathrm{Ll}}$ and $\mathrm{CCl}^{-1-} \mathrm{CxCl} 4^{-1-}$ mice on an Apoe background were treated (i.p.) with OPRAH (10 $\mu \mathrm{g}$, twice a week) while on a HFD for 6 weeks. The oil-red-0-positive lesion area $(\mathrm{g})$ and the Mac2-positive area in the aortic arch (h) were quantified and expressed as percentage of the total area. Data represent mean \pm SEM from the indicated number of mice. ${ }^{*} p \varangle 0.05,{ }^{* *} p \varangle 0.01$, as analyzed by Kruskal-Wallis-test $(a, b, d, e)$ or M ann-Whitney-test $(g, h)$.

To unequivocally prove biological relevance of heterodimer interactions, we generated $\mathrm{CXCl} 4^{\mathrm{LI} / L 1}$ mice with a CXCL4 knock-out and knock-in of the CXCL4L1 variant (which neither exists in mice nor forms heterodimers with CCL5), to study dietinduced atherosclerosis on an Apoe ${ }^{-/}$background (Fig. S15). Notably, CxCl $4^{\mathrm{LI} / L 1}$ mice showed a marked reduction of atherosclerotic lesion size in the aorta and the aortic arch, comparable to that seen in CXCL4-deficient mice (Fig. 5C,D, FIG. S16A,B). Heterozygous $\mathrm{Cxcl} 4{ }^{\mathrm{Ll} /+}$ mice displayed an intermediate gene-dosing effect. Lesion size in the aortic root was attenuated in $\mathrm{CxCl} 4^{-/-}$mice but not $\mathrm{CxCl} 4^{\mathrm{L1} / \mathrm{Ll}}$ mice (Fig. S16C,D), implying regional differences unrelated to heterodimerization. Except for lower macrophage content in $\mathrm{Cxcl} 4^{\mathrm{L} / \mathrm{LI}}$ mice, plaque composition (i.e. phenotype classification, smooth muscle cells, necrotic core, and T-cell content), lipid profiles, body weight, and blood cell counts did not differ among all groups (Fig. 5E, Fig. S17, Table S6). Platelet-specific expression of a CXCL4L1 transgene in Apoe ${ }^{-/}$mice did not alter lesion size, indicating that its effects are not dominant-negative but due to a lack of interaction (Fig. 5F). Treatment with mouse OPRAH restored lesion formation in the aorta including the arch, increased macrophage content in aortic root plaques, but did not change other parameters in $\mathrm{CCl}^{-1-} \mathrm{CxCl}^{-1} \mathrm{Apoe}^{-/}$mice and heterozygous $\mathrm{CxCl} 4^{\mathrm{LI} / \mathrm{wt}} \mathrm{Apoe}^{-/-}$mice expressing non-interacting CXCL4L1 (Fig. 5G,H, Fig. S18, Table S7).

The atheroprotective homeostasis of regulatory T cells (Tregs) is suppressed by DCderived CCL17, a phenotype not replicated in Ccr4-deficient mice [3, 27, 28], possibly implicating other chemokine receptors or heterodimers. Indeed, we detected CCL5CCL17 heteromers in aortic root lesions of Apoe $^{-/}$mice (Fig. 6A), in the intima and adventitia of human coronary arteries with advanced atherosclerosis but not in undiseased vessels/segments (Fig. 6B). Notably, combined interference with CCR4/CCR5 using the CCR5 antagonist DAPTA in CCR4-deficient Apoe ${ }^{-/}$mice increased Treg numbers in the para-aortic lymph nodes, and marginally in peripheral blood (Fig. $6 C, D$ ). Similar results were obtained by treatment with CAN (for 6 weeks), which also reduced lesion size in the aortic root (Fig. 6C-F), thus phenocopying effects of CCL17 deficiency. [27] These findings may be due to limiting CCL17-mediated recruitment of naïve $\mathrm{CD}^{+} \mathrm{T}$ cells, in which Treg conversion or maintenance is suppressed via subsequent CCL17-dependent pathways involving other receptors. 
To exploit inhibitory interactions exemplified by the CXC-type heterodimer CCL5CXCL12, we tested whether [VREY] ${ }^{4}$ inhibits CXCL12-depedent platelet aggregation, as relevant to atherothrombosis. Notably, CXCL12 facilitated platelet aggregation, as

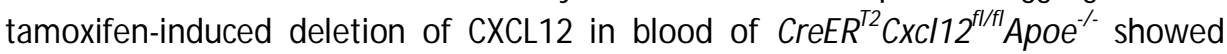
reduced multi-parameter platelet activity and thrombus scores in vitro (Fig. $6 \mathrm{G}, \mathrm{H}$ ). Treating Apoe ${ }^{-/-}$mice with [VREY] ${ }^{4}$ afforded a comparable inhibition of platelet activity (Fig. 6G,H). Likewise, [VREY] $]^{4}$ inhibited CXCL12-induced human platelet aggregation and CXCR4 activation in HEK transfectants, likely due to conformational effects on CXCL12 (Fig. 6I,J). Thus, CXCL12-targeting peptides may be useful as novel antiplatelet therapeutics. 

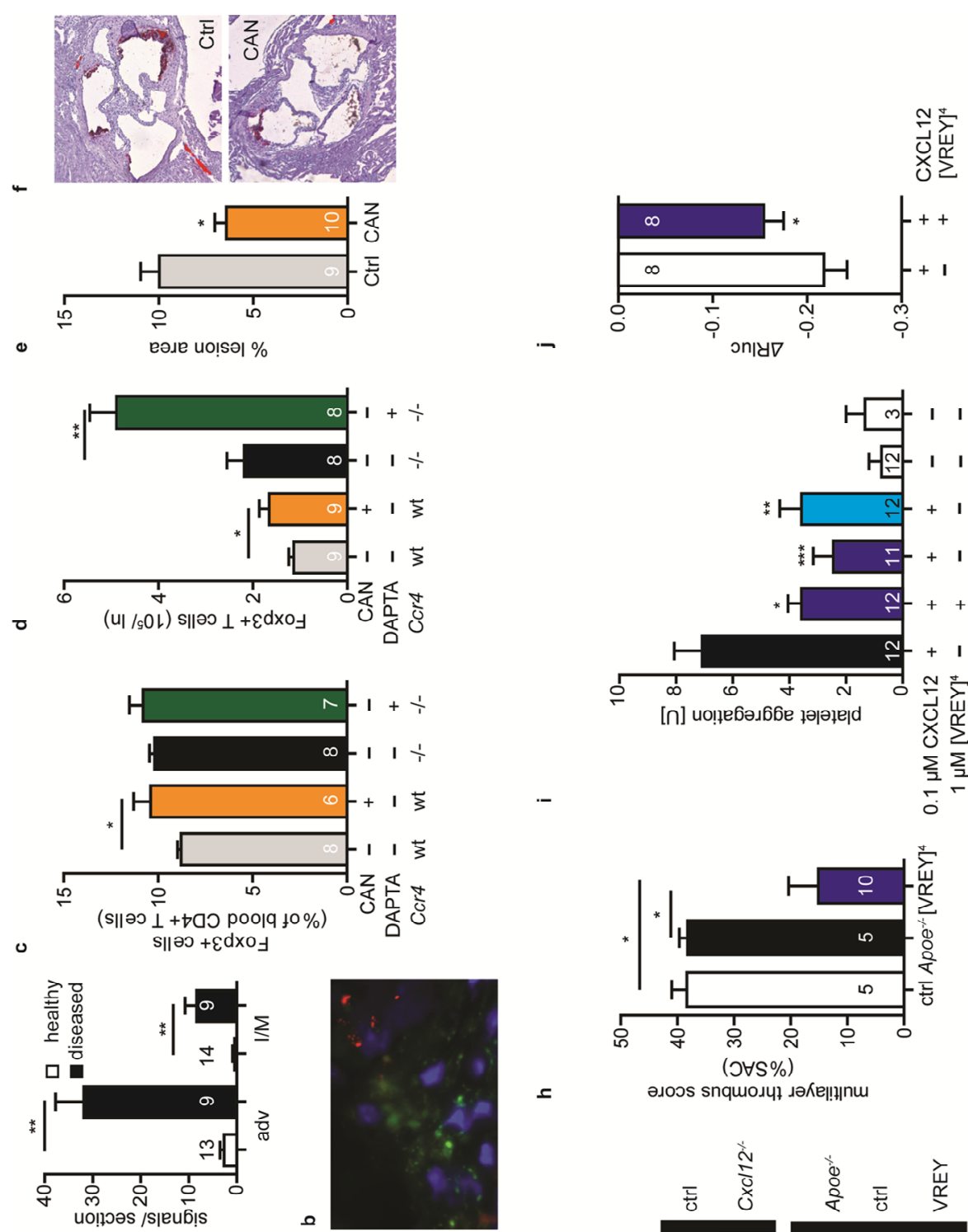

e
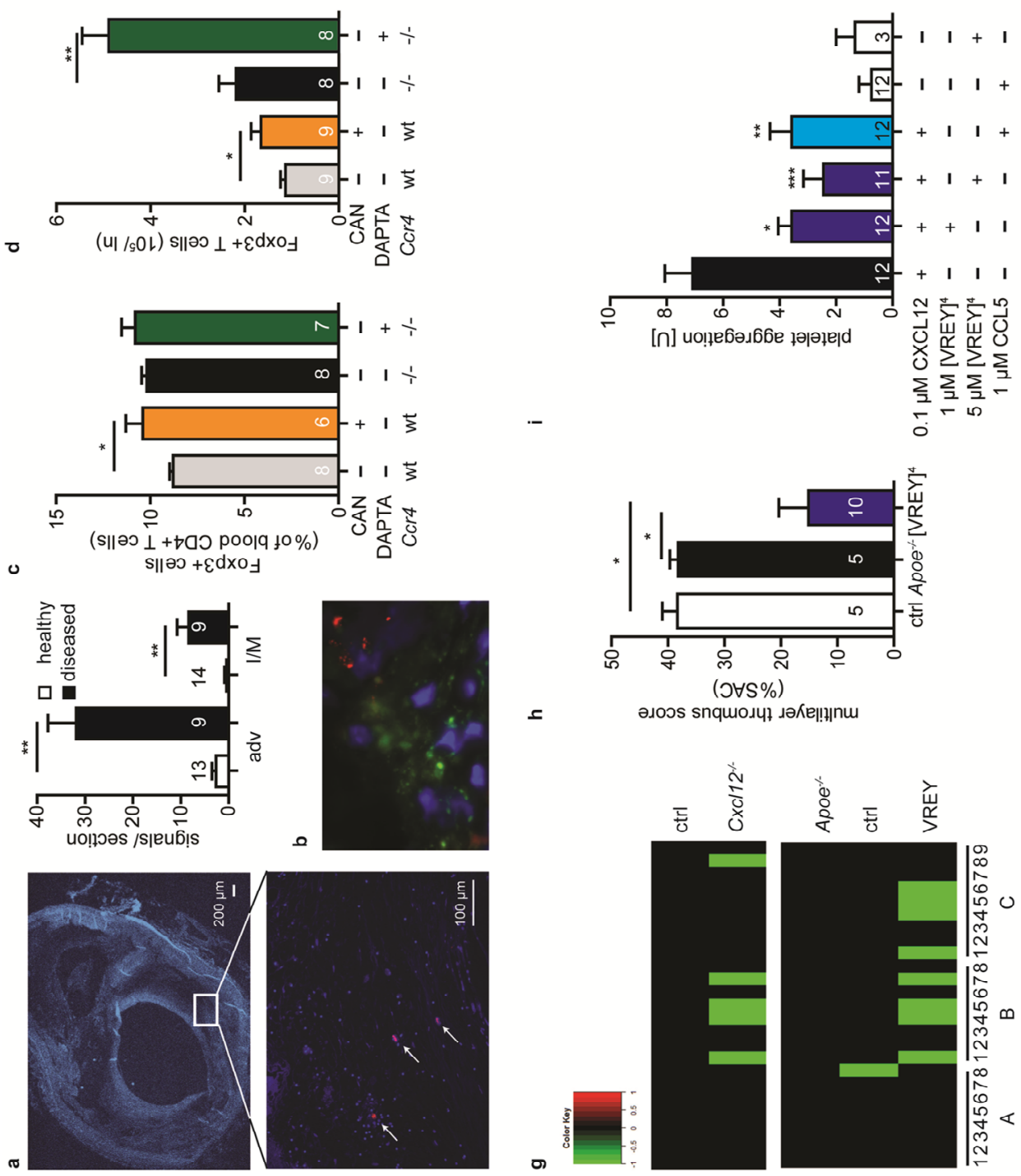
Figure 6: Specific peptides Inhibit atherogenic CCL5-CCL17 and CXCL12-driven platelet activity. $(a, b)$ Interactions of CCL5-CCL17 (red dots indicated by arrows in representative image, left) were detected in the adventitia (adv) and intima/media (I/M) of human coronary arteries with (diseased) or without (healthy) atherosclerotic lesions (a, quantification, right) or in aortic root sections from Apoe mice fed a high-fat diet (HFD) for 12 weeks (b) using a proximity-ligation assay (Duolink $\mathbb{\circledR}$ ). $(c, d)$ Wild-type or $\mathrm{CCl}^{-/-}$bone marrow chimeric Apoe mice were injected intraperitoneally (i.p.) with the CCR5 inhibitor DAPTA or CAN (each at $1 \mathrm{mg} / \mathrm{kg}$ 3-times a week) for 2 weeks and the number of Foxp $3^{+} \mathrm{CD} 4^{+}$Tregs in peripheral blood (C, relative to $\mathrm{CD} 4^{+} \mathrm{T}$ cells) and in para-aortic lymph nodes ( $d$, per lymph node/In) was determined by flow cytometry. (e,f) Apoe ${ }^{\prime}$ mice were injected (i.p.) with CAN (1 mg/kg 3-times per week) while on a HFD for 2 weeks. Oil-red-0-positive lesion areas in the aortic root were quantified and expressed as percentage of the total area (e). Representative images of aortic root stained with oil-red-O are shown (f). (g,h) Blood from Apoe ${ }^{\prime}$ mice treated with or without the CCL5-peptide [VREY] ${ }^{4}$ or from CreERT2CXCl12 $2^{\mathrm{fl} / \mathrm{fl}}$ Apoel following tamoxifen-induced deletion of CXCL12 was perfused over collagen for $4 \mathrm{~min}$ at $1000 \mathrm{~s}-1$. (g) Multi-parameter assessment of thrombus formation using distinct surfaces (a: vWF-BP+Laminin. b: vWF-BP+Laminin+Rhodocytin, c: collagen I) was performed and depicted in a heatmap (59). Parameters were assessed by bright-field and subsequent tri-color fluorescence microscopy: 1 Morphological score, 2 Platelet deposition (surface area coverage, SAC), 3 Thrombus contraction score, 4 Multilayer thrombus score, 5 Multilayered thrombus (\%SAC), 6/7 Phosphatidylserine exposure (\%SAC or platelet count/ field), $8 \mathrm{CD} 62 \mathrm{P}$ expression (\%SAC), 9 allb33 activation (\%SAC). Heatmaps for all microspots (normalized per parameter) and genotype/perturbation were colored as increased (red) or decreased (green) based on statistical significance versus controls. The multilayered thrombus score is exemplified in (h). (i) Platelet aggregation in human blood treated with combinations of CXCL12 (100 nM), [VREY] $]^{4}(500 \mathrm{nM})$ and CCL5 $(1 \mu \mathrm{M})$ was measured by impedance using a Multiplate ${ }^{\circledR}$ analyzer. (j) CAM P signaling was analyzed in Glosensor- and CXCR4-transfected HEK cells $15 \mathrm{~min}$ after stimulation with CXCL12 (40 nM) in the presence/absence of [VREY] ${ }^{4}(100$ $n M)$. Shown is the decrease of the specific Rluc signal over baseline. Data represent mean \pm SEM from the indicated number of independent experiments. ${ }^{*} p \varangle 0.05,{ }^{*} p<0.01$, as analyzed by Mann-Whitney-test $(b, c)$, unpaired t-test $(d, e, j)$ or Kruskal-Wallis-test $(h, i)$.

\section{Discussion}

The comprehensive map of all heteromeric chemokine interactions obtained by immuno-ligand blotting and SPR contributes to a completion of the binary human protein interactome network. $[29,30]$ We found that inflammatory and nonhomeostatic chemokines, e.g. platelet-derived atherogenic CCL5 and CXCL4, favor interactions, whereas homeostatic chemokines are generally less interactive. This may correspond to the need to amplify, fine-tune, and resolve chemokine activity at inflammatory sites through heteromeric interactions, whereas the stand-alone functions of non-interacting chemokines appear sufficient for organogenesis, immune architecture and surveillance, or anti-microbial activity. For example, CXCL4-deficient mice are normal in the absence of challenge (with a largely unaltered immunophenotype), whereas CXCL12 deficiency entails embryonic lethality and CXCL13 deficiency shows its essential role for lymph node development and natural immunity. [31, 32] 
Structure-function analysis revealed an interesting dichotomous pattern wherein CCtype hetero-dimers promote synergy and CXC-type heterodimers cause inhibition. Use of obligate heterodimers such as OPRAH provided conclusive proof that CC-type heterodimers mediate functional synergy. Functional inhibition with a CCL5-derived $\mathrm{N}$-terminal peptide supports a more general role of the $\mathrm{N}$-terminus in CC-type heterodimer formation and synergy. The spacing and shapes adopted by CC-type homodimers can vary with minimal changes in N-terminal sequence.[16] Functional synergy indeed involved flexible $\mathrm{N}$-termini, as illustrated by a tethered version of the obligate heterodimer OPRAH, and could be ascribed to addressing receptor heteromers (increasing potency of CCL5-CCL17) or to auxiliary GAG binding and impaired receptor internalization (increasing efficacy of CCL5-CXCL4).

Chemokine-receptor activation follows a two-site binding mechanism involving interactions of the chemokine N-loop/core with the receptor N-terminus (site I) and of the chemokine $\mathrm{N}$-terminus with extracellular/transmembrane residues (site II). The modeled structure for binding of the atypical CC chemokine VM IP-II to CXCR4 appears to support findings that CC chemokine homodimers cannot bind or activate receptors, as the dimerization interface largely coincides with an intermediate recognition site [33-35]; however, this may not extend to all chemokine-receptor interactions, as $\mathrm{N}$ terminal and core structures in a CC-type heterodimer, e.g. OPRAH, may be differently presented to receptors. Instead, binding may involve receptor complexes enabling synergy. Concomitant peptide-based disruption of CCL5-CCL17 and CCR4-CCR5 formation/function supported that CC-type heterodimers can prompt formation of corresponding receptor complexes, requiring CCR5 transmembrane regions.

The conserved GP motif in CXCL8 can couple sites I and II, dictating both substrates and cross-talk between sites to control receptor activity. [36] Conformational coupling was corroborated by a CC mutant of CXCL8 that retained binding via N-loop-site I interactions for CXCR1 activation. [37] M oreover, a disulfide-trapped CXCL8 dimer had reduced affinity for $\mathrm{CXCR1}$ due to perturbed binding at $\mathrm{N}$-loop residues, giving rise to a model where binding of a CXC-type dimer triggers conformational changes leading to release and high-affinity receptor binding of a monomer [38]. Whether this applies to CC-type heterodimers is unclear; however, findings with OPRAH indicate that dissociation is not essential for function. Conversely, some receptors, e.g. CXCR2, are permissive for dimer binding [39]. Macrophage migration-inhibitory factor (resembling a CXCL8 dimer) features site I and II-binding to CXCR2 without typical Ntermini. $[40,41]$ Thus, N-termini may not need to fit fully into the site II-pocket.

The increased efficacy of CCL5-bearing heterodimers may be explained by several aspects. CCR5 antagonists inhibited both CCL5-CXCL4- and CCL5-CCL17-induced arrest. Thus, CC-type heterodimers can modulate CCR5 functionality, converting it into an arrest receptor such as CCR1 (requiring CCL5 homo-oligomers and extracellular loop 3 
to sense heteromers). [42-44] As revealed by GAG binding-impaired CXCL4, synergy with CCL5 relies on increased cell surface presentation, impeding CCR1 internalization to sustain its signaling activity. The structural basis for CCL5 oligomerization and GAG binding has been elaborated. [45] Polymerization creates distinctive grooves that increase GAG avidity; besides the BBXB motif, CCL5 uses another positively charged motif, KKWVR, which supports CCR5 function. [42] M odels further predict that CXCL4 can assemble hetero-oligomers with CCL5 featuring an altered surface charge distribution that facilitates GAG binding. [45]

Regarding inhibitory effects of CXC-type heterodimers, it is remarkable that a constitutively homo-dimeric CXCL12 variant bridged by N-terminal CXCR4 peptides induces calcium signaling but inhibits chemotaxis, whereas a monomeric variant remains chemotactic, indicating that dimerization limits monomer-induced chemotaxis [46]. Related mechanisms may apply to CXC-type heterodimers, whereby functional activity is impeded by more stable $\beta$-sheet interactions attenuating monomer release. Alternatively, CXC-type heterodimeric interactions may cause conformational alterations, e.g. by aligning the $\alpha$-helices. [12] Consistent with spectral changes, the $\alpha$-helical peptide [VREY] ${ }^{4}$ inhibited CXCL12 function, mimicking effects of full-length CCL5.

Several lines of evidence support the functional relevance of heteromer formation in disease models. First, obligate CC-type heterodimers show high efficacy/potency in recruitment assays, e.g. OPRAH exacerbating LPS-induced ALI as well as chronic macrophage-rich atherosclerosis. Second, knocking-in of CXCL4L1 (not interacting with CCL5) was similarly effective in protecting from atherosclerosis as CXCL4 deficiency, indicating that heterodimer formation with CCL5 was essential for atherogenic activity. Finally, the inhibition of Treg-dependent atherosclerosis by CAN extends findings that CKEY limits atherosclerosis and ALI $[7,11]$ by interfering with residues crucial for heterodimerization.

Notably, structural information regarding the type of interaction and precise location of the interface can be exploited to design peptide inhibitors selectively blocking CCtype heterodimers (exemplified by CKEY targeting CCL5-CXCL4 and CAN targeting CCL5-CCL17). By contrast, [VREY] ${ }^{4}$ mimics inhibitory effects of CXC-type interactions between CCL5 and CXCL12 and could thereby serve to attenuate CXCL12-mediated platelet aggregation. These paradigms illustrate strategies for specific targeting of heterodimer-mediated functions in the chemokine interactome, and may allow for multivalent interference with a diversity of responses in a disease-related chemokine microenvironment. The TASP-scaffolding used for [VREY] $]^{4}$ may also be applicable to bundle different peptides in a poly-antagonistic approach. Alternatively, sequencehybridization could be used to generate mono-molecular poly-antagonists, as described for peptide tri-agonists. [47] Our data enable development of peptide 
therapeutics based on endogenous sequences that are selective in modulating heteromeric but not primary receptor interactions of chemokines and would thus lack many adverse effects associated with direct receptor-ligand antagonism. 


\section{References}

1. Zlotnik, A. and O. Yoshie, The chemokine superfamily revisited. Immunity, 2012. 36(5): 705-716.

2. Bachelerie, F., A. Ben-Baruch, A.M. Burkhardt, C. Combadiere, J.M. Farber, G.J. Graham, R. Horuk, A.H. Sparre-Ulrich, M. Locati, A.D. Luster, A. Mantovani, K. Matsushima, P.M. Murphy, R. Nibbs, H. Nomiyama, C.A. Power, A.E. Proudfoot, M.M. Rosenkilde, A. Rot, S. Sozzani, M. Thelen, O. Yoshie, and A. Zotnik, International Union of Basic and Clinical Pharmacology. [corrected]. LXXXIX. Update on the extended family of chemokine receptors and introducing a new nomenclature for atypical chemokine receptors. Pharmacol Rev, 2014. 66(1): 1-79.

3. Weber, C. and H. Noels, Atherosclerosis: current pathogenesis and therapeutic options. Nat Med, 2011. 17(11): 1410-1422.

4. Koenen, R.R. and C. Weber, Therapeutic targeting of chemokine interactions in atherosclerosis. Nat Rev Drug Discov, 2010. 9(2): 141-153.

5. Fernandez, E.J. and E. Lolis, Structure, function, and inhibition of chemokines. Annual review of pharmacology and toxicology, 2002. 42: 469-499.

6. Crown, S.E., Y. Yu, M.D. Sweeney, J.A. Leary, and T.M. Handel, Heterodimerization of CCR2 chemokines and regulation by glycosaminoglycan binding. J Biol Chem, 2006. 281(35): 25438-25446.

7. Koenen, R.R., P. von Hundelshausen, I.V. Nesmelova, A. Zernecke, E.A. Liehn, A. Sarabi, B.K. Kramp, A.M. Piccinini, S.R. Paludan, M.A. Kowalska, A.J. Kungl, T.M. Hackeng, K.H. $M$ ayo, and $C$. Weber, Disrupting functional interactions between platelet chemokines inhibits atherosclerosis in hyperlipidemic mice. Nat M ed, 2009. 15(1): 97-103.

8. Nesmelova, I.V., Y. Sham, J. Gao, and K.H. M ayo, CXC and CC chemokines form mixed heterodimers: association free energies from molecular dynamics simulations and experimental correlations. J Biol Chem, 2008. 283(35): 24155-24166.

9. Dudek, A.Z, I. Nesmelova, K. Mayo, C.M. Verfaillie, S. Pitchford, and A. Slungaard, Platelet factor 4 promotes adhesion of hematopoietic progenitor cells and binds IL-8: novel mechanisms for modulation of hematopoiesis. Blood, 2003. 101(12): 4687-4694.

10. Nesmelova, I.V., Y. Sham, A.Z Dudek, L.I. van Eijk, G. Wu, A. Slungaard, F. Mortari, A.W. Griffioen, and K.H. Mayo, Platelet factor 4 and interleukin-8 CXC chemokine heterodimer formation modulates function at the quaternary structural level. J Biol Chem, 2005. 280(6): 4948-4958.

11. Grommes, J., J.E. Alard, M. Drechsler, S. Wantha, M. Morgelin, W.M. Kuebler, M. Jacobs, P. von Hundelshausen, P. M arkart, M. Wygrecka, K.T. Preissner, T.M. Hackeng, R.R. Koenen, C. Weber, and O. Soehnlein, Disruption of platelet-derived chemokine heteromers prevents neutrophil extravasation in acute lung injury. Am J Respir Crit Care M ed, 2012. 185(6): 628-636.

12. Carlson, J., S.A. Baxter, D. Dreau, and I.V. Nesmelova, The heterodimerization of platelet-derived chemokines. Biochimica et biophysica acta, 2013. 1834(1): 158-168.

13. Sebastiani, S., G. Danelon, B. Gerber, and M. Uguccioni, CCL22-induced responses are powerfully enhanced by synergy inducing chemokines via CCR4: evidence for the involvement of first beta-strand of chemokine. Eur J Immunol, 2005. 35(3): 746-756.

14. Kuscher, K., G. Danelon, S. Paoletti, L. Stefano, M. Schiraldi, V. Petkovic, M. Locati, B.O. Gerber, and M. Uguccioni, Synergy-inducing chemokines enhance CCR2 ligand activities on monocytes. Eur J Immunol, 2009. 39(4): 1118-1128.

15. Ren, M., Q. Guo, L. Guo, M. Lenz, F. Qian, R.R. Koenen, H. Xu, A.B. Schilling, C. Weber, R.D. Ye, A.R. Dinner, and W.J. Tang, Polymerization of MIP-1 chemokine (CCL3 and CCL4) and clearance of MIP-1 by insulin-degrading enzyme. Embo J, 2010. 29(23): 3952-3966. 
16. Liang, W.G., M. Ren, F. Zhao, and W.J. Tang, Structures of human CCL18, CCL3, and CCL4 reveal molecular determinants for quaternary structures and sensitivity to insulin-degrading enzyme. Journal of molecular biology, 2015. 427(6 Pt B): 1345-1358.

17. Zernecke, A. and C. Weber, Chemokines in atherosclerosis: proceedings resumed. Arterioscler Thromb Vasc Biol, 2014. 34(4): 742-750.

18. Kuo, J.H., Y.P. Chen, J.S. Liu, A. Dubrac, C. Quemener, H. Prats, A. Bikfalvi, W.G. Wu, and S.C. Sue, Alternative C-terminal helix orientation alters chemokine function: structure of the anti-angiogenic chemokine, CXCL4L1. J Biol Chem, 2013. 288(19): 13522-13533.

19. Mayo, K.H., E. Ilyina, V. Roongta, M. Dundas, J. Joseph, C.K. Lai, T. Maione, and T.J. Daly, Heparin binding to platelet factor-4. An NMR and site-directed mutagenesis study: arginine residues are crucial for binding. Biochem J, 1995. 312 ( Pt 2): 357-365.

20. Czaplewski, L.G., J. McKeating, C.J. Craven, L.D. Higgins, V. Appay, A. Brown, T. Dudgeon, L.A. Howard, T. M eyers, J. Owen, S.R. Palan, P. Tan, G. Wilson, N.R. Woods, C.M. Heyworth, B.I. Lord, D. Brotherton, R. Christison, S. Craig, S. Cribbes, R.M. Edwards, S.J. Evans, R. Gilbert, P. Morgan, E. Randle, N. Schofield, P.G. Varley, J. Fisher, J.P. Waltho, and M.G. Hunter, Identification of amino acid residues critical for aggregation of human CC chemokines macrophage inflammatory protein (MIP)1alpha, MIP-1beta, and RANTES. Characterization of active disaggregated chemokine variants. J Biol Chem, 1999. 274(23): 16077-16084.

21. Handel, T.M. and P.J. Domaille, Heteronuclear (1H, 13C, 15N) NMR assignments and solution structure of the monocyte chemoattractant protein-1 (MCP-1) dimer. Biochemistry, 1996. 35(21): 6569-6584.

22. Mayo, K.H. and M.J. Chen, Human platelet factor 4 monomer-dimer-tetramer equilibria investigated by 1 H NMR spectroscopy. Biochemistry, 1989. 28(24): 94699478.

23. Luster, A.D., S.M. Greenberg, and P. Leder, The IP-10 chemokine binds to a specific cell surface heparan sulfate site shared with platelet factor 4 and inhibits endothelial cell proliferation. J Exp Med, 1995. 182(1): 219-231.

24. Dawson, P.E. and S.B.H. Kent, Convenient total synthesis of a 4-helix templateassembled synthetic protein (TASP) molecule by chemoselective ligation. Journal of the American Chemical Society, 1993. 115(16): 7263-7266.

25. Soderberg, O., M. Gullberg, M. Jarvius, K. Ridderstrale, K.J. Leuchowius, J. Jarvius, K. Wester, P. Hydbring, F. Bahram, L.G. Larsson, and U. Landegren, Direct observation of individual endogenous protein complexes in situ by proximity ligation. Nat Methods, 2006. 3(12): 995-1000.

26. Hernanz-Falcon, P., J.M. Rodriguez-Frade, A. Serrano, D. Juan, A. del Sol, S.F. Soriano, F. Roncal, L. Gomez, A. Valencia, A.C. Martinez, and M. Mellado, Identification of amino acid residues crucial for chemokine receptor dimerization. Nat Immunol, 2004. 5(2): 216-223.

27. Weber, C., S. Meiler, Y. Doring, M. Koch, M. Drechsler, R.T. Megens, Z Rowinska, K. Bidzhekov, C. Fecher, E. Ribechini, M.A. van Zandvoort, C.J. Binder, I. Jelinek, M. Hristov, L. Boon, S. Jung, T. Korn, M.B. Lutz, I. Forster, M. Zenke, T. Hieronymus, T. Junt, and A. Zernecke, CCL17-expressing dendritic cells drive atherosclerosis by restraining regulatory T cell homeostasis in mice. J Clin Invest, 2011. 121(7): 28982910.

28. Ketelhuth, D.F. and G.K. Hansson, Adaptive Response of $T$ and B Cells in Atherosclerosis. Circ Res, 2016. 118(4): 668-678.

29. Vidal, M., How much of the human protein interactome remains to be mapped? Sci Signal, 2016. 9(427): eg7. 
30. Rolland, T., M. Tasan, B. Charloteaux, S.J. Pevzner, Q. Zhong, N. Sahni, S. Yi, I. Lemmens, C. Fontanillo, R. M osca, A. Kamburov, S.D. Ghiassian, X. Yang, L. Ghamsari, D. Balcha, B.E. Begg, P. Braun, M. Brehme, M.P. Broly, A.R. Carvunis, D. ConveryZupan, R. Corominas, J. Coulombe-Huntington, E. Dann, M. Dreze, A. Dricot, C. Fan, E. Franzosa, F. Gebreab, B.J. Gutierrez, M.F. Hardy, M. Jin, S. Kang, R. Kiros, G.N. Lin, K. Luck, A. MacWilliams, J. Menche, R.R. Murray, A. Palagi, M.M. Poulin, X. Rambout, J. Rasla, P. Reichert, V. Romero, E. Ruyssinck, J.M. Sahalie, A. Scholz, A.A. Shah, A. Sharma, Y. Shen, K. Spirohn, S. Tam, A.O. Tejeda, S.A. Trigg, J.C. Twizere, K. Vega, J. Walsh, M.E. Cusick, Y. Xia, A.L. Barabasi, L.M. lakoucheva, P. Aloy, J. De Las Rivas, J. Tavernier, M.A. Calderwood, D.E. Hill, T. Hao, F.P. Roth, and M. Vidal, A proteomescale map of the human interactome network. Cell, 2014. 159(5): 1212-1226.

31. Ansel, K.M., V.N. Ngo, P.L. Hyman, S.A. Luther, R. Forster, J.D. Sedgwick, J.L. Browning, M. Lipp, and J.G. Cyster, A chemokine-driven positive feedback loop organizes lymphoid follicles. Nature, 2000. 406(6793): 309-314.

32. Ansel, K.M., R.B.S. Harris, and J.G. Cyster, CXCL13 Is Required for B1 Cell Homing, Natural Antibody Production, and Body Cavity Immunity. Immunity, 2002. 16(1): 6776.

33. Qin, L., I. Kufareva, L.G. Holden, C. Wang, Y. Zheng, C. Zhao, G. Fenalti, H. Wu, G.W. Han, V. Cherezov, R. Abagyan, R.C. Stevens, and T.M. Handel, Structural biology. Crystal structure of the chemokine receptor CXCR4 in complex with a viral chemokine. Science, 2015. 347(6226): 1117-1122.

34. Drury, L.J., J.J. Ziarek, S. Gravel, C.T. Veldkamp, T. Takekoshi, S.T. Hwang, N. Heveker, B.F. Volkman, and M.B. Dwinell, Monomeric and dimeric CXCL12 inhibit metastasis through distinct CXCR4 interactions and signaling pathways. Proc Natl Acad Sci U SA, 2011. 108(43): 17655-17660.

35. Jin, H., X. Shen, B.R. Baggett, X. Kong, and P.J. LiWang, The human CC chemokine MIPlbeta dimer is not competent to bind to the CCR5 receptor. J Biol Chem, 2007. 282(38): 27976-27983.

36. Joseph, P.R., K.V. Sawant, A. Isley, M. Pedroza, R.P. Garofalo, R.M. Richardson, and K. Rajarathnam, Dynamic conformational switching in the chemokine ligand is essential for G-protein-coupled receptor activation. Biochem J, 2013. 456(2): 241-251.

37. Rajarathnam, K., G.N. Prado, H. Fernando, I. Clark-Lewis, and J. Navarro, Probing receptor binding activity of interleukin-8 dimer using a disulfide trap. Biochemistry, 2006. 45(25): 7882-7888.

38. Ravindran, A., P.R. Joseph, and K. Rajarathnam, Structural basis for differential binding of the interleukin-8 monomer and dimer to the CXCR1 N-domain: role of coupled interactions and dynamics. Biochemistry, 2009. 48(37): 8795-8805.

39. Ravindran, A., K.V. Sawant, J. Sarmiento, J. Navarro, and K. Rajarathnam, Chemokine CXCL1 dimer is a potent agonist for the CXCR2 receptor. J Biol Chem, 2013. 288(17): 12244-12252.

40. Kraemer, S., H. Lue, A. Zernecke, A. Kapurniotu, E. Andreetto, R. Frank, B. Lennartz, C. Weber, and J. Bernhagen, MIF-chemokine receptor interactions in atherogenesis are dependent on an N-loop-based 2-site binding mechanism. Faseb J, 2011. 25(3): 894906.

41. Xu, L, Y. Li, D. Li, P. Xu, S. Tian, H. Sun, H. Liu, and T. Hou, Exploring the binding mechanisms of MIF to CXCR2 using theoretical approaches. Physical chemistry chemical physics : PCCP, 2015. 17(5): 3370-3382.

42. Kramp, B.K., R.T. Megens, A. Sarabi, S. Winkler, D. Projahn, C. Weber, R.R. Koenen, and P. von Hundelshausen, Exchange of extracellular domains of CCR1 and CCR5 reveals confined functions in CCL5-mediated cell recruitment. Thromb Haemost, 2013. 110(4): 795-806. 
43. Weber, C., K.S. Weber, C. Klier, S. Gu, R. Wank, R. Horuk, and P.J. Nelson, Specialized roles of the chemokine receptors CCR1 and CCR5 in the recruitment of monocytes and $\mathrm{T}(\mathrm{H}) 1-$ like/CD45RO(+) T cells. Blood, 2001. 97(4): 1144-1146.

44. Baltus, T., K.S. Weber, Z. Johnson, A.E. Proudfoot, and C. Weber, Oligomerization of RANTES is required for CCR1-mediated arrest but not CCR5-mediated transmigration of leukocytes on inflamed endothelium. Blood, 2003. 102(6): 1985-1988.

45. Liang, W.G., C.G. Triandafillou, T.Y. Huang, M.M. Zulueta, S. Banerjee, A.R. Dinner, S.C. Hung, and W.J. Tang, Structural basis for oligomerization and glycosaminoglycan binding of CCL5 and CCL3. Proc Natl Acad Sci U SA, 2016. 113(18): 5000-5005.

46. Veldkamp, C.T., C. Seibert, F.C. Peterson, N.B. De la Cruz, J.C. Haugner, 3rd, H. Basnet, T.P. Sakmar, and B.F. Volkman, Structural basis of CXCR4 sulfotyrosine recognition by the chemokine SDF-1/CXCL12. Sci Signal, 2008. 1(37): ra4.

47. Finan, B., B. Yang, N. Ottaway, D.L. Smiley, T. Ma, C. Clemmensen, J. Chabenne, L. Zhang, K.M. Habegger, K. Fischer, J.E. Campbell, D. Sandoval, R.J. Seeley, K. Bleicher, S. Uhles, W. Riboulet, J. Funk, C. Hertel, S. Belli, E. Sebokova, K. Conde-Knape, A. Konkar, D.J. Drucker, V. Gelfanov, P.T. Pfluger, T.D. Muller, D. Perez-Tilve, R.D. DiM archi, and M.H. Tschop, A rationally designed monomeric peptide triagonist corrects obesity and diabetes in rodents. Nat M ed, 2015. 21(1): 27-36.

48. von Hundelshausen, P., R.R. Koenen, M. Sack, S.F. M ause, W. Adriaens, A.E. Proudfoot, T.M. Hackeng, and C. Weber, Heterophilic interactions of platelet factor 4 and RANTES promote monocyte arrest on endothelium. Blood, 2005. 105(3): 924-930.

49. Feierler, J., M. Wirth, B. Welte, S. Schussler, M. Jochum, and A. Faussner, Helix 8 plays a crucial role in bradykinin $B(2)$ receptor trafficking and signaling. J Biol Chem, 2011. 286(50): 43282-43293.

50. Proudfoot, A.E. and F. Borlat, Purification of recombinant chemokines from E. coli. Methods in molecular biology, 2000. 138: 75-87.

51. Proudfoot, A.E., T.M. Handel, Z. Johnson, E.K. Lau, P. LiWang, I. Clark-Lewis, F. Borlat, T.N. Wells, and M.H. Kosco-Vilbois, Glycosaminoglycan binding and oligomerization are essential for the in vivo activity of certain chemokines. Proc Natl Acad Sci U SA, 2003. 100(4): 1885-1890.

52. Hackeng, T.M., J.H. Griffin, and P.E. Dawson, Protein synthesis by native chemical ligation: expanded scope by using straightforward methodology. Proc Natl Acad Sci U SA, 1999. 96(18): 10068-10073.

53. Dawson, P.E., T.W. Muir, I. Clark-Lewis, and S.B. Kent, Synthesis of proteins by native chemical ligation. Science, 1994. 266(5186): 776-779.

54. Agten, S.M., D. Suylen, H. Ippel, M. Kokozidou, G. Tans, P. van de Vijver, R.R. Koenen, and T.M. Hackeng, Chemoselective oxime reactions in proteins and peptides by using an optimized oxime strategy: the demise of levulinic acid. Chembiochem : a European journal of chemical biology, 2013. 14(18): 2431-2434.

55. Alard, J.E., A. Ortega-Gomez, K. Wichapong, D. Bongiovanni, M. Horckmans, R.T. M egens, G. Leoni, B. Ferraro, J. Rossaint, N. Paulin, J. Ng, H. Ippel, D. Suylen, R. Hinkel, X. Blanchet, F. Gaillard, M. D'Amico, P. von Hundelshausen, A. Zarbock, C. Scheiermann, T.M. Hackeng, S. Steffens, C. Kupatt, G.A. Nicolaes, C. Weber, and O. Soehnlein, Recruitment of classical monocytes can be inhibited by disturbing heteromers of neutrophil HNP1 and platelet CCL5. Sci Transl Med, 2015. 7(317): 317 ra196.

56. Wichapong, K., J.E. Alard, A. Ortega-Gomez, C. Weber, T.M. Hackeng, O. Soehnlein, and G.A. Nicolaes, Structure-Based Design of Peptidic Inhibitors of the Interaction between CC Chemokine Ligand 5 (CCL5) and Human Neutrophil Peptides 1 (HNP1). Journal of medicinal chemistry, 2016. 59(9): 4289-4301. 
57. Virmani, R., F.D. Kolodgie, A.P. Burke, A. Farb, and S.M. Schwartz, Lessons from sudden coronary death: a comprehensive morphological classification scheme for atherosclerotic lesions. Arterioscler Thromb Vasc Biol, 2000. 20(5): 1262-1275.

58. Van Kruchten, R., J.M. Cosemans, and J.W. Heemskerk, Measurement of whole blood thrombus formation using parallel-plate flow chambers - a practical guide. Platelets, 2012. 23(3): 229-242.

59. de Witt, S.M., F. Swieringa, R. Cavill, M.M. Lamers, R. van Kruchten, T. Mastenbroek, C. Baaten, S. Coort, N. Pugh, A. Schulz, I. Scharrer, K. Jurk, B. Zieger, K.J. Clemetson, R.W. Farndale, J.W. Heemskerk, and J.M. Cosemans, Identification of platelet function defects by multi-parameter assessment of thrombus formation. Nature communications, 2014. 5: 4257. 


\section{Supporting Information}

Ligand blots

Chemokines $(1 \mu \mathrm{g})$ were spotted on a nitrocellulose membrane which was immersed overnight with the soluble chemokine $(1-5 \mu \mathrm{g} / \mathrm{ml})$ and reacted with biotinylated antibodies and streptavidin-conjugated HRP and ECL substrate (Thermo Fisher Scientific) essentially as described [48]. The chemiluminescence signal was digitally recorded and analyzed by the luminescence image analyzer LAS 3000 and M ultigauge software (Fuji Photo Film, Düsseldorf, Germany).

Surface plasmon resonance (SPR)

SPR was performed on a BIAcore X100 instrument (GE Healthcare Europe GmbH, Freiburg, Germany) using neutravidin-modified $\mathrm{Cl}$ sensor chips [48]. Biotinylated chemokines were immobilized on flow cells to $0.3-1.3 \times 10^{3}$ response units (RU). Screening of chemokine binding was performed at $100 \mathrm{nM}$ in HBS-EP+ buffer at 30 $\mu \mathrm{l} / \mathrm{min}$ after $20 \mathrm{~s}$. Apparent affinities were calculated from on and off rates after fitting of the curves obtained from increasing analyte concentrations using a 1:1 Langmuir interaction model (BIAevaluation software, GE Healthcare). To assess the inhibitory capacity of peptides, chemokines were incubated with increasing peptide concentrations and binding of chemokine ( $20 \mathrm{nM})$ was recorded and calculated as percentage inhibition. Half maximal inhibitory concentrations (IC50) were determined using a 4-parameter logistic nonlinear regression (GraphPad V5.0).

Nuclear magnetic resonance (NM R) spectroscopy

NM R samples were prepared in Wilmad $3 \mathrm{~mm}$ NMR tubes (160 $\mu$ l). M ost experimental details and solutions conditions of samples are described in the figure legends. Typically, chemokine samples were buffer exchanged and concentrated into $25 \mathrm{mM}$ $\mathrm{Na}$-acetate- $\mathrm{d}_{3}(\mathrm{pH} 4.5)$ containing $0.1 \mathrm{mM}$ EDTA and $0.2 \mathrm{mM}$ sodium azide, through 4 to 5 ultracentrifugation steps over Amicon (Merck Millipore, Darmstadt, Germany) Ultra-4 $3 \mathrm{kDa}$ filter devices. Concentration of the final derived stock solutions of chemokines was determined based on UV absorbance measured on a NanoDrop 2000 spectrophotometer (Thermo Scientific, Wilmington, USA). NM R samples of mixtures of chemokines at defined molar ratios were prepared from these chemokine stock solutions. $5 \%(\mathrm{v} / \mathrm{v}) \mathrm{D}_{2} \mathrm{O}$ was later added to NMR samples for field locking, together with a trace of DSS (4,4-dimethyl-4-silapentane-1-sulfonic acid) as internal chemical shift standard. NMR spectra $\left({ }^{15} \mathrm{~N}-{ }^{1} \mathrm{H}\right.$ HSQC with flip-back pulse, DIPSI, and NOESY) were recorded at $37^{\circ} \mathrm{C}$ on Bruker (Rheinstetten, Germany) Avance III HD 700 and Avance III $850 \mathrm{MHz}$ spectrometers, both equipped with a cryogenically cooled TCI probe. Spectra were processed and analyzed using Bruker Topspin 3.2 and Sparky 
3.114 software (T.D. Goddard and D.G. Kneller, SPARKY 3, University of California, San Francisco).

Resonance assignments of the CCL5 $5^{\mathrm{E} 66 \mathrm{~S}}$ and $\mathrm{CXCL12}$ chemokines were carried out by 2D NOESY and 3D-edited NOESY spectra. Because CCL5 ${ }^{\mathrm{E} 66 \mathrm{~S}}$ show homo-dimers and monomers that are in slow exchange on the NMR chemical shift time scale, resonances for both dimers and monomers are observed in HSQC spectra and are well resolved, allowing assessment of effects on both states [21]. Chemical shift differences $(\delta \Delta)$ induced upon binding were calculated as $\left[\left(\Delta^{1} H\right)^{2}\right]^{1 / 2}+\left[\left(0.25 \Delta^{15} \mathrm{~N}\right)^{2}\right]^{1 / 2}$. (in ${ }^{1} \mathrm{H}$ ppm. $\Delta$ Intensity was calculated as $\left(1-\operatorname{Int}_{\mathrm{i}} / \operatorname{Int}_{0}\right)$, where $\operatorname{Int}_{\mathrm{i}}$ is the resonance intensity of CCL5 ${ }^{\mathrm{E} 66 \mathrm{~S}}$ or CXCL12 resonances in the presence of the other chemokine, and $\mathrm{Int}_{0}$ is the intensity of $\mathrm{CCL}^{\mathrm{E} 66 \mathrm{~S}}$ or CXCL12 resonances in the absence of the other chemokine.

Cells and cell culture

Human CD4 T cells were isolated from whole blood of healthy volunteers after separating peripheral blood mononuclear cells (PBM Cs) with Biocoll (Biochrom, Merck Millipore, Berlin, Germany) using Dynabeads Untouched Human CD4 T Cells kit, stimulated with Dynabeads Human T-Activator CD3/CD28 (both Thermo Fisher Scientific, Waltham, USA) for 3 days and expanded in the presence of Dynabeads with hIL-2 $(30 \mathrm{U} / \mathrm{mL}$ ) for another 3 days. Human monocytes were isolated from PBM Cs, and purified by negative selection using "Monocyte Isolation Kit II" (Miltenyi Biotec, Bergisch Gladbach, Germany). M ouse CD4 T cells were isolated from spleens of mice with indicated genotypes using Dynabeads Untouched mouse CD4 Cells Kit and activated using Dynabeads M ouse T-Activator, Thermo Fisher Scientific), as above for human cells. Mouse dendritic cells were isolated from spleens by positive and negative selection using magnetic beads (Pan DC M icroBeads, mouse, Miltenyi Biotec). Human aortic endothelial cells (HAoEC) were from PromoCell (Heidelberg, Germany). Oligonucleotides were synthesized at M WG-Biotech (Ebersberg, Germany).

The Flp-In system and Flp-In ${ }^{\text {TM }}$ TREX-293 (HEK293) cells were from Invitrogen (Karlsruhe, Germany). Plasmids harboring sequences for CCR1, CCR4, CCR5 and CXCR4 were from Missouri S\&T cDNA Resource Center (www.cdna.org). The pGloSensor ${ }^{\text {TM }}$ 20F-vector and luciferin-EF were from Promega (M annheim, Germany). The sequence of the luciferase-CAMP binding site fusion protein from the pGloSensor ${ }^{\mathrm{TM}}$-20F-vector was amplified and ligated into a bicistronic pIRESneo vector (Clontech) to obtain the reporter gene plasmid. The pcDNA5/FRT/TO vector (Invitrogen) was used to express receptor constructs carrying an $\mathrm{N}$-terminal hemagglutinin-tag or enhanced yellow fluorescent protein (eYFP)[49]. HEK293 cells were transfected with the reporter gene vector using EcoTransfect (OZBioscience Marseille, France), stable clones were 
selected as host cell lines for expressing receptor constructs using the Flp-In system [49], and re-selected with G418 and hygromycin B.

Chemokines and peptides

CCL5 and CXCL12 were recombinantly expressed using codon-optimized genes (Genscript, NJ, USA), and pET-24a(t) or $-32 \mathrm{a}(+)$ vectors, respectively, in E.coli BL21(DE3) cells and purified, essentially as described [50]. To generate ${ }^{15} \mathrm{~N}$-labeled chemokines, we used Spectra M 9 medium (Cambridge Isotope Laboratories, Andover, USA). Mass and disulfide bond integrity were examined by UPLC-QTOF mass spectroscopy. Biotinylation of chemokines was performed while bound to heparin columns. Purified CCL5 ${ }^{\mathrm{E} 26 \mathrm{~A}}$ and the synthesized $\mathrm{CCL}^{\mathrm{MT7}}$ variant were kindly provided by Dr. A. Proudfoot [51]. Other chemokines were purchased from Peprotech (Rocky Hill, USA) or R\&D Systems (Minneapolis, USA). CCL5 and CCL17 C-terminallyconjugated with AF647 were from ALM AC science (Craigavon, UK).

The peptides CAN and CKEY were synthetized by Bachem AG (Bubendorf, Switzerland). All other peptides (Table S4) were synthesized manually by SPPS on PAM resin or thioester (COSR) generating resin using in situ neutralization/HCTU activation for tBoc chemistry [52]. Semi-preparative HPLC was performed using Vydac C18 or C4 HPLC columns using a Waters Deltaprep system. Peptide analysis was performed on a Waters UPLC XEVO-G2QTOF system. The peptide monomer VREY was extended at the $\mathrm{N}$-terminus by introducing a glycine spacer to which (Boc-aminooxy) acetic acid (AO) was coupled (AO-G-EKKWVREYINSLEM S-COOH). A modified cyclic backbone TASP template was used to obtain a parallel 4-helix bundle ( $\mathrm{H}_{2} \mathrm{~N}$-CPKGKGPGKGKG-COSR) [24]. TASP-lysines were modified to present a ketone group using 4-acetylbutyric acid [52]. TASP was cyclized by native chemical ligation (NCL) [24] and the free cysteine was alkylated to prevent dimer formation. Ketone-derivatized TASP and a 2.5-fold excess of aminooxy-VREY were reacted to obtain [VREY] ${ }^{4}$ through oxime linkage.

The total chemical synthesis of OPRAH (obligate PF4-RANTES heterodimer), nOPRAH (n-terminally tethered OPRAH), mOPRAH (mouseOPRAH using the murine orthologs) and ORATH (obligate RANTES-TARC heterodimer) comprised the individual synthesis of CCL5, CXCL4 or CCL17, which were subsequently folded and coupled by oxime chemistry. The individual chemokines were synthesized in three parts that were joined by NCL and folded by oxidation [53]. CCL5 N-termini were modified to introduce aminooxy moieties for oxime ligation. For both human and mouse $\mathrm{CCL}^{1-10}$, Lys( $\varepsilon$-amino-Alloc) was introduced at position $\mathrm{T7}$ to allow for on-resin aminooxy modification. As counterparts in the oxime ligation reactions, ketones (4-acetylbutyric acid) were added in the chemokine $\mathrm{N}$-termini by introducing Lys( $\varepsilon$-amino-Alloc) at position L8 of human CXCL4, at position L13 of mouse CXCL4, and at position G7 of human CCL17 [54]. The folded N-terminally ketone-derivatized chemokines were 
reacted with a 2-fold excess of aminooxy-CCL5. The mixture was placed at $-20^{\circ} \mathrm{C}$ for 1 $\mathrm{h}$ to complete the reaction. The covalent heterodimer product was purified using HPLC. Detailed information about the synthesis of the heterodimers will be published elsewhere (Agten et al., manuscript in preparation).

M olecular dynamics (MD) simulation and binding free energy calculations

Chemokine structures were downloaded from the Protein Data Bank (PDB): codes 1DOK (CCL2), 2L9H (CCL5), 1NR4 (CCL17), 1F9Q (CXCL4), 4UAI (CXCL12). Dimer complexes (CC or CXC type) were manually assembled by superimposition onto the CC-conformation of CCL5 or the CXC-conformation of CXCL4. The different chemokine complexes were subjected to MD simulations as described [55, 56], except applying Amber12SB force field and TIP4P-Ew water model. Free MD simulations were performed for 100 ns and accelerated molecular dynamics were employed for another $30 \mathrm{~ns}$. Snapshots between 100-130 ns were extracted for binding free energy calculation using molecular mechanics/generalized Born surface area (MM/GBSA) approach and the binding free energies were approximated from enthalpy values as described [56]. Default parameters were applied for binding free energy calculation, except using generalized Born model 8 to compute the free energy of solvation.

Transmigration assays

Transmigration assays were performed using Transwell-96 Permeable Support (Corning) with a $5.0 \mu \mathrm{m}$ (human T cells) and $3.0 \mu \mathrm{m}$ (mouse T cells) pore size [43]. Chemokines were added to the bottom chamber and $10^{5}$ activated $T$ cells were allowed to migrate for $2 \mathrm{~h}$ from the top chamber. Receptor antagonists were added to the upper chamber, while compounds modulating chemokine interactions were added to the bottom chamber at 10x molar excess relative to chemokine. The number of cells migrated was analyzed by flow cytometry (FACSCanto II, BD Biosciences, Heidelberg, Germany) and FlowJo v.10 software (Tree Star Inc., Ashland, Orgon, USA). The chemotactic index was calculated as the ratio of chemokine-stimulated to unstimulated migration.

Arrest assays

Confluent human aortic endothelial cell (HAoEC) monolayers were activated with IL$1 \beta$ for $4 \mathrm{~h}$ before incubation with chemokines, synthetic obligate chemokine heterodimers and/or peptides for $30 \mathrm{~min}$. Monocytes or T cells $\left(0.7 \times 10^{6} / \mathrm{ml}\right)$ pretreated with receptor antagonists (C021, DAPTA, M et-RANTES) were perfused over the activated HAoECs in a laminar flow chamber at a shear stress of $1.5 \mathrm{dyn} / \mathrm{cm}^{2}$ for 2 min. Cells were visualized and recorded by video microscopy (Olympus IX 50, Shinjuku, Japan, 20x objective). Firmly adherent leukocytes were counted in 10 high-power fields (HPF) per plate. 


\section{Proximity Ligation Assay}

Proximity ligation was carried out using the Duolink In Situ Red Kit Goat/Rabbit on PFA fixated cryo-sections of aortic roots or lymph nodes of Apoe ${ }^{-/}$mice, using primary polyclonal antibodies to mouse CCL17 (R\&D, AF529), mouse CCL5 (Acris, AP20618PUN) according to the manufacturer's instructions. Mouse dendritic cells and SV40transformed endothelial cells (SVECS) cultured on collagen-coated cover slips were pre-incubated with mouse CCL5, CXCL4 and CCL17 (Biolegend, Fell, Germany) alone or incombination with CAN or CCR5-derived transmembrane peptides TM 1 and TM 4 known to inhibit CCR5 dimerization[26]. The same kit was used on paraffin sections of human coronary arteries using polyclonal antibodies to human CCL5 (AF278-NA, R\&D Systems) and CCL17 (ab182793, Abcam, Cambridge, UK). The study was under approval by the Ethics Committee of the Academic M edical Centre at the University of Amsterdam. Anonymous post-mortem coronary artery specimen did not require informed consent.

Flow cytometry

Whole blood obtained from the retro-orbital plexus of mice was EDTA-buffered and subjected to red blood-cell lysis. Lymph nodes and spleens were mechanically disrupted and passed through a cell strainer. Leukocytes were counted and analyzed by the following antibody cocktail: anti-CD45, anti-CD115, anti-Gr1, anti-CD11b, antiCD19 (eBioscience, clone MB19-1) and anti-CD3 (eBioscience, clone 145-2C11). Leukocyte subsets were defined using Flow)o software: neutrophils (CD45 ${ }^{+} \mathrm{CD} 115$ Gr $\left.1^{\text {high }}\right)$, monocytes $\left(\mathrm{CD} 45^{+} \mathrm{CD} 115^{+}\right)$, classical monocytes $\left(\mathrm{CD} 45^{+} \mathrm{CD} 115^{+} \mathrm{Gr} 1^{\text {high }}\right.$ ), nonclassical monocytes $\left(\mathrm{CD}_{4} 5^{+} \mathrm{CD} 115^{+} \mathrm{Gr} 1^{\text {low }}\right)$ and lymphocytes $\left(\mathrm{CD} 45^{+} \mathrm{CD} 3^{+}\right.$and $\left.\mathrm{CD}_{4} 5^{+} \mathrm{CD} 19^{+}\right)$. Chemokine receptors were analyzed using FITC-anti-Ccr1 (R\&D, FAB5986F), AF647-anti-Ccr3 (BioLegend, clone TG14/Ccr3), PE-anti-Ccr5 (eBioscience, clone HM-CCR5) and PE-anti-Ccr2 (R\&D Systems).

Mice

All animal experimental procedures were designed and conducted in agreement with the German Animal Welfare Legislation and were reviewed and approved by the local authorities (Regierung von Oberbayern, Munich, Germany). All mice were housed in IVC units and maintained on a 12-h dark/12-h light cycle. B6.129P2-Apoe/J (Apoe ${ }^{-/}$) and B6.129P2-CCl5 $5^{\mathrm{tm} 1 \mathrm{Hs}} / \mathrm{J}\left(\mathrm{CCl}^{-1-}\right)$ were obtained from The Jackson Laboratory (Bar Harbour, USA), C57BL/6J were from Janvier (Le Genest-Saint-Isle, France) and the tamoxifen inducible general Cre-deleter C57BL/6-Gt(ROSA)26Sor ${ }^{\text {tm9(Cre/ESR1)Arte }}$ (CreERT2) was from Taconic (TaconicArtemis $\mathrm{GmbH}$, Cologne, Germany).

$\mathrm{CxCl} 4^{\mathrm{L} / \mathrm{LL}}, \mathrm{CxCl} 4^{\mathrm{tg}-\mathrm{Ll}}$ and $\mathrm{CxCl} 12^{-/-}$mice were generated by laser-assisted (XY-Clone Hamilton Thorne) injection of $\mathrm{R} 1 / \mathrm{E}(129 / \mathrm{Sv})$ cells into 8 -cell stage $\mathrm{C} 57 \mathrm{BI} / 6 \mathrm{NCrl}$ 
embryos. Embryo recipients were Crl:CD1(ICR) mice (Charles River). All manipulations were done in the Transgenic Core Facility (TCF) of the MPI-CBG, Dresden. Chimaeras were crossed to $\mathrm{C} 57 \mathrm{~B} / / 6 \mathrm{NCrl}$ mice and their offspring was screened for germline transmission. Details of the targeting constructs used to induce homologous recombination and knockin into the Rosa locus are depicted in Fig. S15.

Bone marrow transplantation

$\mathrm{Apoe}^{-/}$mice underwent lethally whole body irradiation (2x5Gy) and were reconstituted with donor bone marrow cells from Apoe ${ }^{-1-} \mathrm{Crr}^{-1-}$ or $\mathrm{Apoe}^{-1-} \mathrm{CCl} 5^{-1-} \mathrm{CxCl} 4^{-1-}$ mice, essentially as described [7]. After 4 weeks, animals were injected i.p. with the CCR5 antagonist DAPTA (TOCRIS, Bristol, UK) or CAN peptide every second day for 2 weeks.

Atherosclerotic lesion formation, quantification and histological analysis

To induce lesions, 8 week old Apoe - $^{--}$mice fed a high-fat diet (HFD, 21\% fat, $19.5 \%$ casein, $0.15 \%$ cholesterol, ssniff, Soest, Germany) for 2 weeks (bone-marrow chimeras), 6 weeks (OPRAH injection) or 12 weeks (analysis of Cxcl4-deficient and knock-in strains). Mice were anesthetized with ketamine $(80 \mathrm{mg} / \mathrm{kg})$ and xylazine (10 $\mathrm{mg} / \mathrm{kg}$ ) and EDTA-anticoagulated blood was retroorbitally collected. Cell counts were determined using an automated hematology analyzer (scil Animal Care, Viernheim, Germany). Plasma was used to detect cholesterol and triglyceride levels (CHOD-PAP or GPO-PAP kit, Roche, Rotkreuz, Switzerland). After complete bleeding, in situ perfusion fixation was performed using $4 \%$ buffered formaldehyde (Carl Roth, Karlsruhe, Germany) and the heart and entire aorta were excised. The aorta was longitudinally opened and stained en face with Oil-Red-0 to visualize lipid deposition. The lesion area was calculated as percentage of the Oil-Red- $0^{+}$stained area normalized to the respective aortic area (arch, thoracoabdominal, inner curvature, outer curvature). After paraffin-embedding and cutting into $4 \mu \mathrm{m}$ transverse sections for aortic roots or $6 \mu \mathrm{m}$ longitudinal sections for aortic arches, atherosclerotic lesion size was measured after Elastica-van Gieson (EVG) staining (Baacklab, Schwerin, Germany). In aortic roots, the percentage of lesion area of the aortic valves normalized to the area of the internal lumen was determined. In aortic arches, total lesion size was quantified in the inner curvature and the three branches. Cellular content was analyzed by immunofluorescence staining for macrophages, $\mathrm{CD}^{+} \mathrm{T}$ cells and smooth muscle cells (SM Cs) using anti-Mac-2 (Cedarlane Labs, Burlington, Canada), anti-CD3 and antiaSMA antibodies (Dako; Hamburg, Germany). Nuclei were counterstained with DAPI (Vector Laboratories, Burlingame, California, USA). Primary antibodies were visualized using DyLight-488, -550 and -650-conjugated secondary antibodies (Abcam, Cambridge, UK). Images were recorded with a DM 6000B fluorescence microscope (Leica, Solms, Germany), connected to a monochrome digital camera (DFC 365FX) for 
fluorescent imaging or a DFC425C camera for bright-field microscopy. Mac-2-, CD3and $\alpha$ SMA cells were manually quantified as positive cells per plaque area. Stages of atherosclerotic lesions were determined in EVG-stained aortic root sections according to the Virmani classification [57]. Necrotic cores were quantified as anuclear crystalladen areas of lesions and normalized to the lesion area.

Acute lung injury

The acute lung injury (ALI) model was performed as described [11]. ALI was induced in 8 weeks-old male C57Bl/6mice (Janvier, St Berthevin Cedex, France) or $\mathrm{CCl}^{-1-} \mathrm{CXCL} 4^{-1-}$ bone marrow chimeric mice by exposure to aerosolized LPS $(500 \mu \mathrm{g} / \mathrm{ml})$ from Salmonella enteritidis (Sigma, M unich, Germany) for 30 min. Peptides, chemokines or mOPRAH were injected i.v. at indicated doses. Alveolar, interstitial, and intravascular neutrophils were analyzed after $4 \mathrm{~h}$. To label intravascular neutrophils, FITC-Ly-6G (Gr1) (clone RB6-8L5, eBioscience) was applied by tail vein injection 30 min before sacrifice. Broncho-alveolar lavage (BAL) fluid was obtained by repeated injection and withdrawal of PBS. The pulmonary vasculature was rinsed with PBS $0.5 \mathrm{mM}$ EDTA. Lungs were removed, minced and digested with liberase (Roche M annheim Germany), passed through a cell strainer and neutrophils were analyzed by labeling with antimouse PerCP-Cy5.5-Ly-6G, PE-CD115, APC-Cy7-CD45 antibodies (eBioscience).

Competitive chemokine receptor-ligand binding

HEK293 transfectants expressing CCR1, CCR4 or CCR5 were incubated with AF647labeled CCL5 or CCL17 (2.5 nM) in presence or absence of unlabeled CCL5 or CCL17 (at increasing concentrations) for $1 \mathrm{~h}$ at $4^{\circ} \mathrm{C}$. After washing, fluorescence intensity was measured by flow cytometry (FACSCantoll) and analyzed using FlowJo v.10 software (Tree Star Inc., Ashland, Oregon, USA).

Chemokine binding to monocytes

Monocytes were incubated with CCL5 in combination with CXCL4 or CXCL4 ${ }^{R>Q}$ (each $100 \mathrm{nM})$ for $1 \mathrm{~h}$ at $4^{\circ} \mathrm{C}$. CCL5-binding was reacted with a CCL5-antibody $(5 \mu \mathrm{g} / \mathrm{ml}$, Abcam AB9679, Cambridge, UK) and detected with an AF488-conjugated secondary antibody ( $2 \mu \mathrm{g} / \mathrm{ml}$, Thermo Fisher Scientific).

Chemokine receptor internalization

CCR1-, CCR4- or CCR5-expressing HEK transfectants were incubated for $1 \mathrm{~h}$ at $4^{\circ} \mathrm{C}$ with AF647- labeled CCL5 or CCL17 (2.5 nM) in presence of increasing concentrations of unlabeled chemokines. Cells were then washed with cold PBS and fluorescence intensity was analyzed by flow cytometry. 


\section{CAM P signaling}

Levels of CAM P were measured in confluent HEK293 transfectants expressing CXCR4 after stimulation with CXCL12 using Glosensor technology. After incubation with luciferin-EF (2.5 mM) at RT for $2 \mathrm{~h}$, cells were stimulated with CXCL12 in the presence or absence of [VREY] $]^{4}$ and luminescence was recorded at indicated time points, and after further addition of forskolin $(1 \mu \mathrm{M})$ and poly-D-lysine.

Platelet aggregometry and ex vivo thrombus formation

Human venous blood was collected in hirudin-precoated tubes (Sarstedt, Nürnbrecht, Germany). Informed consent was obtained as approved by the Ethics Committee of the Faculty of Medicine, LMU M unich. Platelet aggregation in blood was determined by multiple electrode aggregometry (MEA) using the Multiplate ${ }^{\circ}$ device (Roche Diagnostics, Mannheim, Germany). Whole blood was diluted with $\mathrm{NaCl}$ 1:1 and CXCL12, CCL5 or [VREY] ${ }^{4}$ were added, stirring was started and the increase in electrical impedance was recorded continuously for $5 \mathrm{~min}$. The mean value of two independent determinations is expressed as area under the curve in arbitrary units (U).

The multi-parameter assessment of thrombus formation has been described in detail for human blood $[58,59]$. Mouse blood was collected into 0.1 volume of saline with a final concentration of $4 \mu \mathrm{M}$ PPACK, $4 \mathrm{U} / \mathrm{ml}$ fragmin and $5 \mathrm{U} / \mathrm{ml}$ heparin. Microspotcoated coverslips, coated as described with three distinct surfaces (a: VWF + laminin. b: VWF + laminin + CLEC-2 ligand. c: collagen type I, Horm), were mounted onto a parallel-plate flow chamber and a shear rate of $1000 \mathrm{~s}^{-1}$ was applied. In thrombi, platelets were stained with monoclonal antibodies against CD62P (FITC), activated integrin $\alpha_{\| b} \beta_{3}$ (PE-JON/A)t, and AF647-annexin-A5. Parameters were assessed by bright-field and sub-sequent tri-color fluorescence microscopy.

\section{Statistical analysis}

Data are expressed as mean \pm standard error of the mean (SEM) unless otherwise specified. If D'Agostino \& Pearson omnibus and/or Shapiro-Wilk normality test indicated Gaussian distribution, an unpaired t-test for side-by-side comparisons or one-way ANOVA with Newman-Keuls post-test for multiple comparisons were performed. Otherwise, Mann-Whitney-tests for side-by-side comparison and KruskalWallis-test for multiple comparisons were performed using GraphPad Prism version 5.04 for Windows (GraphPad Software, San Diego, USA). For animal studies, a power analysis was performed using BiAS software (version 11.02). We assumed a detectable biological difference of at least $50 \%$ among up to four groups with a standard deviation $<15 \%$, an $\alpha$ of 0.05 , and a resultant power of 0.8 . The number of biological replicates for each data point is included in the figure legends. 
a

\begin{tabular}{|c|c|c|c|c|c|c|c|c|c|}
\hline CCL1 & $\mathrm{CCL} 2$ & $\mathrm{CCL}_{3}$ & CCL3L1 & CCL4 & CCL4L1 & $\mathrm{CCL} 5$ & $\mathrm{CCL} 7$ & $\mathrm{CCl} 8$ & CCL11 \\
\hline CCL13 & CCL14 & CCL15 & CCL16 & CCL17 & CCL18 & CCL19 & $\mathrm{CCL} 20$ & CCL21 & $\mathrm{CCL}_{22}$ \\
\hline $\mathrm{CCL}_{23}$ & $\mathrm{CCL} 24$ & CCL25 & $\mathrm{CCL} 26$ & $\mathrm{CCl}_{27}$ & CCL28 & XCL1 & CXCL1 & CXCL2 & CXCL3 \\
\hline CXCLL & CXCL5 & CXCL6 & CXCL7 & CXCL8 & CXCL9 & CXCL10 & CXCL11 & CXCL12a & CXCL12 $\beta$ \\
\hline CXCL13 & CXCL14 & CXCL16 & CXCL17 & CXCL4L1 & CX3CL1 & & & & \\
\hline
\end{tabular}

b

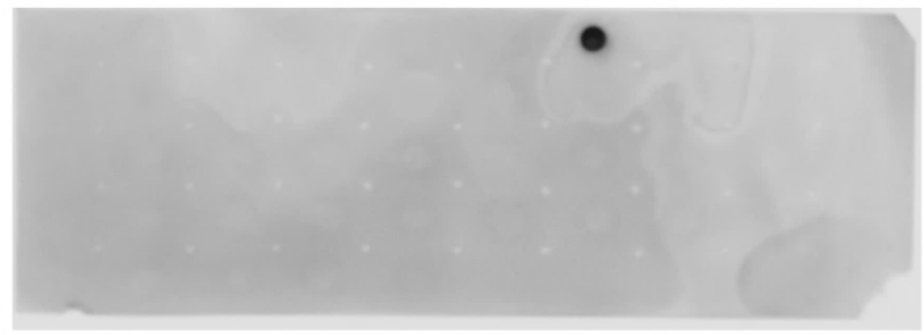

C

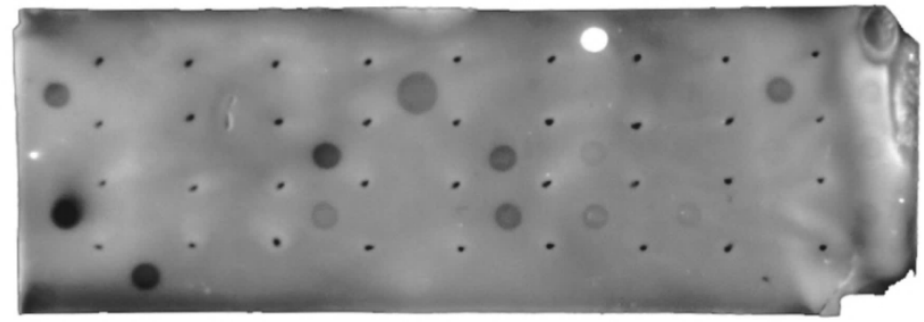

d

\begin{tabular}{|l|l|l|l|l|l|l|l|l|l|}
\hline 0.0000 & 0.0751 & 0.0293 & 0.0000 & 0.0000 & 0.0000 & 1.0000 & 0.0000 & 0.0000 & 0.0000 \\
\hline 0.1960 & 0.0000 & 0.0000 & 0.0000 & 0.3420 & 0.0000 & 0.0000 & 0.0000 & 0.1533 & 0.0074 \\
\hline 0.0000 & 0.0000 & 0.0000 & 0.2205 & 0.0000 & 0.1891 & 0.0280 & 0.0000 & 0.0000 & 0.0766 \\
\hline 0.2908 & 0.0000 & 0.0000 & 0.0957 & 0.0000 & 0.1509 & 0.0000 & 0.0306 & 0.0689 & 0.0218 \\
\hline 0.0000 & 0.1484 & 0.0000 & 0.0000 & 0.0038 & & & & & \\
\hline
\end{tabular}

Figure S1: Representative ligand blot and densitometric values. (a) Chemokines were spotted on a nitrocellulose membrane $(1 \mu \mathrm{l}, 1 \mathrm{ng})$ as indicated. In this example, CCL5 served as the positive control (orange). (b,c) The membrane was left untreated to test for antibody specificity (b) or incubated overnight at $4^{\circ} \mathrm{C}$ with $100 \mathrm{nM} \mathrm{CCL5}$ (c). CCL5 partners were detected using a biotinylated antibody to CCL5 and a HRP-conjugated secondary antibody (c). (d) The absolute luminescence signal (area and density) was digitally recorded; background was subtracted and expressed relative to the signal of the positive control (CCL5). 


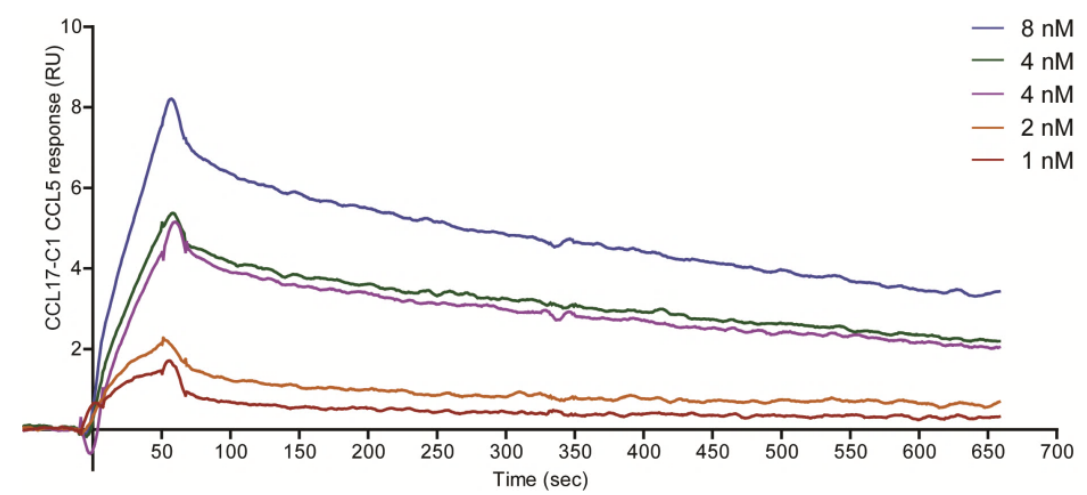

Figure S2: Interaction of CCL5 with CCL17 analyzed by SPR. To validate chemokine interactions of interest, we performed kinetics analyses of their saturation binding curves using surface plasmon resonance (SPR). In this example, CCL17 was biotinylated and immobilized onto a neutravidin-coated sensor chip C1 (Biacore). CCL5 was perfused at $90 \mu \mathrm{l} / \mathrm{min}$ in running buffer (HBS-EP+, pH 7.4) and regenerated with $100 \mathrm{mM} \mathrm{NaOH}, 0.05 \%$ SDS and 30\% acetonitrile. Onrates $\left(\kappa_{a}\right)$ and off-rates $\left(\kappa_{d}\right)$ were calculated from fitting the curves by non-linear regression using the 1:1 Langmuir interaction model. 


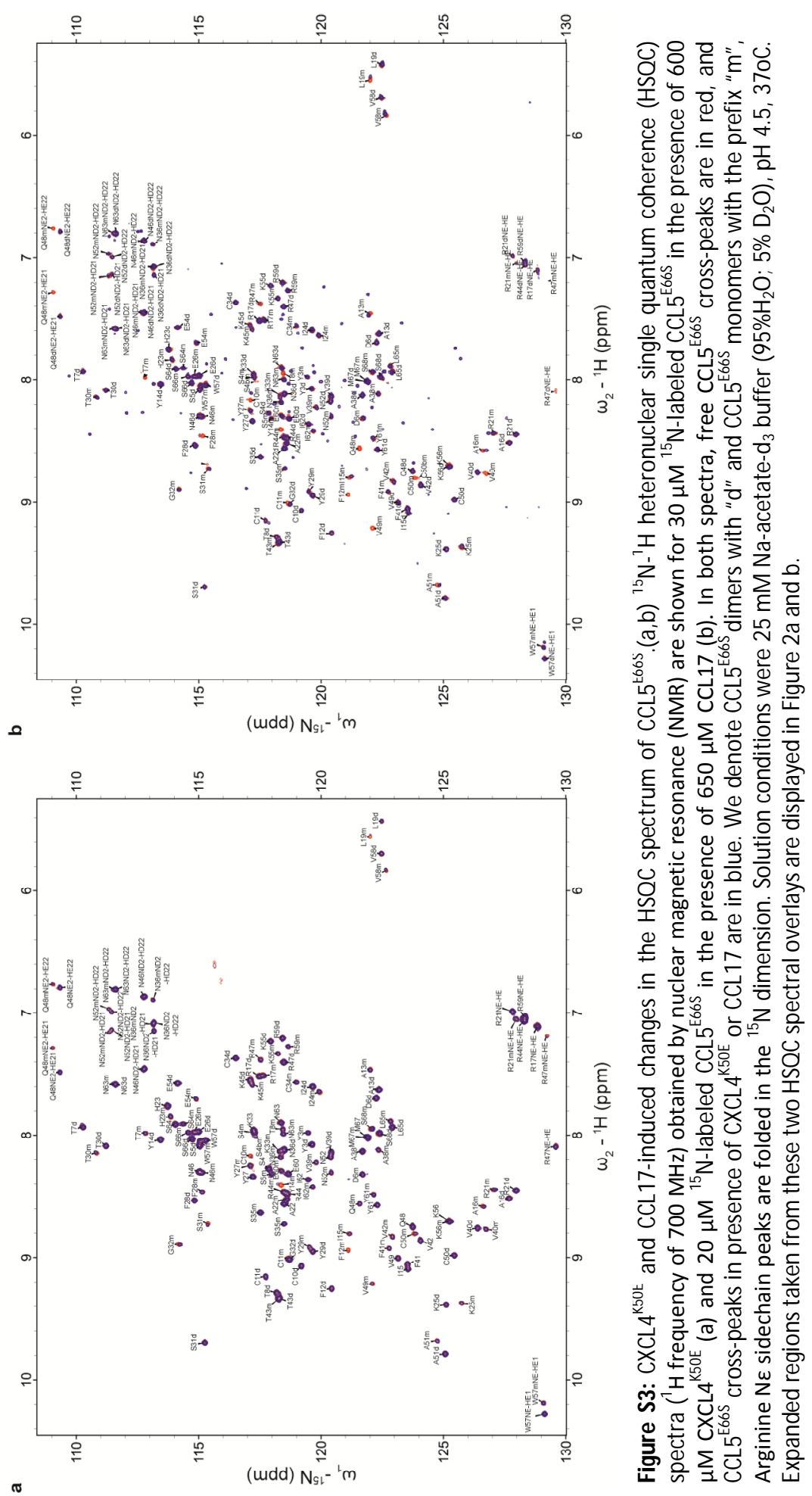


a

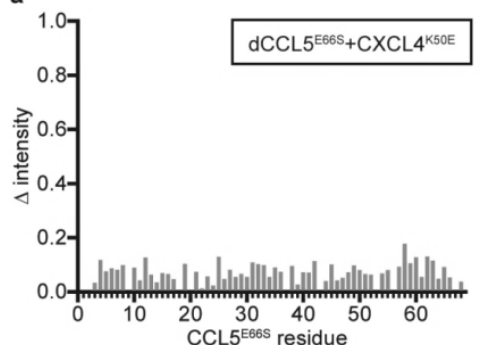

c
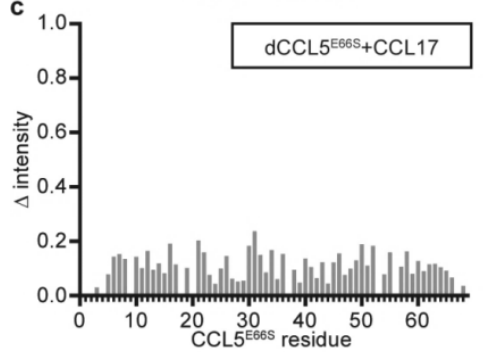

e

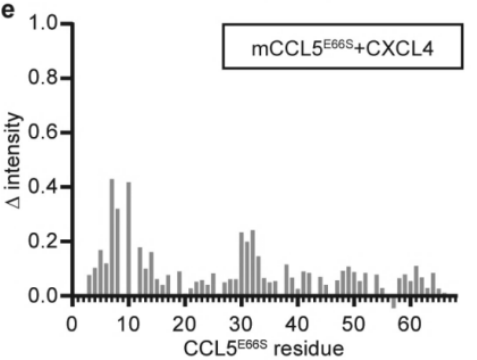

g

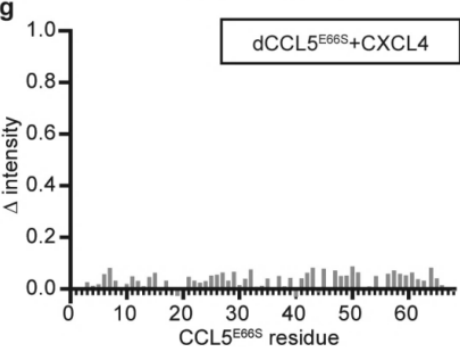

b

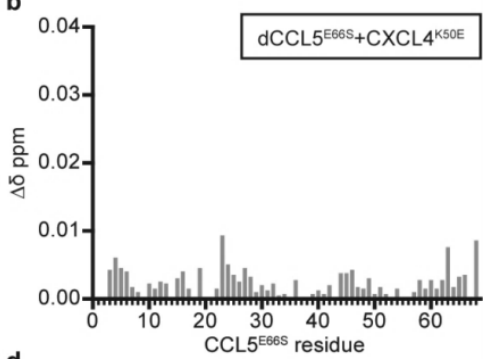

d

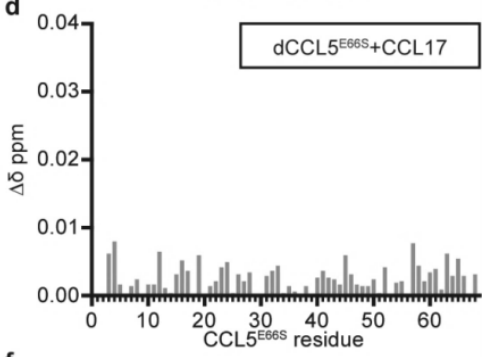

f

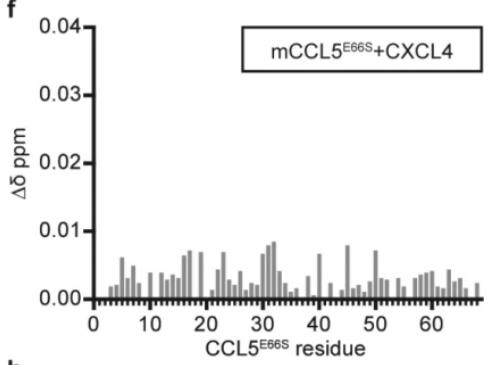

h

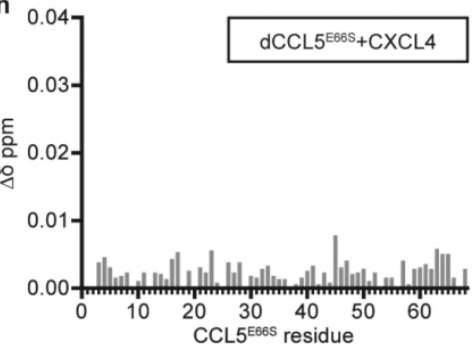

Figure S4: Chemical shift and resonance intensity changes of $\mathrm{CCL}^{\mathrm{tb} b \mathrm{~s}}$ residues. Chemical shift $(\delta \Delta)$ and resonance intensity ( $\Delta$ Intensity) changes for ${ }^{15} \mathrm{~N}$-labeled $\operatorname{CCL5}{ }^{\mathrm{E} 66 \mathrm{~S}}(30 \mu \mathrm{M})$ in the presence of CXCL4 ${ }^{\mathrm{K} 50 \mathrm{E}}$ or CXCL4 $(600 \mu \mathrm{M})$ or for ${ }^{15} \mathrm{~N}$-labeled $\mathrm{CCL}^{\mathrm{E} 66 \mathrm{~S}}(20 \mu \mathrm{M})$ in the presence of CCL17 $(650 \mu \mathrm{M})$ were quantified and plotted vs the CCL5 amino acid sequence. We denote $C C L{ }^{\mathrm{E} 665}$ dimers with " $\mathrm{d}$ " and $C C L 5^{\mathrm{E} 66 \mathrm{~S}}$ monomers with the prefix " $\mathrm{m}$ ". (a) $\Delta$ Intensity values for $\mathrm{dCCL}^{\mathrm{E} 66 \mathrm{~S}}$ plus CXCL4 ${ }^{\mathrm{K} 50 \mathrm{E}}$; (b) $\delta \Delta$ values for $\mathrm{dCCL}^{\mathrm{E} 66 \mathrm{~S}}$ plus CXCL4 ${ }^{\mathrm{K} 50 \mathrm{E}}$; (c) $\Delta$ Intensity values for $\mathrm{dCCL} 5^{\mathrm{E} 66 \mathrm{~S}}$ plus CCL17; (d) $\delta \Delta$ values for dCCL5 $5^{\mathrm{E} 66 \mathrm{~S}}$ plus CCL17; (e) $\Delta$ Intensity values for $\mathrm{mCCL} 5^{\mathrm{E} 66 \mathrm{~S}}$ plus CXCL4; (f) $\delta \Delta$ values for mCCL5 ${ }^{\mathrm{E} 66 \mathrm{~S}}$ plus CXCL4; (g) $\Delta$ Intensity values for $\mathrm{dCCL}^{\mathrm{E} 66 \mathrm{~S}}$ plus CXCL4; (h) $\delta \Delta$ values for dCCL5 ${ }^{\mathrm{E} 66 \mathrm{~S}}$ plus CXCL4. Solution conditions were $25 \mathrm{mM} \mathrm{Na}$-acetate- $\mathrm{d}_{3}$ buffer $\left(95 \% \mathrm{H}_{2} \mathrm{O} ; 5 \% \mathrm{D}_{2} \mathrm{O}\right)$, $\mathrm{pH} 4.5,37^{\circ} \mathrm{C}$. 

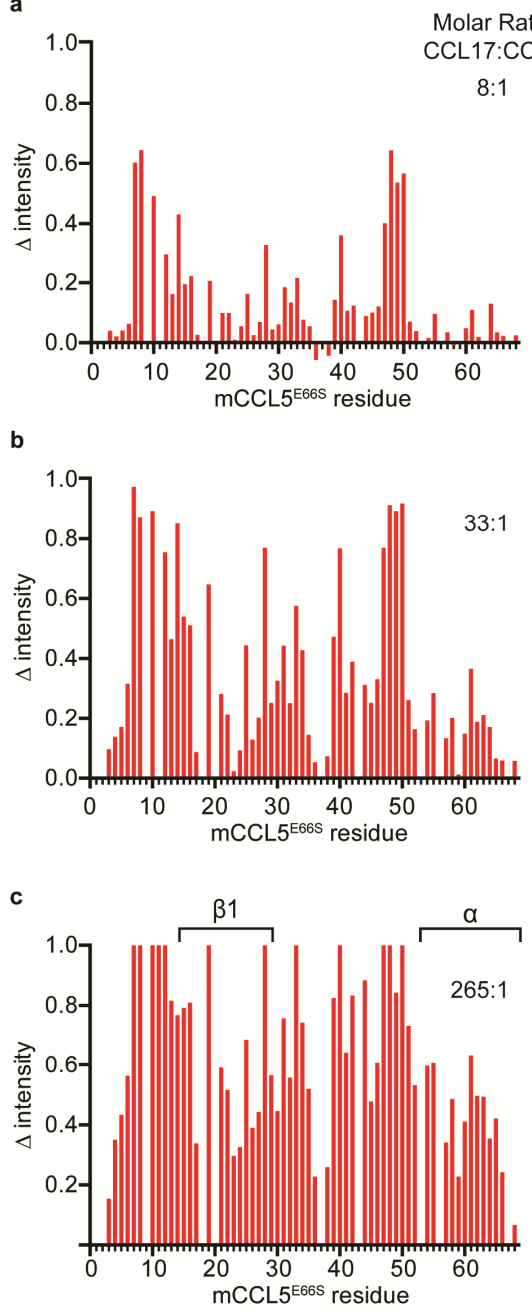

d

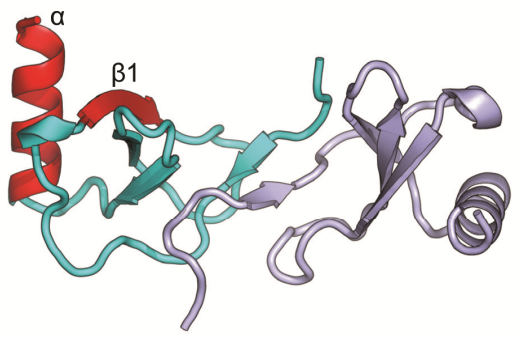

。

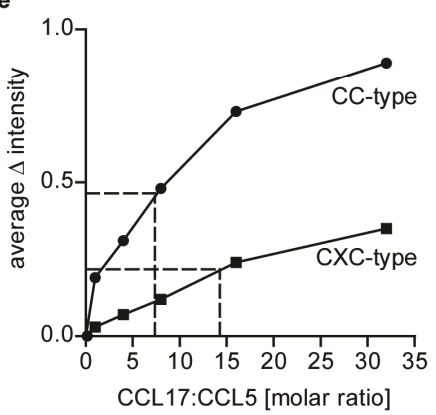

Figure 55: Concentration-dependent formation of CC- versus CXC type heterodimers. Changes in resonance intensity $\left(\Delta\right.$ Intensity) for ${ }^{15} \mathrm{~N}$-labeled $C C L 5^{5665}$ monomer resonances in the presence of increasing concentrations of CCL17 are plotted vs the amino acid sequence of CCL5. The final CCL17:CCL5 ${ }^{\mathrm{E} 665}$ molar ratios were 8:1 (a), 33:1 (b) and 265:1 (c), as indicated. The total concentration of CCL5 ${ }^{\mathrm{E} 665}$ was $20 \mu \mathrm{M}$ at the two lowest ratios and $10 \mu \mathrm{M}$ at the 265:1 ratio. $\Delta$ Intensity was calculated as in Figure $\mathrm{S} 4$. Solution conditions were $25 \mathrm{mM}$ Na-acetate- $\mathrm{d}_{3}$ buffer $(95 \% \mathrm{H} 2 \mathrm{O} ; 5 \% \mathrm{D} 2 \mathrm{O}), \mathrm{pH} 4.5,37^{\circ} \mathrm{C}$. (d) $\Delta$ Intensity values increasing the most by the highest CCL17 concentration are highlighted in red on the X-ray crystal structure of CCL5 (PDB access code 1U4L). (e) $\Delta$ Intensity values averaged over residues at the CC-type (residues 3-16; 30-35, 46-50) or CXC-type (residues 24-30, 53-68) heterodimer interfaces are plotted vs the CCL17:CCLL ${ }^{\mathrm{E} 66 \mathrm{~S}}$ molar ratio. 
a

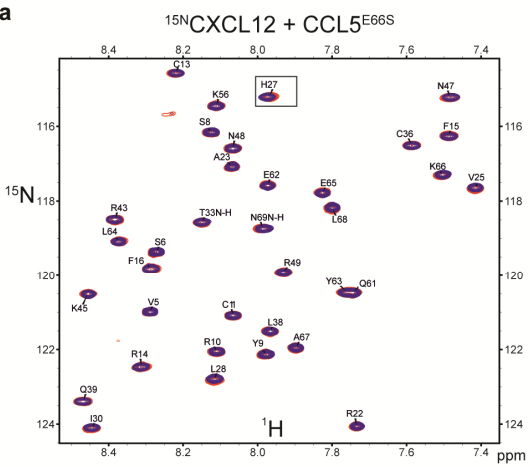

C
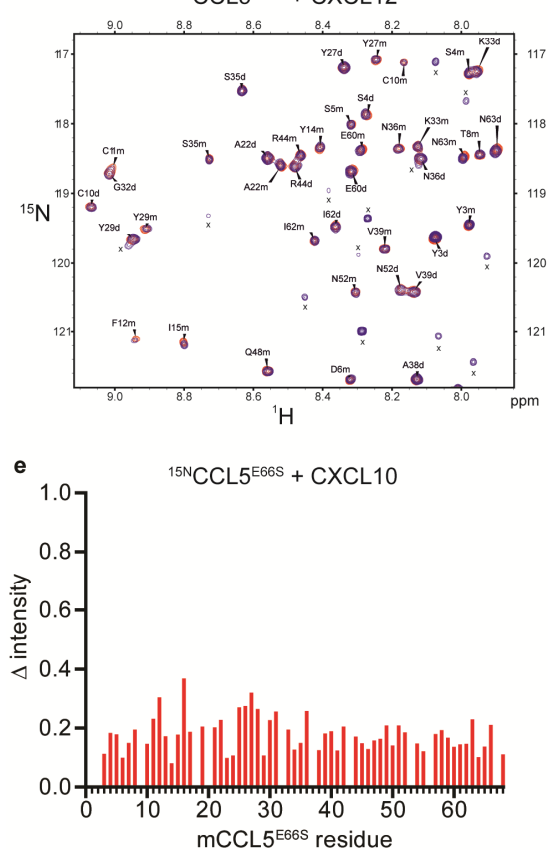
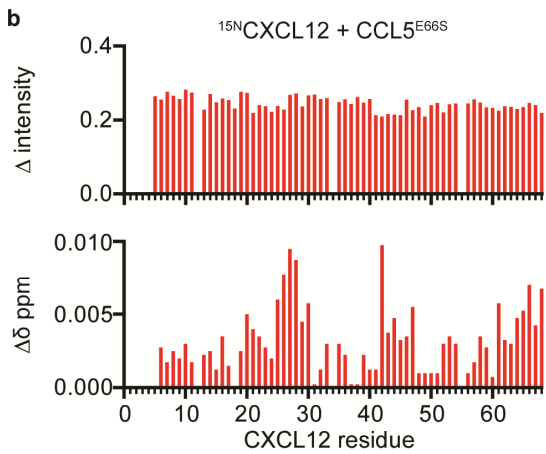

d
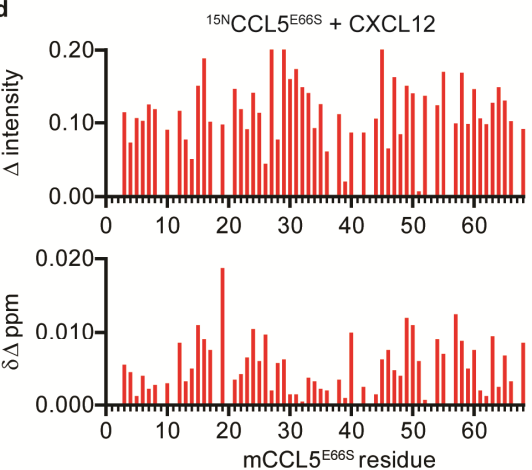

${ }^{15 N} \mathrm{CCL} 5^{\mathrm{E} 66 \mathrm{~S}}+\mathrm{CCL} 3$

Figure 56: CCL5-induced changes in HSQC spectra of CXCL12. (a) ${ }^{15} \mathrm{~N}-{ }^{1} \mathrm{H}$ heteronuclear single quantum coherence (HSQC) spectra ( ${ }^{1} \mathrm{H}$ frequency of $700 \mathrm{M} \mathrm{Hz}$ ) for ${ }^{15} \mathrm{~N}$-labeled CXCL12 (30 $\left.\mu \mathrm{M}\right)$ in the absence (red contours) and presence (blue contours) of CCL5 ${ }^{\mathrm{E} 665}(315 \mu \mathrm{M})$ are overlaid. (b) From the HSQC spectra shown in a, $\delta \Delta$ and $\Delta$ Intensity values (calculated as in Figure S4) are plotted vs the amino acid sequence of CXCL12. (c) ${ }^{15} \mathrm{~N}-{ }^{1} \mathrm{H}$ HSQC spectra ( ${ }^{1} \mathrm{H}$ frequency of 700 $\mathrm{MHz}$ ) for ${ }^{15} \mathrm{~N}$-labeled $\mathrm{CCL}^{\mathrm{E} 66 \mathrm{~S}}(20 \mu \mathrm{M})$ in the absence (red contours) and presence (blue contours) of CXCL12 $(770 \mu \mathrm{M})$ are overlaid. (d) From the HSQC spectra shown in c, $\delta \Delta$ and $\Delta$ Intensity values (calculated as described in the legend to Figure S4) are plotted versus the amino acid sequence of CCL5. (e) From ${ }^{15} \mathrm{~N}-{ }^{1} \mathrm{H}$ HSQC spectra of ${ }^{15} \mathrm{~N}-\mathrm{CCL}^{\mathrm{E}}{ }^{665}(20 \mu \mathrm{M})$ in the absence and presence of CXCL10 (1.0 mM) (data not shown), $\Delta$ Intensity values (calculated as in Figure S4) are plotted vs the amino acid sequence of CCL5. Solution conditions were $25 \mathrm{mM} \mathrm{Na}$ acetate- $\mathrm{d}_{3}$ buffer $\left(95 \% \mathrm{H}_{2} \mathrm{O} ; 5 \% \mathrm{D}_{2} \mathrm{O}\right), \mathrm{pH} 4.5,37^{\circ} \mathrm{C}$. 
a

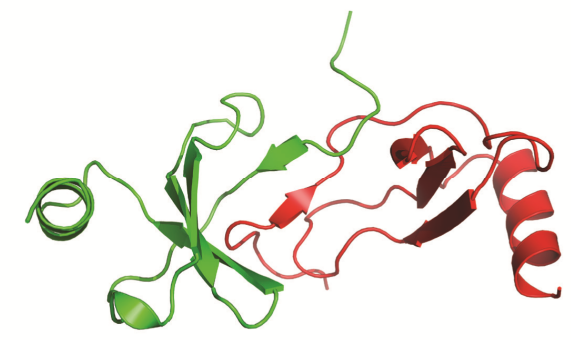

c

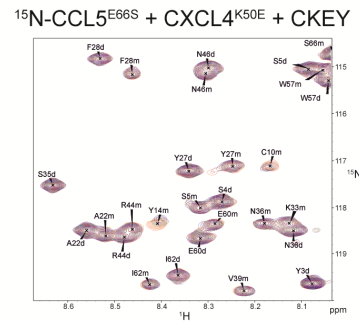

b

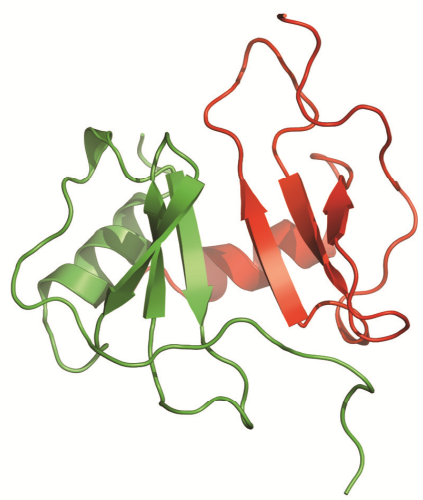

d monomeric CCL5/+CAN $320 \mu \mathrm{M}$
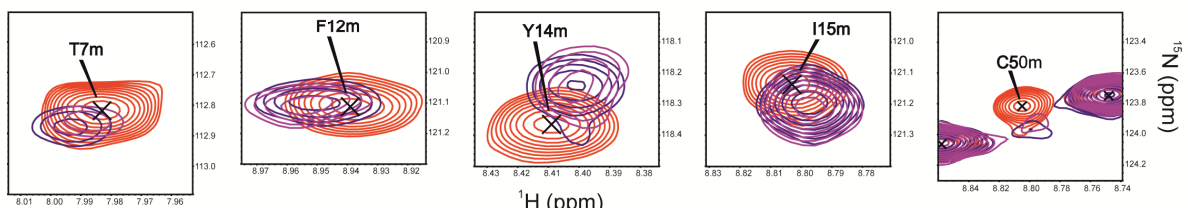

Figure S7: Targeting of chemokine heterodimers by specific peptides. (a,b) Structures of CCL5CCL17 (CC-type, a) and CCL5-CXCL12 (CXC-type, b) modelled after MD simulation plus minimization (CCL5 in green, CCL17 and CXCL12 in red) are illustrated. (c) ${ }^{15} \mathrm{~N}-{ }^{1} \mathrm{H}$ heteronuclear single quantum coherence ( $\mathrm{HSQC}$ ) spectral expansions for $\mathrm{mCCL}^{\mathrm{E} 66 \mathrm{~S}}$ residues $\mathrm{C} 10$ and $\mathrm{Y} 14$ at the heterodimer interface are shown to exemplify the inhibitory effect that increasing concentrations of CKEY peptide has on the formation of ${ }^{15} \mathrm{~N}-\mathrm{CCL} 5{ }^{\mathrm{E} 66 \mathrm{~S}} \mathrm{CXCL}{ }^{\mathrm{K} 50 \mathrm{E}}$ heterodimers. (d) ${ }^{15} \mathrm{~N}-{ }^{1} \mathrm{H}$ HSQC spectral expansions for five residues at the heterodimer interface are shown to exemplify the inhibitory effect that CAN peptide has on the formation of ${ }^{15} \mathrm{~N}-\mathrm{CCL} 5^{\mathrm{E} 66 \mathrm{~S}}$-CCL17 heterodimers. Red contour lines show relatively sharp resonances of free $\mathrm{CCL}^{\mathrm{E} 66 \mathrm{~S}}$ monomer peaks, blue contours indicate the corresponding broadened peak caused by heterodimer formation with CXCL4 ${ }^{\mathrm{K} 50 \mathrm{E}}$ or CCL17, while other contours show the reverse trend in linewidth and chemical shift on $\mathrm{CCL}^{\mathrm{E} 66 \mathrm{~S}}$ heterodimer peaks caused by the competitive binding to CKEY or CAN. 


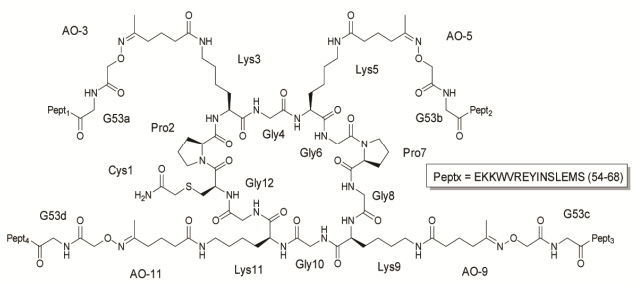

C
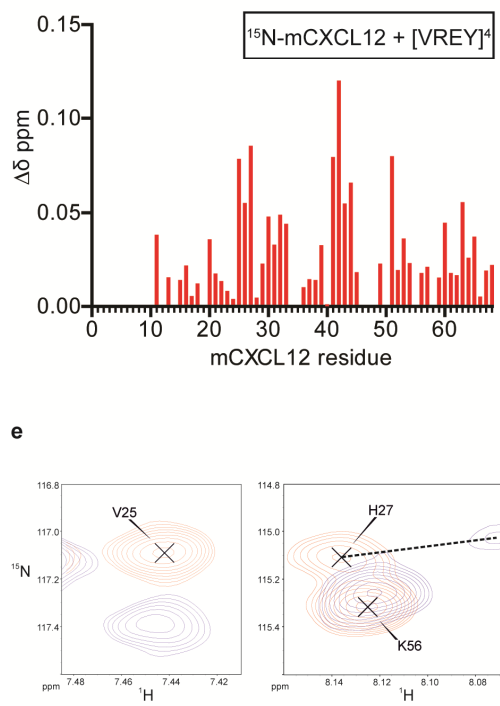

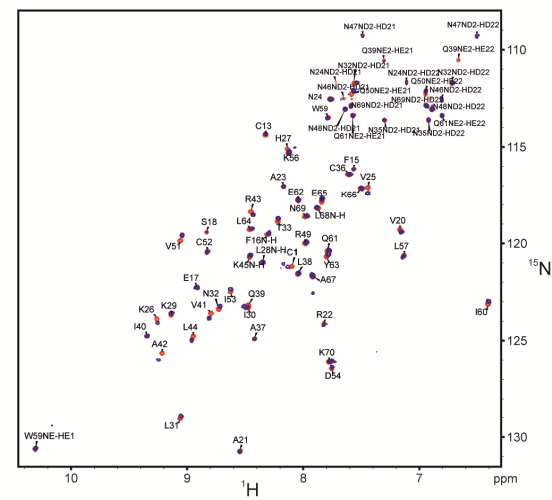

d

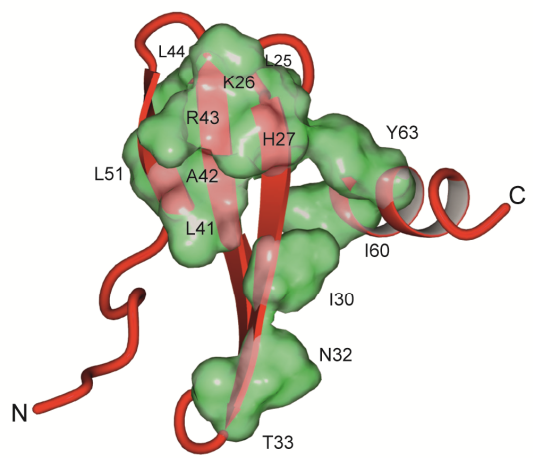

Figure S8: Efficient targeting of CCL5-CXCL12 heterodimer by [VREY]4. (a) Chemical structure of 4 VREY molecules on a TASP scaffold resulting in [VREY] $]_{4}$ (b) Overlays of ${ }^{15} \mathrm{~N}-{ }^{1} \mathrm{H}$ heteronuclear single quantum coherence (HSQC) spectral expansions of $10 \mu \mathrm{M}$ monomeric ${ }^{15} \mathrm{~N}-\mathrm{CXCL12}$ in the absence (red contours) and presence (blue contours) of $40 \mu \mathrm{M}$ [VREY $]_{4}$ peptide. (c) Using these HSQC data, $\delta \Delta$ values (calculated as in Figure $S 4$ ) are plotted versus the amino acid sequence of CXCL12. (d) Structural pertubation plot of CXCL12 (monomeric) induced by [VREY] $]_{4}$, as taken from the experimental derived delta ppm values. (e) ${ }^{15} \mathrm{~N}-{ }^{1} \mathrm{H}$ HSQC spectral expansions for five residues at the heterodimer interface are shown to exemplify the inhibitory effect that [VREY] has on the formation of ${ }^{15} \mathrm{~N}-\mathrm{CXCL} 12-\mathrm{CCL} 5$ heterodimers. Solution conditions were $25 \mathrm{mM}$ potassium phosphate buffer $(95 \% \mathrm{H} 20 ; 5 \% \mathrm{D} 2 \mathrm{O}), \mathrm{pH} 7.1,25^{\circ} \mathrm{C}$. Poor solubility of [VREY] $]_{4}$ at pH values lower than 7 prevents the study of heterodimer formation at standard $\mathrm{pH} 4.5$ buffer conditions. 
a
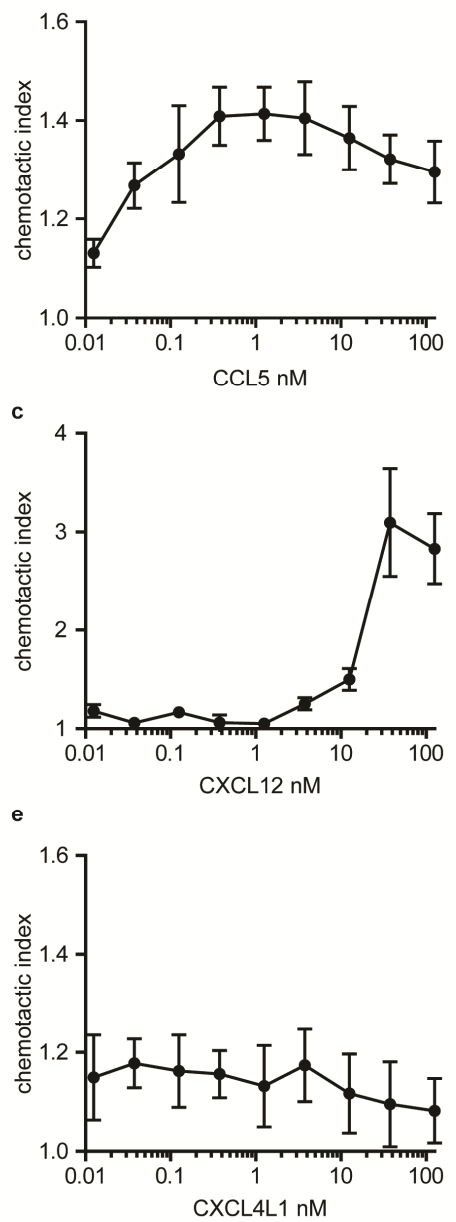

b

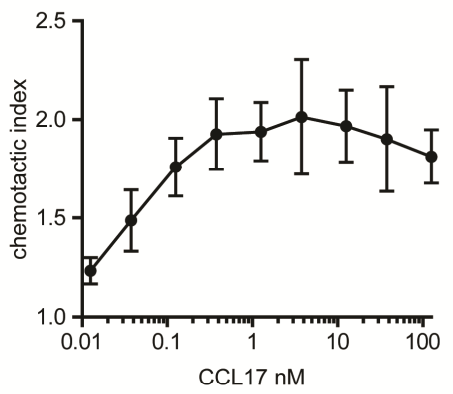

d
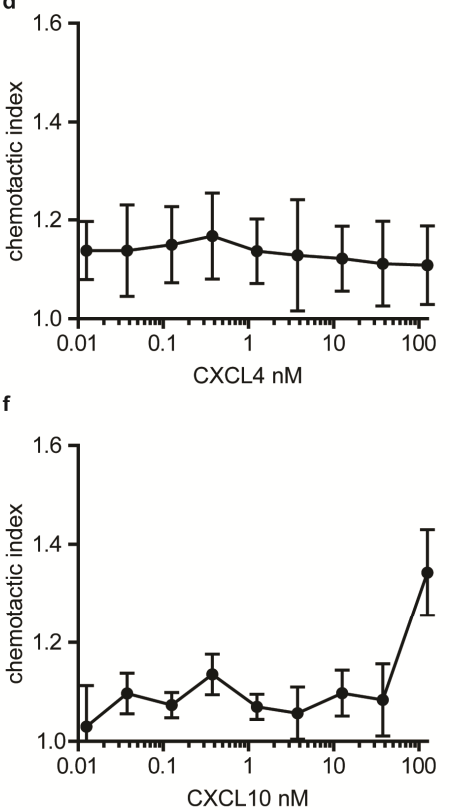

Figure 59: Dose-dependency of T-cell chemotaxis elicited by single chemokines. (a-f) Chemotaxis assays were performed using IL-2- and CD3/C28-activated human T cells in $3 \mu \mathrm{m}$ Transwell-filter plates. Chemokines were added into the bottom chamber at indicated concentrations: CCL5 (a), CCL17 (b), CXCL12 (c), CXCL4 (d), CXCL4L1 (e), CXCL10 (f). The chemotactic index was calculated as the ratio of chemokine-induced versus unstimulated migration, as determined by counting cells in the bottom chamber. Data represent mean $\$$ SEM of $n=5-20$ independent experiments. 
a

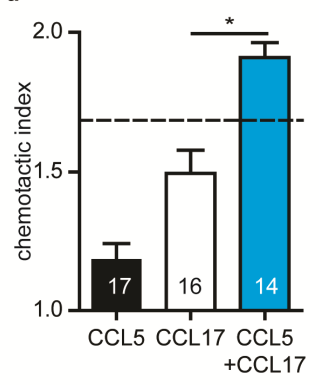

d

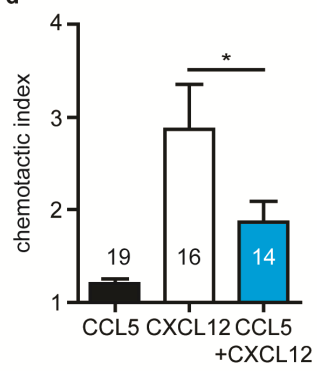

g

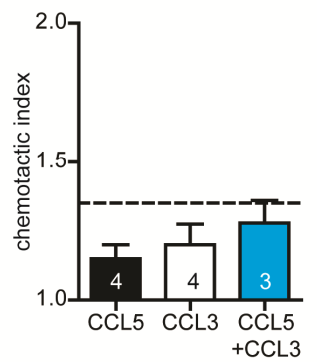

b

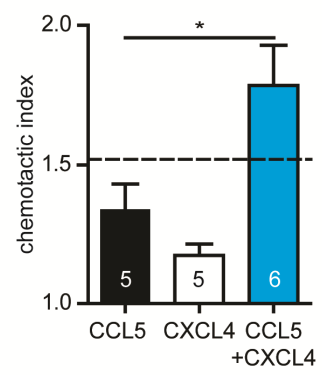

e

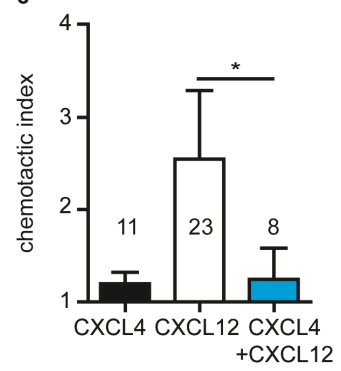

h

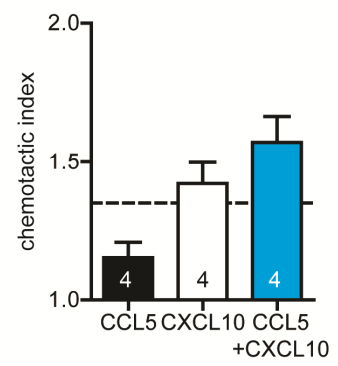

c

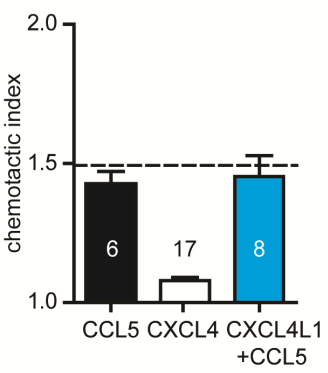

f

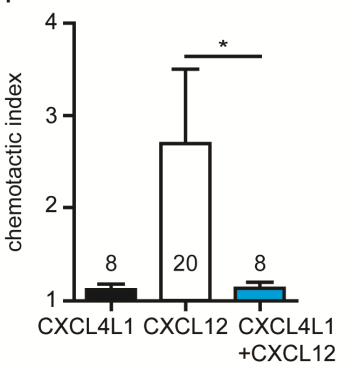

Figure S10: Differential effects of chemokine combinations on T-cell chemotaxis. (a-h) Chemotaxis assays were performed using IL-2- and CD3/C28-activated human T cells in Transwell-filter plates. Combinations of CCL5 (1 nM) with CCL17 $(0.1 \mathrm{nM})$, (a), of CXCL4 or CXCL4L1 with CCL5 (all at $4 \mathrm{nM}$ ) (b,c), of CXCL12 with CCL5, CXCL4, or CXCL4L1 (all at $40 \mathrm{nM}$ ) (df) and of CCL5 (1 nM) with CCL3 or CXCL10 (both at $100 \mathrm{nM}),(\mathrm{g}, \mathrm{h})$ were added to the bottom chamber. The chemotactic index was calculated as the ratio of chemokine-induced versus unstimulated migration. Dashed lines indicate a virtually calculated additive effect $(a-c, g, h)$. Data represent mean \pm SEM from the indicated number of independent experiments. $* p<0.05$, as analyzed by Krukal-Wallis-test. 
a

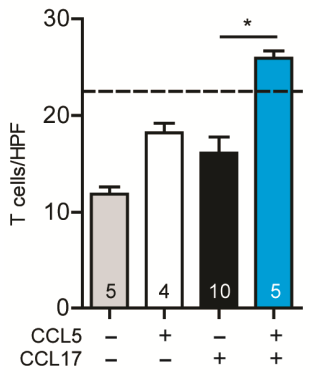

e
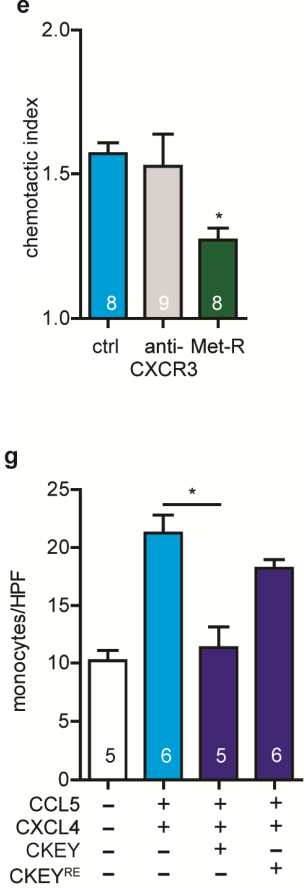

b

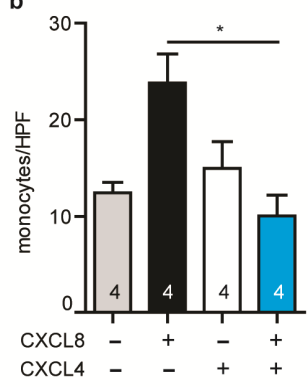

d

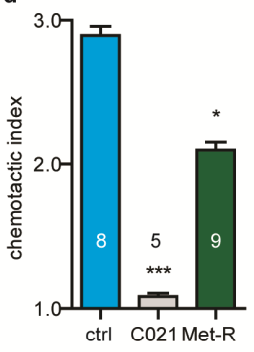

h

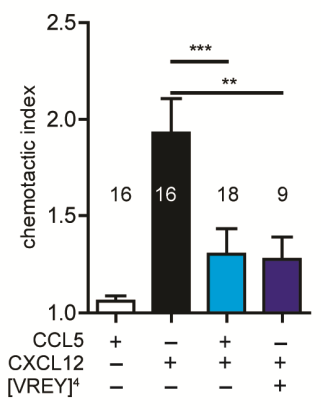

C

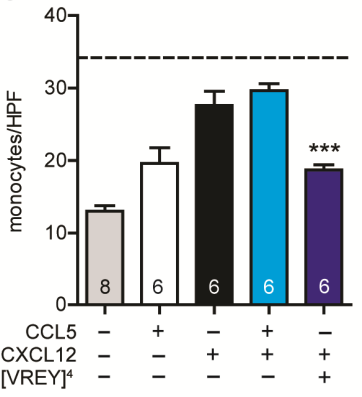

f

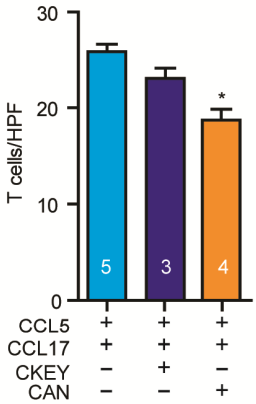

i

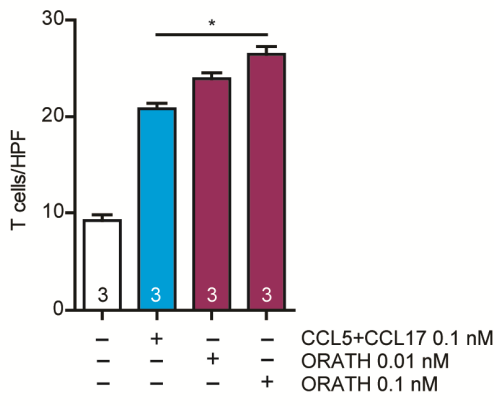

Figure S11: Differential effects of chemokine heterodimerization on leukocyte recruitment. (a-i) The firm arrest of IL-2- and CD3/C28-activated human T cells $(a, f, i)$ or isolated monocytes $(b, c, g)$ perfused over IL-1 $\beta$-stimulated human aortic endothelial cells (HAoECs) at $1.5 \mathrm{dyne} / \mathrm{cm}^{2}$ was analyzed by counting high-power fields (HPF) and chemotaxis assays were performed using IL-2and CD3/C28-activated human T cells in Transwell-filter plates (d,e). For T-cell arrest, CCL5 (1 $\mathrm{nM}$ ) and CCL17 (0.1 nM) were immobilized on HAoECs in combination with CAN or CKEY (both $10 \mathrm{nM})(\mathrm{a}, \mathrm{f})$. For monocyte arrest, HAoECs were pre-incubated with CXCL8 and/or CXCL4 (b) and with CCL5 and/or CXCL12 (all at $40 \mathrm{nM}$ ) in combination with a 10-fold excess of [VREY] ${ }^{4}$ (c). The effect of CCL5 (1 nM) plus CCL17 (0.1 nM) on T-cell chemotaxis was inhibited by blocking CCR4 (C021) or CCL5 receptors with M et-RANTES (M et-R) (d). The effect of CCL5 plus CXCL4 (both 4 $\mathrm{nM}$ ) on T-cell chemotaxis was inhibited by blocking CCL5 receptors with Met-R (e). Isolated human blood monocytes were perfused on IL-13-activated HAoEC pre-incubated with CCL5 (4 $\mathrm{nM}$ ) plus CXCL4 (40 nM) and CKEY or CKEY ${ }^{\mathrm{RE}}$ with the substitutions R44A and E26A (both 400 $\mathrm{nM}$ ), and arrest was quantified (g). A combination of CXCL12 with or without CCL5 (both $40 \mathrm{nM}$ ) and a 10 -fold excess of [VREY] 4 were added to the bottom chamber to assess T-cell chemotaxis (h). Arrest of activated T cells on IL-1 $\beta$-stimulated HAoECs pre-incubated with CCL5 (1 nM) plus 
CCL17 (0.1 nM) or with covalently bound CCL5-CCL17 heterodimer ORATH (Obligate RAntes Tarc Heterodimer) at indicated concentrations (i). Dashed lines indicate a virtually calculated additive effect $(a, c)$. Data represent mean $\$ S E M$ from the indicated number of independent experiments. $* p \varangle 0.05, * * p \varangle 0.01, * * * p \varangle 0.001$, as analyzed by Kruskal-Wallis-test $(a-d, f, g, i)$ or one-way ANOVA (e,h).
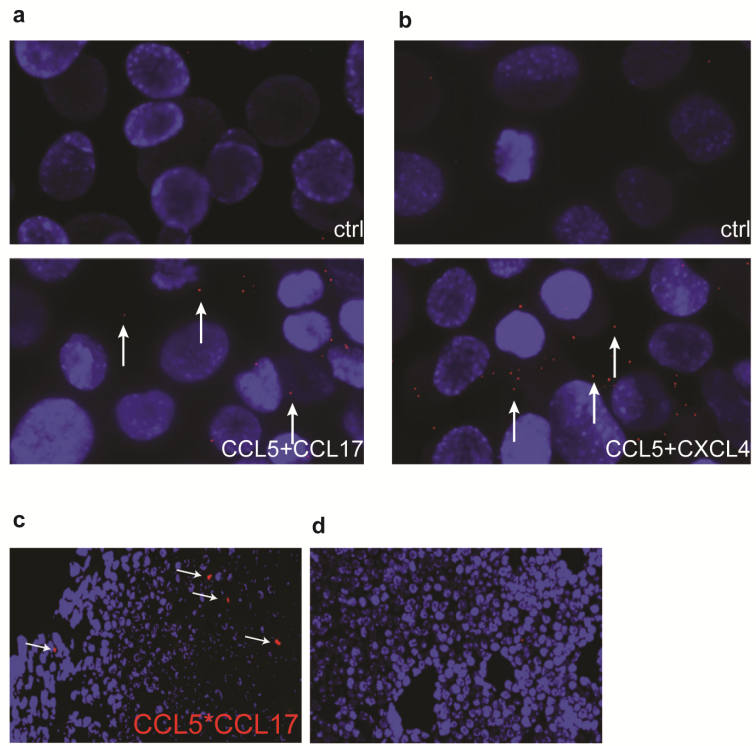

Figure S12: Microscopy of chemokine interactions at the cell surface. (a-d) Interactions of murine CCL5 with CCL17 or CXCL4 were analyzed using an antibody-based proximity-ligation assay (Duolink $₫)$. $(a, b)$ Signals indicative of interaction were detected on the surface of mouse Simian-virus 40-transformed endothelial cells (SVECS) after incubation with CCL5 in combination with CCL17 (a) or CXCL4 (b) (6 nM each) by fluorescence microscopy. The endogenous presence of CCL5-CCL17 (c) was detected by proximity ligation in frozen sections of murine para-aortic lymph nodes but not in controls (d). 

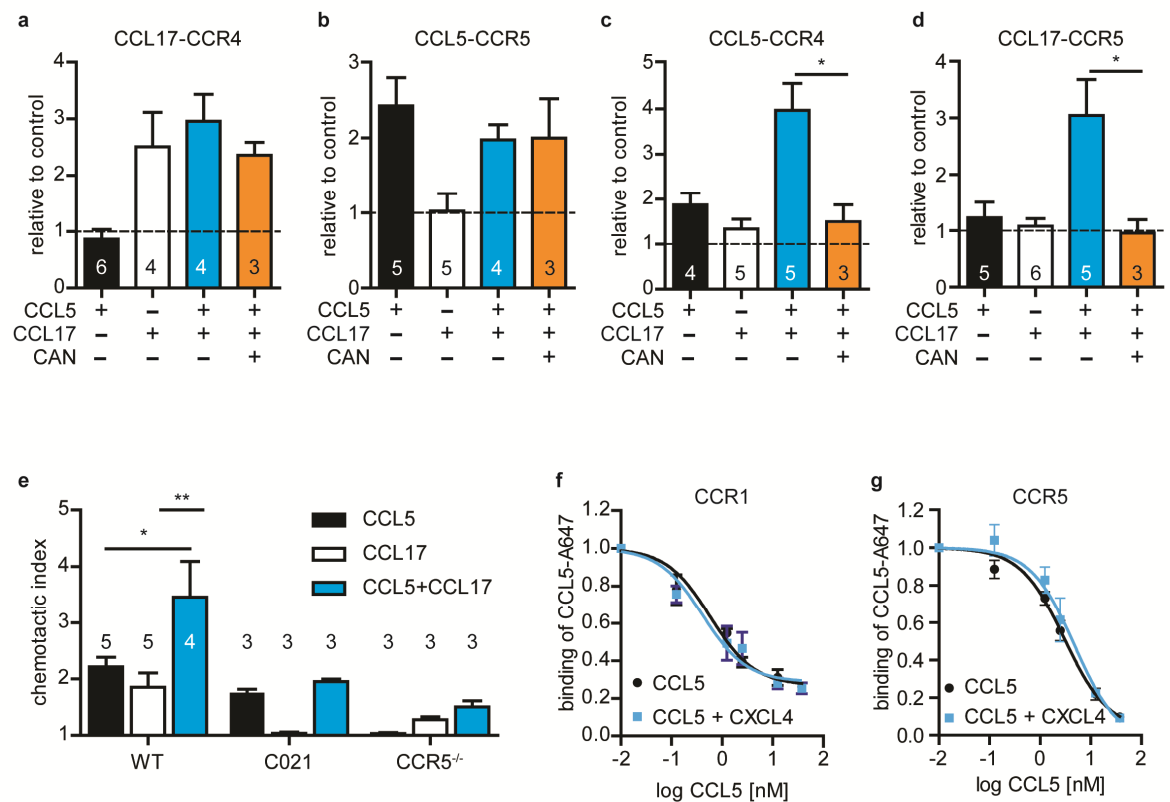

Figure S13: Mechanisms for synergy of chemokine heterodimers. (a-d) Interactions between CCL5, CCL17, CCR4, and CCR5 were detected on the surface of adherent dendritic cells (DCS) using a proximity-ligation assay (Duolink ${ }^{\circledR}$ ) after the cells were incubated with CCL5, CCL17, or both (all at $6 \mathrm{nM}$ ). The proximity ligation signals generated by the direct or indirect interactions between CCL17-CCR4 (a), CCL5-CCR5 (b), CCL5-CCR4 (c), and CCL17-CCR5 (d) were measured. Dashed lines indicate a virtually calculated additive effect (a-d). (e) Migration of activated primary mouse T cells was elicited by CCL5, CCL17, or both (all at $6 \mathrm{nM}$ ) and compared between cells from wild-type (WT) or CCR5-deficient (Ccr5-/-) mice, wild-type (WT) mice or cells pretreated with C021 (a CCR4 inhibitor). (f,g) Binding competition assays were performed, whereby CCL5-Alexa647 (2.5 nM) bound to CCR1-expressing (f) or CCR5-expressing (g) HEK transfectants was displaced by unlabeled CCL5 at indicated concentrations in presence or absence of CXCL4 (40 nM) ( $n=5$ and $n=3$, respectively). Data represent mean $\pm S E M$ from a number of independent experiments, as indicated. ${ }^{*} \varangle 0.05,{ }^{*} \mathrm{p} \varangle \Delta .01$, as analyzed by MannWhitney-test (a-d) or two-way ANOVA (e). 


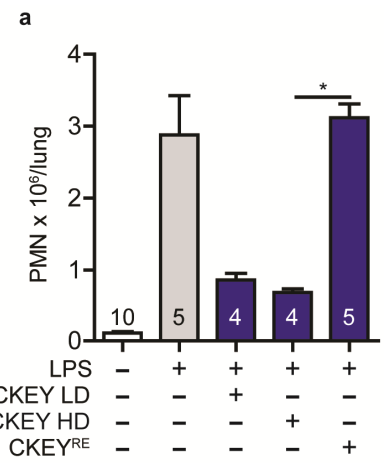

b
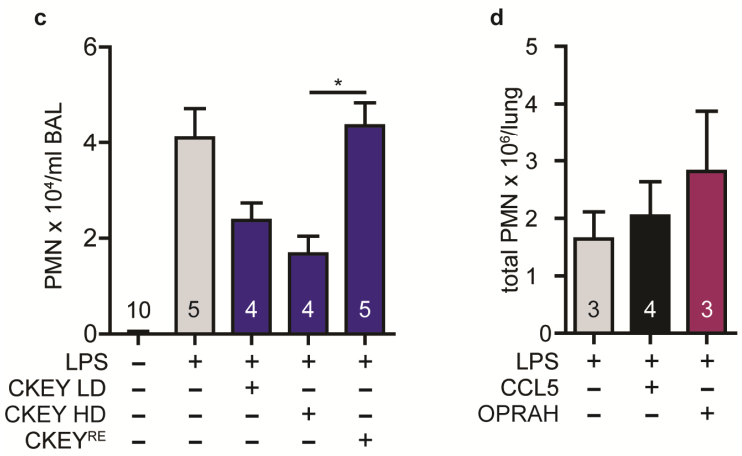

Figure S14: Relevance of chemokine heterodimer formation in acute lung injury. (a-d) Acute lung injury was induced by LPS inhalation of 10 week old female C57/B6 mice and 30 minutes before sacrifice a FITC conjugated Ly6G antibody was injected i.v., to discriminate intravascular from interstitial neutrophils. (a-c) CKEY was injected i.v. at low dose $(1 \mathrm{mg} / \mathrm{kg}$, LD) or high dose (10 mg/kg, HD), as well as the variant CKEY ${ }^{\mathrm{RE}}$ with the substitutions R44A and E26A. Neutrophils were counted by FACS from total lungs (a), the interstitial space (b) or bronchoalveolar lavage (BAL) fluid (c). (d) Lethally irradiated female C57/B6 mice were transplanted at 10 weeks of age with bone marrow from $\mathrm{CCl}^{-1-} \mathrm{CxCl} 4^{-1-}$ mice. Acute lung injury was induced by LPS inhalation and CCL5 $(150 \mu \mathrm{g} / \mathrm{kg}$ ) or the obligate PF4-RANTES heterodimer (OPRAH, $300 \mu \mathrm{g} / \mathrm{kg}$ ) were injected i.v. Neutrophils from total lungs were counted. Data represent mean $\pm S E M$ from the indicated number of independent experiments. $* p<0.05$, as analyzed by Kruskal-Wallis-test. 
a

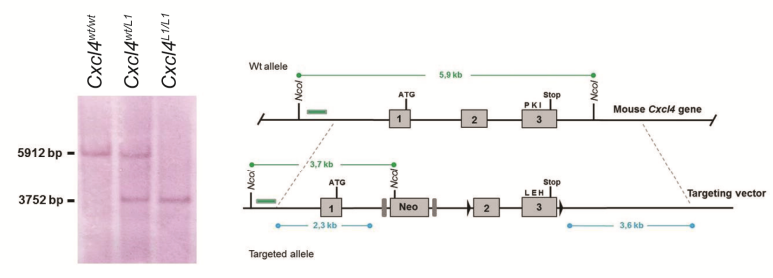

b
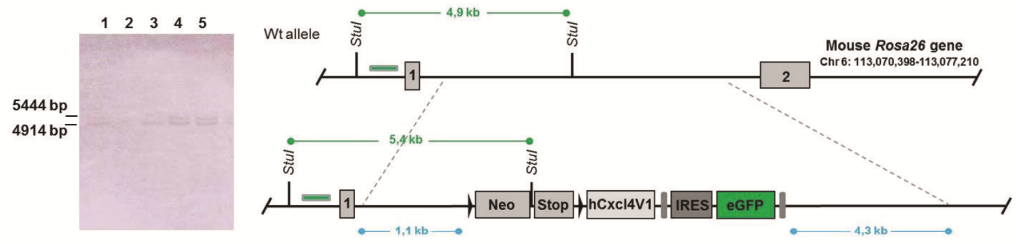

Targeted allele

c
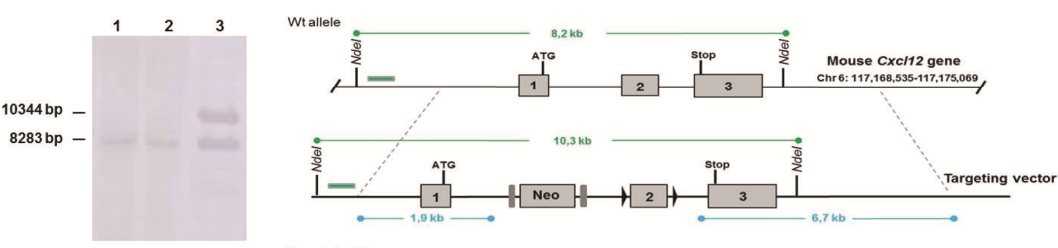

Targeted allele

Figure S15: Generation of mice deficient in $\mathrm{Cxcl} 4$ or $\mathrm{Cxcl} 12$ or carrying $\mathrm{Cxcl} 4$ variants. (a-c) Targeting strategy to generate $\mathrm{Cxcl} 4 \mathrm{l} 1$ knock-in, $\mathrm{Cxcl} 4$ knock-out and $\mathrm{Cxcl} 12$ knock-out mice. The exon-intron structures of the gene loci and the targeting vector (right) and correct targeting as evidenced by southern blotting (left) are shown. Green bars indicate the position of the probe, grey bars indicate flippase recognition target (frt) sites, black triangles indicate loxP sites. (a) $\mathrm{CxCl} 4^{\mathrm{LI} / L 1}$ mice were generated by homolgous recombination with a targeting vector of mutated murine $\mathrm{Cxcl} 4$ (Pf4), which included a $2.3 \mathrm{~kb} 5^{\prime}$ homology arm harboring exon 1, intron 1-2 and a frt-flanked neomycin selection cassette ( $\mathrm{NeO}$ ). The $3^{\prime}$ recombination arm spanned 3.6 $\mathrm{kb}$, loxP sites flanked exons 2-3 (the coding part of $\mathrm{Cxcl} 4$ gene) substituting prolin P64 by leucin $(\mathrm{L})$, lysine $\mathrm{K} 72$ by glutamate $(\mathrm{E})$ and isoleucine 173 by histidine $(\mathrm{H})$ to obtain the murine orthologue of human CXCL4L1. CxCl4 ${ }^{-1-}$ mice resulted from off-springs of CreERT2-CxCI4L1/L1 parents after ubiquitous deletion of $\mathrm{Cxcl} 4$ by tamoxifen. Southern blots demonstrated wild-type $\mathrm{Cxc} / 4^{\mathrm{wt} / \mathrm{wt}}$ and correct targeting of heterozygous $\mathrm{Cxcl} 4^{\mathrm{wt} / \mathrm{L} 1}$ and homozygous $\mathrm{CxCl} 4^{\mathrm{w} / \mathrm{Ll}}$. (b) Transgenic $\mathrm{CxCl}^{\mathrm{tg}-\mathrm{Ll}}$ mice were generated by inserting the human CXCL4L1 gene into the Rosa26 locus. The targeting vector contained a $1.1 \mathrm{~kb} \mathrm{5'}$ arm harboring intron 1-2, a Neo selection and Stop cassettes flanked by loxP sites, IRES and eGFP were flanked by frt sites. The $3^{\prime}$ recombination arm spanned $4.3 \mathrm{~kb}$ containing intron 1-2. Southern blots demonstrated correctly targeted ES clones (4 and 5). (c) Shown is the mouse Cxcl12 locus and the targeting vector consisting of a $1.9 \mathrm{~kb} 5^{\prime}$ homolgy arm including exon 1 and intron 1-2, frt-flanked Neo, loxP-flanked exon 2 and the $3^{\prime}$ recombination arm spanning $6.7 \mathrm{~kb}$. Southern blots show wildtype $(1,2)$ and correctly targeted heterozygous (3) ES clones. Cxcl12 $2^{-1-}$ mice were generated by conditional inactivation of $\mathrm{Cxcl} 12$ by intercrossing CreERT2 and injecting tamoxifen i.p. 
a
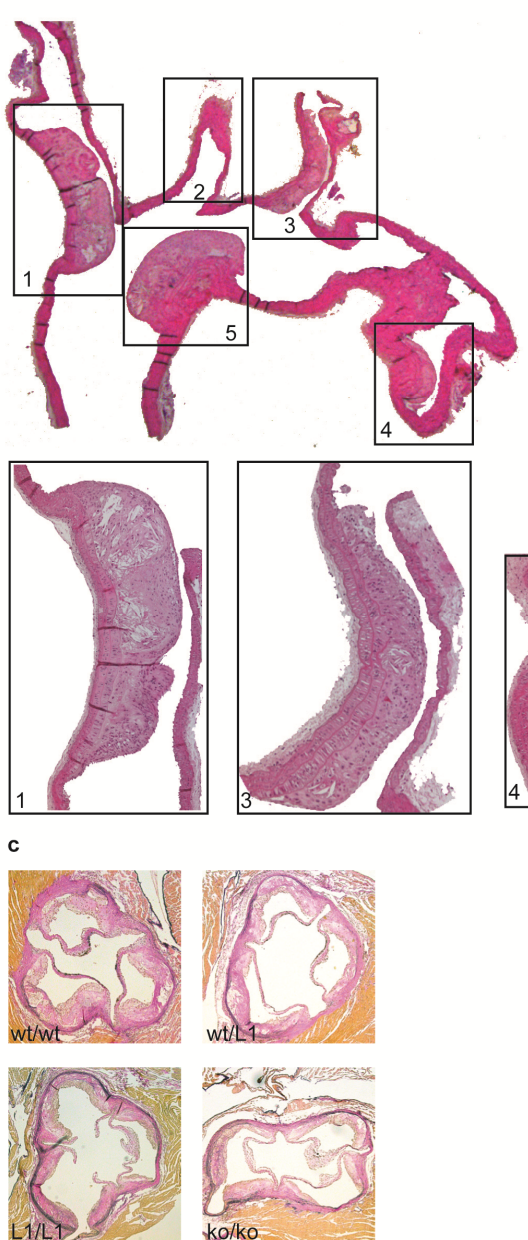
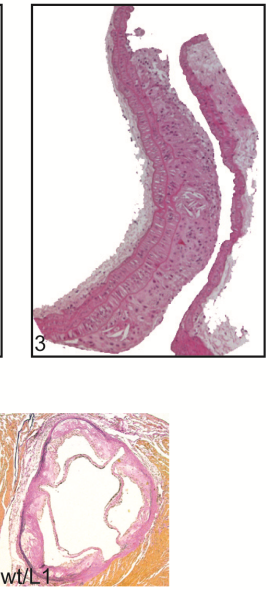

135er d

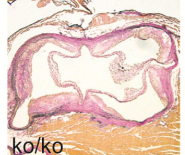

b
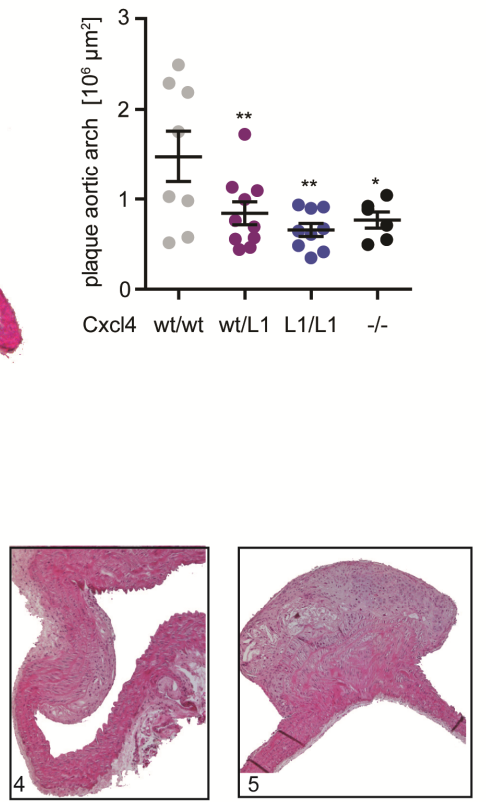

d

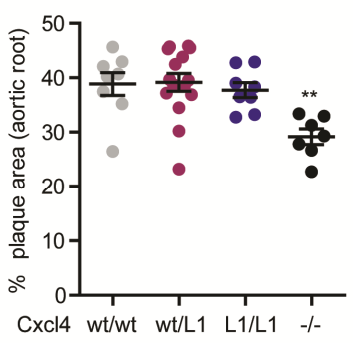

Figure S16: Analysis of atherosclerotic lesion in mice expressing $\mathrm{Cxcl} 4$ or its variant. (a) Overview and zoom-in insets of a longitudinal section through the aortic arch presenting typical sites of plaque development (1: brachiocephalic trunc; 2: left common carotid artery; 3: left subclavian artery; 4: arch; 5: lesser curvature). (b-d) Apoe - $^{--}$mice homozygous for wild-type Cxcl4 (wt/wt), heterozygous for Cxcl4 and Cxcl4l1 (wt/L1), homozygous for CxCl4|1 (L1/L1), or deficient for $\mathrm{Cxcl} 4$ and $\mathrm{Cxcl} 4 \mathrm{I} 1$ (-/-) were fed a HFD for 12 weeks. (c) Shown are representative Elastica-van Gieson (EVG) staining of aortic root cross-sections. (d) Quantification of (c). Data represent mean \pm SEM from the indicated number of mice. ${ }^{*} p<0.05, * * p<0.01$ versus wt/wt, as analyzed by one-way ANOVA $(b, d)$. 

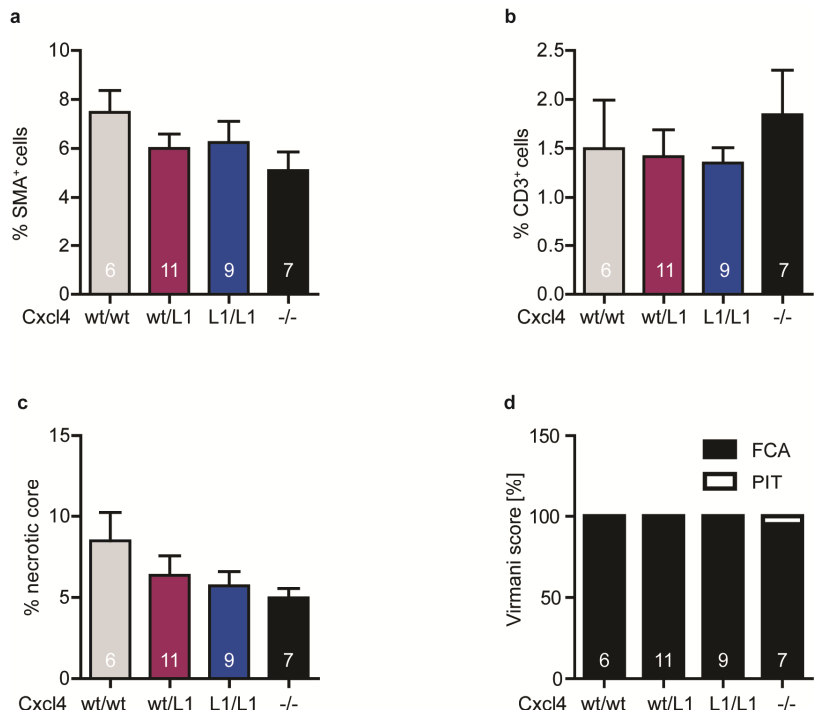

Figure S17: Composition of aortic root lesions in mice expressing CxCl4 or its variant. Apoe ${ }^{-1-}$ mice homozygous for wild-type Cxcl4 (wt/wt), heterozygous for Cxcl4 and Cxcl4l1 (wt/L1), homozygous for Cxcl4I1 (L1/L1), or deficient for Cxcl4 and Cxcl4l1 (-/-) were fed a HFD for 12 weeks. Cross-sections of paraffin-embedded roots were analyzed for the content (percentage) of smooth muscle cells by staining smooth muscle-actin (SM A) (a), of T cells by staining CD3 (b), for necrotic core (c) or for staging the plaque phenotype according to the Virmani classification into advanced i.e. fibrous cap atheroma (FCA) or early lesions i.e. pathological intimal thickening (PIT) (d). Data represent mean $₫$ SEM from the indicated number of mice, as analyzed by Kruksal-Wallis-test (a-c).
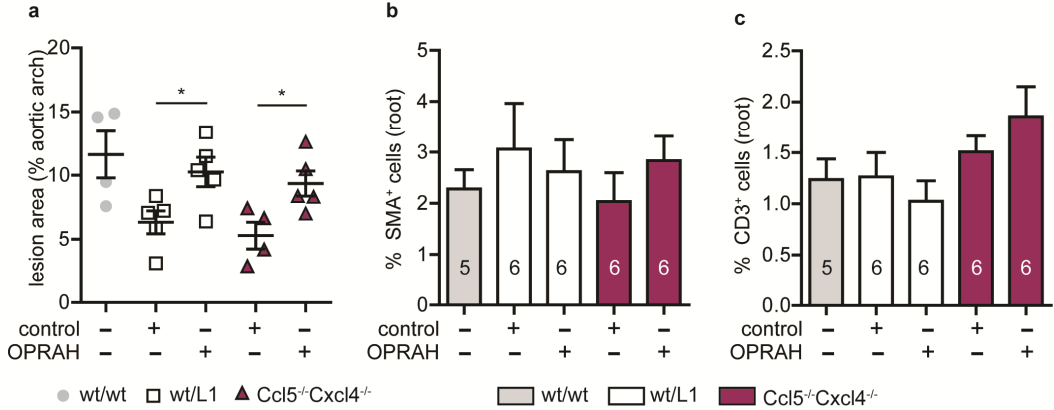

Figure S18: Obligate chemokine heterodimers mimic natural heterodimers. Apoe ${ }^{-1-}$ mice, homozygous for wild-type Cxcl4 (wt/wt), heterozygous for Cxcl4 and Cxcl4l1 (wt/L1), or deficient for $\mathrm{Cxcl} 4$ and $\mathrm{CCl} 5\left(\mathrm{Cll}^{-1-} \mathrm{CxCl}^{-1-}\right)$ were fed a HFD for 6 weeks. Atherogenesis was exacerbated by injecting i.p. the obligate RANTESPF4 heterodimer (OPRAH) or saline (control) 3 times a week for 6 weeks. Shown is the lesion size of the aortic arch (a) content of SMA+ smooth muscle cells in aortic root plaque (b) and CD3+T cells (c). Data represent mean $\pm S E M$ from the indicated number of mice. ${ }^{*} p \varangle 0.05$, as analyzed by $M$ ann-Whitney-test). 


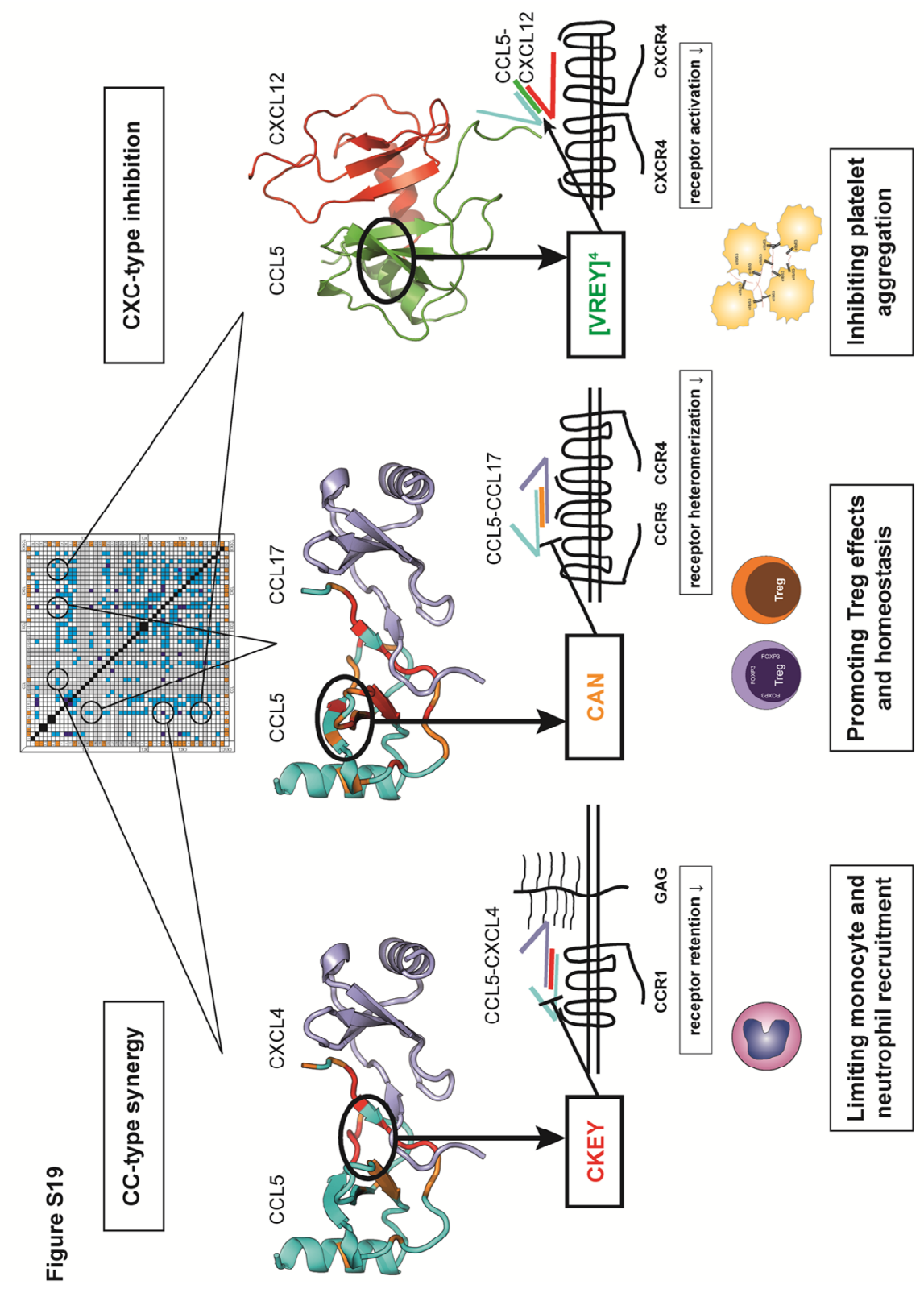




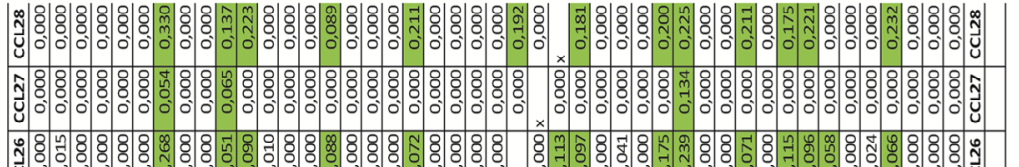

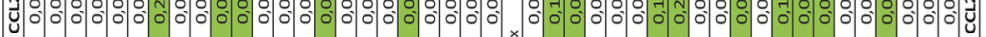
ปุ

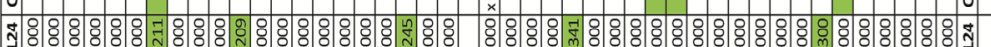
ปู 行: งิ ปु

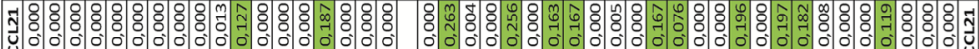

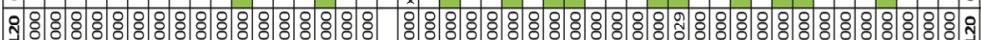

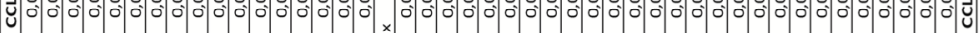
ᄀ

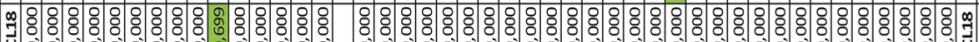

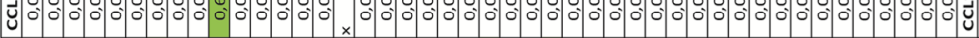

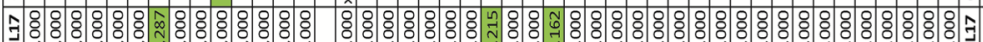
Uु ป :

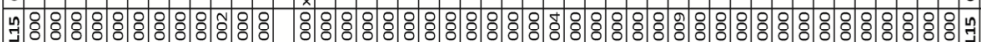

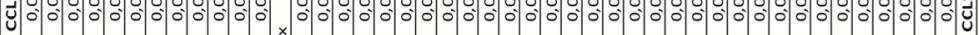

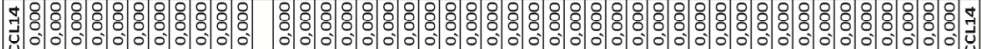

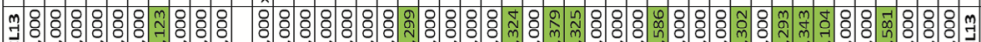

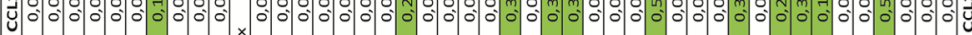

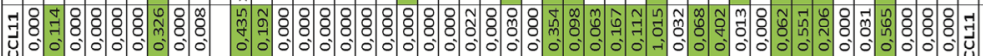
ปี

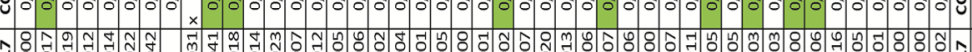
Uु

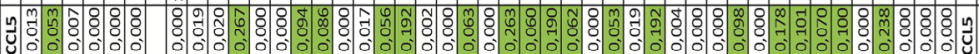
ง $400^{\circ} 0^{\circ} 0^{\circ} \times 0^{\circ} 0^{\circ} 0^{\circ} 0^{\circ} 0^{\circ} 0^{\circ} 0^{\circ} 0^{\circ} 0^{\circ} 0^{\circ} 0^{\circ} 0^{\circ} 0^{\circ} 0^{\circ} 0^{\circ} 0^{\circ} 0^{\circ} 0^{\circ} 0^{\circ} 0^{\circ} 0^{\circ} 0^{\circ} 0^{\circ} 0^{\circ} 0^{\circ} 0^{\circ} 0^{\circ} 0^{\circ} 0^{\circ} 0^{\circ} 0^{\circ} 0^{\circ} 0^{\circ} 0^{\circ} 0^{\circ} 0^{\circ} 0^{\circ} 0^{\circ} 0^{\circ}$

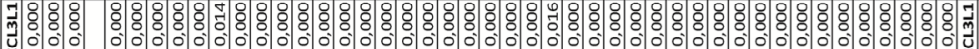

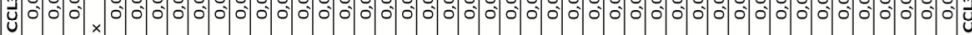

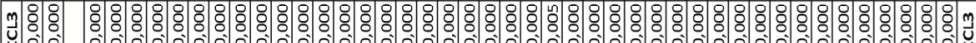
$000 \times 1000000000000000000000000000000000000000000010$

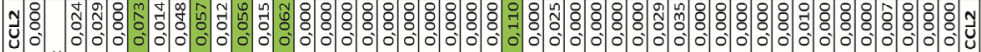

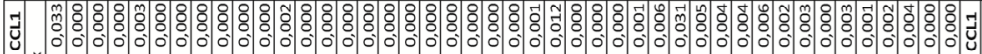

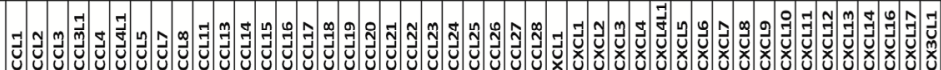

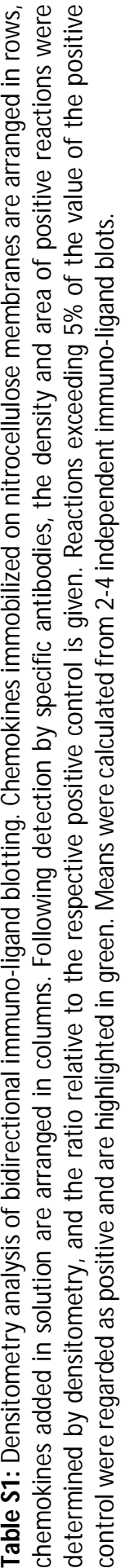




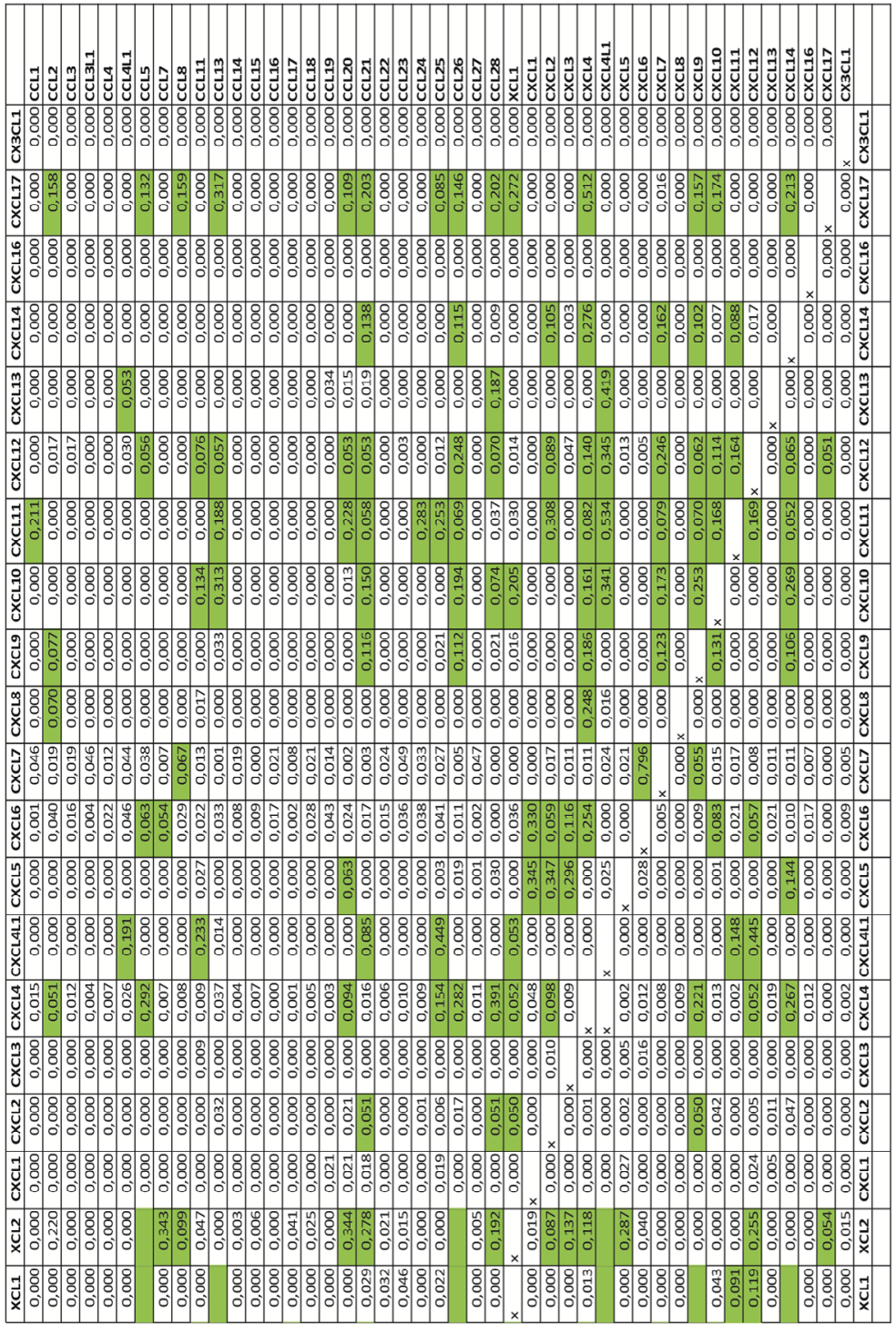

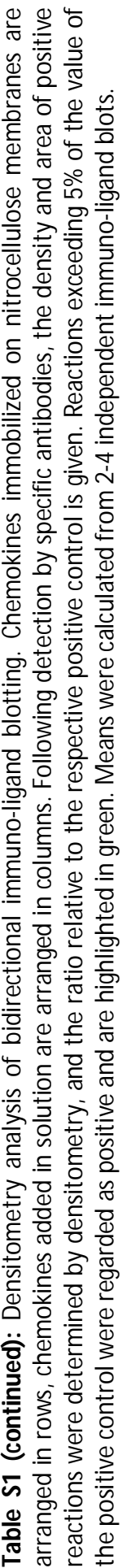




\begin{tabular}{|c|c|c|c|}
\hline Chemokine & $\mathrm{k}_{\mathrm{a}}\left(\mathrm{M}^{-1} \mathrm{~S}^{-1}\right) \times 10^{4}$ & $\mathrm{k}_{\mathrm{d}}\left(\mathrm{s}^{-1}\right) \times 10^{-4}$ & $K_{D}(n M)$ \\
\hline \multicolumn{4}{|l|}{ CCL5 chip } \\
\hline $\mathrm{CCl} 2$ & $1.5 \pm 0.6$ & $15 \pm 6.1$ & $95 \pm 40$ \\
\hline CCL11 & $286 \pm 115$ & $1450 \pm 667$ & $51 \pm 11$ \\
\hline CCL17 & $169 \pm 25$ & $161 \pm 35$ & $9.6 \pm 1.5$ \\
\hline CXCL4 & $45 \pm 19$ & $18 \pm 6.4$ & $4.1 \pm 1.8$ \\
\hline $\mathrm{CXCL} 4^{\mathrm{R} \times \mathrm{Q}}$ & $30 \pm 17$ & $11 \pm 0.1$ & $4.5 \pm 2.6$ \\
\hline CXCL4L1 & 0 & - & - \\
\hline CXCL7 & $11 \pm 2.2$ & $30 \pm 18$ & $27 \pm 16$ \\
\hline CXCL10 & $24 \pm 1.5$ & $21 \pm 3.2$ & $8.8 \pm 1.9$ \\
\hline CXCL12 & $1.6 \pm 0.1$ & $94 \pm 5.8$ & $578 \pm 61$ \\
\hline \multicolumn{4}{|l|}{ CXCL4 chip } \\
\hline CCL5 & $20 \pm 14$ & $7.7 \pm 2.7$ & $5.2 \pm 2.8$ \\
\hline CCL5 $5^{\text {tobs }}$ & $3.2 \pm 0.1$ & $2.2 \pm 0.1$ & $6.7 \pm 0.5$ \\
\hline $\mathrm{CCL}^{\mathrm{MTT}}$ & 0 & - & - \\
\hline$C C L 5^{\mathrm{L} 2 \mathrm{AA}}$ & $9.2 \pm 5.2$ & $499 \pm 110$ & $678 \pm 365$ \\
\hline CCL5 $5^{\text {44AANA4I }}$ & 0 & - & - \\
\hline CXCL7 & 0 & - & - \\
\hline CXCL8 & $0.3 \pm 0.1$ & $2.9 \pm 0.4$ & $105 \pm 11$ \\
\hline CXCL12 & $33 \pm 9.1$ & $113 \pm 28$ & $35 \pm 8.6$ \\
\hline \multicolumn{4}{|l|}{ CXCL12 chip } \\
\hline CXCL4 & $2.2 \pm 0.7$ & $4.6 \pm 2.9$ & $20 \pm 7.4$ \\
\hline CXCL4L1 & $10 \pm 6.1$ & $12 \pm 5.7$ & $13 \pm 6.1$ \\
\hline CCL5 & $4.9 \pm 1.2$ & $159 \pm 80$ & $298 \pm 119$ \\
\hline$C C L 5^{\text {tobs }}$ & $42 \pm 29$ & $1415 \pm 1217$ & $319 \pm 60$ \\
\hline \multicolumn{4}{|l|}{ CCL17 chip } \\
\hline CCL5 & $16 \pm 3.3$ & $14 \pm 2.1$ & $8.6 \pm 1.8$ \\
\hline$C C L 5^{\text {tobs }}$ & $69 \pm 4.8$ & $27 \pm 4.5$ & $3.9 \pm 0.4$ \\
\hline $\mathrm{CCL}^{\mathrm{MII}}$ & $0.8 \pm 0.2$ & $11 \pm 2.2$ & $145 \pm 64$ \\
\hline$C C L 5^{\mathrm{t} \angle \mathrm{A} A}$ & $49 \pm 0.8$ & $20 \pm 3.9$ & $4.1 \pm 0.8$ \\
\hline CCL5 5 44AANA4/ & $8.5 \pm 1.4$ & $25 \pm 2.9$ & $30 \pm 5.5$ \\
\hline
\end{tabular}

Table S2: Kinetics analysis of chemokine binding by surface plasmon resonance. Biotinylated CCL5, CXCL4, CXCL12 and CCL17 were immobilized on neutravidin-coated C1 sensor chips. Analytes were injected over the 2 flow cells at flow rates and concentrations described in Online Methods. All kinetic rate analyses were performed in running buffer, $\mathrm{pH} 7.4$ at $25^{\circ} \mathrm{C}$ $(n=3)$. Responses from analyte injections were overlaid with the fit of a 1:1 interaction model to determine on-rates $\left(k_{a}\right)$, off-rates $\left(k_{d}\right)$, and dissociation constants $\left(K_{D}\right)$. 


\begin{tabular}{|c|c|c|c|c|c|c|}
\hline & $\begin{array}{l}\text { Alntensity } \\
\text { (top 10) }\end{array}$ & $\begin{array}{l}\text { DIntensity } \\
\text { (all) }\end{array}$ & $\begin{array}{l}\text { Ratio } \\
\text { (10/all) }\end{array}$ & $\begin{array}{l}\text { Dimer } \\
\text { type } \\
\text { preferred }\end{array}$ & $\begin{array}{l}\Delta G \text { for } \\
C C- \\
\text { type }\end{array}$ & $\begin{array}{l}\Delta G \text { for } \\
C X C- \\
\text { type }\end{array}$ \\
\hline $\mathrm{CCL}^{\mathrm{E} 66 \mathrm{~S}} / \mathrm{CCL} 17$ & 0.85 & 0.37 & 2.3 & CC & & \\
\hline CCL5/CCL17 & & & & $\mathrm{CC}$ & -61.3 & -45.7 \\
\hline $\mathrm{CCL}^{\mathrm{E} 66 \mathrm{~S}} / \mathrm{CXCL} 4$ & 0.25 & 0.11 & 2.3 & $\mathrm{CC}$ & -53.2 & -40.3 \\
\hline CCL5/CXCL4 & & & & CC & -62.6 & -44.9 \\
\hline $\mathrm{CCL}^{\mathrm{E} 66 \mathrm{~S}} / \mathrm{CCL} 12$ & 0.48 & 0.37 & 1.3 & $\mathrm{CC} / \mathrm{CXC}$ & & \\
\hline CCL5/CCl12 & & & & CC & -56.8 & -34.6 \\
\hline $\mathrm{CCL5}^{\mathrm{to6s}} / \mathrm{CXCL12}$ & 0.15 & 0.11 & 1.4 & $\mathrm{CXC} / \mathrm{CC}$ & -7.9 & -44.5 \\
\hline CCL5/CXCL12 & & & & CXC & -7.5 & -31.5 \\
\hline CXCL4/CXCL12 & & & & CXC & -3.0 & -67.7 \\
\hline $\mathrm{CCL}^{\mathrm{t665}} / \mathrm{CCL} 3$ & 0.7 & 0.61 & 1.1 & none & & \\
\hline
\end{tabular}

Table S3: Weighted averaging of $\Delta$ Intensity changes and MDS-based in silico modeling. The changes in resonance intensity ( $\Delta$ Intensity) of ${ }^{1} \mathrm{H}-{ }^{15} \mathrm{~N}$ resonances in heteronuclear single quantum coherence spectra of ${ }^{15} \mathrm{~N}-\mathrm{CCL}^{\mathrm{E} 66 \mathrm{~S}}$ in the presence of indicated $\mathrm{CXC}$ and $\mathrm{CC}$ chemokines were recorded and calculated as 1 minus the ratio presence/absence of any given chemokine. Average $\Delta$ Intensity values are shown; "top 10" indicates the average of the 10 resonances showing the greatest reduction in intensity; "all" means the average over all resonances. Free energies $(\Delta G)$ for various pairs of chemokines were calculated from molecular dynamics simulations (MDS) of pre-constructed CC-type or CXC-type heterodimers, as indicated. Values assessed using data from $100-130 \mathrm{~ns}$ of $M D$ simulation. $\Delta \mathrm{G}$ values are given in $\mathrm{kcal} / \mathrm{mol}$.

\begin{tabular}{|llll|}
\hline Peptide & Sequence & Configuration & CCL5 origin \\
\hline CCL5 $^{1-33}$ & SPYSSDTTPCCFAYIARPLPRAHIKEYFYTSGK & Linear & $1-33$ \\
CKEY $^{\text {CKEY }}$ & CKEYFYTTSGKCSNPAVVFITRC & Cyclic & $25-45$ \\
CAN & CKAYFYTTSGKCSNPAVVFITAC & Cyclic & $25-45$ \\
VREY & CKSSNPAVVFVTRKNRQVSANC & Cyclic & $33-53$ \\
[VREY] $^{4}$ & EKKWVREYINSLEM S & Linear & $54-68$ \\
\hline
\end{tabular}

Table S4: Sequence and origin of peptide inhibitors. * The synthetic unprotected pro-helical VREY $\alpha$ COSH peptide was reacted with a templateassembled synthetic protein (TASP) molecule resulting in a 4-helix TASP. 


\begin{tabular}{|c|c|c|c|}
\hline Peptide Inhibitor & Ligand (immobilized) & Analyte (soluble) & $\mathrm{IC}_{50}(\mu \mathrm{M})$ \\
\hline \multirow[t]{3}{*}{$\mathrm{CCL}^{1-33}$} & CCL5 & CXCL4 & 1.7 \\
\hline & CCL17 & CCL5 & 0.24 \\
\hline & CXCL12 & CCL5 & 2.4 \\
\hline \multirow[t]{3}{*}{ CKEY } & CCL5 & CXCL4 & 1.9 \\
\hline & $\mathrm{CCl} 17$ & CCL5 & ND \\
\hline & CXCL12 & CCL5 & ND \\
\hline $\mathrm{CKEY}^{\mathrm{RE}}$ & CCL5 & CXCL4 & ND \\
\hline \multirow[t]{3}{*}{ CAN } & CCL5 & CXCL4 & ND \\
\hline & CCL17 & CCL5 & 0.27 \\
\hline & CXCL12 & CCL5 & ND \\
\hline \multirow[t]{3}{*}{ [VREY] $^{4}$} & CCL5 & CXCL4 & ND \\
\hline & CCL17 & CCL5 & ND \\
\hline & CXCL12 & CCL5 & 2.7 \\
\hline
\end{tabular}

Table S5: CCL5 derived peptides specifically inhibit heterodimer formation of CCL5. Chemokines were biotinylated and immobilized on neutravidin-coated $\mathrm{Cl}$ sensor chips. The RU signal of the soluble chemokine was obtained at $50 \mathrm{nM}$. The inhibition of chemokine heterodimerization by the peptides $\mathrm{CCL} 5^{1-33}, \mathrm{CKEY}, \mathrm{CKEY}{ }^{\mathrm{RE}}, \mathrm{CAN}$, and [VREY] $]_{4}$ was tested at increasing concentrations and is indicated by IC50 values ( $n=3)$. Owing to aggregation of peptides, IC50 values $>5.0 \mu \mathrm{M}$ could not be determined (ND).

\begin{tabular}{|lccccc|}
\hline CXCL4 genotype & CXCL4 $^{\text {wt/wt }}$ & CXCL4 $^{\text {w/LL }}$ & CXCL4 $^{\text {LI/LI }}$ & CXCL4 $^{-1-}$ & P-value \\
\hline Cholesterol $(\mathrm{mg} / \mathrm{dl})$ & $1048 \pm 202$ & $1088 \pm 146$ & $1152 \pm 177$ & $1017 \pm 88$ & ns \\
Triglycerides $(\mathrm{mg} / \mathrm{dl})$ & $394 \pm 179$ & $426 \pm 144$ & $256 \pm 120$ & $379 \pm 159$ & $\mathrm{~ns}$ \\
Body weight $(\mathrm{g})$ & $22.9 \pm 1.7$ & $26.1 \pm 4.4$ & $25.9 \pm 3.1$ & $25.3 \pm 2.5$ & $\mathrm{~ns}$ \\
& & & & & \\
RBC $\left(10^{6} / \mu \mathrm{L}\right)$ & $9.1 \pm 0.4$ & $8.9 \pm 0.6$ & $8.9 \pm 0.5$ & $9.5 \pm 0.4$ & ns \\
WBC $\left(10^{3} / \mu \mathrm{L}\right)$ & $4.5 \pm 1.4$ & $4.5 \pm 1.3$ & $5.3 \pm 1.8$ & $4.5 \pm 1.5$ & ns \\
& & & & & \\
Lymphocytes $\left(10^{3} / \mu \mathrm{L}\right)$ & $3.1 \pm 1.1$ & $3.2 \pm 1.0$ & $4.0 \pm 1.3$ & $3.2 \pm 1.2$ & ns \\
Neutrophils $\left(10^{3} / \mu \mathrm{L}\right)$ & $1.3 \pm 0.7$ & $1.2 \pm 0.4$ & $1.1 \pm 0.6$ & $1.2 \pm 0.4$ & ns \\
Platelets $\left(10^{3} / \mu \mathrm{L}\right)$ & $1019 \pm 204$ & $844 \pm 242$ & $868 \pm 280$ & $937 \pm 229$ & ns \\
\hline
\end{tabular}

Table S6: Lipid parameters and peripheral blood counts of different CXCL4 genotypes. Wild-type mice (wt/wt), homozygous CXCl4 ${ }^{L 1 / L 1}$ mice with a CXCL4 knock-out and knock-in of the human variant CXCL4L1, heterozygous $\mathrm{CxCl}^{\mathrm{L1} /+}$ mice and $\mathrm{CxCl} 4$-deficient $\mathrm{CxCl} 4^{-1-}$ mice on a Apoe ${ }^{-1-}$ genetic background were fed a high-fat diet for 12 weeks. Lipid parameters, body weight and differential peripheral blood counts were determined using standard methodology. Data represent mean \pm SEM from 8-15 mice, analyzed by Kruskal-Wallis-test (ns; not significant). 


\begin{tabular}{|c|c|c|c|c|c|c|}
\hline Genotype & $\mathrm{Wt} / \mathrm{wt}$ & $\mathrm{CXCL4}{ }^{\mathrm{L} / \mathrm{wt}}$ & $\mathrm{CXCL} 4^{\mathrm{L} / \mathrm{wt}}$ & $\begin{array}{l}\mathrm{CCL}^{-1-} \\
\mathrm{CXCL}^{-/-}\end{array}$ & $\begin{array}{l}\mathrm{CCL5}^{-1-} \\
\mathrm{CXCL4}^{-/-}\end{array}$ & $\begin{array}{c}\mathrm{P}- \\
\text { value }\end{array}$ \\
\hline Treatment & ctrl & ctrl & OPRAH & ctrl & OPRAH & \\
\hline $\begin{array}{l}\text { Cholesterol } \\
(\mathrm{mg} / \mathrm{dl})\end{array}$ & $\begin{array}{c}1019 \pm \\
182\end{array}$ & $905 \pm 103$ & $969 \pm 169$ & $968 \pm 124$ & $754 \pm 239$ & ns \\
\hline $\begin{array}{l}\text { Triglycerides } \\
\text { (mg/dl) }\end{array}$ & $140 \pm 50$ & $121 \pm 28$ & $105 \pm 20$ & $152 \pm 56$ & $93 \pm 66$ & ns \\
\hline Body weight (g) & $25.2 \pm 2.6$ & $23.0 \pm 1.9$ & $23.6 \pm 2.6$ & $31.7 \pm 2.2$ & $31.8 \pm 4.6$ & ns \\
\hline $\mathrm{RBC}\left(10^{6} / \mu \mathrm{L}\right)$ & $9.1 \pm 0.2$ & $8.6 \pm 1.2$ & $9.1 \pm 0.3$ & $9.1 \pm 0.5$ & $8.2 \pm 1.1$ & ns \\
\hline WBC $\left(10^{3} / \mu \mathrm{L}\right)$ & $4.2 \pm 0.8$ & $3.7 \pm 0.9$ & $3.8 \pm 0.8$ & $4.0 \pm 0.9$ & $3.6 \pm 0.4$ & ns \\
\hline $\begin{array}{l}\text { Lymphocytes } \\
\left(10^{3} / \mu \mathrm{L}\right)\end{array}$ & $3.0 \pm 0.6$ & $2.5 \pm 0.7$ & $2.7 \pm 0.6$ & $2.8 \pm 0.9$ & $2.4 \pm 0.4$ & ns \\
\hline $\begin{array}{l}\text { Neutrophils } \\
\left(10^{3} / \mu \mathrm{L}\right)\end{array}$ & $1.1 \pm 0.2$ & $1.1 \pm 0.3$ & $1.0 \pm 0.2$ & $1.2 \pm 0.3$ & $1.1 \pm 0.2$ & ns \\
\hline $\begin{array}{l}\text { Platelets } \\
\left(10^{3} / \mu \mathrm{L}\right)\end{array}$ & $822 \pm 97$ & $777 \pm 194$ & $821 \pm 86$ & $1102 \pm 45$ & $\begin{array}{c}1213 \pm \\
319\end{array}$ & ns \\
\hline
\end{tabular}

Table S7: Effect of OPRAH on lipid parameters and peripheral blood counts. Wild-type mice (wt/wt), heterozygous $\mathrm{Cxcl} 4^{\mathrm{LL} / \mathrm{wt}}$ mice and $\mathrm{CCl}^{-1-} \mathrm{Cxcl} 4^{-1-}$ mice on an $\mathrm{Apoe}^{-/-}$genetic background were fed a high-fat diet for 6 weeks and were treated (i.p.) with vehicle (ctrl) or OPRAH (10 $\mu \mathrm{g}$, twice a week). Lipid parameters, body weight and differential peripheral blood counts were determined using standard methodology. Data represent mean \pm SEM from 5-6 mice, analyzed by Kruskal-Wallis-test (ns; not significant). 



\section{Chapter 7}

\section{Covalent attachment of tissue type plasminogen activator to fibrin through $\mathrm{N}$ - terminal modification with a fibrin}

crosslinking sequence from $\alpha_{2}$-Antiplasmin Agten SM, van de Vijver P, Swieringa F, Scheer L, Hackeng TM in preparation 


\section{Abstract}

We present the site-specific modification of a thrombolytic drug, recombinant tissue plasminogen activator (tPA). A main disadvantage of the current tPA thrombolytic therapy is the risk on bleeding. To partly overcome this, a tPA molecule with very high affinity for fibrin would be required. We therefore modified tPA with the A14 peptide derived from the $\mathrm{N}$-terminus of $\alpha_{2}$-antiplasmin. The A14 peptide is covalently linked to fibrin polymers by factor XIIIa and can thus be used to exclusively site-direct tPA to its target by covalent coupling to the fibrin-stabilized blood clot. Site specific modification of the large serine protease was achieved by oxidation of the $\mathrm{N}$-terminal serine followed by oxime ligation of the resulting glyoxyloyl protein with an aminooxyacetyl functionalized A14 peptide. We showed that other groups prone to oxidation (glycosylated amino acids) were not affected by the oxidation strategy. The activity of the synthesized chimera proteins was tested both in static conditions as well as under flow in a plasma clot lysis assay. Chimera proteins showed no difference in activity compared to TPA, which was explained by potential restricted mobility of the protease on the fibrin mesh by the covalent attachment to the clot. Although the activity of tPA was not enhanced, the protein was successfully site-specifically modified using $\mathrm{N}$-terminal serine oxidation showing the selective efficacy of modification of large post-translationally modified proteins.

\section{Introduction}

Clinically approved drugs can be modified to improve their mode of action and decrease their side effects. Thrombolytic drugs dissolve blood clots by activating plasminogen to plasmin that subsequently cleaves fibrin clots into soluble components.[1, 2] Clinically used thrombolytic drugs are alteplase (recombinant tissue plasminogen activator, tPA), reteplase (single chain, unglycosylated mutant of tPA), tenecteplase (recombinant tissue plasminogen activator mutated at three positions) and urokinase (uPA). Both TPA and UPA are large serine proteases (527 aa and 411 aa) that are used to treat different thrombolytic events.[1, 3-6] While tPA is widely used to treat for example acute myocardial infarction and cerebral stroke, UPA is mainly used in case of pulmonary embolisms. [7, 8]

Although recombinant tPA has been approved for clinical use since 1984 it has some disadvantages. The efficacy of tPA is limited which results in requirement of high doses and consequently the main side effect is an increased bleeding tendency.[1, 4] Modification of tPA could improve its efficacy and decrease the risk of bleeding complications. Our hypothesis is that this can be achieved by coupling of a peptide derived from the $\mathrm{N}$-terminus of $\alpha_{2}$-antiplasmin $\left(\alpha_{2}-\mathrm{AP}\right)$; a serine protease inhibitor that inhibits plasmin. [9] The N-terminus of $\alpha_{2}$-AP is covalently linked to fibrin by FXIIIa during clot formation.[10] In this way, fresh clots that prevent blood loss are 
protected against early lysis by plasmin. A chimera of tPA and the $\mathrm{N}$-terminus of $\alpha_{2}-\mathrm{AP}$ (A14) can thus target tPA to pathological fibrin clots and covalently attach tPA to the clot. This may lead to a higher efficacy of tPA resulting in lower doses of tPA and a decrease in bleeding tendencies during thrombolytic therapy. A similar recombinant chimera of $\alpha_{2}$-antiplasmin and uPA has been reported, however no benefit was seen in vivo.[11] A possible explanation for this observation is that attachment of the $\alpha_{2}$ antiplasmin sequence to UPA compromised the folding and activity of the UPA part of the hybrid. Therefore, the aim of the current study was to modify a native, correctly folded thromobolytic enzyme, tPA, with a fibrin crosslinking sequence derived from $\alpha_{2}$-antiplasmin by specific coupling to the $\mathrm{N}$-terminus and to assess of the fibrinolytic activity of this chimeric protein.

Site specific modification of large and complex proteins is most often a difficult task to achieve since proteins contain many functional groups. In the case of tPA two locations for site specific modification were available, the first was a free cysteine to which maleimides can be coupled (cysteine-83), and the second was an N-terminal serine that can be oxidized to form a glyoxyloyl-protein which can subsequently be modified using oxime ligation (Scheme 1).[12, 13]<smiles>N[C@@H](CO)C(=O)[In]=[W]</smiles>

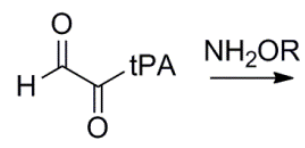<smiles>[R]O/N=C/C(=O)C(C)C</smiles>

Scheme 1: Schematic representation of the oxidation of the N-terminal serine of tPA followed by the reaction of the resulting glyoxyloyl-peptide with an aminooxy to form an oxime.

The oxime ligation is particularly useful since it can be performed using unprotected, folded proteins because of the orthogonal nature of oxime chemistry.[14] M oreover, tPA's free cysteine was found to be partially blocked as it exists in a mixed disulfide bond with glutathione and a free cysteine making modification more difficult.[15] Therefore, the chosen approach was to modify tPA via the N-terminal serine. Peptides were used to model the oxidation reaction after which tPA was conjugated to A14 moieties. tPA chimeras were characterized by mass spectrometry and in various clot lysis assays.

\section{Results}

Site specific oxidation of model peptides

The size of tPA directly correlates with the number of functional groups present in the protein and the number of groups prone to oxidation. tPA contains 35 cysteine residues forming 17 disulfide bonds, 5 methionine residues, 4 glycosylation sites and evidence for a hydroxylysine has been found (Figure 1).[1, 6, 16] All these groups can be oxidized and thus complicate the modification of tPA via $\mathrm{N}$-terminal serine 
modification. However, since this is still an attractive approach for the site specific modification of large, complex and unprotected proteins, a method for site specific oxidation was explored.

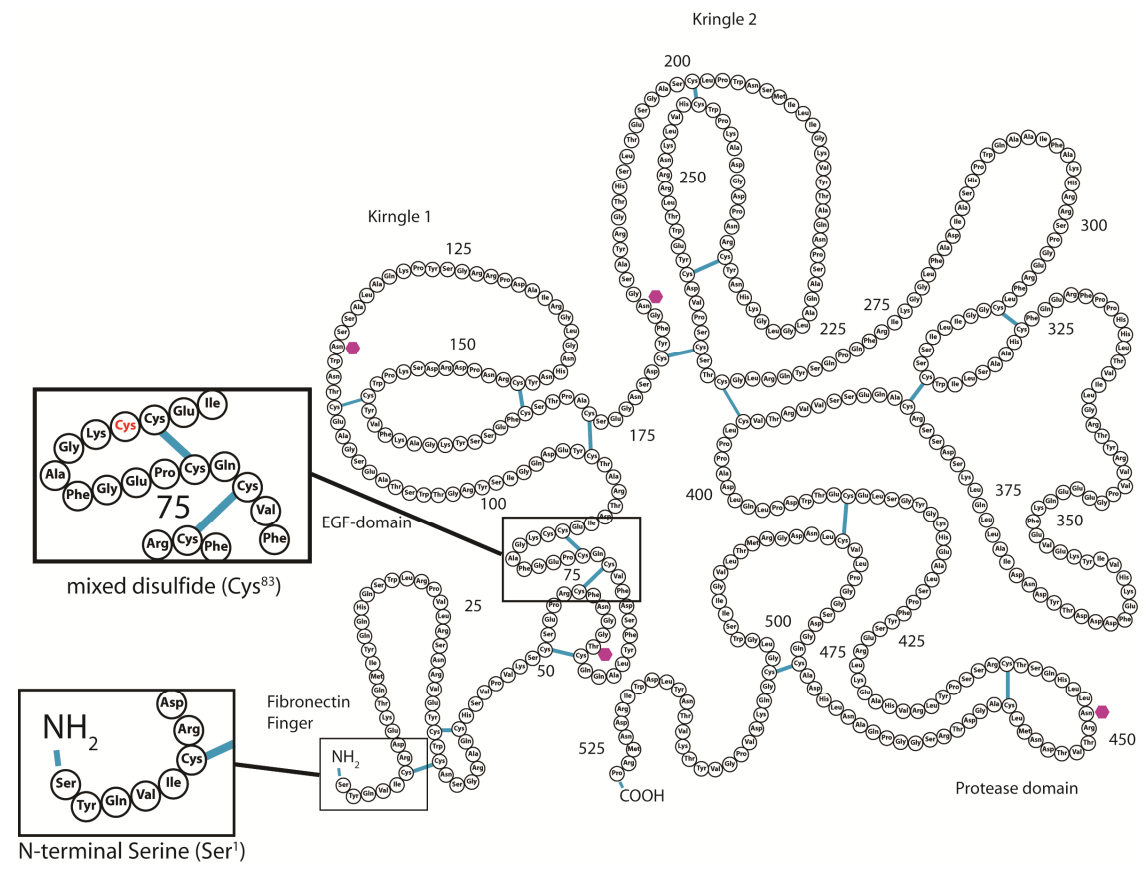

Figure 1: Primary sequence of tPA; showing the $\mathrm{N}$-terminal serine and cysteine-83 involved in the mixed disulfide. Disulfides and $\mathrm{N}$ - and $\mathrm{O}$-linked glycosylation sites are indicated in blue and pink, respectively. Figure adapted from Collen.[1]

First, a test peptide was synthesized to optimize experimental conditions of the ligation reaction. The test peptide $\mathrm{H}_{2} \mathrm{~N}-\mathrm{SYQVWK}-\mathrm{NH}_{2}$ contained the first four amino acids of tPA followed by tryptophan to facilitate UV quantification and a C-terminal lysine to improve aqueous solubility. Conversion of the $\mathrm{N}$-terminal serine into an aldehyde was readily achieved using periodate treatment (Figure 2). The reaction was performed in phosphate buffer $(\mathrm{pH} 7.3)$ using 1.5 equiv. of periodate for 30 min after which the reaction was quenched by the addition of 3 equiv. of glycerol. Upon analysis of the quenched reaction mixture, we found remaining starting product, along with glyoxyloyl-peptide and hydrated glyoxyloyl-peptide (Figure 2). The choice for incomplete conversion was deliberate and intended to increase the probability of sitespecific modification at the $\mathrm{N}$-terminus without side reactions at any other residue in the protein. Low amounts of reaction at other residues were expected to be very difficult to detect in a complex protein. However, selectivity for $\mathrm{N}$-terminal serine oxidation was still achieved because a 2-amino alcohol is considerably more reactive towards periodate treatment when compared to diols as are present in the glycosyl groups.[17] 
a

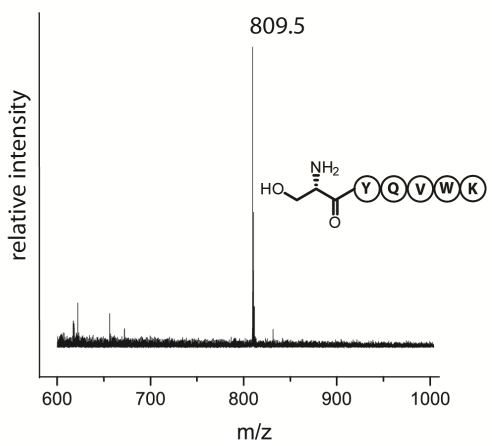

b

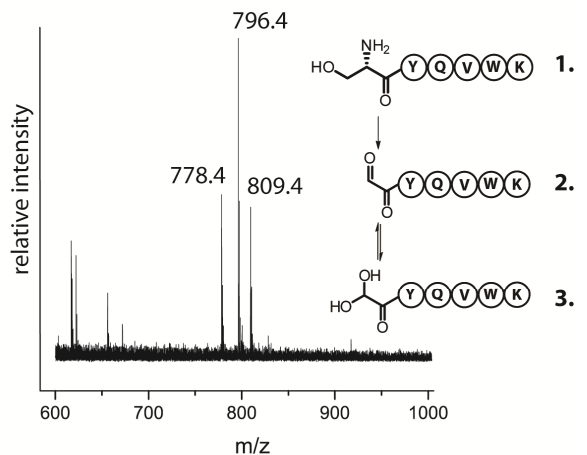

Figure 2: MALDI-TOF spectra of the test-peptide (SYQVWK). a: MALDI-TOF spectra of testpeptide before oxidation. b: MALDI-TOF spectra of test-peptide after oxidation using sodium periodate. Mass $809.5\left(1 \mathrm{H}^{+}\right)$corresponds with the non-oxidized peptide (1), $778.4\left(1 \mathrm{H}^{+}\right)$with the oxidized peptide (2). Mass $796.4\left(1 \mathrm{H}^{+}\right)$corresponds with the hydrated form of the oxidized peptide (3).

\section{Site specific oxidation of tPA}

Full length tPA was oxidized using varying concentrations of $\mathrm{NalO}_{4}$. The oxidation reaction was followed by MALDI-TOF mass spectrometry. Small aliquots of the reaction mixture were removed at regular time intervals, subjected to a short trypsin treatment and analyzed. Under these conditions, only limited trypsinolysis occurred and the N-terminal fragment of tPA could be studied (Figure 3). Precise detection of the mass change induced by the oxidation of the $\mathrm{N}$-terminal serine in full length tPA by MALDI-TOF analysis was not possible due to heterogeneity (glycosylation) of the tPA molecule.

In order to prevent over-oxidation of tPA, methionine was added to the reaction mixture and the reaction again was quenched using glycerol. All experiments with full length tPA were performed in an arginine containing buffer to prevent solubility problems. Although the oxidation of the $\mathrm{N}$-terminal serine could easily be followed by using limited proteolysis (Figure3), it was more difficult to assess whether oxidation had occurred at any other positions in the molecule, thereby possibly giving rise to additional aminooxy-reactive functional groups. 
a

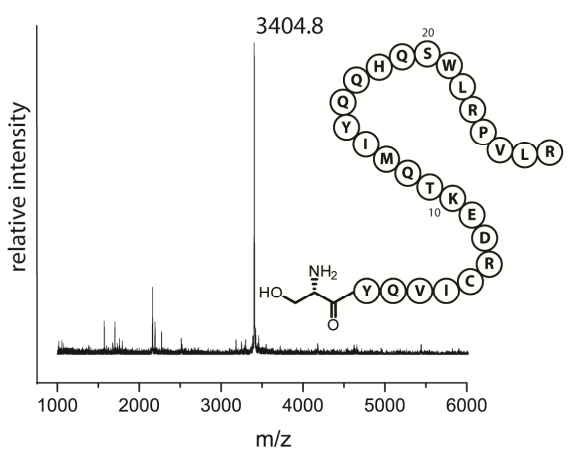

b

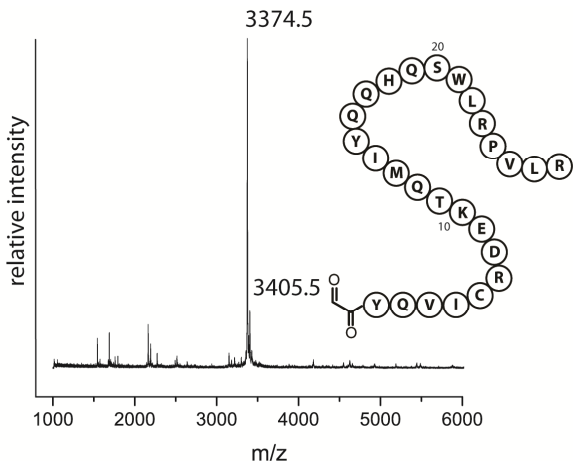

Figure 3: MALDI-TOF spectra of the N-terminus of tPA. a: MALDI-TOF spectrum of the Nterminus of tPA after limited digestion by trypsin of the full length protein before oxidation. Mass $3404.8\left(1 \mathrm{H}^{+}\right)$corresponds to the non-oxidized N-terminus of tPA. b: MALDI-TOF spectrum of the N-terminus of tPA after oxidation using $\mathrm{NalO}_{4}$, Mass $3374.5\left(\mathrm{HH}^{+}\right)$corresponds to the oxidized $\mathrm{N}$-terminus of tPA.

\section{A14 modification of tPA}

To challenge over-oxidation and subsequent multiple A14 ligation, an excess of aminooxy modified A14 peptide (Scheme 2) was subjected to oxime ligation with the oxidized tPA. The C-terminal two lysine residues of the A14 peptide were modified with an aminooxy group for oxime ligation and a biotin moiety to enable detection or quantification.

Mass analysis showed an increase in mass in agreement with that of the peptide but analysis was complicated by the fact that recombinant tPA has different degrees of glycosylation of the protein. Therefore tPA was deglycosylated using anhydrous hydrofluoric acid before analysis.[18] Mass analysis showed two main peaks (62.5 kDa; $\left.64,1 \mathrm{kDa}: 1 \mathrm{H}^{+}\right)$for native tPA (Figure $4 \mathrm{~A}$ ) and a single peak $\left(60.3 \mathrm{kDa}: 1 \mathrm{H}^{+}\right)$for the deglycosylated protein (Figure $4 \mathrm{~B}$ ). The mass differences with the glycosylated tPA range between 2.2-3.8 $\mathrm{kDa}$. 

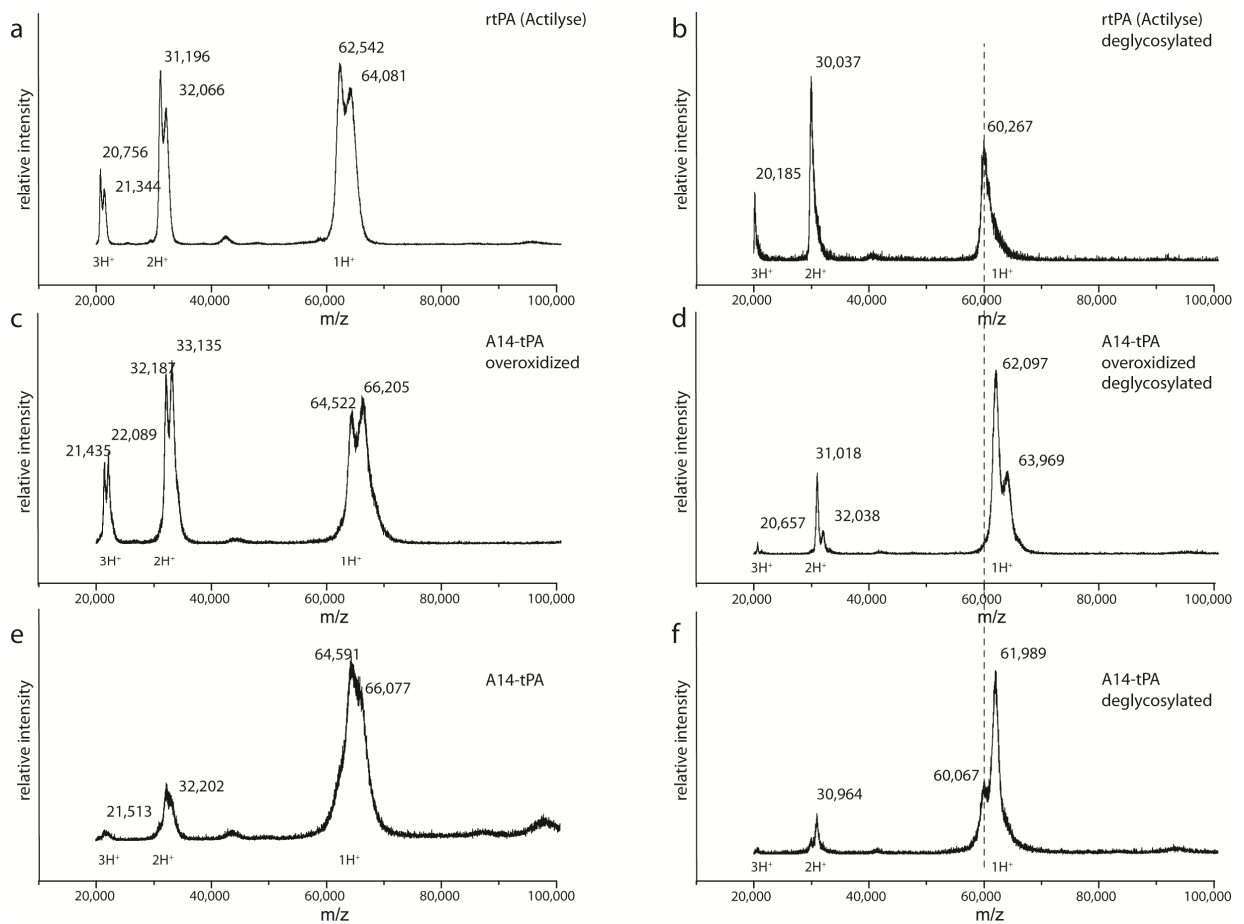

Figure 4: MALDI-TOF spectra of tPA constructs. a: Full length TPA before deglycosylation. $b$ : Full length tPA before deglycosylation. C: Over-oxidized (2 equiv. $\mathrm{NalO}_{4}$ ) oxime ligated A14-tPA before deglycosylation. d: Over-oxidized oxime ligated A14-tPA after deglycosylation. e: Optimal oxidized (1.35 equiv. $\mathrm{NalO}_{4}$ ) oxime ligated A14-tPA. f: Optimal oxidized oxime ligated A14-tPA after deglycosylation. Indicated are $3 \mathrm{H}^{+} ; 2 \mathrm{H}^{+} ; 1 \mathrm{H}^{+}$states representing $1 / 3 ; 1 / 2$, and full mass of the protein, respectively. Dashed line in $\mathrm{B}$; $\mathrm{D}$; E represents deglycosylated mass of unmodified tPA.

It was now possible to determine the degree of oxidation in the full protein and determine the optimal conditions for oxidation. tPA was oxidized using increasing concentrations of periodate and then modified with the A14 peptide. The protein was subsequently deglycosylated. It was observed that oxidation using 2 equiv. of $\mathrm{NalO}_{4}$ followed by oxime ligation led to a mass increase of approximately $2 \mathrm{kDa}$ (Figure 4C). Deglycosylation of the chimeric protein however, did not lead to a single peak as expected for a single modification, but showed a minor second peak indicating multiple peptides had been coupled to tPA (Figure 4D). In addition, preservation of double A14 ligation after deglycosylation suggests that most or all coupling had occurred at the protein part rather than the carbohydrate part of tPA (Figure 4D). Since the modified proteins are expected to express very similar physicochemical properties, integration of peaks on the MALDI spectra was used to determine a ratio of 70/30 for the single and double modified tPA. These tests led to an optimal stoichiometry of 1.35 equiv. of $\mathrm{NalO}_{4}$ per equiv. of tPA. This ensured only the $\mathrm{N}$ terminal serine to be affected, but did not lead to a complete conversion to the 
glyoxylyl-protein. Using these optimal conditions with subsequent oxime ligation led to the desired mono A14-tPA construct (Figure 4E; 4F). Furthermore, the use of Lmethionine to prevent unwanted oxidation and the neutral $\mathrm{pH}$ at which the reaction is performed, led to a selective oxidation of the $\mathrm{N}$-terminal serine governed by the high reactivity of the 2-amino alcohol to periodate treatment.[12, 17] The chosen conditions led to a $\sim 70 \%$ conversion to the A14 modified-protein (Figure 4F).

SDS-PAGE and Western blot analysis of tPA constructs

Two variants of the $\alpha_{2}$-AP N-terminal peptide (A14) were prepared: a peptide containing the native $\alpha_{2}$-AP motif and a Q3A mutant representing a glutamine to alanine replacement, the latter becoming nearly unreactive in the FXIIla-catalyzed fibrin crosslinking reaction. This resulted in 2 chimeric protein constructs to be used for biological studies, one with a native A14 sequence (A14-tPA) and the other with the Q3A mutation (nA14-tPA), which was used as a negative control. The covalent linkage of A14 to tPA was confirmed by SDS-PAGE and Western blot analysis (Figure 5).

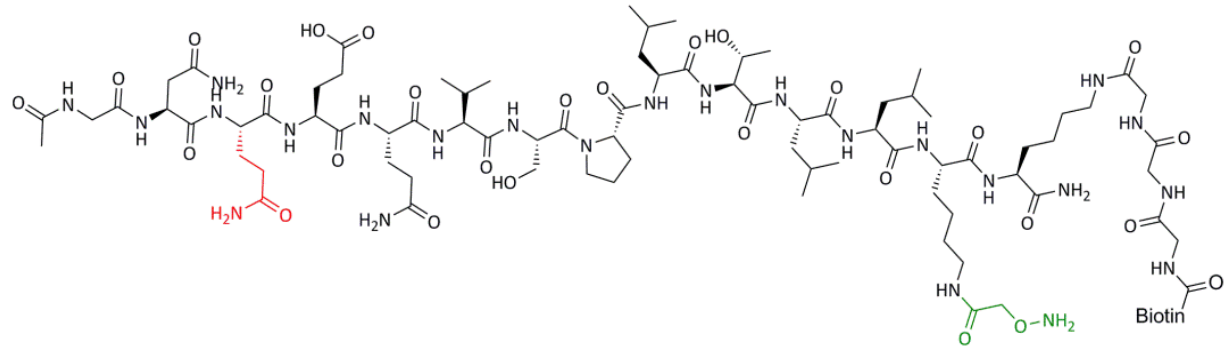

Scheme 2: Schematic representation of A14 peptide modified with an aminooxy group for oxime ligation (green) and a biotin moiety for detection. The active glutamine residue involved in FXIIla-mediated coupling to fibrin is highlighted in red. 


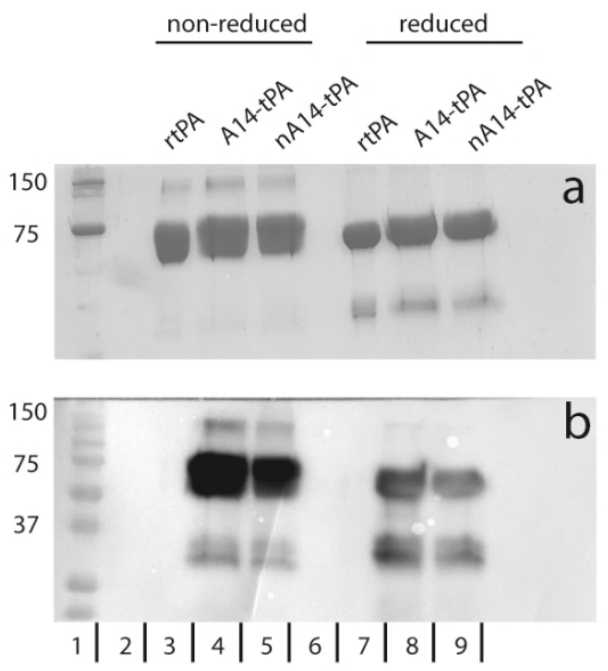

Figure 5: SDS-PAGE and Western blot analysis of tPA constructs, a: SDS-PAGE analysis of tPA and chimera proteins in reducing and non-reducing conditions (CBB staining). b: Western blot analysis of SDS-PAGE from Panel A using streptavidin-HRP detecting exclusively chimera proteins that contain a biotinylated A14 moiety.

The SDS-PAGE gel and Western blot show both non-reduced (lane 3 to 5) and reduced (lane 7 to 9) tPA constructs. Unmodified tPA (lane 3 and 7) shows a band around the expected mass of $67 \mathrm{kDa}$ and a band corresponding to dimerized tPA around $130 \mathrm{kDa}$. When reduced, the dimer is no longer detected and a band around $30 \mathrm{kDa}$ becomes apparent corresponding to the two-chain variant of tPA, which is also observed for the A14 modified constructs (lane 8 and 9). Western blot analysis of these samples with streptavidin-HRP detected the A14 modified constructs only, since these contain a biotin. A14 coupling to tPA is confirmed as both A14-tPA and nA14-tPA (lanes 4, 5 and $8,9)$ are detected and show bands around $130 \mathrm{kDa}$ for the tPA-dimer, around $67 \mathrm{kDa}$ for the monomer and two bands around $30 \mathrm{kDa}$ for the two-chain variant of tPA. The double band pattern at $30 \mathrm{kDa}$ is caused by heterogeneous glycosylation of tPA which results in two variants of the detected $\mathrm{N}$-terminal fragment.

\section{A14-tPA fibrin cross-linking}

We determined the ability of A14-tPA to be covalently crosslinked to fibrin by FXIIIa. A14-tPA was incubated with fibrinogen, thrombin and FXIII during which thrombin cleaves fibrinopeptides $A$ and $B$ off fibrinogen to initiate fibrin formation. Simultaneously FXIII is activated, after which a fibrin D domain is crosslinked with one E domain and A14-tPA is covalently attached to lysine-303 on the A $\alpha$ chain of fibrin. $[19,20]$ By taking advantage of the biotin tag present on A14- and nA14-tPA we could visualize the covalent linkage between IPA and fibrin (Figure 6). The SDS-PAGE gel shows the fibrinogen $\alpha, \beta$ and $\gamma$ chains (lane 2), which after fibrin formation result in 
$\alpha-\alpha$ and $\gamma-\gamma$ crosslinks (lane 4,6$)$.[21] Western blot analysis once again detects A14tPA (lane 3) and nA14-tPA (lane 5), but also shows covalent crosslinking of A14-tPA to the $A \alpha$-chain of fibrin resulting in a main band around $130 \mathrm{kDa}$ and higher molecular weight aggregates (lane 4). Efficient crosslinking of A14-tPA to fibrin was thus observed, resulting in a high molecular weight product, whereas nA14-tPA shows no covalent attachment to fibrin (lane 6).

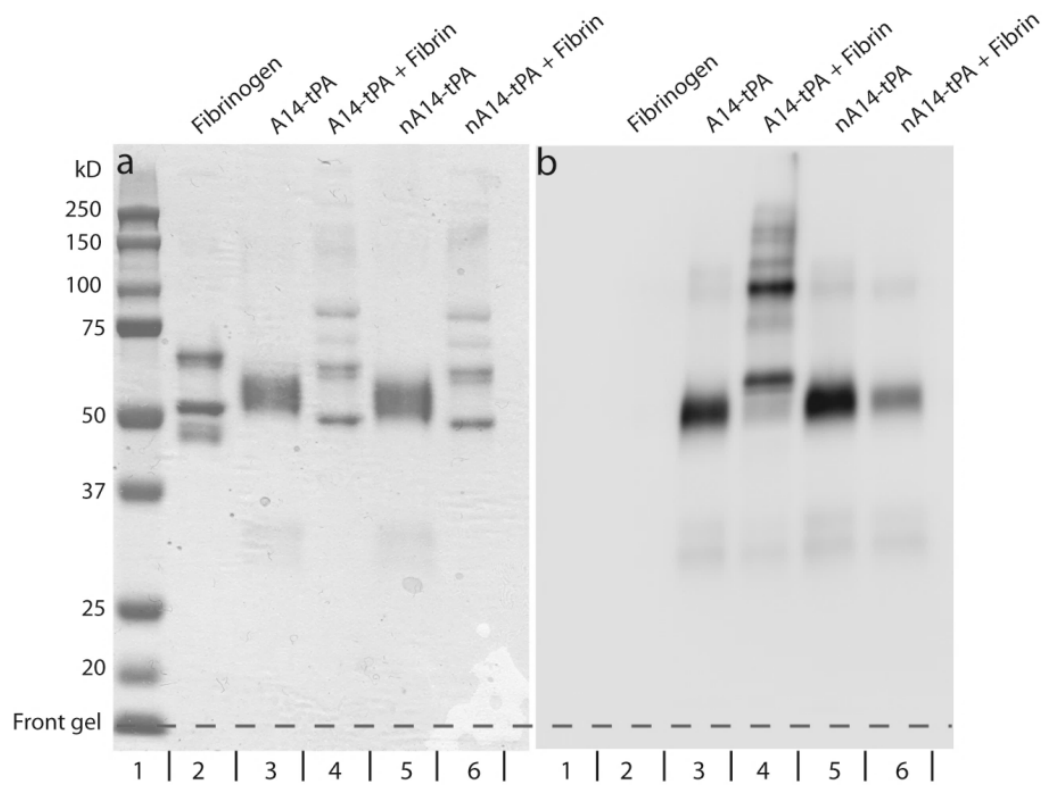

Figure 6: SDS-PAGE and Western blot analysis of tPA crosslinking to fibrin a: SDS-PAGE gel analysis of cross-linking of A14-tPA to fibrin. b: Western blot analysis using streptavidin-HRP showing covalent attachment of A14-tPA to fibrin.

A14-tPA plasma clot lysis

The activity of the chimera tPA proteins was evaluated using multiple in vitro clot lysis assays. First, the activity of tPA and TPA chimeras was measured using a tPA specific chromogenic substrate. Activities of the different tPA preparations were normalized on basis of their activities in order to perform subsequent assays with comparable activities. Compared to freshly reconstituted tPA; chimeric tPA activities varied between $105-150 \%$ (data not shown).

Subsequently, the lysis time of a plasma clot in the presence of increasing concentrations of tPA was determined in an in vitro plasma clot lysis assay.[22] Plasma clot formation was performed in presence of tPA; the turbidity of the mixture at 405 $\mathrm{nm}$ was taken as a measure for clot density. In this assay both clot formation and fibrinolysis are monitored, after which the half-life of clot lysis time was determined 
and plotted against plasminogen activator concentration (Figure 7A). When comparing tPA to the 2 chimeric proteins, no differences in clot lysis time were observed. However, the experimental setting under static conditions allowed all tPA variants to remain in the well, unaffected by physiological blood flow conditions.

Therefore, in order to mimic fibrinolysis under more physiological conditions, we used a microfluidic flow assay. In this assay a clot is formed by flowing recalcified citrated whole blood to which fluorescent fibrinogen was added over a collagen surface, which contains a microspot of tissue factor (TF) to trigger coagulation. In the beginning platelets will adhere to the surface, which will gradually form more stable aggregates after which they are surrounded by a fibrin mesh (Figure 7B). Subsequently, the formed fibrin mesh is broken down by switching to a buffer containing tPA variants.[23] The degradation of the fibrin mesh is monitored and is a direct measurement for the activity of the tPA constructs (Figure 7C). Results show a dose dependent decrease in clot lysis time with increasing tPA concentration, but no difference is observed when comparing the different constructs.

a

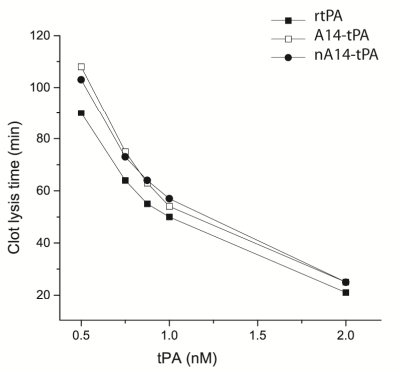

C
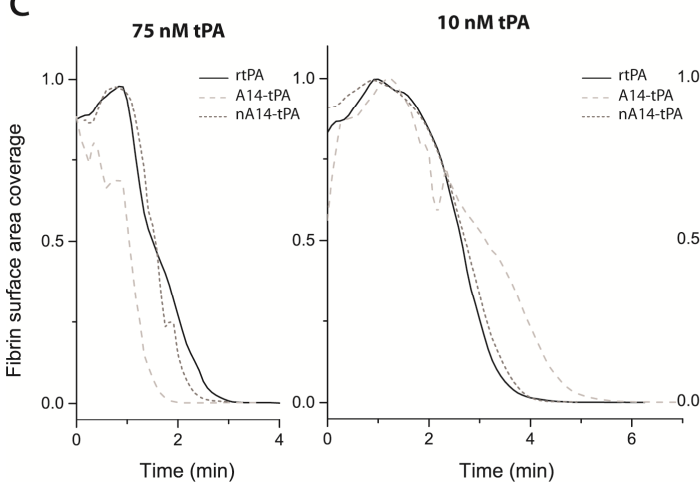

b

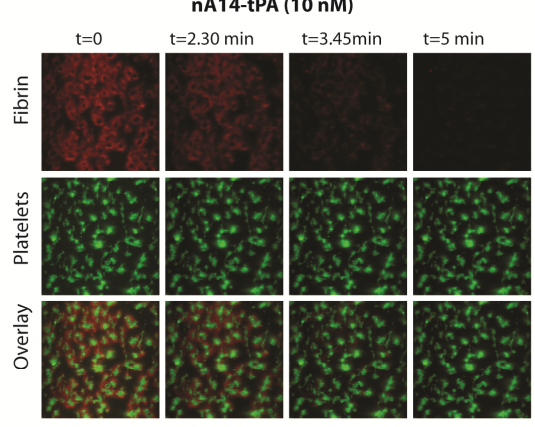

3 nM tPA

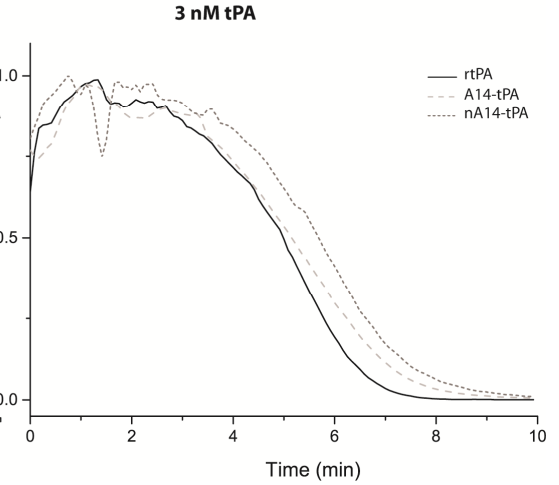

Figure 7: The effect of tPA chimeras on plasma clot lysis assays. a: plasma clot lysis under static conditions. b: Representative images of clot lysis under flow followed over time. Fluorescent signal of fibrin and platelets are monitored. C: Real time monitoring of fibrinolysis by TPA chimeras compared to tPA. Degradation of fluorescent fibrin over time, with varying indicated concentrations of plasminogen activator added. 


\section{Discussion}

We were able to site-selectively modify tPA via oxidation of the N-terminal serine residue followed by oxime ligation with an aminooxy modified $\alpha_{2}$-AP $\mathrm{N}$-terminal peptide, named A14. We could show a single modification was present in a complex protein molecule. Selective labeling of the $\mathrm{N}$-terminus of tPA was obtained by a slight under oxidation (70\%) of the $\mathrm{N}$-terminal serine followed by reaction with an excess of A14 peptide. A14-modified tPA effectively cross-linked to fibrin, in contrast to the negative control nA14-tPA, in which the crucial glutamine-3 residue was replaced by alanine. In spite of the selective cross-linking activity, both the static and the flow plasma clot lysis assays did not show an enhanced fibrinolytic activity of the A14-tPA compared to native tPA.

An explanation for the observed results would be that the introduced A14 moiety is unstable. The covalent attachment of A14 to tPA was first shown by M ALDI-TOF mass spectrometry (Figure 4) and confirmed with SDS-PAGE and Western blot analysis by making use of the biotin tag present in A14 (Figure 5). Furthermore, no evidence was observed for loss of the A14 moiety, since low molecular weight fragments were not detected on SDS PAGE analysis.

Since the A14 moiety behaves as predicted, an explanation may be found in the TPA part of the chimera protein. Covalent crosslinking of tPA to fibrin might sterically hinder tPA function. For example, the inside of the blood clot might be less accessible for A14-tPA because it is retained at the periphery of the clot. This should, however, lead to clear observed differences between A14-tPA and nA14-tPA, which are not apparent from either of the plasma clot lysis assays. It remains unclear though if multiple effects cancel each other out. Under flow conditions, non-bound plasminogen activator will be washed away. Covalent crosslinking of tPA to fibrin will lead to increased concentrations at the site of the fibrin clot. If steric hindrance, however, leads to a decreased efficiency of plasminogen to plasmin conversion the net effect will be less obvious. This decreased efficiency of conversion can be explained by enhanced plasminogen activation by tPA when it is bound to fibrin. It was found that a ternary complex is formed when tPA binds to fibrin followed by addition of plasminogen, which leads to strongly promoted plasminogen activation.[24] The tPA binding sites on fibrin are identified to be Aa148-160 and Y312-324, where the latter is an exclusive binding site for tPA.[25-27] However, the crosslinking site of A14 to fibrin is identified to be Aa303 lysine, which, although crystal structures are inclusive about this region, is probably located far from the tPA binding site.[19, 20] Covalent crosslinking of tPA to fibrin Aa303 would thus lead to tPA being unable to bind to its natural binding site. 
In conclusion, we have shown that TPA can be selectively modified using an oxidation/oxime linking strategy leading to an efficient cross linking of A14-tPA to a fibrin clot. The linker length used in this study may have constrained the enzyme away from its natural binding site, leading to a lower efficiency of plasminogen conversion. However, fibrinolytic activity was unchanged when compared to unmodified tPA. It remains to be investigated if chimeric proteins in which A14 is linked to tPA by a longer linker will lead to an enhancement of fibrinolytic function. 


\section{References}

1. Collen, D. and H.R. Lijnen, The tissue-type plasminogen activator story. Arterioscler Thromb Vasc Biol, 2009. 29(8): 1151-1155.

2. Collen, D. and H.R. Lijnen, Thrombolytic agents. Thromb Haemost, 2005. 93(4): 627630.

3. Astrup, T. and P.M. Permin, Fibrinolysis in the animal organism. Nature, 1947. 159(4046): 681.

4. DeM ers, G., W.J. Meurer, R. Shih, S. Rosenbaum, and G.M. Vilke, Tissue Plasminogen Activator and Stroke: Review of the Literature for the Clinician. The Journal of Emergency M edicine, 2012. 43(6): 1149-1154.

5. Holmes, W.E., D. Pennica, M. Blaber, M.W. Rey, W.A. Guenzler, G.J. Steffens, and H.L. Heyneker, Cloning and Expression of the Gene for Pro-urokinase in Escherichia coli. Nat Biotech, 1985. 3(10): 923-929.

6. Pennica, D., W.E. Holmes, W.J. Kohr, R.N. Harkins, G.A. Vehar, C.A. Ward, W.F. Bennett, E. Yelverton, P.H. Seeburg, H.L. Heyneker, D.V. Goeddel, and D. Collen, Cloning and expression of human tissue-type plasminogen activator CDNA in E. coli. Nature, 1983. 301(5897): 214-221.

7. Tow, D.E., H.N. Wagner, R.A. Holmes, K.S. Harrison, U. Scheffel, J.K. Langan, and R. Longo, Urokinase in Pulmonary Embolism. New England Journal of Medicine, 1967. 277(22): 1161-1167.

8. Kwiatkowski, T.G., R.B. Libman, M. Frankel, B.C. Tilley, L.B. M orgenstern, M. Lu, J.P. Broderick, C.A. Lewandowski, J.R. M arler, S.R. Levine, and T. Brott, Effects of Tissue Plasminogen Activator for Acute Ischemic Stroke at One Year. New England Journal of Medicine, 1999. 340(23): 1781-1787.

9. Wiman, B. and D. Collen, Purification and characterization of human antiplasmin, the fast-acting plasmin inhibitor in plasma. Eur J Biochem, 1977. 78(1): 19-26.

10. Miserus, R.J., M.V. Herias, L. Prinzen, M.B. Lobbes, R.J. Van Suylen, A. Dirksen, T.M. Hackeng, J.W. Heemskerk, J.M. van Engelshoven, M.J. Daemen, M.A. van Zandvoort, S. Heeneman, and M.E. Kooi, Molecular MRI of early thrombus formation using a bimodal alpha2-antiplasmin-based contrast agent. JACC Cardiovasc Imaging, 2009. 2(8): 987-996.

11. Lijnen, H.R., J.M. Stassen, H.J. Rapold, H. Nakamura, Y. Kobayashi, and D. Collen, Biochemical and Biological Properties of a Recombinant Chimera Consisting of AminoAcids Asn-1 to Lys-12 of Alpha-2-Antiplasmin (Fibrin Cross-Linking Site) and AminoAcids Leu-4 to Leu-411 of Single Chain Urokinase-Type Plasminogen-Activator. Fibrinolysis, 1992. 6(2): 87-98.

12. Dixon, H.B.F., N-terminal modification of proteins-a review. J Protein Chem, 1984. 3(1): 99-108.

13. Geoghegan, K.F. and J.G. Stroh, Site-Directed Conjugation of Nonpeptide Groups to Peptides and Proteins Via Periodate-Oxidation of a 2-Amino Alcohol - Application to Modification at N-Terminal Serine. Bioconjugate Chem, 1992. 3(2): 138-146.

14. Canne, L.E., A.R. Ferre- D'Amare, S.K. Burley, and S.B.H. Kent, Total Chemical Synthesis of a Unique Transcription Factor-Related Protein: CM yc-Max. Journal of the American Chemical Society, 1995. 117(11): 2998-3007.

15. Wu, S.-L., H. Jiang, W.S. Hancock, and B.L. Karger, Identification of the Unpaired Cysteine Status and Complete Mapping of the 17 Disulfides of Recombinant Tissue Plasminogen Activator Using LC-MS with Electron Transfer Dissociation/Collision Induced Dissociation. Analytical Chemistry, 2010. 82(12): 5296-5303. 
16. Molony, M.S., S.-L. Wu, L.K. Keyt, and R.J. Harris, The unexpected presence of hydroxylysine in non-collagenous proteins, in Techniques in Protein Chemistry, W.C. John, Editor 1995, Academic Press. p. 91-98.

17. Gaertner, H.F., K. Rose, R. Cotton, D. Timms, R. Camble, and R.E. Offord, Construction of protein analogues by site-specific condensation of unprotected fragments. Bioconjugate Chem, 1992. 3(3): 262-268.

18. Mort, A.J. and D.T.A. Lamport, Anhydrous hydrogen fluoride deglycosylates glycoproteins. Analytical Biochemistry, 1977. 82(2): 289-309.

19. Kimura, S. and N. Aoki, Cross-linking site in fibrinogen for alpha 2-plasmin inhibitor. J Biol Chem, 1986. 261(33): 15591-15595.

20. Tamaki, T. and N. Aoki, Cross-linking of alpha 2-plasmin inhibitor and fibronectin to fibrin by fibrin-stabilizing factor. Biochim Biophys Acta, 1981. 661(2): 280-286.

21. Ariens, R.A., H. Philippou, C. Nagaswami, J.W. Weisel, D.A. Lane, and P.J. Grant, The factor XIII V34L polymorphism accelerates thrombin activation of factor XIII and affects cross-linked fibrin structure. Blood, 2000. 96(3): 988-995.

22. Mutch, N.J., L. Thomas, N.R. Moore, K.M. Lisiak, and N.A. Booth, TAFla, PAl-1 and $\alpha 2-$ antiplasmin: complementary roles in regulating lysis of thrombi and plasma clots. Journal of Thrombosis and Haemostasis, 2007. 5(4): 812-817.

23. Whyte, C.S., F. Swieringa, T.G. Mastenbroek, A.S. Lionikiene, M.D. Lance, P.E. van der Meijden, J.W. Heemskerk, and N.J. Mutch, Plasminogen associates with phosphatidylserine-exposing platelets and contributes to thrombus lysis under flow. Blood, 2015. 125(16): 2568-2578.

24. Hoylaerts, M., D.C. Rijken, H.R. Lijnen, and D. Collen, Kinetics of the activation of plasminogen by human tissue plasminogen activator. Role of fibrin. J Biol Chem, 1982. 257(6): 2912-2919.

25. Schielen, W.J., H.P. Adams, K. van Leuven, M. Voskuilen, G.I. Tesser, and W. Nieuwenhuizen, The sequence gamma-(312-324) is a fibrin-specific epitope. Blood, 1991. 77(10): 2169-2173.

26. Schielen, W.J., H.P. Adams, M. Voskuilen, G.I. Tesser, and W. Nieuwenhuizen, The sequence A alpha-(154-159) of fibrinogen is capable of accelerating the t-PA catalysed activation of plasminogen. Blood Coagul Fibrinolysis, 1991. 2(3): 465-470.

27. Yonekawa, O., M. Voskuilen, and W. Nieuwenhuizen, Localization in the fibrinogen gamma-chain of a new site that is involved in the acceleration of the tissue-type plasminogen activator-catalysed activation of plasminogen. Biochem J, 1992. 283 ( Pt 1): 187-191. 


\section{Supporting Information}

Reagents. 2-(6-Chloro-1H-Benzotriazol-1-yl)-1,1,3,3-tetramethylaminium hexafluorophosphate (HCTU) and Boc-Trp(Hoc)-OH were obtained from Peptides International. Boc-Leu-OH, Boc-Phe-OH, Boc-Asp(OCHx)-OH, Boc-Ser(Bzl)-OH, Boc-Pro$\mathrm{OH}$, Boc-Gly-OH，Boc-Tyr(BrZ)-OH，Boc-Cys(4-MeBzl)-OH，Boc-Glu(OcHx)-OH，BocLys(Fmoc)-OH, Boc-Val-OH and Boc-Ala-OH were obtained from Nova Biochem. BocLys(ClZ)-OH, Boc-Asn(Xan)-OH, Boc-His(Dnp)-OH， Boc-Arg(Tos)-OH.EtOAc were purchased from Midwest Bio-tech Inc. Boc-GIn(Xan)-OH, Boc-Thr(Bzl)-OH and BocLys(Boc)-OH.DCHA were obtained from Bachem. The $0.63 \mathrm{meq} / \mathrm{g}$ M BHA-polystyrene resin was obtained from ChemPep Inc. N,N-Diisopropylethylamine (DIPEA), N,Ndimethylformamide (DMF), dichloromethane, diethylether and acetonitrile were purchased from Biosolve. Methanol, Boc- $\beta-\mathrm{Ala}-\mathrm{OH}$, and hydrogen fluoride were from Fluka. $\alpha$-cyano-4-hydroxycinnamic acid, and $p$-cresol were from Sigma-Aldrich. Anhydrous acetic acid and ethylenedinitrilotetraacetic acid disodium salt dihydrate (EDTA) were obtained from Merck and trifluoroacetic acid (TFA) from Halocarbon Biograde. All solvents were analytical grade (p.a.) and were used as received.

HPLC Analysis and Purification. Analytical HPLC was performed using a Vydac $\mathrm{Cl} 8$ HPLC column ( $4.6 \mathrm{~mm} \times 150 \mathrm{~mm}, 1 \mathrm{~mL} / \mathrm{min}$ flow rate) connected to a Varian Prostar system consisting of two Varian Prostar 215 delivery modules and a Varian Prostar $320 \mathrm{UV} / \mathrm{Vis}$ detector $(\lambda=214 \mathrm{~nm})$. A linear gradient of 0-67\% buffer $B$ in buffer $A$ over 30 minutes was used, where buffer $A=0.1 \mathrm{v}-\%$ TFA in $\mathrm{H}_{2} \mathrm{O}$ and buffer $B=0.1 \mathrm{v}-\%$ TFA, $10 \mathrm{v}-\% \mathrm{H}_{2} \mathrm{O}$ in $\mathrm{CH}_{3} \mathrm{CN}$.

Semi-preparative HPLC was performed using Vydac C18/C4 HPLC columns (10 mm x $250 \mathrm{~mm}, 5 \mathrm{~mL} / \mathrm{min}$ flow rate or $22 \mathrm{~mm} \times 250 \mathrm{~mm}, 10 \mathrm{~mL} / \mathrm{min}$ flow rate) connected to a Waters Deltaprep System consisting of a Waters Prep LC Controller and a Waters 2487 Dual wavelength Absorbance Detector $(\lambda=214 \mathrm{~nm})$. Peptides were eluted using a shallow gradient of $B$ in $A$, based on an exploratory analytical HPLC run (vide supra). Product containing fractions were analyzed by Electrospray Ionization Mass Spectrometry (ESI-MS) (vide infra), pooled, and lyophilized.

Electrospray Mass Spectrometry. ESI-MS was performed on an Applied Biosystems SCIEX API 150 EX electrospray ionization quadrupole (ESI-Q) mass spectrometer. Peptide masses were calculated from the experimental mass to charge $(\mathrm{m} / \mathrm{z})$ ratios of all the protonation states observed in the ESI-MS spectrum of a peptide using Analyst 1.4.2 software (Sciex).

MALDI Mass Spectrometry. MALDI-MS was performed on an Applied Biosystems 4800 M ALDI TOF/TOF analyzer. Samples were prepared in $\mathrm{CH}_{3} \mathrm{CN}(45 \mathrm{v}-\%)$ in $\mathrm{H}_{2} \mathrm{O}+$ $0.1 \%$ TFA and mixed with $\alpha$-Cyano-4-hydroxycinnamic acid (CHCA) (1:1) as matrix. Reflective positive mode was used to measure samples with an expected mass 
between 1000 and $5000 \mathrm{Da}$, linear high mass mode was used to measure samples with an expected mass above $20000 \mathrm{Da}$.

Synthesis of biotinylated A14 peptides. Ac-Gly-Asn-GIn-Glu-Gln-Val-Ser-Pro-Leu-ThrLeu-Leu-Lys(aminooxyacetyl)-Lys(Gly-Gly-Gly-biotin)-- $\mathrm{NH}_{2}$

Following the general peptide solid phase methods described above, Fmoc-Lys(Boc)$\mathrm{OH}$ was coupled to MBHA resin $(0.6 \mathrm{mmol})$. After deprotection of the lysyl- $\mathrm{N} \varepsilon-\mathrm{Boc}$ group, three glycine residues were introduced following standard SPPS methods. After removal of the Glycine-N $\alpha$-Boc group, biotin was attached by reacting the resin bound peptide with $2.2 \mathrm{mmol}$ of biotin, $1.0 \mathrm{~mL}$ of DIPEA and $2.0 \mathrm{mmol}$ of HCTU in DM F (4.0 $\mathrm{mL}$ ). This step was repeated once. The resin-bound Fmoc-Lys(Gly-Gly-Gly-biotin)MBHA ( $0.3 \mathrm{mmol}$ ) was $\mathrm{Na}-\mathrm{Fmoc}$ deprotected ( $4 \times 3 \mathrm{~min}$ treatment with $20 \%$ piperidine in DMF) and used for the synthesis of Boc-Glu(OCHX)-Gln-Val-Ser-Pro-Leu-Thr(OBzl)Leu-Leu-Lys(aminooxyacetyl)-Lys(Gly-Gly-Gly-biotin)-M BHA. 2/3 of this product was Nterminally extended, acetylated, coupled with Boc-aminooxyacetic acid, subjected to $\mathrm{HF}$ acidolysis and purified, resulting in $2.1 \mathrm{mg}(1.0 \mu \mathrm{mol})$ of Ac-Gly-Asn-Gln-Glu-GlnVal-Ser-Pro-Leu-Thr-Leu-Leu-Lys(aminooxyacetyl)-Lys(Gly-Gly-Gly-biotin)-NH ${ }_{2}$. ESI-MS showed a mass of $2066.24 \pm 1.21$, fitting well between the calculated monoisotopic mass (2065.06) and the average mass (2066.34).

The remaining $1 / 3$ of Boc-Glu(OcHx)-Gln-Val-Ser-Pro-Leu-Thr(OBzl)-Leu-LeuLys(aminooxyacetyl)-Lys(Gly-Gly-Gly-biotin)-MBHA was N-terminally extended, acetylated, coupled with Boc-aminooxyacetic acid, subjected to HF acidolysis and purified, resulting in $1.2 \mathrm{mg}(1.0 \mu \mathrm{mol})$ of Ac-Gly-Asn-Ala-Glu-Gln-Val-Ser-Pro-Leu-ThrLeu-Leu-Lys(aminooxyacetyl)-Lys(Gly-Gly-Gly-biotin)-NH2. ESI-MS showed a mass of $2008.99 \pm 1.42$, fitting well between the calculated monoisotopic mass (2008.04) and the average mass (2009.29).

$\mathbf{N}$-terminal serine oxidation of tPA. Full length recombinant tPA (Actilyse) $(15 \mu \mathrm{M}, 1.0$ equiv.) was dissolved in $0.5 \mathrm{M}$ arginine phosphate buffer $(\mathrm{pH} 7.3)$ containing $1.5 \mathrm{mM}$ L-methionine (100 equiv.) and $0.01 \%$ polysorbate- $80 . \mathrm{NalO}_{4}(20 \mu \mathrm{M}, 1.35$ equiv.) was added and left to react for $30 \mathrm{~min}$ at $0{ }^{\circ} \mathrm{C}$ after which the reaction was quenched with glycerol ( $75 \mu \mathrm{M}, 5$ equiv.). The resulting product was purified using a Sephadex G-50 size exclusion column eluting with $0.1 \mathrm{M} \mathrm{CH}_{3} \mathrm{COOH}$.

Glyoxylyl-tPA oxime ligation with A14. Glyoxylyl-t-PA (150 $\mu \mathrm{M}, 1$ equiv.) was dissolved in $0.4 \mathrm{M}$ arginine acetate buffer $(\mathrm{pH} 4.0)$ and reacted with $\mathrm{A} 14(750 \mu \mathrm{M}, 5$ equiv.) for $24 \mathrm{~h}$ at RT. The resulting product was purified using a Sephadex G-50 size exclusion column eluted with $0.5 \mathrm{M}$ arginine phosphate buffer $(\mathrm{pH} 7.2)$ containing $0.01 \%$ tween-80 
Short trypsin digestion of tPA. tPA $(13 \mu \mathrm{M})$ was dissolved in $0.1 \mathrm{M}$ Tris. $\mathrm{HCl}$ buffer (pH 8) containing $0.8 \mathrm{mM} \mathrm{DTT}, 0.74 \mathrm{mM} \mathrm{CaCl} 2$ and $0.9 \mathrm{M} \mathrm{Gn} . \mathrm{HCl}$. $1.6 \mu \mathrm{M}$ bovine TPCKtrypsin was added. A sample was taken within seconds after addition of trypsin.

Deglycosylation of tPA using anhydrous HF. To $200 \mu \mathrm{g}$ of lyophilized tPA, $10 \mathrm{~mL}$ of anhydrous $\mathrm{HF}$ was added. The mixture was left to react for $1 \mathrm{~h}$ at $0{ }^{\circ} \mathrm{C}$ without stirring. After reaction, the $\mathrm{HF}$ was slowly evaporated; the protein was dissolved in $300 \mu \mathrm{L}$ $\mathrm{CH}_{3} \mathrm{CN}(45 \mathrm{v}-\%)$ in $\mathrm{H}_{2} \mathrm{O}+0.1 \%$ TFA and analyzed using M ALDI mass spectrometry.

tPA activity via chromogenic substrate. Activity of the different tPA constructs was evaluated using chromogenic substrate S2288 (Chromogenix) or T2943 (Sigma). To

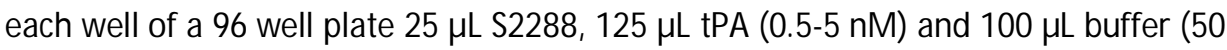
$\mathrm{mM}$ Tris pH 7.9, $175 \mathrm{mM} \mathrm{NaCl}, 20 \mathrm{mM}$ EDTA, $0.5 \mathrm{mg} / \mathrm{mL}$ ovalbumin) was added. Substrate conversion was followed over time. The construct with the highest activity was set to $100 \%$, concentration of the other constructs was adjusted to the same level of activity accordingly.

FXIlla mediated crosslinking of A14-tPA to fibrin. Lyophilized human fibrinogen was obtained from Kordia (Stago). Before use it was resuspended in water, and subsequently dialyzed against Hepes-buffered saline ( $25 \mathrm{mM}$ Hepes, $175 \mathrm{mM} \mathrm{NaCl}, \mathrm{pH}$ 7.7 at room temperature) and quantified spectrophotometrically. Fibrinogen $(6.1 \mu \mathrm{M})$ was incubated with hFXIII- $\mathrm{A}_{2}(0.1 \mu \mathrm{M}$, Zedira), thrombin $(40 \mathrm{nM}$,$) and A14-tPA (500$ $\mathrm{nM}$ ) in buffer (10 mM CaCl $2,50 \mathrm{mM}$ Tris, $150 \mathrm{mM} \mathrm{NaCl}, \mathrm{pH}$ 7.4). Formed fibrin clots (2 minute incubation) were dissolved in SDS sample buffer (40 mM Tris, 3.33\% SDS, 6.25\% ß-mercaptoethanol, $50 \%$ glycerol, pH 6.7). Samples were analyzed on gel and with western blot. Western blot analysis was performed using streptavidin-HRP.

Plasma clot lysis. To each well of a 96 well plate $20 \mu \mathrm{L} \mathrm{CaCl} 2\left(53 \mathrm{mM}\right.$ in $\mathrm{H}_{2} \mathrm{O}$ ) was added. A dilution series of tPA ( $5 \mu \mathrm{L}$, final concentrations $791 \mathrm{pM}-158 \mathrm{pM}$ ) in buffer $(45 \mu \mathrm{L})(10 \mathrm{mM}$ Tris- $\mathrm{HCl}, 0.01 \%$ tween-20 pH 7.5$)$ was added to plasma $(30 \mu \mathrm{L})$ which was subsequently added to $\mathrm{CaCl}_{2}$ mix to reach a final volume of $100 \mu \mathrm{L}(20 \mu \mathrm{L}+80 \mu \mathrm{L})$. The mixtures were briefly mixed and placed in a plate reader. Absorbance was measured every minute at $630 \mathrm{~nm}$ and $405 \mathrm{~nm}$ at $37^{\circ} \mathrm{C}$.

Fibrinolysis under flow. Thrombus formation and fibrinolysis under flow were performed as previously described. [23] Basically, recalcified citrate-anticoagulated whole blood was perfused over a collagen/tissue factor coated surface and following thrombus formation fibrin lysis was monitored by as the disappearance of fluorescently labeled fibrin(ogen). Quantification of this process was performed using FIJI (open source). 


\section{Chapter 8}

Discussion 
Site-selective modification in proteins and peptides remains a difficult task, and the complexity with the high number of functional groups has led to a wide range of methods all with their respective advantages and drawbacks. Highly selective reactions have been developed that can be employed with completely unprotected proteins, such as the widely used copper catalyzed click reaction (CuAAC) or derivatives thereof.[1, 2] The reactive moieties required (azide, alkyne) are, however, not easily introduced in a protein and often require multiple steps or an unspecific labelling step to thiols or amines. An alternative orthogonal approach is found in the reaction between a ketone or aldehyde with an aminooxy to form an oxime. In contrast to the azide or alkyne required for CuAAC, a ketone can be introduced in a protein using a variety of methods most of which are site-selective and do not require protecting group chemistry (Chapter 2). While this is an obvious advantage, the oxime is often overlooked because the reaction is known to be a slow reaction. Improvements in oxime ligation reaction rates have been achieved through the introduction of nucleophilic catalysis by aniline and derivatives (Chapter 2), but little research was performed regarding the reactive moieties.

We found that a widely used keto acid, levulinic acid, was not suitable for introduction of a ketone moiety in proteins when subsequent oxime ligation was required. When coupled to an amine the levulinoyl moiety is prone to an intramolecular cyclization reaction that leads to a pyrrolidone ring which is unable to react with an aminooxy to an oxime (Chapter 3). Although levulinic acid has been used extensively, this cyclization reaction has gone largely unnoticed. We believe the main reason for this are the high concentrations of the two reactants used in previous studies, which led to acceptable oxime yields and minor side product formation. However, when the same reaction is performed at lower concentrations, typically with protein modifications, intramolecular cyclization will appear more predominantly, as it is independent of the concentration used.. We investigated alternative keto acids to replace levulinic acid and found that none of the alternatives show an intramolecular cyclization reaction (Chapter 3). However, a difference was observed when using aromatic ketones as opposed to aliphatic ketones. The aromatic ketone reacted 5 -fold slower than the aliphatic ketones, most likely because the reactive carbocation is stabilized in this case. The use of alternative ketones drastically increased reaction yields, but the reaction still required nucleophilic catalysis by aniline to reach acceptable reaction rates.

While studying oxime formation we encountered an interesting chance finding. An instrument failure led to a delay in measurement of the first time point in an oxime reaction that was expected to reach completion within 10 hours. In an attempt to save this measurement, the sample was frozen with the idea that this would slow down the reaction. Surprisingly, the oxime reaction was near completion after 1 hour at $-20^{\circ} \mathrm{C}$. We followed up upon this phenomenon and found that slow freezing greatly 
catalyzes oxime formation, especially at neutral pH (Chapter 4). More specifically, we found the freezing process to be vital, since a similar reaction mixture that contained methanol, and thus did not freeze, saw no rate enhancement when reacted at $-20^{\circ} \mathrm{C}$. In addition, the freezing rate proved to be an important factor. Increasing the freezing rate by lowering the temperature to $-80^{\circ} \mathrm{C}$ or $-196{ }^{\circ} \mathrm{C}$ did not result in catalysis of oxime formation. We believe that slow freezing, by expelling reactants from growing ice crystals, leads to a large concentrations in the remaining liquid phase, which will lead to a faster than expected oxime formation. In contrast, increasing freezing rates will either snap freeze the status quo of reaction concentrations, or allow a shorter time for oxime formation in the liquid state before the reaction mixture is fully frozen, explaining why no rate increase is observed. At this point it remains unclear if catalysis by freezing can be employed to increase the reaction rates of other chemical reactions. Similar effects have been earlier, mainly in relation to the food industry although some studies have found other reactions to proceed faster in frozen aqueous solutions.[3] We hypothesize that other reactions, especially those performed in water, can be catalyzed by slow freezing of the reaction mixture. However, a real benefit will only be obtained with reactions known to occur with a low reaction rate. Freeze "catalysis" has some advantages over nucleophilic catalysis with aniline. With freezing no purification steps after ligation are required and the detrimental effects of aniline on some proteins can be avoided. Notably, freeze catalysis is not suitable for every purpose; some proteins do not tolerate repeated freezing.

While we managed to improve oxime yields and reaction rates, some aspects of the oxime have remained underexposed in this thesis. We have focused mainly on the use of ketones, despite the fact that aldehydes react much faster, most likely due to decreased steric hindrance. This was a deliberate choice, since ketoximes are more stable compared to aldoximes and the intended applications required stable constructs. Furthermore, optimization of the aminooxy group required for oxime formation was not performed while its current use certainly has some drawbacks. The aminooxy group is highly reactive which leads to potential by-product formation that can occur during oxime formation.[4] Most of these by-products arise from reactions of the aminooxy moiety with carbonyls present in solvents, such as formaldehyde, acetaldehyde or acetone. In our studies we have observed these side reactions, but were unable to completely abolish them. Minute formaldehyde contaminations proved to be very difficult to avoid, and were the major cause of incomplete oxime reactions. In addition, a major side-product observed in our studies was the degradation of the $\alpha$-aminooxy group into the corresponding unreactive alcohol. In some cases it was possible to separate the desired compound from the alcohol, but this side-reaction also occurred during oxime ligation and therefore led to incomplete oxime reactions. In future studies these problems should be tackled to achieve higher yields. Degradation of the aminooxy to the alcohol is likely caused by acidic hydrolysis 
and can therefore occur during TFA treatment with peptide synthesis, during HF cleavage or during HPLC purification with solvents containing TFA. Fmoc-based peptide synthesis could potentially avoid multiple TFA- and HF-treatments and would thus be a viable alternative. Hydrolysis during HPLC purification may be avoided by choosing an alternative additive to the mobile phase, i.e. triethylamine instead of TFA.

To apply our oxime formation optimization to a more translational setting, we synthesized a covalent heterodimer of 2 chemokines involved in atherosclerosis, namely RANTES and PF4 (Chapter 5). Many processes in inflammatory diseases are governed by small chemotactic cytokines named chemokines. These small proteins have become interesting pharmaceutical targets accordingly. Previous research has shown that chemokines RANTES and PF4 play a pivotal role in the initiation and progression of atherosclerosis through formation of heterodimers. With the synthesis of a covalent heterodimer, we have shown that physical formation of a heterodimer is responsible for initiation and progression of atherosclerosis, as opposed to combined receptor stimulation of the separate chemokines that could explain previous observations. Moreover, while performing oxime ligations of RANTES to PF4, we observed a stimulatory effect of the native protein-protein interaction between RANTES and PF4, on the rate of oxime formation, confirming the affinity these chemokines have for each other.

Subsequently, the full spectrum of chemokine interactions was investigated, and chemical protein synthesis and oxime ligation were applied to synthesize a different covalent heterodimer as well as peptide inhibitors of chemokine interactions (Chapter 6). New protocols developed in previous chapters were applied; the ketone functionality was introduced using one of the alternative keto acids and oxime ligations were frozen to accelerate the reaction. Although all protein and peptide targets were synthesized successfully, the overall yields of chemical protein synthesis were typically low. This was mainly due to the need of multiple purification steps, which were required after every ligation step and oxidative folding of the chemokines. This approach is therefore not suitable for large scale production of these target molecules. Preliminary studies have started to investigate if a semi-synthetic approach could improve yields in chemokine heterodimer synthesis.

In the final chapter of this thesis such a semi-synthetic approach is used to synthesize an improved thrombolytic agent, tissue plasminogen activator (tPA), with a novel fibrin crosslinking functionality (Chapter 7). Recombinantly expressed tPA is used to treat patients suffering from ischemic stroke to break down pathological blood clots to regain blood circulation in the brain. We synthesized a hybrid protein consisting of a fibrin crosslinking tag derived from $\alpha_{2}$-antiplasmin (A14), which was covalently linked to the $\mathrm{N}$-terminus of recombinantly expressed tPA using oxime ligation. We could show that A14 was covalently attached to tPA, but it remained difficult to assess 
whether other sites prone to oxidation were affected by treatment with periodate. Furthermore, no enhancement of function was observed when the synthesized hybrid was compared to unmodified tPA. We believe this is mainly due to the crosslinking position on fibrin (A $\alpha$ Lys-303), which is located far away from the natural binding site

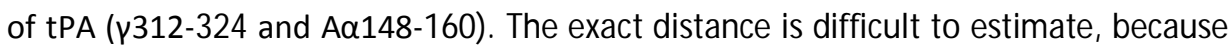
the $\mathrm{C}$-terminal end of the A $\alpha$ chain is not resolved in the crystal structure, but we estimate it to be approximately $100 \AA$. These results are currently being followed up with the synthesis of a hybrid protein that contains a long linker, which will allow crosslinking to fibrin but will not restrict tPA in binding to its natural position from which it can optimally degrade fibrin.

Overall, we have made improvements to the use of the oxime ligation and have shown its utility in various protein and peptide targets. The improvements and applications in respect to oxime chemistry presented in this thesis and its publications might further boost the interest and use of oximation in chemical biology and translational chemistry.

\section{References}

1. Rostovtsev, V.V., L.G. Green, V.V. Fokin, and K.B. Sharpless, A stepwise huisgen cycloaddition process: copper(I)-catalyzed regioselective "ligation" of azides and terminal alkynes. Angew Chem Int Ed Engl, 2002. 41(14): 2596-2599.

2. Tornoe, C.W., C. Christensen, and M. Meldal, Peptidotriazoles on solid phase: [1,2,3]triazoles by regiospecific copper(i)-catalyzed 1,3-dipolar cycloadditions of terminal alkynes to azides. J Org Chem, 2002. 67(9): 3057-3064.

3. Naidu, B.N., W.Y. Li, M.E. Sorenson, T.P. Connolly, J.A. Wichtowski, Y.H. Zhang, O.K. Kim, J.D. M atiskella, K.S. Lam, J.J. Bronson, and Y. Ueda, Organic reactions in frozen water: Michael addition of amines and thiols to the dehydroalanine side chain of nocathiacins. Tetrahedron Lett, 2004. 45(5): 1059-1063.

4. Bure, C., D. Lelievre, and A. Delmas, Identification of by-products from an orthogonal peptide ligation by oxime bonds using mass spectrometry and tandem mass spectrometry. Rapid Commun Mass Sp, 2000. 14(23): 2158-2164. 



\section{Chapter 9}

Summary 
The work in this thesis established novel approaches to site directed bioconjugation of chemically (semi-) synthesized proteins and their use in deciphering mechanisms and optimizing therapy in cardiovascular disease. In Chapter 1 of this thesis state of the art chemical protein synthesis and bioconjugation by oxime chemistry is explained and research objectives are set.

In Chapter $\mathbf{2}$ methods for introducing ketone or aldehyde functionalities in peptides and proteins are reviewed. Modifications in proteins can be made site specifically using oxime chemistry, but the necessary ketones or aldehydes are normally not found in proteins. Introduction of this carbonyl moiety in a protein is therefore the first step towards oxime ligation. Several methods are highlighted where a distinction between 5 main methods is made. These include chemical treatment, enzymatic modification, genetic methods, glycan modification and chemical synthesis. In addition, the nucleophilic catalysis of aniline and its more recently developed derivatives are reviewed.

Chapter 3 deals with the optimization of oxime formation in peptides and proteins. Levulinic acid was widely used to introduce a ketone functionality in biological molecules by reaction with a free amine present on lysine residues or the $\mathrm{N}$-terminus of a protein. However, its use was frequently marked by low yields and slow reactions. We explained low yields by the formation of an intramolecular cyclic species of the levulinoyl moiety that is unable to react with an aminooxy to form an oxime. Aside from elucidation of this mechanism, we also proposed alternative keto-acids that do not exhibit this intramolecular cyclization and can thus be used to introduce stable ketone functionalities in proteins and peptides.

Chapter 4 reports on an unexpected method of catalysis of oxime formation. It was found that slow freezing of the reaction mixture leads to a large increase in reaction rate. A model system was used to obtain more insight into the mechanism by which this is achieved; the reaction mixture was frozen at 3 different temperatures; $-20^{\circ} \mathrm{C}$, $80{ }^{\circ} \mathrm{C}$. and $-196{ }^{\circ} \mathrm{C}$, which showed that slow freezing to $-20{ }^{\circ} \mathrm{C}$ was a definite requirement. In comparison to aniline-catalyzed reactions, the most pronounced improvement by slow freezing was observed for reactions performed at neutral $\mathrm{pH}$ and low concentrations. Finally, the method was applied to the fluorescent labeling of a small protein.

In Chapter $\mathbf{5}$ the optimization of ketone incorporation and improved oxime catalysis were employed to synthesize a covalent heterodimer of chemokines RANTES (CCL5) and PF4 (CXCL4). A combination of native chemical ligation (NCL) and oxime ligation was used to link two fully folded proteins. The heterodimer obtained by total chemical synthesis was subsequently evaluated structurally using NM R and biological activity was studied using a monocyte arrest assay. In addition, the natural affinity between 
chemokines RANTES and PF4 was luminously illustrated by the observation that chemokine PPIs catalyze oxime ligation. We could show that synergistic enhancement of function of the chemokine combination was caused by physical formation of a heterodimer.

Chapter 6 establishes the "Chemokine Interactome", a functional interplay between different chemokines to modulate or modify function. This was investigated using immuno-ligand blotting and surface plasmon resonance. Two covalently linked chemokine pairs were synthesized by solid phase peptide chemistry, native chemical ligation, and oxime chemistry, and functionally and structurally characterized. Functional interactions involved in atherosclerosis were followed up upon in vitro by chemotactic and arrest assays and in vivo in different mouse models. Moreover, peptide inhibitors for chemokine heterodimerization were developed and evaluated. With this extensive study, insight is gained in the formation of functional chemokine heterodimers that can be exploited for therapeutic targeting.

In Chapter 7 the oxime bond is used to modify recombinant tissue plasminogen activator (tPA), which is used as a thrombolytic agent to treat stroke, with a fibrin crosslinking sequence (A14) derived from $\alpha_{2}$-antiplasmin, aiming at an improved, more efficient thrombolytic agent. Current use of tPA often leads to bleeding complications, because of high required doses. Modification of tPA is achieved by a combination of oxidation of the $\mathrm{N}$-terminal serine followed by oxime ligation with A14. Different A14-tPA constructs were evaluated in plasma clot lysis assays both in static conditions and under flow. We could show that modification of tPA could be achieved site specifically; an improvement in function was, however, not observed. In this ongoing project optimized constructs are currently being developed which may lead to a more efficient thrombolytic agent. 

Samenvatting 
Het werk in dit proefschrift presenteert nieuwe methodes voor de plaats specifieke bioconjugatie van (semi-) gesynthetiseerde eiwitten. Hiermee kunnen hun werkingsmechanismes ontcijferd worden en therapieën gebruikt voor de behandeling van hart- en vaat ziekten geoptimaliseerd worden. In Hoofdstuk $\mathbf{1}$ van dit proefschrift worden chemische eiwit synthese en bioconjugatie met behulp van oxime chemie geïntroduceerd en de doelstellingen van het onderzoek bekend gemaakt.

In Hoofdstuk 2 worden methodes besproken die gebruikt kunnen worden voor de introductie van een keton of aldehyde in peptiden en eiwitten. Modificaties in eiwitten kunnen namelijk plaats specifiek gemaakt worden met behulp van oxime chemie, maar de benodigde ketonen en aldehyden komen van nature niet voor in eiwitten. Meerdere methodes worden besproken, waar een onderscheid tussen 5 hoofd groepen wordt gemaakt. Deze omvatten chemische behandeling, enzymatische modificatie, genetische methodes, sacharide modificatie en chemische synthese. Verder wordt de nucleofiele katalyse van aniline en de meer recent ontwikkelde derivaten besproken.

Hoofdstuk 3 behandelt de optimalisatie van oxime chemie in peptiden en eiwitten. Levulinezuur werd frequent gebruikt voor de introductie van een keton in biologische moleculen. Het ketozuur werd gereageerd met een vrije amine zoals die voorkomen op de zijketens van lysine of de $\mathrm{N}$-terminus van een eiwit. Het gebruik hiervan leidde echter vaak tot lage opbrengsten en langzame reacties. Wij ontdekten dat dit verklaard kan worden door de formatie van een intramoleculair gevormde cyclische variant van levulinezuur, die niet meer in staat is te reageren met een aminooxy om een oxime te vormen. Naast het ontrafelen van dit reactiemechanisme, hebben we ook alternatieven onderzocht die deze cyclische variant niet vormen en dus gebruikt kunnen worden om stabiele ketonen in eiwitten en peptiden te introduceren.

In Hoofdstuk 4 rapporteren we een onverwachte methode van katalyse van de oxime reactie. Langzaam bevriezen van het reactiemengsel bleek te zorgen voor een grote toename in reactiesnelheid. Vervolgens werd een model systeem gebruikt om meer inzicht te krijgen in het mechanisme van deze toename. Het reactiemengsel werd bevroren bij 3 verschillende temperaturen $\left(-20^{\circ} \mathrm{C},-80{ }^{\circ} \mathrm{C}\right.$ en $\left.-196{ }^{\circ} \mathrm{C}\right)$, waarbij bleek dat langzaam vriezen bij $-20^{\circ} \mathrm{C}$ een absoluut vereiste was. In vergelijking met aniline gekatalyseerde reacties, werd de grootste toename in reactiesnelheid gevonden bij neutrale $\mathrm{pH}$ en lage concentraties. Uiteindelijk werd de methode gebruikt voor het fluorescent labelen van een groter eiwit.

In Hoofdstuk $\mathbf{5}$ werd de optimalisatie van het keton en de vernieuwde oxime katalyse toegepast voor de synthese van een covalente heterodimeer van de chemokines RANTES (CCL5) en PF4 (CXCL4). Een combinatie van natieve chemische ligatie (NCL) en oxime ligatie werd gebruikt om de volledig gevouwen eitwitten met elkaar te 
verbinden. De structuur van de nieuw gevormde heterodimeer werd geëvalueerd met behulp van NMR en de biologsiche activiteit werd gemonitord met een monocyten arrest assay. Verder konden wij aantonen dat de affiniteit tussen de twee chemokines aanwezig is doordat de chemische ligatie versneld werd door eiwit-eiwit interacties. Uiteindelijk konden we aantonen dat de functieversterking van het chemokine paar wordt veroorzaakt door de fysieke formatie van een heterodimeer.

In Hoofdstuk 6 wordt het "Chemokine Interactoom" geïntroduceerd, een functionele interactie tussen verschillende chemokines om hun functie te moduleren of modificeren. Het interactoom werd onderzocht met immuno-ligand blotting en surface plasmon resonance. Twee covalent gelinkte chemokine paren werden gesynthetiseerd met behulp van vaste fase peptide chemie, native chemische ligatie en oxime ligatie. Deze heterodimeren werden functioneel en structureel gekarakteriseerd. Functionele interacties die van belang zijn in atherosclerose werden verder opgevolgd in vitro met chemotactische en arrest assays en in vivo in verschillende muizen modellen. Verder werden peptide inhibitoren voor chemokine heterodimerisatie ontwikkeld en getest. Met deze uitgebreide studie is inzicht verkregen in de formatie van chemokine heterodimeren die gebruikt kan worden voor therapeutische toepassingen.

In Hoofdstuk 7 wordt de oxime gebruikt voor de modificatie van recombinant tissue plasminogeen activator (rtPA), dat gebruikt wordt voor de trombolytische behandeling van hersenbloedingen, met een fibrine crosslinking sequentie (A14) afgeleid van $\alpha 2$-antiplasmine, gericht op een verbeterd, meer efficiënt trombolyticum. Het huidige gebruik van rtPA leidt vaak tot bloedingsneigingen als gevolg van de hoge gebruikte dosis. De modificatie van rtPA wordt bereikt door de oxidatie van de Nterminale serine gevolgd door oxime ligatie met A14. Verschillende A14-tPA constructen werden getest in plasma clot lysis assays in zowel statische als flow condities. We konden aantonen de modificatie van rtPA plaats specifiek gedaan kon worden, een verbetering in functie werd echter niet waargenomen. In dit lopende project worden geoptimaliseerde constructen ontwikkeld die uiteindelijk moeten leiden tot een efficiënter trombolyticum. 

Valorisation 
Over the past few years an increasing interest is shown in valorization of research performed in an academic setting. Research should have a societal impact and a clear utilization. One of the definitions of valorization is:

"The process of value-creation out of knowledge, by making this knowledge suitable and available for economic or societal utilization and to translate this into highpotential products, services, processes and industrial activity."

This thesis describes the development of a chemical reaction (oximation) and the subsequent (cardiovascular) applications for which it can be used. While it is difficult at first to see a direct benefit to society of this fundamental research, the applications for which it has been used in later chapters already provide a hint towards potential products.

The first chapters ( 1 and 2 ) of this thesis discuss the formation and catalysis of the oxime bond. This so-called oximation reaction has long been overlooked in the bioconjugation field, but has received increasing attention over the past few years. With this ever increasing interest, more knowledge is gained about the usefulness of this technique in for example the development of novel medicines. The oxime bond is formed by reaction of a ketone with an aminooxy; both of these functionalities are normally not present in a protein. We have shown that a frequently used keto-acid, levulinic acid, is not suitable for introduction of a ketone in proteins and leads to low yields when performing subsequent oxime ligations. Interestingly, the postulated demise of levulinic acid (Chapter 3) does not hold true for other fields of chemistry. Levulinic acid, a 5-carbon building block, is suggested to be useful for a range of applications and could potentially become the next big biobased chemical. This furthermore shows that although an application might not be immediately apparent, fundamental research is necessary to eventually find these applications.

Optimization of the ketone involved in oxime ligation led to the accidental discovery of reaction rate acceleration by freezing. While we did not test this mechanism with other reactions in aqueous systems, we expect a similar result. Optimization of a chemical reaction reduces possible side reactions, increases yield and with that decreases cost and the environmental strain.

After optimization of the oximation process, the focus changed to applying the acquired knowledge to important questions in cardiovascular research. Atherosclerosis is a major health problem and can lead to serious conditions such as myocardial infarction or stroke. Remarkably, a cause of the disease is not known, and current treatment is mostly based on lifestyle changes (i.e. reducing cholesterol levels) and surgical interventions in late stage disease. Our research focused on the initiation of atherosclerosis. In early stages of disease development leukocytes (predominantly monocytes) play an important role and are attracted to a site of inflammation where 
they differentiate into macrophages. This process is governed by small chemotactic cytokines known as chemokines. More than 40 different chemokines exist in the human body, each with its own function and expression pattern. Recent research has shown that these chemokines do not act alone, interactions between chemokines occur to modulate their function. In the process of atherosclerosis an interaction between two chemokines (CCL5 and CXCL4) was hypothesized, because of an increased monocyte arrest when the 2 chemokines were mixed. It was unclear, however, if this effect was a result of the formation of a heterodimer or a result of combined receptor activation. With the synthesis of a covalent heterodimer we could show that the increased monocyte arrest can be attributed to the formation of a heterodimer of chemokines CCL5 and CXCL4. With the synthesis of this heterodimer we have synthesized a molecule that can induce a disease state, the exact opposite of what would be beneficial for the general society. However, this molecule has provided us with insights into its mechanism of action, which can subsequently be used for the development of inhibitors. This study was followed up by an extensive mapping of all possible chemokine interactions. Subsequently, interactions with an atherogenic effect where further investigated and eventually led to the development of inhibitors of these interactions. First results show that this approach can inhibit monocyte arrest in vitro and atherosclerosis in an in vivo mouse model, and thus may be a viable therapeutic approach to inhibit plaque formation in an early stage. In order to develop these inhibitors into approved pharmaceuticals more research is required, but a first step is taken.

A different application of oximation was found in the modification of an existing drug. Tissue plasminogen activator (tPA) is currently being used to dissolve blood clots in stroke patients. The treatment is effective but often leads to bleeding complications as a result of the high required dose. We attempted to overcome this problem by modifying tPA to result in a molecule with a very high affinity for fibrin, which would decrease the required effective dose. We used an oxime bond to link a peptide that is covalently crosslinked to fibrin. Although current constructs show no improvement over unmodified TPA, we are confident that this approach will be beneficial when further improvements are made. Moreover, this method is useful for the modification of other (large) proteins currently being used as treatment for various diseases. 

Curriculum vitae 


\section{About the author}

Stijn Agten was born on March 12th 1987 in Heerlen, the Netherlands. He graduated from secondary school in 2005 at sg St. Ursula in Horn, the Netherlands where he obtained his VWO diploma for Nature \& Health. In 2005 he started his bachelor study Biomedical Engineering at the Technical University Eindhoven. After receiving his bachelor in 2009, he continued with a master in Biomedical Engineering at the same university. During his master an internship was conducted at the Institute of Molecular Bioscience (Brisbane, Australia). His graduate project focused on the nuclear receptor coactivator interaction. He obtained his master diploma in 2012. In August 2012 he started his PhD research in the Cardiovascular Research Institute Maastricht (CARIM), Department of Biochemistry, under the supervision of Prof. Dr. T.M. Hackeng. His research focused on the development of bioconjugation techniques and their application in cardiovascular research with a special focus on the oxime bond. 


\section{Over de auteur}

Stijn Agten werd geboren op 12 maart 1987 te Heerlen. In 2005 behaalde hij zijn VWO-diploma met afstudeerprofiel Natuur \& Gezondheid aan sg. St. Ursula te Horn. In 2005 begon hij met de bacheloropleiding Biomedische Technologie op de Technische Universiteit Eindhoven. Na het behalen van zijn bachelor-graad in 2009, volgde hij aan dezelfde universiteit de masteropleiding Biomedical Engineering. Gedurende zijn master voerde hij een stage uit aan het Institute of Molecular Bioscience (Brisbane, Australie). Zijn afstudeerproject focuste op de interactie tussen nucleaire receptoren en hun coactivatoren. In 2012 behaalde hij zijn master-diploma. In augustus 2012 begon hij zijn promotieonderzoek binnen het Cardiovasculair Research Institute Maastricht (CARIM) bij de vakgroep Biochemie van de Universiteit van Maastricht onder supervisie van Prof. Dr. T.M. Hackeng. Zijn onderzoek richtte zich op de ontwikkeling van bioconjugatie technieken en hun toepassing binnen cardiovasculair onderzoek met een speciale rol voor de oxime bond. 

Publications 


\section{Publications}

Haase C, Burton MF, Agten SM, Brunsveld L, A facile strategy to prevent trifluoroacetylation of $\mathrm{N}$-terminal proline peptides, Tetrahedron Letters, 29 Aug 2012;53(35):4763-4765

Fuchs S, Nguyen HD, Phan TT, Burton M F, Nieto L, de Vries-van Leeuwen IJ, Schmidt A, Goodarzifard M, Agten SM, Rose R, Ottmann C, Milroy LG, Brunsveld L. Proline primed helix length as a modulator of the nuclear receptor-coactivator interaction. J Am Chem Soc. 2013 M ar 20;135(11):4364-71.

Agten SM, Suylen DP, Ippel H, Kokozidou M, Tans G, van de Vijver P, Koenen RR, Hackeng TM. Chemoselective oxime reactions in proteins and peptides by using an optimized oxime strategy: the demise of levulinic acid. Chembiochem. 2013 Dec 16;14(18):2431-4.

Agten SM, Suylen DP, Hackeng TM. Oxime Catalysis by Freezing. Bioconjug Chem. 2016 Jan 20;27(1):42-6.

Agten SM, Dawson PE, Hackeng TM. Oxime conjugation in protein chemistry: from carbonyl incorporation to nucleophilic catalysis. J Pept Sci. 2016 M ay;22(5):271-9.

Agten SM, Koenen RR, Ippel H, Eckardt V, von Hundelshausen P, Mayo KH, Weber C, Hackeng TM, Probing Functional Heteromeric Chemokine PPIs through Conformationassisted Oxime Ligation, Angewandte Chemie Intl. Ed., 2016, 10.1002/anie.201607036R2

von Hundelshausen P, Agten SM, Eckardt V, Schmitt M, Blanchet X, Ippel H, Neideck C, Bidzhekov K, Wichapong K, Faussner A, Drechsler M, Grommes J, Li H, Dijkgraaf I, Nicolaes G, Döring Y, Soehnlein O, Lutgens E, Heemskerk J, Koenen RR, Mayo KH, Hackeng TM, Weber $C$, Chemokine interactome mapping enables tailored intervention in acute and chronic inflammation, under revision

Agten SM, van de Vijver P, Swieringa F, Scheer L, Hackeng TM, Covalent attachment of tissue type plasminogen activator to fibrin through $\mathrm{N}$-terminal modification with a fibrin crosslinking sequence from $\alpha_{2}$-Antiplasmin, in preparation 


\section{Oral communications}

Agten SM, Suylen DPL, Ippel H, Dijkgraaf I, van de Vijver P, Koenen RR, Hackeng TM, Chemoselective reactions in proteins and peptides using an optimized oxime strategy: the demise of levulinic acid, $5^{\text {th }}$ International Chemical protein synthesis Meeting, Vienna, Austria, M arch 2013

Agten SM, Suylen DPL, Ippel H, Dijkgraaf I, van de Vijver P, Koenen RR, Hackeng TM, Chemoselective reactions in proteins and peptides using an optimized oxime strategy: the demise of levulinic acid, Dutch peptide symposium 2013, Amsterdam, April 2013

Agten SM, Suylen DPL, Ippel H, Dijkgraaf I, van de Vijver P, Mayo KH, Weber C, Koenen RR, Hackeng TM, Synthesis of covalent RANTES-PF4 heterodimers using an optimized oxime strategy, NWO, M olecules: Synthesis and properties, Lunteren, November 2013

Agten SM, Suylen DPL, Ippel H, Mayo KH, Weber C, Koenen RR, Hackeng TM, Total chemical synthesis of covalent RANTES-PF4 heterodimers to study initiation and progression of atherosclerosis", Dutch Peptide symposium 2015, Nijmegen, M ay 2015

Agten SM, Suylen DPL, Ippel H, M ayo KH, Weber C, Koenen RR, Hackeng TM, Chemical synthesis of covalent RANTES-PF4 heterodimers to study initiation and progression of atherosclerosis, CHAINS 2015, Veldhoven, November 2015

Agten SM, Suylen DPL, Hackeng TM, Oxime catalysis by freezing, International Chemical ligation meeting, Lille, France, M ay 2016

\section{Awards}

2016 - CARIM postdoctoral talent fellowship

2013 - Poster award, 10th Australian Peptide conference, Penang

2013 - Poster competition award, 5th International Chemical protein synthesis meeting, Vienna

2011 - Travel grant, Nora Baart Stichting, Netherlands society for biochemistry and molecular biology (NVBMB) 

Dankwoord 
$\mathrm{Na} 200$ pagina's wetenschappelijk onderzoek zijn we dan uiteindelijk aangekomen bij het (voor sommigen) belangrijkste en meest gelezen deel van een proefschrift. Ik ga ervan uit dat een ieder die hier aan belandt is, zich ook door de rest van het proefschrift geworsteld heeft. Het is een cliché, maar het gepresenteerde werk is uiteraard niet door mij alleen uitgevoerd. In dit hoofdstuk wil ik graag iedereen bedanken die deel heeft uitgemaakt van het onderzoek.

Allereerst mijn promotor, prof. dr. Tilman Hackeng. Beste Tilman, binnen enkele minuten van mijn sollicatiegesprek voelde ik me op mijn plaats op de afdeling biochemie. Het was voor mij dan ook geen moeilijke keuze om mijn PhD project binnen jouw groep uit te voeren. Ik heb genoten van de afgelopen 4 jaar die helemaal niet als "echt werk" aanvoelden en kan alleen maar hopen dat ik eenzelfde sfeer en werkomgeving ergens anders ook kan vinden. Jouw deur stond altijd open en ik ben er zeker van dat ik dit resultaat zonder jouw supervisie nooit had bereikt. Ook wil ik je speciaal bedanken voor het onmiddellijk betrekken van mij in het project in samenwerking met München, dat mij extreem gemotiveerd en veel geleerd heeft.

Daarnaast mijn co-promotor, dr. Rory Koenen. Beste Rory, biochemie kan niet meer bestaan zonder biologische toepassingen. In mijn eerste project werd dit al meteen duidelijk, en jij hebt mij geïntroduceerd in de wondere wereld van cel cultuur en microscopie. Jouw enthousiasme om elk project aan te pakken zijn een inspiratie voor een ieder.

Members of the assessmentcommittee; prof. dr. C.G. Schalkwijk, prof. dr. C. F. W. Becker, prof. dr. P. Timmerman en prof. dr. E.A.L. Biessen. I would like to thank you all for the time and attention spent for the assessment of my thesis.

Dennis, vanaf mijn eerste dag op het lab was jij onmisbaar voor mij. Zonder jou was mijn eerste zuivering al compleet gefaald. We hebben samen meerdere congressen bezocht en natuurlijk een weekje pretparken in Orlando. Bedankt voor de geweldige samenwerking.

Hans, bedankt voor het begrijpbaar en soms onbegrijpbaar maken van de NM R data in al mijn projecten.

I would also like to thank my collaborators in the chemokine interactome project. Prof. dr. Christian Weber, dr. Philipp von Hundelshausen, prof. dr. Kevin M ayo and dr. Hans Ippel thank you for the fruitful collaboration and the nice visits to Munich and Maastricht.

Mijn kamergenoten, sommige al een tijdje vertrokken anderen met wie ik bijna 4 jaar een kamer heb gedeeld; Pieter bedankt voor de begeleiding in mijn eerste jaar, je hebt een grote indruk op me gemaakt. Ik kon bij jou met elke synthetische vraag terecht. Ingrid, bedankt voor de prettige samenwerking en veel succes met de rest 
van je carrière. Kristien, bedankt voor de gezellige korte tijd dat wij een kantoor deelden. Farida en Tanja bedankt voor alle leuke gesprekken, sommigen niet helemaal voor mij bedoeld, en alle hulp bij mijn vragen, werk gerelateerd of totaal niet. Ik neem aan dat jullie dit ook wel in het Nederlands kunnen lezen. Nahla, thank you for all the sweets and pleasant company. Stepan, good luck with the remainder of your PhD period.

Tevens wil ik mijn mede-PhD studenten en collega's bedanken voor het creëren van een geweldige sfeer op de afdeling met vele feestjes, filmavonden, congressen en uitstapjes. In het bijzonder Stella, altijd enthousiast en positief en dat heb je zeker op mij overgedragen. Bedankt: Roy, Danielle, Armand, Rick, Kanin, Annemiek, Linda, Alexandra, Peter, Jelle, Jens, Suzanne, Frauke, Niko, Hans, Bogac.

In het bijzonder wil ik nog de Biochemical Brothers bedanken, Jelle en Niko, bedankt dat jullie samen met mij de uitdaging zijn aangegaan en IRONM AN M aastricht tot een goed einde hebben gebracht. Ik hoop dat dit een terugkerend event gaat worden op de afdeling.

Ook wil ik graag mijn trainingsmaatjes bij Zv Kimbria bedanken, waar ik iedere avond even mijn hoofd kon leegmaken.

Verder wil ik iedereen bedanken die mij (moreel) gesteund heeft tijdens mijn PhD periode en de verdediging van mijn proefschrift.

Tot slot wil ik mijn familie bedanken. Vrijwel ieder weekend ben ik naar huis gekomen en dat was niet zonder reden, thuis is voor mij nog altijd bij jullie. Papa en mama bedankt voor de steun de afgelopen jaren, als ik iets nodig had, stonden jullie altijd voor me klaar. 